\title{
Wnt/Frizzled signaling in myocardial infarction
}

Citation for published version (APA):

Hermans, K. C. M. (2016). Wnt/Frizzled signaling in myocardial infarction: characterization and interventions with peptide fragments of Wnt . [Doctoral Thesis, Maastricht University]. Maastricht University. https://doi.org/10.26481/dis.20160511kh

Document status and date:

Published: 01/01/2016

DOI:

$10.26481 / \mathrm{dis} .20160511 \mathrm{kh}$

Document Version:

Publisher's PDF, also known as Version of record

\section{Please check the document version of this publication:}

- A submitted manuscript is the version of the article upon submission and before peer-review. There can be important differences between the submitted version and the official published version of record.

People interested in the research are advised to contact the author for the final version of the publication, or visit the DOI to the publisher's website.

- The final author version and the galley proof are versions of the publication after peer review.

- The final published version features the final layout of the paper including the volume, issue and page numbers.

Link to publication

\footnotetext{
General rights rights.

- You may freely distribute the URL identifying the publication in the public portal. please follow below link for the End User Agreement:

www.umlib.nl/taverne-license

Take down policy

If you believe that this document breaches copyright please contact us at:

repository@maastrichtuniversity.nl

providing details and we will investigate your claim.
}

Copyright and moral rights for the publications made accessible in the public portal are retained by the authors and/or other copyright owners and it is a condition of accessing publications that users recognise and abide by the legal requirements associated with these

- Users may download and print one copy of any publication from the public portal for the purpose of private study or research.

- You may not further distribute the material or use it for any profit-making activity or commercial gain

If the publication is distributed under the terms of Article $25 \mathrm{fa}$ of the Dutch Copyright Act, indicated by the "Taverne" license above, 


\section{Wnt/Frizzled Signaling in Myocardial Infarction}

Characterization and Interventions with Peptide Fragments of Wnt

Kevin Hermans 
Wnt/Frizzled Signaling in Myocardial Infarction:

Characterization and Interventions with Peptide Fragments of Wnt

Thesis, Maastricht University, Maastricht, The Netherlands

Layout: Kevin Hermans

Cover design: Jan de Jonge

Printed by: MultiCopy Parkstad

ISBN: $\quad$ 978-90-9029696-8

(c) Kevin C.M. Hermans, 2016 


\title{
Wnt/Frizzled Signaling in Myocardial Infarction
}

Characterization and Interventions with Peptide Fragments of Wnt

\author{
PROEFSCHRIFT \\ ter verkrijging van de graad van doctor aan de Universiteit Maastricht, \\ op gezag van de Rector Magnificus, Prof. dr. L.L.G. Soete \\ volgens het besluit van het College van Decanen, \\ in het openbaar te verdedigen \\ op woensdag 11 mei 2016 om 12.00 uur
}

door

Kevin Carolus Martha Hermans

geboren te Brunssum 2 juli 1987 


\section{Promotores}

Prof. dr. H.A.J. Struijker Boudier

Prof. dr. P. Timmerman (Universiteit van Amsterdam)

\section{Co-promotor}

Dr. W.M. Blankesteijn

\section{Beoordelingscommissie}

Prof. dr. T.M. Hackeng (voorzitter)

Prof. dr. H.P. Brunner-La Rocca

Dr. M.M. Maurice (UMC Utrecht)

Prof. dr. F.W. Prinzen

Dr. R.G. Schoemaker (Rijksuniversiteit Groningen)

The research described in this thesis was supported by a grant of the Dutch Heart Foundation (DHF 2010B196).

Financial support by the Dutch Heart Foundation for the publication of this thesis is gratefully acknowledged. 


\section{Contents}

Chapter 1 Introduction, aims and outline of the thesis

Chapter 2 Wnt signaling in cardiac disease

Chapter 3 Expression of Wnt/Frizzled signaling components following myocardial infarction in mice and humans

Chapter 4 UM206, a selective Frizzled antagonist, attenuates adverse remodeling after myocardial infarction in swine

Chapter 5 Variable effects of UM206 on the wound healing after myocardial infarction

Chapter 6 Multiple-constrained peptide mimetics of Wnt inhibit canonical Wnt signaling

Chapter 7 General Discussion

Chapter 8 Summary

Samenvatting

Valorisatie addendum

Dankwoord

Curriculum Vitae

List of publications 



\section{Chapter}

\section{Introduction, aims and outline of the thesis}




\section{Introduction}

Myocardial infarction (MI) is the result of an occluded artery in the heart, causing an interrupted blood flow to the distal region that leads to myocardial damage. The dead cardiomyocytes in the affected myocardium will evoke an inflammatory reaction, which is the start of the wound healing process. Macrophages and other phagocytic cells clear the dead tissue in the affected region. This is followed by infiltration of (myo)fibroblasts into the infarcted area and deposition of extracellular matrix (ECM) that replaces the lost cardiomyocytes. Finally, the number of cells in the infarcted region will reduce and the deposited ECM will mature into a stabilized $\mathrm{scar}^{(1)}$. The quality of the wound healing process following $\mathrm{MI}$ is of major importance for maintaining cardiac structure and dimensions. Inadequate wound healing can result in ventricular stiffening, thinning of the left ventricular wall, left ventricular dilation and ultimately in the development of heart failure.

Worldwide, over 26 million people are estimated to suffer from heart failure regardless of the etiology ${ }^{(2)}$. Approximately $20 \%$ of men and $23 \%$ of women over 65 years of age will develop heart failure within five years of having a first $\mathrm{MI}^{(3)}$. Dilatation of the left ventricle due to $\mathrm{MI}$ is a major cause of heart failure. Current therapy for heart failure aims at improving the function of the remaining myocardium rather than optimizing the wound healing process. It includes drug classes that target e.g. the renin-angiotensin-aldosterone system (RAAS) and the $\beta$-adrenergic system. These drug classes exert beneficial effects on the prognosis of heart failure patients. Nevertheless, these drugs do not cure heart failure or target the wound healing process of the infarcted area but only delay further deterioration of the cardiac function.

There is a need for novel therapies that target the process of adverse remodeling following $\mathrm{MI}$ in order to prevent the subsequent dilatation of the left ventricle and development of heart failure. A candidate for such a target is the Wnt/Frizzled signaling pathway. This is a complex pathway with multiple components and downstream mechanisms. It is active during embryogenesis and is involved in the 
development of the cardiovascular system ${ }^{(4,5)}$. In the healthy adult organism, Wnt signaling is limited and is mainly involved in tissue homeostasis. However, a sudden reactivation of Wnt/Frizzled signaling is commonly observed following development of a pathological condition such as an MI. The evidence of Wnt/Frizzled signaling being involved in the wound healing process following $\mathrm{MI}$ is expanding and previous studies have shown that interventions in the Wnt/Frizzled signaling pathway following $\mathrm{MI}$, have a distinct effect on the outcome ${ }^{(6,7)}$. A previous study from our lab demonstrated that administration of UM206, a peptide fragment of Wnt5a, has beneficial effects on cardiac dimensions and function in a mouse model of $\mathrm{MI}$, thereby preventing development of heart failure ${ }^{(8)}$.

Given the importance of adequate wound healing in the prevention of heart failure development following $\mathrm{MI}$ and the role of Wnt signaling in this wound healing, we have investigated the importance of this pathway in this process both from a pathophysiological and a therapeutic point of view. This resulted in the following aims:

\section{Aims of this thesis}

- Determine the expression of components of Wnt/Frizzled signaling in different mouse strains, known to have a divergent wound healing process, and in post mortem human infarct samples.

- Determine the optimal dosage regimen of UM206 in the wound healing process following MI.

- Test the effectiveness of UM206 on the wound healing process in a translationally relevant swine model of cardiac ischemia.

- Develop new peptide antagonists based on the crystal structure of Wnt in complex with the Frizzled cysteine rich domain (CRD).

\section{Outline of the thesis}

Following this introduction and aims of the thesis, an introduction into Wnt/Frizzled signaling is provided in Chapter 2 accompanied by an overview of the implications of 
this signaling in cardiovascular development, myocardial infarction, heart failure, cardiac hypertrophy, atherosclerosis and arrhythmias.

The wound healing process following MI is substantially different between several mouse strains ${ }^{(9)}$. To investigate whether this discrepancy in infarct healing can be attributed to differential regulation of Wnt signaling, we describe in Chapter 3 the expression profiles of several Wnt/Frizzled genes in four different mouse strains and link them to cardiac parameters. Furthermore, Wnt/Frizzled gene expression in human post mortem samples at different stages following $\mathrm{MI}$ is determined.

In Chapter 4, a translationally relevant swine model of reperfused MI was used in order to confirm the initial beneficial findings of UM206 found in mice, in a clinically more relevant situation. To this end, swine were exposed to two hours of local myocardial ischemia followed by reperfusion and were treated continuously with either UM206 or control solvent for five weeks. As was done in the previous mouse study, cardiac function as well as gene expression of a wide array of genes involved in Wnt signaling and cardiac wound healing was analyzed.

Chapter 5 provides an overview of all mouse studies that were performed with UM206 as a treatment. A systematic overview of eight individual studies addresses the importance of the experimental conditions on the outcome of the study. The effectiveness of UM206 was analyzed in relation to dose, timing, source of UM206 and genetic background.

The crystal structure of the Wnt/Frizzled complex demonstrated that UM206 has no direct interaction with the Frizzled CRD. In Chapter 6, the development of novel peptide fragments of Wnt3a and Wnt5a is described. The peptide sequence is based on two predicted sites of interaction between Wnts and the Frizzled CRD. A peptide library was designed to identify crucial characteristics of the peptides in order to interfere with Wnt signaling. In this study, an in vitro assay was used in order to test inhibitory capacity of these peptides on canonical Wnt/Frizzled signaling.

In Chapter 7 a brief summary of the findings of this thesis is presented. This is followed by a discussion that places the findings in a broader scientific perspective. 


\section{References}

1. Cleutjens JP, Blankesteijn WM, Daemen MJ, Smits JF. The infarcted myocardium: simply dead tissue, or a lively target for therapeutic interventions. Cardiovascular research. 1999;44(2):232-41.

2. Ambrosy AP, Fonarow GC, Butler J, Chioncel O, Greene SJ, Vaduganathan M, et al. The global health and economic burden of hospitalizations for heart failure: lessons learned from hospitalized heart failure registries. Journal of the American College of Cardiology. 2014;63(12):1123-33.

3. Mozaffarian D, Benjamin EJ, Go AS, Arnett DK, Blaha MJ, Cushman M, et al. Heart disease and stroke statistics--2015 update: a report from the American Heart Association. Circulation. 2015;131(4):e29-322.

4. Dejana E. The role of wnt signaling in physiological and pathological angiogenesis. Circulation research. 2010;107(8):943-52.

5. Gessert S, Kuhl M. The multiple phases and faces of wnt signaling during cardiac differentiation and development. Circulation research. 2010;107(2):186-99.

6. Hermans KC, Blankesteijn WM. Wnt Signaling in Cardiac Disease. Comprehensive Physiology. 2015;5(3):1183-11209.

7. Hermans KC, Daskalopoulos EP, Blankesteijn WM. Interventions in Wnt signaling as a novel therapeutic approach to improve myocardial infarct healing. Fibrogenesis \& tissue repair. 2012;5(1):16.

8. Laeremans H, Hackeng TM, van Zandvoort MA, Thijssen VL, Janssen BJ, Ottenheijm HC, et al. Blocking of frizzled signaling with a homologous peptide fragment of wnt3a/wnt5a reduces infarct expansion and prevents the development of heart failure after myocardial infarction. Circulation. 2011;124(15):1626-35.

9. van den Borne SW, van de Schans VA, Strzelecka AE, Vervoort-Peters HT, Lijnen PM, Cleutjens JP, et al. Mouse strain determines the outcome of wound healing after myocardial infarction. Cardiovascular research. 2009;84(2):273-82. 



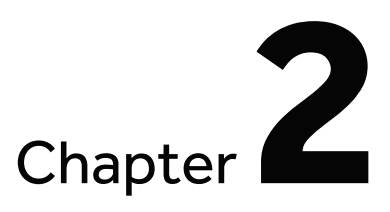

\section{Wnt signaling in cardiac disease}

Kevin C.M. Hermans \& W. Matthijs Blankesteijn Comprehensive Physiology 2015, 5:1183-1209

Wiley Publishers

(C) 2015 American Physiological Society 


\section{Abstract}

Wnt signaling encompasses multiple and complex signaling cascades and is involved in many developmental processes such as tissue patterning, cell fate specification, and control of cell division. Consequently, accurate regulation of signaling activities is essential for proper embryonic development. Wnt signaling is mostly silent in the healthy adult organs but a reactivation of Wnt signaling is generally observed under pathological conditions. This has generated increasing interest in this pathway from a therapeutic point of view. In this review article, the involvement of Wnt signaling in cardiovascular development will be outlined, followed by its implication in myocardial infarct healing, cardiac hypertrophy, heart failure, arrhythmias, and atherosclerosis. The initial experiments not always offer consensus on the effects of activation or inactivation of the pathway, which may be attributed to (I) the type of cardiac disease, (II) timing of the intervention, and (III) type of cells that are targeted. Therefore, more research is needed to determine the exact implication of Wnt signaling in the conditions mentioned above to exploit it as a powerful therapeutic target. 


\section{Introduction}

Cardiovascular disease is one of the main causes of morbidity and mortality worldwide. Although it comprises of several distinct conditions such as hypertension, atherosclerosis, and heart failure, many of the underlying pathological pathways including inflammation, fibrosis, and cell death - are common. With the introduction of the diuretics, inhibitors of the renin-angiotensin system, adrenoceptor blockers, and calcium antagonists in the last decades, the progression of cardiovascular disease can be slowed down and average survival time of the patients is improved. However, regression or even cure of the underlying pathology is rarely achieved with these drug classes. This has evoked extensive research programs for novel therapeutic targets, yielding important new drug classes such as the statins, primarily designed for treatment of lipid disorders leading to atherosclerosis, and aldosterone antagonists for heart failure. Unfortunately, in the last decade the vast majority of the phase III clinical trials of new cardiovascular drugs, in particular those targeting heart failure, have yielded disappointing results ${ }^{(242)}$. The recent PARADIGM-HF trial is an exception, showing a beneficial effect of a combined neprilysin inhibitor/angiotensin receptor blocker over enalapril on mortality and hospitalization for heart failure ${ }^{(159)}$. The lack of success of most of the novel therapies can be attributed to an inadequate understanding of the underlying disease mechanisms in individual patients resulting in "one size fits all" therapy rather than tailored targeting of the molecular mechanisms that need adjustment in an individual patient. This calls for a better understanding of these molecular mechanisms to improve the success rate of new therapies in well-defined subgroups of patients ${ }^{(217)}$.

One of these molecular mechanisms is Wnt signaling, a pathway that has been shown to be involved in the development of the cardiovascular system but is reactivated in a variety of cardiovascular conditions. In this review article, we will start with a description of the complexity of the Wnt signaling mechanisms, followed by a description of its involvement in cardiovascular development. Subsequently, we will focus on different cardiovascular pathologies and present the experimental evidence 
for the involvement of Wnt signaling in its development and/or progression. We will conclude with an evaluation of the potential of this signaling pathway in better diagnosis and therapy of cardiovascular disease.

\section{Wnt/Frizzled Signaling}

The first Wnt gene, then called int-1, was discovered by Nusse and Varmus in $1982^{(186)}$ and to date the family of Wnt proteins consists of at least 19 members. The term "Wnt" was derived from a combination of the Drosophila segment polarity gene Wingless and the mouse proto-oncogene Int-1 since these genes encode similar secretory glycoproteins ${ }^{(185)}$. Wnts have an essential role in many developmental and physiological processes. They control many biological processes such as tissue patterning, cell fate specification, control of asymmetric cell division, and processes controlling self-renewal of adult tissue ${ }^{(47)}$. More recently it has become evident that Wnt signaling is implicated in pathological processes as well. Wnt signaling is involved in an increasing number of diseases ranging from cancer to cardiovascular diseases.

\section{Wnt proteins}

Wnts are glycosylated proteins, $\sim 350$ to 400 amino acids in size, and share $27 \%$ to $83 \%$ of their sequence identity among family members ${ }^{(166)}$. Wnts are characterized by a conserved pattern of 22-24 cysteines and a posttranslational palmitoylation on a serine residue $\left(\mathrm{Ser}^{209}\right.$ on $\mathrm{Wnt3a}$ ) at the $\mathrm{N}$-terminal side that makes them hydrophobic ${ }^{(101)}$. The region around this residue is highly conserved and targeted mutations of this serine or surrounding amino acids significantly reduces the secretion and thereby the activity of the protein ${ }^{(124,145)}$. Porcupine, which has structural similarities to membrane-bound O-acyltransferases, is required for Ser209-dependent palmitoylation and reduced expression levels inhibit palmitoylation and secretion of the Wnt protein ${ }^{(232)}$. The necessity of Porcupine activity is emphasized by the evidence that mutations in this $\mathrm{X}$-linked gene result in early embryonic death in male mice ${ }^{(20)}$ and causes focal dermal hypoplasia syndrome in human female heterozygotes ${ }^{(234)}$. Secretion is also dependent on the recognition of 
the palmitoylated serine residue by the conserved transmembrane protein Wntless/Evi that results in binding and trafficking of Wnt proteins to the cell surface $^{(15,22,90)}$. Once Wnt proteins are secreted, the palmitoylation is thought to control the membrane localization due to their high hydrophobicity. On the other hand, the covalently attached lipid could interact with a carrier protein such as Swim ${ }^{(176)}$ or lipoprotein particles ${ }^{(196)}$ to shield this hydrophobic fragment in an aqueous environment and thereby promote long-range signaling. For more than two decades, attempts have been made to purify Wnt proteins from recombinant material, without success, which is in large part because of their hydrophobic nature. Willert et al. were the first ones able to purify biologically active Wnt3a ${ }^{(259)}$ and more recently protocols have been published that outline the purification process for a large subset of Wnts ${ }^{(260)}$.

In 2012, Janda et al. were the first to present the crystal structure of the Xenopus Wnt8 in complex with the cysteine-rich domain (CRD) of the receptor for this ligand, Frizzled8 (Fzd8) ${ }^{(101)}$. They demonstrated that Wnt has a rather unusual shape that resembles the outline of a hand with a thumb and index finger grasping the Fzd8-CRD at two opposing sites (Fig. 1). This structure and the way of binding to Frizzled are not known for any other protein or complex respectively. The thumb at the $\mathrm{N}$-terminal domain, also known as "site 1," contains the palmitic acid lipid at the tip and engages a groove on the Fzd8-CRD, whereas the index finger at the C-terminal domain, known as "site 2," forms a strong hydrophobic contact with a groove on the opposite side of the Fzd8-CRD. This leaves a gap with conformational plasticity in the center of the complex, which might be involved in dimerization or binding to co-receptors and might be important for Wnt/Frizzled specificity as well ${ }^{(44,101)}$.

\section{Receptors}

Wnt ligands have been suggested to interact with several classes of receptors of which the best studied class is the Frizzled family. These are seven transmembrane receptors with sizes ranging from 500 to 700 amino acids and have a large extracellular $\mathrm{N}$-terminal domain that contains a CRD that participates in binding to 


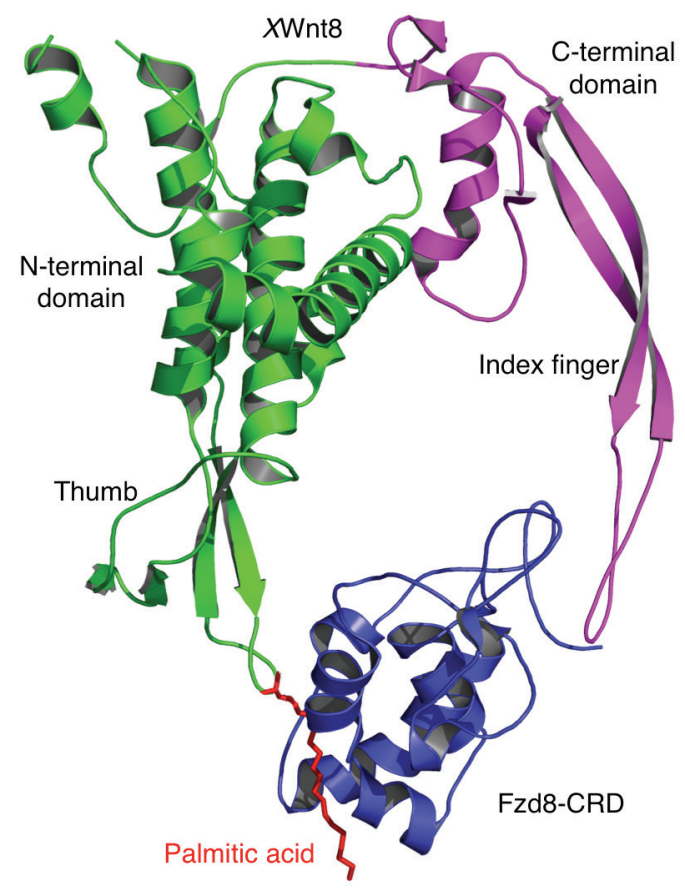

Figure 1 | Crystal structure of Xenopus Wnt8 in complex with the cysteine rich domain (CRD) of Frizzled8 (Fzd8). The structure of the Wnt protein mimics the palm of a hand with an index finger at the $\mathrm{C}$-terminal domain and a thumb and the $\mathrm{N}$-terminal domain. The index finger and the palmitic acid both make contact with the CRD leaving a gap in the middle that might be important for Wnt/Frizzled specificity.

Wnt ligands ${ }^{(219)}$. It is suggested that Frizzled signaling is activated in two steps by first capturing Wnt by the CRD, followed by interaction with the membrane part of the receptor to commence signaling ${ }^{(203)}$. Frizzled proteins have at least three intracellular loops and a C-terminal domain that communicate with downstream signaling factors in the cellular cytoplasm ${ }^{(174)}$. Frizzleds belong to the class of G-protein-coupled receptors (GPCRs) as they possess many characteristics of this class. Frizzled receptors are found in homo- and heteromeric oligomers with other family members ${ }^{(109)}$, which is typical for GPCRs. Other features of GPCRs such as glycosylation and phosphorylation sites for cyclic AMP-dependent protein kinase (PKA), protein kinase C (PKC), and casein kinase 2 (CK2) are shared by Frizzleds as well. On the other hand, they lack some other hallmarks such as conserved amino acid patterns important for G-protein coupling in the second intracellular loop ${ }^{(9)}$. 
Therefore, they have been classified by the International Union of Pharmacology as a novel and separate family of GPCRs, the "Class Frizzled"(68). To date, 10 different Frizzled receptors have been identified in mammals. Genome sequences unveil a very high level of homology between the Frizzleds by sharing more than 20 residues of identity, suggesting that distinction to downstream signaling must be located in the non-identical intracellular loops ${ }^{(252)}$. Furthermore, the receptor tyrosine kinase families Ror and Ryk have been identified as receptors for several Wnts too ${ }^{(113)}$. The Ror family consists of two members, Ror1 and Ror2, which are single-pass transmembrane receptors and characterized by an extracellular CRD, an intracellular cytoplasmic tyrosine kinase and proline-rich domains ${ }^{(69)}$. It has been demonstrated that Ror2 can associate and induce signaling with Wnt5a, but not with Wnt3a $a^{(165,190)}$. Ryk is a single-pass transmembrane receptor as well and contains an extracellular domain similar to Wnt inhibitory factor-1 (WIF 1$)^{(198)}$ that is able to interact with Wnt1 and $\mathrm{Wnt3} \mathrm{a}^{(143)}$. The single-pass transmembrane low-density lipoprotein receptorrelated protein (LRP) 5 and 6 have been shown to act as co-receptors, specifically required for canonical signaling (discussed in more detail below), by forming oligomers and activating intracellular signaling by acting as docking site for Axin ${ }^{(53,163)}$.

\section{Signaling pathways}

To date at least three different Wnt signaling pathways have been described, namely, the Rho/c-jun N-terminal kinase (JNK) (Fig. 2A), the calcium (Fig. 2B), and the - best studied - $\beta$-catenin pathway (Fig. 3). The latter pathway is also known as the canonical pathway, uses $\beta$-catenin as second messenger and is regulated at many levels. In cells not exposed to Wnts, the major signaling components such as the receptors and $\beta$ catenin are kept in "off state." For $\beta$-catenin this is done by a complex that includes adenomatous polyposis coli (APC), glycogen synthase kinase (GSK) $3 \beta$, casein kinase 1 (CK1), and Axin. This complex interacts with $\beta$-catenin, which results in phosphorylation of serine and threonine residues by GSK3 $\beta$ and CK1. This complex is known as the $\beta$-catenin destruction complex since the phosphorylation leads to ubiquitination and degradation of $\beta$-catenin by the proteasome ${ }^{(116)}$. By this 


\section{Non-canonical Wnt/Frizzled signaling}

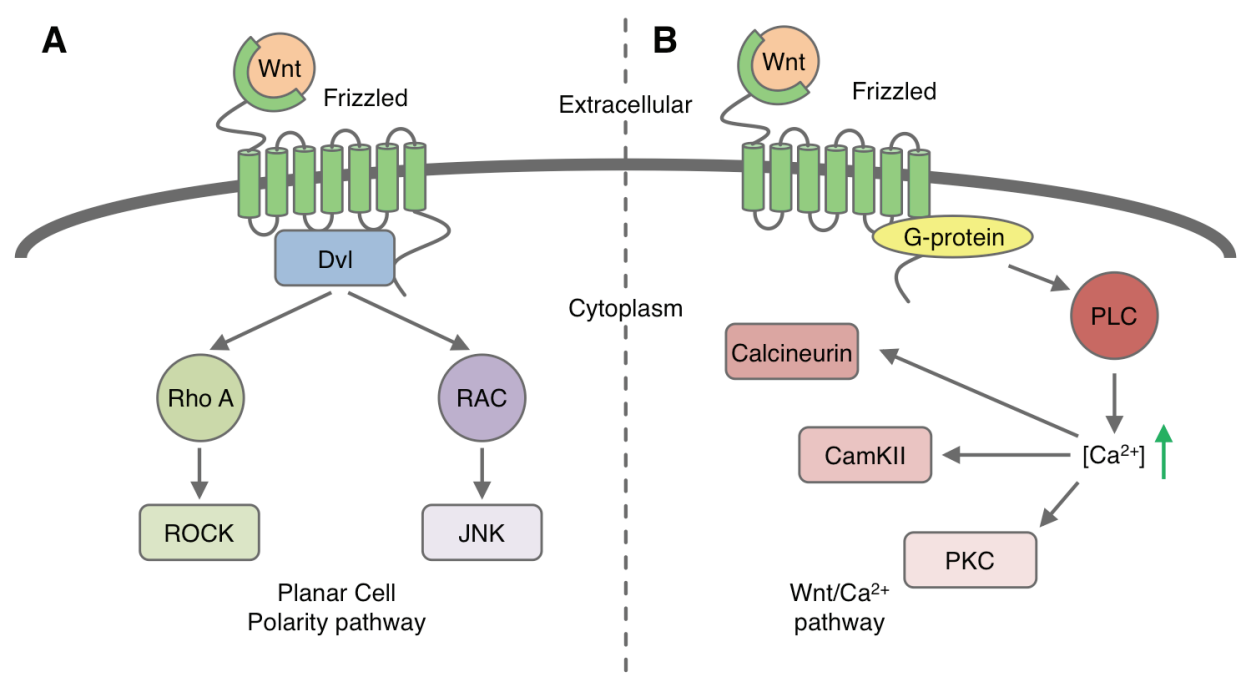

Figure 2 | Schematic overview of the non-canonical signaling pathways. (A) In the planar cell polarity pathway, Wnt binds to Frizzled and activates signaling independent from low-density lipoprotein receptor-related protein (LRP) 5/6. Dishevelled (Dvl) activates the small GTPases Rho and RAC that thereafter activate Rho kinase (ROCK) and c-jun N-terminal kinase (JNK) respectively. (B) The Wnt/Ca ${ }^{2+}$ signals through G-proteins that activate phospholipase-C (PLC). PLC causes a rise in intracellular $\mathrm{Ca}^{2+}$ that activates the $\mathrm{Ca}^{2+}$-dependent enzymes calcineurin, calcium/calmodulin-dependent kinase II (CaMKII), and protein kinase $\mathrm{C}$ (PKC). These enzymes can modulate the translocation of NFAT to the nucleus.

mechanism, cytoplasmic levels of $\beta$-catenin are kept low and the protein cannot enter the nucleus to activate gene transcription. Frizzled receptors are prevented from signaling by the negative regulator Dickkopf (DKK) that interacts with the LRP co-receptor. This leads to internalization of the LRPs and thereby reducing the availability of Wnt signaling ${ }^{(108)}$. Upon binding of Wnt to Frizzled and the LRP coreceptor, signaling is activated and results in the formation of a complex involving Dishevelled (Dvl), Axin, and GSK3 $\beta$ which leads to the breakdown of the destruction complex ${ }^{(48)}$. Now $\beta$-catenin is no longer phosphorylated, allowing it to accumulate in the cytoplasm and subsequently enter the nucleus where it interacts with T-cell factor/Lymphoid enhancing factor (TCF/LEF) transcription factors. These factors can activate transcription of a wide range of target genes including cyclin D1, c-jun, cmyc, fra-1, Axin2, Wnt1 inducible signaling pathway proteins (WISP) ${ }^{(112,133,201)}$, and many more. Axin2 is able to downregulate $\beta$-catenin and acts as a negative regulator 
of canonical Wnt signaling ${ }^{(103)}$. In the absence of Wnt signaling, the TCF/LEF complex acts together with Groucho as repressors of Wnt target genes. $\beta$-Catenin, together with the co-activators CBP, BCL9 and Pygopus, is able to transform the TCF/LEF complex into a transcriptional activator for the same target genes ${ }^{(80)}$.

The non-canonical signaling pathways (Fig. 2) do not make use of $\beta$-catenin. Wnt can stimulate the planar cell polarity (PCP) pathway (Fig. $2 \mathrm{~A})$, which regulates the orientation with adjacent cells and induces cytoskeletal rearrangements that lead to

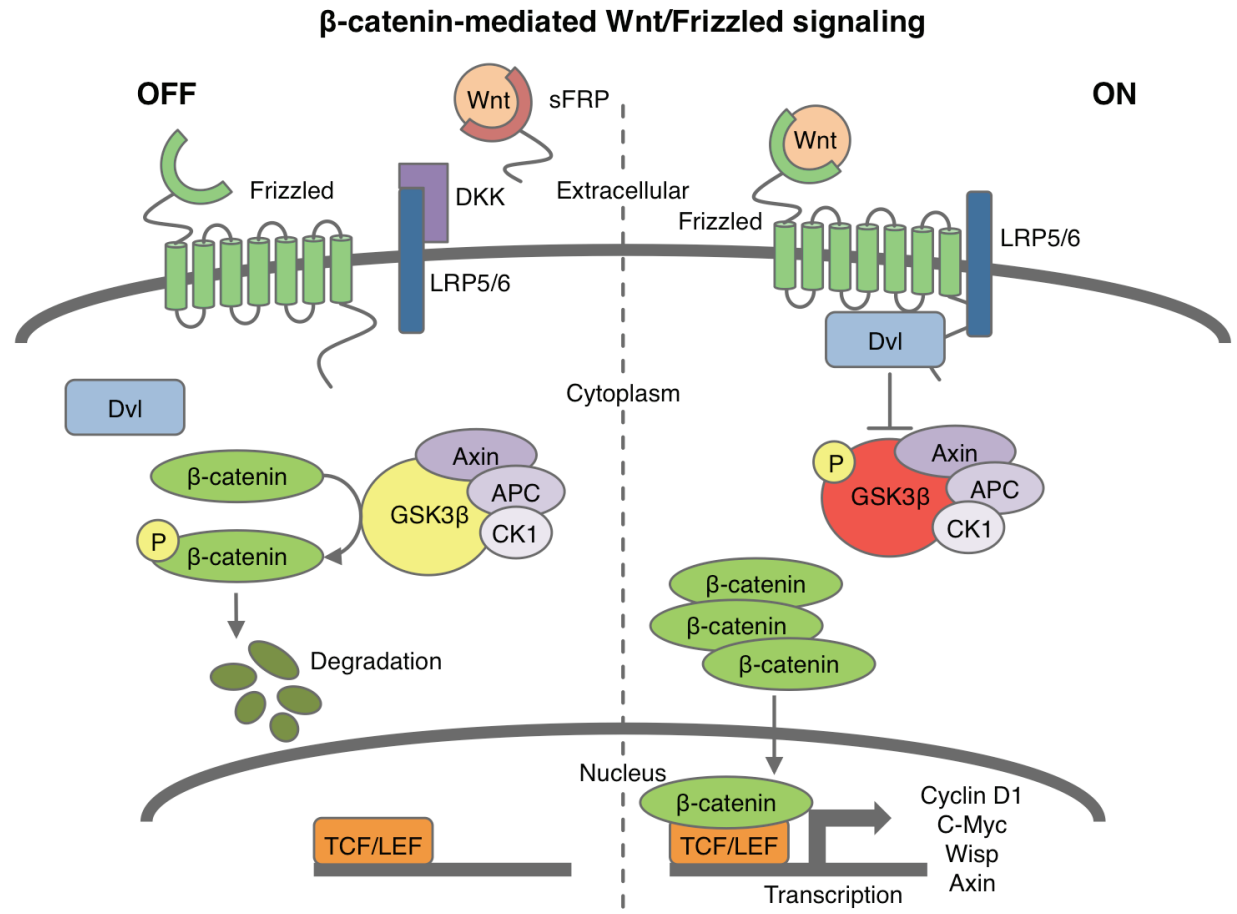

Figure 3 | Schematic overview of the canonical/ $\beta$-catenin-mediated signaling pathway. In the "off state" (left) the Frizzled receptor is not engaged by a Wnt protein. Wnts can also be scavenged by secreted frizzled-related proteins (sFRP), thereby inhibiting signaling. In addition, canonical signaling is also prevented by inhibition of the low-density lipoprotein receptor-related protein (LRP) 5/6 co-receptors by Dickkopf (DKK). In the absence of signaling, the $\beta$-catenin degradation complex consisting of glycogen synthase kinase $3 \beta$ (GSK3 $\beta$ ), Axin, adenomatous polyposis coli (APC), and casein kinase 1 (CK1) phosphorylates $\beta$-catenin, which causes ubiquitination and degradation of the latter. In this way, cytoplasmic $\beta$-catenin levels are kept low and prevent the protein from entering the nucleus to activate gene transcription. In the "on state" (right) Wnt binds to Frizzled and activates signaling together with the LRP co-receptors. Now Dvl is mobilized and inactivates the $\beta$-catenin degradation complex. Hence, $\beta$ catenin accumulates in the cytoplasm and is able to translocate to the nucleus where it interacts with the TCF/LEF transcription factors. These factors induce the transcription of Wnt-responsive genes. 
the development of lateral asymmetry in several structures. This is achieved by activation of the small GTPases RAC and Rho by Dvl, that thereafter activate JNK and Rho kinase ${ }^{(226)}$. Wnt can also induce calcium-dependent signaling via G-proteins (Fig. 2B). These proteins activate phospholipase- $C$ (PLC) which causes release of calcium from intracellular stores. The rise in intracellular $\mathrm{Ca}^{2+}$ can activate $\mathrm{Ca}^{2+}$-dependent enzymes such as the calcium/calmodulin-dependent kinase II (CaMKII), PKC, and calcineurin. Activation of CaMKII phosphorylates NFAT and thereby inhibits translocation to the nucleus ${ }^{(146)}$, whereas activated calcineurin can dephosphorylate NFAT, leading to an accumulation in the nucleus ${ }^{(61)}$. Less well-understood pathways involve the binding of Wnt to Ror and Ryk receptors. Ror2 has been shown to activate the JNK and/or inhibit the $\beta$-catenin pathway upon Wnt5a-mediated signaling ${ }^{(184)}$ whereas Ryk signaling has been linked to activation of members of the Src family of tyrosine kinases ${ }^{(261)}$.

\section{Modulation of signaling by endogenous and pharmacological agents}

Besides Wnts, two other families are known to activate Wnt signaling namely, Norrin and $\mathrm{R}$-spondin ${ }^{(58)}$. Alternative modulation of Wnt signaling can occur through several endogenous proteins. Two major classes have been described that prevent ligandreceptor interaction, but by different mechanisms. The DKK class inhibits signaling by interacting with LRP co-receptors, which causes internalization of the LRPs and thereby abrogate signaling. It has been indicated that DKK1-mediated LRP5/6 internalization is accompanied by interaction with single pass transmembrane proteins of the Kremen family ${ }^{(149)}$. On the contrary, in the absence of DKK1, Kremen can activate Wnt signaling through LRP5/6 ${ }^{(88)}$. This discrepancy is explained by the different mechanisms of internalization, since activation of Wnt signaling is also dependent on internalization ${ }^{(267)}$. The second class comprises of the secreted frizzled-related protein (sFRP) family that also includes WIF1 and Cerberus ${ }^{(108)}$. With their Frizzled-like CRD they can scavenge Wnts in the extracellular space and thereby affect the interaction between Wnt and Frizzled. Five family members of sFRPs, sFRP1-5, have been identified thus far $^{(120)}$. Besides their effect on Wnt signaling, 
sFRPs can also have other effects. For example, sFRP2 has been suggested to play a role in fibrosis ${ }^{(194)}$. Other small protein families such as, Wise/SOST, insulin-like growth factor (IGF)-binding protein 4, Shisa, adenomatosis polyposis coli downregulated 1, and Tiki1 have also been described to inhibit Wnt signaling but are not adequately studied thus far ${ }^{(58)}$

Several small molecule Wnt signaling modulators have been discovered to date that act on various targets of the signaling cascade (Table 1). To specifically inhibit the canonical signaling one could imagine that targeting the complex formation between $\beta$-catenin and TCF/LEF would be very effective since this is the most downstream part of this pathway. A few compounds have been suggested to target at this level, such as CGP049090 and PKF115-854 ${ }^{(132)}$; however, their efficacy and specificity still have to be confirmed thoroughly. Additional research on targeting $\beta$-catenin is probably omitted as it contains a large binding domain that is not easy to target with pharmacological agents ${ }^{(95)}$. On the other hand, ICG-001 is a small molecule that

Table 1 | Overview of Compounds that can Inhibit/Stimulate Wnt Signaling

\begin{tabular}{|c|c|c|c|}
\hline Target & Compound & Mechanism of action & Effect \\
\hline Porcupine & IWP2 & $\begin{array}{l}\text { Inactivation of porcupine thereby inhibiting Wnt } \\
\text { secretion }\end{array}$ & Inhibition \\
\hline Fzd1/2 & UM206 & Inhibits binding Wnt3a/5a to Fzd1/2 & Inhibition \\
\hline CK1 & Pyrvinium & $\begin{array}{l}\text { Stabilizing CK1 thereby promoting } \beta \text {-catenin } \\
\text { degradation }\end{array}$ & Inhibition \\
\hline Axin & $\begin{array}{l}\text { IWR } \\
\text { XAV939 }\end{array}$ & $\begin{array}{l}\text { Stabilizing Axin thereby promoting } \beta \text {-catenin } \\
\text { degradation }\end{array}$ & Inhibition \\
\hline GSK3 $\beta$ & $\begin{array}{l}\text { Lithium Chloride } \\
\text { SB-216763 } \\
\text { AR-A014418 } \\
\text { CHIR } \\
\text { BIO }\end{array}$ & $\begin{array}{l}\text { Inhibits GSK3 } \beta \text { thereby reducing } \beta \text {-catenin } \\
\text { degradation }\end{array}$ & Stimulation \\
\hline unknown & KY02111 & unknown & Inhibition \\
\hline$\beta$-catenin & $\begin{array}{l}\text { CGP049090 } \\
\text { PKF115-854 } \\
\text { ICG-001 }\end{array}$ & Prevents $\beta$-catenin mediated transcription & Inhibition \\
\hline
\end{tabular}


targets $\beta$-catenin as well, albeit on another binding region. ICG-001 is able to specifically block the interaction between $\beta$-catenin and one of its transcriptional coactivators, cyclic AMP response element-binding protein (CBP), thereby preventing $\beta$-catenin TCF-mediated transcription ${ }^{(66)}$. Recently, a new small molecule, KY02111 $11^{(168)}$, has been identified to inhibit canonical Wnt signaling, though its direct target has not been discovered yet. In vitro experiments indicate that it might function downstream from GSK3 $\beta$ and APC in the $\beta$-catenin degradation complex but additional research is needed to clarify this. Another protein in this complex is Axin. Stabilization of Axin by molecules such as IWR ${ }^{(37)}$ and XAV939 ${ }^{(94)}$ increase the $\beta$ catenin degradation and thereby inhibit the canonical pathway. Degradation complex member $\mathrm{CK} 1$ has also been described as a target for inhibition. This is carried out by the FDA-approved drug Pyrvinium that has been shown to boost the activity of CK1 by increasing $\mathrm{CK}_{1}$ a-kinase activity ${ }^{(214,235)}$. Porcupine is essential for processing and secretion of Wnts and would therefore be an ideal target to specifically affect Wnt signal transduction. Screening of a synthetic chemical library has led to the discovery of IWP2, which is able to inactivate porcupine with a high degree of selectivity and thereby block secretion of Wnts ${ }^{(37)}$. Notably, no small molecule has been unveiled that prevents the interaction between a Wnt ligand and Frizzled receptor. Nevertheless, there is a 13-amino-acid-enclosing peptide fragment of Wnt3a/Wnt5a, UM206, that has been described by our group to inhibit Wnt/Frizzled signaling by utilizing a Wnt3a binding site on the Fzd1 and Fzd2 receptor $^{(128)}$. The exceptional structure and shape of Wnt ligands with their two binding sites (Fig. 1), that recently has been published $^{(101)}$, might complicate the screening for small molecules that block binding to the receptor with a high specificity and affinity.

Most agonists for Wnt signaling target GSK3 $\beta$, as inhibition of this protein results in accumulation of $\beta$-catenin in the nucleus and subsequent transcription of target genes. Hence, GSK3 $\beta$ is an attractive and easy target for promoting Wnt signaling. The most classical compound that has been utilized for this purpose is Lithium Chloride ( $\mathrm{LiCl}$ ). LiCl potently inhibits GSK3 3 (IC $502 \mathrm{mmol} / \mathrm{L})$, yet it is not an inhibitor of other protein kinases ${ }^{(119)}$. Since the late 1990 s several other compounds have been 
identified that inhibit GSK3 $\beta$ with more potency and selectivity than $\mathrm{LiCl}$. These compounds include SB-216763 $3^{(49)}, \mathrm{BIO}^{(161)}, \mathrm{CHIR}^{(208)}, \mathrm{AR}-\mathrm{A} 014418^{(24)}$, and thiadiazolidinones ${ }^{(152)}$, and have $\mathrm{IC}_{50}$ values in the micro- to nanomolar range. There are differences between the compounds with respect to the mechanisms of action. Thiadiazolidinones are non-ATP competitive inhibitors, whereas SB216763, ARA014418 and CHIR do compete for these binding sites. The numerous agents that are available demonstrate that GSK3 $\beta$ is an easy target. However, GSK3 $\beta$ is not only involved in Wnt signaling but also functions as a "hub" in various other signaling events. GSK3 $\beta$ activity can be regulated by other singling pathways such as the IGF pathway $^{(222)}$ and $\beta$-adrenergic signaling ${ }^{(173)}$. As a consequence, GSK3 $\beta$ inhibition has pleiotropic effects by affecting other pathways as well. For this reason, study outcomes have to be carefully interpreted when using these compounds.

To sum up, Wnt signaling can be inhibited at distinct levels of the pathway with the current available modulators. However, to expand our understanding of the Wnt pathway, there is a need for the discovery of more compounds. An interesting challenge will be to block the interaction between specific subsets of Wnts, Frizzleds and their co-receptors to pinpoint the effect of distinct ligand/receptor combinations.

\section{Wnt Signaling in Cardiovascular Development}

\section{Cardiogenesis}

Wnt/Frizzled signaling is fundamental for a wide range of developmental mechanisms including the formation of the embryonic heart. A substantial amount of research has been done to elucidate the role of Wnt signaling in cardiogenesis and to disclose the causes of congenital heart diseases. In addition, this research is also beneficial from a therapeutic point of view to enhance cardiac regeneration or differentiation from cardiac progenitor cells following a traumatic event. It has been demonstrated that Wnt signaling plays an important role in many processes involving cardiac development and differentiation ${ }^{(31,65,76,118,239)}$. 
In mammals, the multichambered heart is the first organ that is formed during development to provide the growing embryo with sufficient nutrients and oxygen ${ }^{(228)}$. Different, partially overlapping, phases can be distinguished during the development of the vertebrate heart. Formation is initiated by specification of myocardial and endocardial precursor cells in the heart-forming fields of the anterior lateral plate mesoderm. The heart is formed from two heart fields. Cardiac progenitor cells from the first heart field contribute to the left ventricle and atria whereas precursor cells from the second heart field mainly contribute to the outflow tract, right ventricle and atria $^{(33)}$. Following specification of precursor cells, the linear heart tube is formed by cell migration and morphogenetic movements. These initial processes are followed by cardiac looping, chamber formation, septation, and formation of the cardiac valves $^{(31)}$. The expression of Wnt ligands, Frizzled receptors, or extracellular Wnt inhibitors occurs during all of these phases and involves complex expression patterns in different regions and cell types.

\section{Wnt signaling in the different stages of cardiogenesis}

Even before cardiac progenitor cells can be specified from the mesoderm, this germ layer has to be formed. Canonical Wnt signaling has been shown to be essential for mesoderm formation. Knock-out of $\beta$-catenin, or absence of functional Wnt3a fails to generate mesodermal-specific tissue ${ }^{(97,140)}$. Initial data demonstrated conflicting results concerning the Wnt/ $\beta$-catenin function during cardiac specification. In chicken and Xenopus embryos, activation of canonical Wnt signaling in the anterior mesoderm suppressed cardiac differentiation whereas inhibition favors cardiac development ${ }^{(153,218)}$. On the other hand, cell culture experiments have proven active Wnt signaling to be favorable for cardiac-specific gene expression ${ }^{(179)}$. More recent data resolve this conflict by indicating time dependent effects of Wnt signaling. In zebrafish embryos, application of Wnt8a before gastrulation results in more, while administration after gastrulation results in less cardiomyocytes. This effect could be reversed by administering DKK1 at specific time points ${ }^{(241)}$. These findings suggest a 
biphasic function, or possibly a gradient, of Wnt/ $\beta$-catenin signaling during cardiogenesis.

Not only canonical, but also non-canonical Wnt signaling contributes to cardiac specification in the mesodermal germ layer. To this end, Wnt11 is the best studied protein and has been shown to be required for cardiac differentiation through activation of non-canonical signaling involving PKC and JNK ${ }^{(64,197)}$. In addition, in Xenopus embryonic explants, Wnt11 is sufficient to trigger a contractile phenotype, as also observed by the Wnt/ $\beta$-catenin inhibitor DKK $1^{(197)}$. However, DKK1 has been described strictly as canonical Wnt inhibitor and Wnt11 has also been defined as a dominant negative inhibitor of canonical Wnts ${ }^{(157,257)}$, suggesting that this effect is not solely due to non-canonical signaling but by suppression of $\beta$-catenin-mediated signaling as well.

Wnt signaling is also involved in later stages of cardiac development. A prerequisite for cardiac morphogenesis is cell adhesion and direct cell-cell contact in which $\mathrm{N}$ cadherin plays a vital role. $\mathrm{N}$-cadherin deficient mice do form cardiomyocytes but fail to develop a linear heart tube due to absence of these cell-cell contacts ${ }^{(205)}$. Noncanonical Wnt signaling, in particular Wnt11 through involvement of PKC, has been shown to orchestrate $\mathrm{N}$-cadherin expression ${ }^{(263)}$. In addition, Wnt signaling regulates the expression of $\mathrm{N}$-cadherin and the strength of $\mathrm{N}$-cadherin mediated cell adhesion in neonatal cardiomyocytes ${ }^{(71,237)}$. Subsequent formation of structural components of the heart has shown to be mediated by canonical signaling. Specific $\beta$-catenin downregulation in the second heart field results in absence of the outflow tract and right ventricle ${ }^{(2,50,118,127,139)}$. Overexpression of $\beta$-catenin on the other hand, results in enlargement of second heart field-derived structures ${ }^{(2,127)} \cdot \beta$-Catenin mediated Wnt signaling has also been implicated in endocardial cushion development, which eventually gives rise to the heart valves ${ }^{(98)}$. Inhibition of canonical Wnt signaling prevents the development of these structures whereas enhanced signaling leads to enlarged endocardial cushions. Finally, there is some evidence that the formation of the cardiac conduction system is also under the control of Wnt signaling. Looped 
hearts from chickens, treated with Endothelin-1 (ET-1) reveal an upregulation of Wnt7a and Wnt11 and this could be verified in peripheral and central sections of the conduction system, respectively ${ }^{(28)}$.

Taken all together, Wnt signaling, either canonical or non-canonical, plays an important role in cardiac development including formation of the mesoderm, myocardial specification, morphogenesis of the heart, and valve formation. Nevertheless, the activation or inhibition of canonical/non-canonical signaling during the several processes is tightly regulated and demonstrates to be crucial for proper heart development.

\section{Vascular development}

During vertebrate development, the embryo reaches a size where it can no longer rely on diffusion for the transport of oxygen and nutrients. To solve this, the formation of a circulatory system precedes the organogenesis, a process generally referred to as vasculogenesis. Subsequently, the vasculature grows and differentiates to accommodate the needs of the newly formed tissues, which is called angiogenesis ${ }^{(150)}$. The first step in vasculogenesis is the differentiation of mesodermal progenitor cells in the extraembryonic yolk sac into endothelial and hematopoietic cells, which form a primary vascular plexus ${ }^{(70)}$. Bone Morphogenetic Protein 4 and fibroblast growth factor 2 are important mediators of the differentiation of the mesodermal cells into either endothelial or hematopoietic lineages. The proliferation of the endothelial cells, required to form a vascular network, is under the control of vascular endothelial growth factor (VEGF), retinoic acid, and Notch signaling ${ }^{(150)}$. The angiogenic maturation of the vascular plexus involves sprouting, a process that requires the dissociation and migration of endothelial tip cells which are followed by stalk cells. The differentiation of endothelial cells into either tip or stalk cells is reversible, and depends on the balance of proangiogenic factors such as VEGF and anti-angiogenic factors such as Notch signaling(207). 


\section{Wnt signaling in vascular morphogenesis}

Wnt signaling has been associated with many of the processes involved in vasculogenesis. Endothelial cells express a wide array of Wnt and Frizzled genes as well as some Wht modulators such as sFRPs and DKKs ${ }^{(70,79)}$. Differentiation of endothelial cells from embryonic stem cells can be enhanced by stimulation with Wnt3a as well as Wnt5a, and both canonical and non-canonical signaling appear to be required $^{(250,268)}$. Targeted deletion of Fzd5 was shown by Ishikawa et al. to lead to a defective vasculogenesis in the mouse placenta, a disorganization of the capillary plexus and markedly reduced endothelial cell proliferation, resulting in embryonal lethality at day 10.75 post-coitum ${ }^{(100)}$. Wnt3a enhances the proliferation and migration of HUVEC by both $\beta$-catenin dependent and independent mechanisms through interaction with $\mathrm{Fzd} 4$ and Fzd6 ${ }^{(212)}$. These observations are supportive for a prominent but complex role of Wnt signaling in the earliest stages of vascular development.

In angiogenesis, endothelial cells undergo functional specialization as each sprout is formed by a tip cell, involved in guiding the vessel in the required direction, followed by rapidly proliferating stalk cells which allow the elongation and form the endothelial lining of the newly formed vessel. As shown in Figure 4, Wnt signaling plays a direct role in the stalk cells, as stimulation of canonical Wnt signaling promotes tube formation in vitro and increases vascular density in in vivo models ${ }^{(79,250)}$. Inhibition of Wnt signaling showed mixed results, as overexpression of sFRP2 has been shown to either promote $^{(56)}$ or reduce ${ }^{(182)}$ angiogenesis and overexpression of DKK1 promoted vascularization $^{(4)}$. No evidence for a direct effect of Wnt signaling on tip cells has yet been presented, but Wnt signaling does have an indirect effect on angiogenesis by controlling the expression of the Notch ligand Delta-like ligand 4 (DII4) via a $\beta$-catenin mediated mechanism (Fig. 4). Dll4 is thought to regulate the specification of endothelial cells into tip and stalk cells during angiogenic sprouting, and tip cells express higher levels of DII4. This DII4 is thought to activate Notch signaling in the neighboring stalk cells in the sprout, thereby suppressing the tip phenotype in the stalk cells ${ }^{(192)}$. The importance of DII4 in vascular development is highlighted by the 


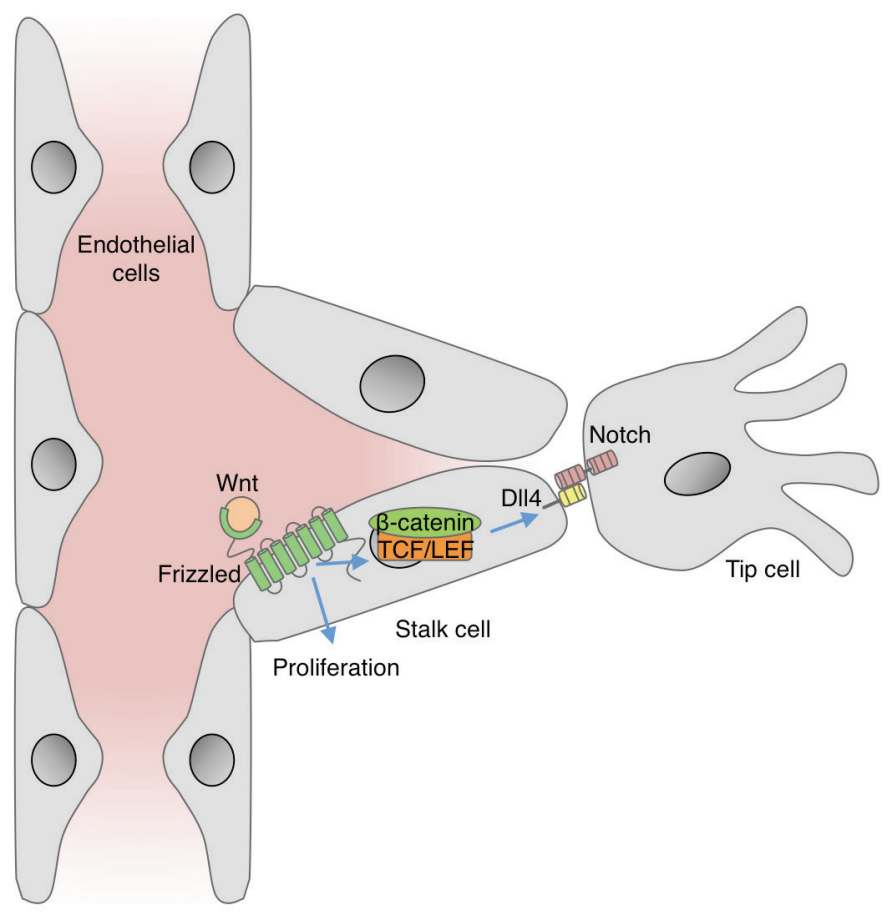

Figure 4 | Effect of Wnt signaling on sprouting angiogenesis. In sprouting angiogenesis, tip cells guide the sprout into the required direction whereas the following sprout cells can proliferate and form the new vessel. Activation of Wnt signaling promotes the proliferation of stalk cells and their organization into tube-like structures. There is no evidence for a direct effect of Wnt signaling on tip cells, but Wnt signaling can affect these cells indirectly by augmenting the expression of Delta-like ligand 4 (DII4) in the stalk cells, which can activate the Notch signaling in the tip cells in a paracrine way, thereby inducing a stalk-like phenotype in these cells.

observation that haploinsufficiency for DII4 results in embryonic lethality due to a defective vasculature reminiscent of those observed in Notch knock-outs ${ }^{(73)}$. Interestingly, similar vascular defects have been reported in mice carrying an endothelium-specific gain-of-function mutant of $\beta$-catenin, suggesting an important role for this second messenger in the transcriptional control of DII4 (55). On the other hand, endothelial-specific deletion of $\beta$-catenin also led to aberrant vascular development, hyperbranching, and diffuse hemorrhages, the latter likely being the result of impaired adherens junctions where $\beta$-catenin plays a vital role in cell adhesion $^{(35,55)}$. 
The next important event in the formation of a functional vascular network is the specification of arteries and veins. VEGF is an important inducer of arteriogenesis through activation of the Notch pathway, highlighting a second important role of this pathway next to stalk cell stabilization. As pointed out in two recent reviews from the Dejana group ${ }^{(54,172)}$, canonical Wnt signaling can act upstream of Notch signaling by upregulating the expression of its ligand DII4, thereby inducing an arterial gene program. Alternatively, canonical Wnt signaling can increase the levels of the transcription factor Sox 17 which in turn activates the transcription of Notch4, thereby promoting arterial specification. Venous differentiation can be induced by the expression of chicken ovalbumin upstream promoter transcription factor II (COUPTFII) resulting in repression of Notch signaling ${ }^{(269)}$. No effects of Wnt signaling on venous differentiation have been described to date.

Endothelial cells do not have uniform properties throughout the body but can specialize according to the needs of the organs. This specialization is induced via crosstalk with the cells of the surrounding tissue and affects the permeability, transcellular transport systems, and the expression of adhesion molecules ${ }^{(60)}$. In the blood-brain barrier (BBB), the endothelial cells of the capillaries adhere strongly via tight junctions, allowing the tight control of the crossing of most molecules and ions $^{(187)}$. Targeted deletion of Wnt7a and $7 \mathrm{~b}$ resulted in severe defects in central nervous system (CNS) vascular development and brain hemorrhage ${ }^{(229)}$.Moreover, the BBB-specific transporter GLUT1 and the tight junction protein claudin-3 are also controlled by canonical Wnt signaling ${ }^{(137,229)}$. In a recent study, Zhou et al. showed that the sensitivity of the vasculature to canonical Wnt signaling differs in different brain regions and that loss of LRP5 dramatically affected the vasculature of the retina, but not of the brain ${ }^{(276)}$. Interestingly, these authors also observed that Wnt signaling was required to maintain the plasticity of the BBB in mature CNS vasculature.

Two mutations in components of the Wnt signaling have been linked to disorders of the retinal vasculature. In familiar exudative vitreoretinopathy, mutations in the Fzd4 gene result in the translation of a truncated protein that lacks signaling activity. This 
leads to a reduced signaling via CaMKII/PKC, both components of the Wnt/Ca ${ }^{2+}$ signaling ${ }^{(209)}$. A similar phenotype can be observed in patients suffering from Norrie disease. This condition causes a progressive vasculopathy of the retina and other parts of the CNS and is associated with mutations in the Norrin protein ${ }^{(160)}$. This cysteine-rich protein, although unrelated to Wnt, has been shown to activate the Fzd4 receptor, which explains the similarity in phenotype between mutations in this receptor and the Norrin protein ${ }^{(271)}$.

\section{Wnt Signaling in Infarct Healing}

More than seven million people each year are estimated to suffer from myocardial infarction $(\mathrm{MI})^{(258)}$. MI is the consequence of a partially or completely occluded coronary artery due to a thrombus, stenosis (due to atherosclerosis) or a coronary spasm. As a result blood flow is impaired and the myocardium is deprived from oxygen and nutrients. Depending on the duration of the ischemia, myocyte death can occur followed by a long-lasting and complex wound healing process that aims to replace the lost cardiomyocytes and to prevent cardiac rupture, and thereby support the contractile function of the heart.

The wound healing process consists of several phases involving various cell types and aiming to end up with the formation of a well-healed scar. The inflammatory phase is initiated early after MI (12-16 h post-MI) and is triggered by the release of chemokines and cytokines from necrotic cardiomyocytes that attract inflammatory cells into the infarcted area. Dead tissue is removed by phagocytic cells such as macrophages. This is followed by infiltration of fibroblasts that deposit extracellular matrix (ECM) components, not only in the infarct but also in remote regions ${ }^{(46)}$. Fibroblasts can differentiate into myofibroblasts under influence of mechanical tension and the antiinflammatory cytokine transforming growth factor (TGF) $\beta 1$. Myofibroblasts also secrete ECM proteins and express alpha smooth muscle actin (aSMA) that contracts the scar and prevent dilatation of the infarct ${ }^{(59)}$. Finally, the number of cells in the infarct decrease and the deposited ECM will mature into a stabilized scar by crosslinking of collagens. Remodeling of the left ventricle can proceed for months 
post-MI and can cause hypertrophy in the remaining cardiomyocytes and dilatation of the left ventricle by thinning of the infarct scar. This pathological remodeling develops slowly and may lead to heart failure.

\section{Wnt signaling following MI}

Under physiological conditions in the adult heart, Wnt signaling is mostly silent. However, in cardiovascular pathology re-expression of fetal genes is generally observed $^{(126)}$. Recent evidence also demonstrates an altered expression of components of Wnt signaling pathways in experimental models following MI (Fig. 5). Mice that underwent left anterior descending coronary artery (LAD) ligation to induce MI, demonstrated an upregulation in mRNA expression of Fzd1, 2, 5, and 10 and a downregulation of Fzd8 in infarcted hearts 1 week post-MI. Fzd 3, 4, 6, and 7 were not changed and Fzd9 was not measured in this study. In addition, of the Wnt ligands, only Wnt10b mRNA expression was increased, whereas the mRNA expression of Wnt7b was decreased $^{(18)}$. Moreover, another study has shown increased expression of Wnt2, Wnt4 Wnt10b, and Wnt11 as well, 5 days after LAD ligation ${ }^{(5)}$. Previous work from our group showed that induction of $\mathrm{Ml}$ in rats resulted a gradual increase in expression of Fzd2 in the infarcted area in the initial repair phase and peaked at 7 days post-MI. This expression co-localized with the spatial movement of myofibroblasts toward the infarct region, suggesting a role in myofibroblast migration and alignment ${ }^{(26)}$. Dvl, the protein that inhibits the $\beta$-catenin degradation complex, is activated upon active Wnt signaling and has been shown to be upregulated following $\mathrm{MI}$ in rats. In line with the Fzd2 expression observed by our group, Dvl expression is gradually increased until 7 days after MI, followed by a decline to baseline levels after 28 days $^{(39)}$. It is suggested by the authors that Dvl might play a role in the proliferation and migration of myofibroblasts and vascular endothelial cells since positive staining for Dvl was extended into endothelial and smooth muscle cells of the preexisting and newly formed blood vessels in the infarcted area. Since Dvl is a downstream effector of Fzd2, these findings correspond to the aforementioned study of our group. Microarray analysis in rats subjected to MI displayed a Wnt pathway activation in the 


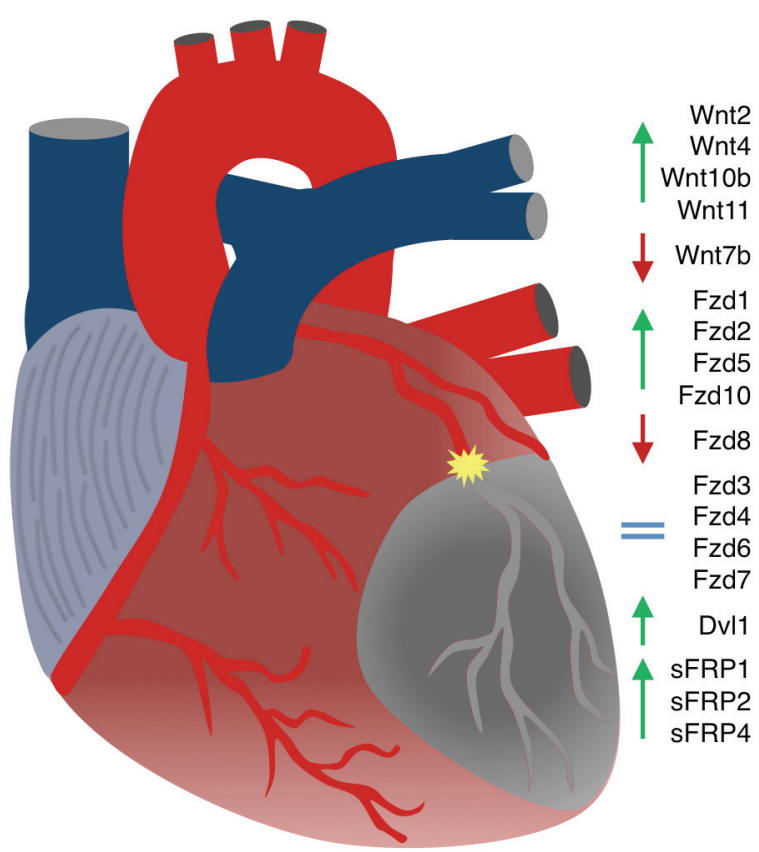

Figure 5 | Expression patterns of Wnt signaling components \pm 1 week after $\mathrm{Ml}$ in experimental animal models. A green arrow indicates an upregulation, a red arrow downregulation and "=" indicates no difference in gene expression. Fzd; Frizzled, sFRP; secreted frizzled-related protein.

infarct region after 1 day by increased expression of WISP1 and APC. However, the factor important for transcription of target genes, $\beta$-catenin, was downregulated by $50 \%$. After 4 weeks, WISP2 and sFRP4 were elevated both in infarct and remote region ${ }^{(129)}$. Increased WISP1 expression was also observed in mice following MI. Here a time-dependent increase of WISP1, both mRNA and protein, was detected in the non-infarct zone of the left ventricle and remains elevated till 1 week post-MI ${ }^{(52)}$.

sFRPs demonstrate an altered expression following MI as well. In mice, sFRP1 mRNA expression was increased in the infarct zone compared to healthy myocardium 1 week post-MI and returned to baseline levels 1 week afterward ${ }^{(18)}$. sFRP2 revealed a similar pattern with a 20- to 30-fold upregulation of mRNA at 4 days, that increased to 80 - to 100 -fold at 1 week and gradually declined to 30 - to 40-fold expression 14 days post-MI ${ }^{(120)}$. On the other hand, in rats the level of sFRP2 expression peaked at 3 days and was not detectable anymore at 2 weeks following $\mathrm{MI}^{(89)}$. It must be noted 
that these are protein levels whereas the previously mentioned study used mRNA as a measure of sFRP2 expression. Finally, sFRP4 gene expression peaked early following MI too (3-5 days), but remained increased for 3 weeks and returned to baseline at 28 days ${ }^{(156)}$.

Using immunohistochemical techniques, our group has shown the presence of $\beta$ catenin in endothelial cells in granulation tissue at 1 week post-MI, suggesting a role in proliferation and migration of these cells during neovascularization of the infarct area $^{(27)}$. A recent study on the response of canonical Wnt signaling to cardiac injury provides better insights to the types of cells that have active canonical Wnt signaling and the absolute increase in Wnt signaling. To this end C57BL/6 Axin2-LacZ reporter mice were used ${ }^{(188)}$. As demonstrated in Figure 3, Axin2 is a target gene of $\beta$-catenin mediated gene transcription and acts as a negative regulator in Wnt signaling. Hence, active canonical Wnt signaling is indicated by LacZ positive cells. At 3 days post-MI, there was no increase in $\mathrm{LacZ}^{+}$cells compared to sham mice $(9.44 \pm 0.30 \%)$. However, the increase of active Wnt signaling started between 3 and 7 days $(14.47 \pm 0.75 \%)$ post-MI and stabilized between $14(22.42 \pm 0.97 \%)$ and 21 days $(24.98 \pm 1.37 \%)$. Significant upregulation of Wnt signaling was observed throughout the whole myocardium and included different cell populations. Progenitor cells, endothelial cells, leukocytes, and fibroblasts all demonstrated upregulated signaling, but they had a distinct response in time suggesting cell-specific activation of Wnt signaling after MI. TOPGAL reporter mice, encoding LacZ upon activation of TCF/LEF by $\beta$-catenin, also demonstrated activation of Wnt signaling already 4 days after MI, but not after $24 \mathrm{~h}^{(5)}$. This activation disappeared 3 weeks after induction of MI. Wnt signaling was scattered throughout the myocardium at 4 days, whereas this was confined to the infarct and peri-infarct regions by 7 days post-MI. Wnt signaling was observed in endothelial cells, macrophages and $\mathrm{aSMA}^{+}$cells and they demonstrated that most of the latter cells originated from (partly subepicardial) endothelial cells that had undergone endothelial to mesenchymal transition, suggesting that canonical Wnt signaling is involved in this process after ischemic injury. This was confirmed by Duan 
et al. by demonstrating that epicardial to mesenchymal transition is governed by Wnt $1 / \beta$-catenin mediated signaling following $\mathrm{MI}^{(63)}$.

These studies clearly demonstrate that significant activation of canonical Wnt signaling arises in the heart following ischemia. This makes it an interesting target for novel pharmacological treatments following $\mathrm{MI}$ to improve the wound healing process.

\section{Modulation of Wnt signaling post-MI}

As demonstrated in the previous section, Wnt signaling is activated following $\mathrm{MI}$ in several cell types throughout the myocardium, suggesting an extensive role for Wnt signaling in cardiac repair. The current pharmacotherapeutic arsenal that is applied following $\mathrm{MI}$ is not specifically aiming at cardiac remodeling and the progression to heart failure, but mainly focuses on repressing the symptoms. Hence, novel agents are required to develop more efficient therapeutic strategies post-MI. One of these targets could be the Wnt signaling pathway. Lately, more and more studies have attempted to intervene in Wnt signaling post-MI by acting on different levels of the pathway. An overview of these studies will be provided below.

\section{Modulation of SFRPs}

The group of Duplàa has extensively studied the role of FrzA, also known as SFRP1, in mice following experimental MI. Overexpression of sFRP1 in mice was shown to reduce infarct size and prevent cardiac rupture following $\mathrm{MI}$ while improving cardiac function. These effects were supported by decreased apoptosis and early leukocyte infiltration and an increased collagen deposition and capillary density in the $\operatorname{scar}^{(17,18)}$. More recently they transplanted bone marrow-derived cells (BMCs) overexpressing sFRP1 in wild-type recipient mice and compared myocardial infarct healing with mice overexpressing SFRP1 specifically in endothelial cells or in cardiomyocytes to drive expression in leukocytes and better understand the mechanism behind the beneficial effect of sFRP1. sFRP1, overexpressed in BMCs, was able to diminish leukocyte infiltration following $\mathrm{MI}$, by switching the pro- and anti-inflammatory cytokine 
balance, resulting in a decreased scar size and better cardiac function. These effects were not observed in mice overexpressing SFRP1 in endothelial cells or cardiomyocytes, indicating a specific role for SFRP1 in the inflammatory response ${ }^{(16)}$.

The protective role of sFRP2 in infarct healing was first demonstrated by Mirotsou et al. Injection of conditioned medium from mesenchymal stem cells (MSCs) overexpressing the Akt gene reduced the infarct size within $72 \mathrm{~h}$ following $\mathrm{MI}$ in rats. The involvement of SFRP2 was proven by the loss of effect when these MSCs were treated with siRNA against SFRP2 ${ }^{(169)}$. Injection of SFRP2 in the infarcted rat myocardium inhibited type I collagen deposition and significantly reduced left ventricular fibrosis. Furthermore, it prevented anterior wall thinning and improved cardiac function 4 weeks after $\mathrm{MI}^{(89)}$. In contrast, sFPR2 knock-out mice subjected to MI also demonstrated reduced fibrosis, accompanied by improved cardiac function from 14 days post-Ml and onward ${ }^{(120)}$. The previously described actions carried out by sFRP2 are most likely not the result of altered Wnt signaling but more due to its effects on collagen processing. SFRP2 is able to inhibit BMP1 that plays a key role in the collagen synthesis and maturation after tissue injury and cannot be fulfilled by SFRP1 or $3^{(89)}$. The discrepancy between the discussed studies can possibly be explained by the biphasic effects of sFRP2 on BMP1 activity: both low and high levels of SFRP2 could activate and inhibit pro-collagen processing by BMP1, respectively ${ }^{(154)}$. To further exemplify the role of SFRP2 in fibrosis, more research is needed to understand the concentration-dependent action of SFRP2 on individual effectors.

Recombinant sFRP4 administration was shown to be beneficial following permanent $\mathrm{MI}$ as well as in the reperfused myocardium in rats ${ }^{(156)}$. SFRP4 was able to increase cardiac wall thickness and to reduce scar size and was accompanied by prevention of impaired cardiac function. These effects were suggested to be mediated by inhibition of canonical Wnt signaling as demonstrated by both decreased amounts of inactive GSK3 $\beta$ and $\beta$-catenin compared to control animals. 
In summary, sFRPs were proven to be associated with wound healing following MI, although next to their described antagonistic effects on Wnt signaling they can also control other mechanisms post-MI such as inflammation and fibrosis.

\section{Interventions at the receptor level}

DKK2, known as a Wnt signaling antagonist, binds to LRP5/6 to inhibit signaling and was shown to possess a therapeutic effect when injected in the rat myocardium after 60 min of ischemia followed by reperfusion ${ }^{(167)}$. One week after MI, the infarct size was significantly decreased together with the degree of fibrosis in DKK2-treated animals. DKK2 also reduced the amount of apoptotic cells and increased neovascularization the infarcted heart. Functional analysis at 3 weeks showed improved cardiac function by better systolic performance and cardiac dimensions compared to non-treated animals.

Administration of the canonical agonist Wnt3a into the border region of the infarct, directly after the ischemic injury was established, impaired the regenerative response as demonstrated by increased infarct size and left ventricular volume 1 week after $\mathrm{MI}^{(189)}$. Moreover, cardiac performance was diminished compared with vehicle treated animals. This outcome is governed by a significant reduction of cardiac side population (CSP) cells and involves insulin growth factor-binding protein 3 (IGFBP3). The Wnt3a mediated suppression in CSP cells is thought to alter myocardial healing by significant reduction of new cardiomyocyte generation. In a study from our group, treatment with a peptide fragment of Wnt3a/Wnt5a (UM206) following MI for 5 weeks, reduced infarct expansion by increased wall thickness and higher myofibroblasts numbers in the infarct region. This was accompanied by improvement of cardiac function and prevention of heart failure development ${ }^{(128)}$. The effect of UM206 is thought to be established by antagonizing binding of Wnt3a and Wnt5a to Fzd1 or Fzd2 receptors leading to inhibition of Wnt signaling. A less well-understood mechanism is the increase of Dvl1 and $\beta$-catenin by a single exogenous injection of high-mobility group box 1 protein into the infarcted myocardium (HMGB1). This led to reduced collagen volume in the infarct and improved cardiac function in treated 
animals $^{(275)}$. These data suggest that HMGB1 is able to activate canonical Wnt signaling through Dvl1; however, Dvl normally mediates Wnt signal delivery from the receptor to the intracellular compartment proposing that HMGB1 can intervene in Frizzled activation.

\section{Modulation of the $\beta$-catenin degradation complex}

The FDA-approved drug Pyrvinium, used as an anti-helminthic agent, potently inhibits Wnt signaling ( $\mathrm{IC}_{50}$ of $\left.\sim 10 \mathrm{nmol} / \mathrm{L}\right)$ by activating $\mathrm{CK} 1 \mathrm{a}$, thereby preventing Axin degradation and promoting the breakdown of $\beta$-catenin. A single injection of this drug into the border zone of the infarct resulted in an improved left ventricular remodeling 30 days after $\mathrm{MI}$ as demonstrated by a decrease of the diastolic left ventricular internal diameter ${ }^{(214)}$. However, the systolic dimensions, contractile function and infarct size were not different between the treated and control group. Favorable cardiac remodeling is thought to be promoted by increased proliferation of differentiated cardiomyocytes in the remote myocardium, as demonstrated by increased amount of proliferating cells. Inducible cardiomyocyte-specific knock-out of GSK3 $\beta$ following MI led to less ventricular dilatation and more preserved cardiac function at 8 weeks after $\mathrm{MI}$, although there was no difference in ejection fraction at 1 week after $\mathrm{MI}^{(262)}$. This could implicate that deletion of the GSK3 $\beta$ gene does not have a direct effect on the scar formation or wound healing, as also demonstrated by similar infarct size between groups, but apparently affects cardiomyocytes to become hypertrophic and reinforce cardiac function as was seen by increased crosssectional areas of the knock-out cardiomyocytes. In contrast with the previous study, Wnt signaling was promoted in the latter study, but both resulted in better cardiac function. As already said, this could mean that the timing of the intervention is critical for the outcome.

The role of GSK3a, the related isoform of GSK3 $\beta$, in Wnt signaling is not completely clarified. However, there is evidence suggesting that it can also regulate $\beta$-catenin levels in a way similar to GSK3$\beta^{(14)}$. Two studies from the same group investigated the effect of GSK3a knock-out on MI. Global deletion of GSK3a in mice subjected to MI- 
promoted ischemic injury and increased left ventricular dysfunction ${ }^{(130)}$, while cardiomyocyte-specific deletion limited remodeling and preserved cardiac function post-MI ${ }^{(1)}$. A plausible explanation for this striking difference is the development of functional deterioration in aging mice with a global knock-out ${ }^{(274)}$, implying that cardiac deterioration post-MI in the global knock-out involves a secondary effect.

\section{Modulation of $\beta$-catenin}

$\beta$-Catenin is one of the most downstream targets that can be modulated in the canonical Wnt signaling cascade. Modulation can be achieved in several ways such as adenoviral overexpression, genetic deletion, or small molecule modulation, simulating a stimulation or inhibition of canonical Wnt signaling. ICG-001 is a small molecule able to interfere between binding of $\beta$-catenin and one of its co-activators, $\mathrm{CBP}$, thereby preventing $\beta$-catenin/CBP-mediated gene transcription. When administered for 10 days post-MI, this molecule has been shown to improve ejection fraction by $8.4 \%$ compared to controls at 4 weeks post-MI ${ }^{(216)}$. This mild effect was supported by a trend toward preserving cardiac morphology but did not affect the amount of fibrotic tissue and regeneration of cardiomyocytes. Disruption of $\beta$ catenin signaling by specific $\beta$-catenin knock-out in epicardial cells decreased epicardial expansion, epithelial to mesenchymal transition and led to impaired cardiac function and left ventricular dilatation after induction of ischemia-reperfusion injury ${ }^{(63)}$. This was thought to be the result of the absence of fibroblast generation through epithelial to mesenchymal transition, caused by Wnt1/ $\beta$-catenin signaling. Furthermore, knocking out $\beta$-catenin in fibroblasts demonstrated similar effects suggesting that a profibrotic response following cardiac injury is pivotal for sustained cardiac function and is mediated by $\mathrm{Wnt} 1 / \beta$-catenin signaling. Indeed, adenoviral overexpression of a constitutively active form of $\beta$-catenin induced differentiation of fibroblasts into myofibroblasts and activated cell cycle in the latter ${ }^{(83)}$. In addition, it showed anti-apoptotic effects and induced hypertrophy in cardiomyocytes. These mechanisms all led to improved post-infarct remodeling as seen by decreased infarct size and enhanced cardiac function. Another study investigated the effect of both 
cardiac-specific stabilization and depletion of $\beta$-catenin on infarct healing ${ }^{(270)}$. Surprisingly, mortality and infarct size were reduced in $\beta$-catenin-depleted mice accompanied by improved cardiac function, whereas the opposite was observed in mice expressing the constitutively active form of $\beta$-catenin.

In conclusion, the discussed studies demonstrate contradictive results on whether to stimulate or inhibit $\beta$-catenin. To further improve infarct healing, it might be possible that both inhibition and stimulation of $\beta$-catenin are necessary but at different time points or in different cell types. More research is needed to clarify this.

\section{Modulation of Wnt signaling in stem cells/progenitor cells}

Lately, extensive studies on the differentiation of stem cells or progenitor cells toward cardiomyocytes have been performed. This is of huge interest for the treatment of $\mathrm{MI}$, since these cells could be transplanted into the injured region and thereby regenerate healthy myocardium and prevent deterioration of cardiac function. There is increasing evidence that Wnt signaling is involved in the differentiation of stem cells toward cardiomyogenic cells ${ }^{(72,239,245)}$.

There are inconsistent results on whether to stimulate or inhibit Wnt signaling as well as targeting canonical or non-canonical signaling to achieve stem cell differentiation. Activation of non-canonical signaling by Wnt5a or Wnt11 (conditioned medium) in human circulating endothelial progenitor cells resulted in differentiation to cardiomyogenic cells (as demonstrated by cardiac gene expression) via activation of PKC ${ }^{(122,123)}$, whereas this was not observed when cells were treated with Wnt3aconditioned medium (canonical activation) ${ }^{(122)}$. This is supported by the observation that skeletal muscle-derived stem cells transfected with Wnt11 also have increased expression of cardiac markers and some of the cells beat spontaneously, although they were not fully differentiated ${ }^{(265)}$. These cells were also able to improve survival in mice when transplanted into acutely infarcted myocardium, although infarct size and cardiac function were not different.

Inhibition of canonical signaling by small molecules, such as XAV939, KY02111, IWP-4, and IWR-1 has also been shown to cause differentiation of pluripotent or embryonic 
stem cells toward cells with a cardiomyocyte phenotype ${ }^{(96,106,168,251)}$. Contrarily, there are also studies claiming that canonical signaling should be stimulated (by Wnt3a or Rspondin) to provoke cardiac differentiation of stem cells. Disruption of canonical Wnt signaling with the endogenous antagonist DKK1 resulted in complete absence of differentiation ${ }^{(107,127)}$. Along with this, cardiac function and remodeling were improved when sheets of differentiated human (induced) pluripotent stem cells were transplanted over myocardial infarcts in swine ${ }^{(107)}$. An explanation for this inconsistency can be given by the work of Lian et al., demonstrating that differentiation is fully dependent on the timing of inhibition or stimulation of canonical Wnt signaling ${ }^{(136)}$. Inhibition of canonical signaling in the early stage completely blocked cardiomyocyte-specific differentiation whereas stimulation at that point augmented differentiation (50\% of the cells are spontaneously contracting cardiac cells). When canonical Wnt signaling was inhibited sequentially after stimulation in the early phase, it resulted in a significant yield of contracting cardiogenic cells (up to $98 \%)$. This underscores that timing of modulation is absolutely critical for cardiac differentiation of stem cells.

Injection of MSCs, overexpressing components of the Wnt signaling cascade, into the infarcted myocardium shortly after induction of it, has also been demonstrated to be favorable for infarct healing. sFRP2 overexpressing MSCs were proven to increase engraftment together with reduced infarct size and better cardiac function ${ }^{(6,7)}$. Similar results were observed with overexpression of GSK3$\beta^{(41)}$, thereby illustrating that inhibition of Wnt signaling with this technique is advantageous. Nonetheless, Wnt11 transduced MSCs manifested identical effects ${ }^{(277)}$, implicating an involvement of noncanonical signaling as well.

Altogether, Wnt signaling is essential for induction of cardiac-specific cells from stem cells. Nevertheless, a better understanding of the involvement of the different signaling pathways can advance in more efficient in vitro differentiation protocols. Timing, type of modulation and the type of precursor cells seem to be critical factors in this process and once optimized one should focus on how to improve engraftment into the injured tissue to maximize the therapeutic effect. 


\section{Role of Wnt signaling in preconditioning}

Ischemic preconditioning (IPC) is defined as a mechanism that reduces ischemia/reperfusion injury by introducing brief periods of ischemia prior to the major prolonged ischemic event and was first described to be beneficial in the myocardium in 1986 by Murry et al. ${ }^{(178)}$. One of the crucial steps in the protective molecular signaling cascade is to prevent opening of the mitochondrial permeability transition pore (mPTP). This opening results in the collapse of the membrane potential, uncoupling of the respiratory chain and hydrolysis of ATP. Moreover, cytochrome C and other pro-apoptotic factors are able to translocate into the cytosol, which initiates the apoptotic pathway. Also large quantities of $\mathrm{Ca}^{2+}$ are released in the cytosol, which can activate harmful calcium-dependent proteases, leading to cell death $^{(57,102)}$.

GSK3 $\beta$ plays a central role in IPC. Increased inhibition of GSK3 $\beta$ induced by IPC limits opening of the mPTP and is thereby cardio-protective ${ }^{(104)}$. To mimic the IPC-induced inhibition of GSK3 $\beta$, inhibitors targeting this protein can be utilized in advance of ischemia/reperfusion injury. The inhibitors LiCl and SB-216763 mimicked the effects of IPC (improved cardiac function and reduced infarct size) in a rat model of ischemia/reperfusion ${ }^{(236)}$. Diabetic rat hearts demonstrated diminished levels of inactivated GSK3 $\beta$ and do, therefore, minimally benefit from IPC. However, this can be rescued by treatment with GSK3 $\beta$ inhibitors ${ }^{(266)}$. Interruption of Wnt/Frizzled signaling in sFRP1 transgenic mice limits the cardioprotection by IPC as well ${ }^{(19)}$, whereas IPC-induced protection is completely lost in GSK3 $\beta$ knock-in mice ${ }^{(246)}$. On the contrary, there is also evidence that mice which express constitutively active GSK3 $\beta$ still benefit from IPC at identical levels as wild-type littermates ${ }^{(183)}$. However, the latter model has a double knock-in with GSK3 $\beta$ as well as GSK3a, which might explain the difference. Remote IPC in the hindlimb activates the PI3K/Akt pathway in the heart, which inactivates GSK3 $\beta$ and thereby reduces myocardial infarct size and enhances cardiac function after prolonged ischemia followed by reperfusion ${ }^{(134)}$. This was also associated with increased levels of cytosolic $\beta$-catenin in the myocardium, 
its nuclear translocation, and expression of target genes and thus suggests that this not only the effect of Wnt/ $\beta$-catenin-independent signaling.

\section{Wnt Signaling and Cardiac Hypertrophy}

Cardiac hypertrophy is the response of the heart to an increased workload and is characterized by an increase in cardiomyocyte size. This is the predominant mechanism of the heart to compensate for the higher workload since cardiomyocytes have limited capacity to proliferate as they are terminally differentiated cells. Several subtypes of cardiac hypertrophy are known (Fig. 6). Concentric hypertrophy is seen in patients with pressure overload, such as patients with hypertension or aortic stenosis. This is characterized by increased wall thickness and reduced ventricular lumen, caused by cross-sectional increase of cardiomyocytes. The other subtype is eccentric hypertrophy, which is defined by thinning of the ventricle wall and an increase in ventricular luminal size due to lengthening or sliding of cardiomyocytes. This is caused by volume overload, for example, due to valvular defects or MI. Although both forms of hypertrophy initially aim to reduce the left ventricular wall stress, sustained cardiac hypertrophy often leads to heart failure ${ }^{(193)}$.

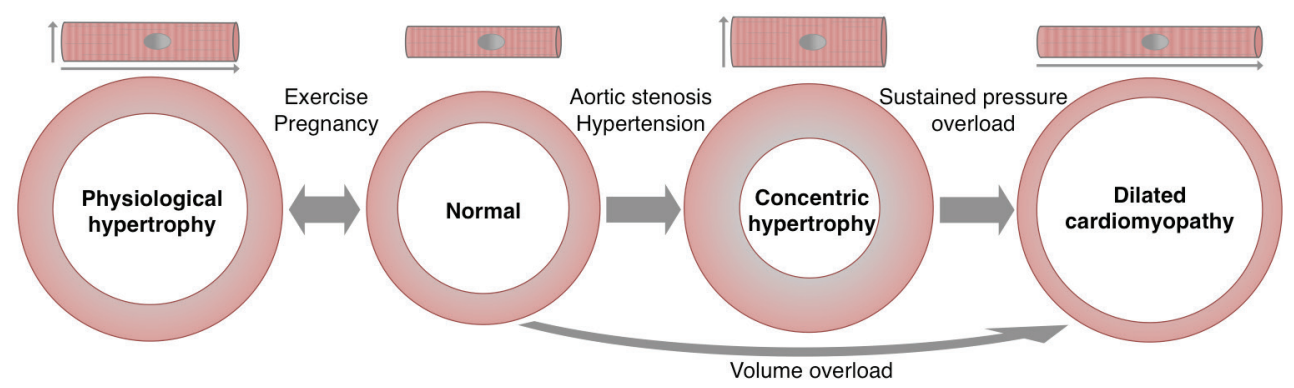

Figure 6 | Hypertrophic response of the heart to different types of stress. Physiological hypertrophy is induced by pregnancy or intensive exercise training. Cardiomyocytes increase in thickness and in length. This type of hypertrophy is reversible. Concentric hypertrophy is the result of disorders that cause pressure overload and goes along with thickening of the cardiomyocytes, reduced left ventricular volume, increased fibrosis, and stiffening of the heart muscle and is usually not reversible. Prolonged pressure overload can result in dilated cardiomyopathy in which the heart muscle is overstretched and loses contractile force. In addition, chronic volume overload can also result in dilated cardiomyopathy. 
Another way to classify hypertrophy is to distinguish between physiological and pathological hypertrophy. Pregnancy or intensive exercise training can induce physiological hypertrophy and increases wall thickness proportional to chamber volume. In this way normal cardiac structure and function is maintained and is in most cases completely reversible. Pathological remodeling of the heart can be induced by, as already mentioned, hypertension, valvular disease, or MI and is associated to adverse remodeling ultimately leading to dilated cardiomyopathy and heart failure ${ }^{(21,62)}$.

Development of physiological and pathological hypertrophy is regulated by distinct signaling pathways (Fig. 7). Physiological hypertrophy is associated with growth factors such as IGF and growth hormone that provoke phosphoinositide 3'kinase signaling and by that activate Akt signaling resulting in expression of hypertrophyassociated genes. The expression of these genes predominantly takes place through inactivation, by Akt, of GSK3 $\beta$ that is normally active in resting cells and suppresses hypertrophic gene transcription ${ }^{(21)}$. Activation of the neurohumoral pathway is regulating pathological hypertrophy and involves hypertrophic stimuli such as, Angiotensin II (Angll), ET-1, and catecholamines that activate the calcineurin/NFAT pathway leading to transcription of hypertrophic genes ${ }^{(211)}$.

Current available therapies to prevent/treat pathological cardiac hypertrophy include angiotensin converting enzyme inhibitors and/or angiotensin receptor blockers, $\beta$ blockers, $\mathrm{Ca}^{2+}$ channel blockers, and vasodilators/diuretics to reduce to volumetric load $^{(158)}$. During the progression toward hypertrophy, re-expression of fetal genes is observed $^{(191)}$. As Wnt signaling is involved in cardiogenesis, this could suggest that it is also involved in the development of cardiac hypertrophy. Indeed, several studies have already shown the involvement of Wnt signaling in cardiac hypertrophy and could thereby serve as a novel therapeutic target for cardiac hypertrophy ${ }^{(25,36)}$. 


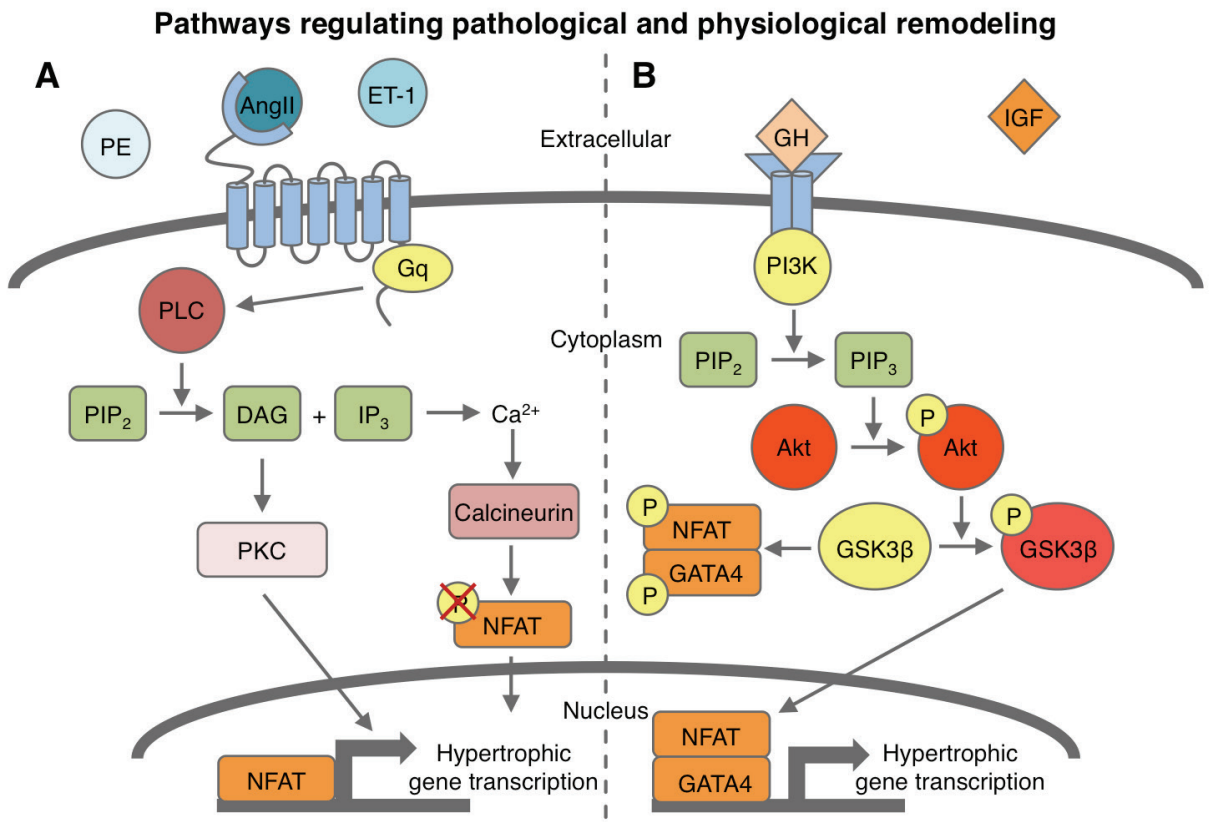

Figure 7 | Signaling pathways leading to pathological and physiological hypertrophy. In pathological hypertrophy (A), neurohumoral regulators such as angiotensin II (Angll), endothelin-1 (ET-1), and catecholamines like phenylephrine (PE), activate Phospholipase-C (PLC) through G-protein-coupled receptors. Activated PLC hydrolyzes $\mathrm{PIP}_{2}$ into inositol triphosphate $\left(\mathrm{IP}_{3}\right)$ and diacylglycerol (DAG). $\mathrm{PP}_{3}$ causes a rise in intracellular $\mathrm{Ca}^{2+}$, which activates calcineurin that in turn dephosphorylates NFAT. DAG activates protein kinase $C$ (PKC) that induces hypertrophic gene transcription together with NFAT. Physiological hypertrophy (B) is initiated by growth factors such as growth hormone $(\mathrm{GH})$ and insulin-like growth factor (IGF) that provoke phosphoinositide 3 'kinase (PI3K) signaling. Activated PI3K phosphorylates $\mathrm{PIP}_{2}$ to $\mathrm{PIP}_{3}$ that subsequently activates Akt through phosphorylation. Activated Akt inactivates glycogen synthase kinase $3 \beta$ (GSK3 $\beta$ ) by phosphorylation. Now, GSK3 $\beta$ can no longer inactivate transcription factors such as NFAT and GATA4, which causes translocation to the nucleus and subsequent hypertrophic gene transcription.

\section{Dishevelled and cardiac hypertrophy}

Dvl proteins are 500 to 600 amino acids in length and play a role in canonical as well as non-canonical Wnt signaling. They contain several domains through which they moderate signaling. At the $\mathrm{N}$-terminus of DVI1 the "DIX" domain is located that allows for multimerization that amplifies signaling by offering high local concentrations of binding sites. In addition, the $\mathrm{N}$-terminal domain contains a PDZ and DEP domain. The DEP and PDZ domains are involved in G-protein-coupled signaling and the PCP pathway and are therefore committed to non-canonical signaling. The DIX domain, 
together with the PDZ domain, is involved in canonical signaling by binding to, and inactivation of $\operatorname{Axin}^{(248)}$.

The association of Dvl with cardiac hypertrophy has been confirmed in several studies. A commonly used model to study the development of cardiac hypertrophy is the pressure overload-induced hypertrophy model by transverse aortic constriction (TAC). In this setting, an increased expression level of Dvl1 was observed in rats ${ }^{(147)}$. Three-month-old transgenic mice with cardiac-specific overexpression of the Dvl1 gene had severe cardiac hypertrophy (no TAC) ${ }^{(147)}$. This was defined by an increase in cardiomyocyte size, left ventricular dilatation, and reduced ejection fraction that altogether ended up in cardiomyopathy and premature death before 6 months of age. Activation of canonical and non-canonical signaling was observed by increased expression of $\beta$-catenin, JNK, PKC, and CaMKII. The response to TAC in Dvl1 knockout mice has been studied by our research group ${ }^{(243)}$. Onset of cardiac hypertrophy was attenuated in mice lacking the Dvl1 gene as assessed by left ventricular wall thickness and heart weight. The underlying mechanism of this observation comprises an increased amount of active GSK3 $\beta$ and decreased $\beta$-catenin levels. In addition, the active form of Akt (stimulator of cardiac hypertrophy) was reduced in knock-out animals, suggesting that Dvl1 plays also a role in the activation of Akt by pressure overload. Dapper1 is also able to trigger canonical Wnt signaling through activation of Dvl2, but not Dvl1 or $-3^{(82)}$. Transgenic mice overexpressing Dapper1 exhibited upregulation of hypertrophic markers and increased heart weight resulting in cardiac hypertrophy.

Thus, Dvl can be regarded as a critical factor in Wnt signaling that is able to induce cardiac hypertrophy when expressed in higher levels and engages both canonical and non-canonical pathways as well as Akt-mediated signaling.

\section{GSK3 $\beta$ and cardiac hypertrophy}

GSK3 $\beta$ phosphorylates multiple transcription factors that can trigger cardiac hypertrophy, including activator protein-1, $\beta$-catenin, GATA4, NFAT, and CBP, thereby inhibiting their function ${ }^{(105,110)}$. It is a downstream target of Dvl as well as Akt 
and is negatively regulated by these factors. Other kinases including PKA, PKC, p90ribosomal-, and p60/p85-s6 kinases also inhibit GSK3 $\beta$ activity ${ }^{(111,230)}$. GSK3 $\beta$ negatively regulates most of its substrates, thus inhibition discharges its substrates from continuous degradation. GSK3 $\beta$ is disarmed by phosphorylation at serine- 9 and this can be executed by most of the hypertrophic stimuli such as ET-1, phenylephrine, $\beta$-adrenoreceptor activation, or aortic constriction ${ }^{(84,86,173)}$.

Genetic ablation of GSK3 $\beta$ in mice demonstrated the importance of this gene for cardiac development ${ }^{(110)}$. No live neonates were recovered when the GSK3 $\beta$ gene was deleted. The embryos demonstrated congenital cardiac defects like ventricular septal defects, a right ventricle with a double outlet and hypertrophic cardiomyopathy (HCM). The latter was the result of hyperproliferation of cardiomyocytes rather than hypertrophy and was associated with increased nuclear translocation of proliferation regulators GATA4, c-Myc, and cyclin D1. However, studies that negatively affect GSK3 $\beta$ as a target for induction of cardiac hypertrophy are somewhat contradictive and also hypertrophic human hearts do not show altered GSK3 $\beta$ expression ${ }^{(85)}$. In a pressure-overload model in rats, inhibition of GSK3 $\beta$ with $\mathrm{LiCl}$ is suggested to accelerate the development of cardiac hypertrophy through a $\beta$-catenin-dependent mechanism ${ }^{(233)}$. Conditional GSK3 $\beta$ knock-out in mice did not have any effect on TAC-induced cardiac hypertrophy compared to control animals ${ }^{(262)}$. On the contrary, transgenic mice carrying a dominant negative form of GSK3 $\beta$-developed physiological hypertrophy (without experimental procedures) as demonstrated by increased left ventricular weight/body weight ratios and increased cardiac contractility, whereas the extent of TAC induced hypertrophy was not affected in these transgenic mice ${ }^{(91)}$. Nevertheless, they were more resistant to cardiac decompensation and had significantly fewer apoptotic cells and less fibrosis 8 weeks after TAC, suggesting GSK3 $\beta$ does not primarily affect pathological hypertrophy but inhibition can prevent cardiac decompensation in a later stage after TAC.

Expression of constitutively active GSK3 $\beta$ in cardiomyocytes in vitro prevented the induction of the hypertrophic response to ET-1 and phenylephrine ${ }^{(84)}$. Transgenic 
mice expressing this form of GSK3 $\beta$ exhibit an impaired hypertrophic response to calcineurin activation ${ }^{(10)}$ and are able to reverse hypertrophy 1 week after TAC ${ }^{(213)}$. Constitutively active GSK3 $\beta$ expressing mice with a genetic background of HCM demonstrated a reduced hypertrophic response, although cardiac function was impaired compared to littermates with the HCM background alone ${ }^{(144)}$.

Taken together, both GSK3 $\beta$ knock-out and overexpression impair cardiogenesis $^{(110,164)}$ and the degree of GSK3 $\beta$ activity plays indeed a role in cardiac hypertrophy. When overactive, it likely inhibits pathological hypertrophy but also physiological hypertrophy. On the other hand, reduced GSK3 $\beta$ activity was only seen in advanced heart failure patients and not in hypertrophic patients ${ }^{(85)}$, suggesting that (at least) in humans, the role of GSK3 $\beta$ in the development of cardiac hypertrophy is limited, whereas its role in the progression toward heart failure is more obvious. Finally, as already mentioned, GSK3 $\beta$ is not only involved in Wnt signaling and therefore its downstream signaling effects may not solely be conferred to this pathway.

\section{$\beta$-Catenin and cardiac hypertrophy}

When not targeted for degradation by GSK3 $\beta$, which phosphorylates the protein at specific serine residues at the $\mathrm{N}$-terminal end, $\beta$-catenin is able to translocate to the nucleus and serve as a transcription factor. Another function of $\beta$-catenin is to be part of adherens junctions in the catenin/cadherin complex, fundamental for cell structure, and adhesion. The destination of $\beta$-catenin is determined by phosphorylation of specific tyrosine residues ${ }^{(87)}$.

A redistribution of $\beta$-catenin is observed in $\mathrm{HCM}$ hamsters ${ }^{(155)}$. Here, $\beta$-catenin accumulates in intercalated disks of cardiomyocytes in HCM hearts ( $\beta$-catenin is reduced in cytoplasm and nucleus) which could contribute to the increased wall stiffness in cardiac hypertrophy. On the contrary, in rats with spontaneously hypertensive heart failure (SHHF) more nuclear translocation of $\beta$-catenin is observed $^{(273)}$. This inconsistency can possibly be explained by the difference in animal models. The SHHF rats first developed hypertrophy but this advances into heart 
failure, whereas HCM hamsters remain in a more hypertrophic state, suggesting multiple roles for $\beta$-catenin which are determined by the stage of hypertrophy.

It has been demonstrated in vitro that $\beta$-catenin is stabilized in cardiomyocytes upon exposure to hypertrophic stimuli such as phenylephrine and ET-1, suggesting that this signaling is Wnt independent ${ }^{(86)}$. Moreover, $\beta$-catenin overexpression is sufficient to induce hypertrophic growth in cardiomyocytes whereas depletion attenuates phenylephrine-induced cardiomyocyte hypertrophy ${ }^{(86,272)}$.

Gain or loss of function studies with $\beta$-catenin in vivo need to be conditional since $\beta$ catenin signaling is crucial and has to be tightly regulated during embryonic development ${ }^{(80)}$. Along with in vitro studies, $\beta$-catenin is stabilized in cardiomyocytes after exposure to hypertrophic stimuli in vivo and overexpression is sufficient to induce hypertrophic growth of cardiomyocytes in the myocardium ${ }^{(86)}$. Stabilization of $\beta$-catenin in the latter study by hypertrophic stimuli such as ET-1 or phenylephrine is distinct from $\beta$-catenin stabilization induced by canonical Wnt signaling. When applying these hypertrophic stimuli, GSK3 $\beta$ is inactivated by protein kinase $B$ rather than Dvl and thereby inhibits degradation of $\beta$-catenin ${ }^{(86)}$. However, subsequent signaling is similar as canonical Wnt induced signaling as it has been demonstrated that $\beta$-catenin/TCF/LEF signaling is essential to both physiological and pathological hypertrophic growth of cardiomyocytes ${ }^{(38)}$. Cardiac-specific deletion of $\beta$-catenin attenuated TAC-induced hypertrophy ${ }^{(204)}$. Heart weight/body weight ratios were lower compared to controls but cardiac function was not altered. On the contrary, Baurand et al. reported that $\beta$-catenin stabilization abolished hypertrophy in response to Angll ${ }^{(23)}$. Nevertheless, this was at the price of declined heart function. These divergent results could be related to the different hypertrophy models (TAC vs. Angll infusion) that induce different signaling pathways.

In conclusion, the exact role of $\beta$-catenin in cardiac hypertrophy is not completely clear. No $\beta$-catenin is seen in the nucleus when cardiac hypertrophy is present, but when this develops further into heart failure, $\beta$-catenin translocation to the nucleus is increased. On the other hand, stabilization of $\beta$-catenin is sufficient to induce 
hypertrophic growth in cardiomyocytes. Additional experiments are required to verify the precise role during hypertrophy development, established hypertrophy and consecutive progression toward cardiac failure. Furthermore, it has to be clarified whether $\beta$-catenin-induced hypertrophy is pathological and/or physiological and thus reversible.

\section{Non-canonical signaling in cardiac hypertrophy}

It has been demonstrated that Wnt5a activates non-canonical signaling and induces hypertrophy in cardiomyocyte cultures ${ }^{(81)}$. As mentioned previously, mice overexpressing Dvl develop cardiac hypertrophy through activation of both canonical and non-canonical signaling ${ }^{(147)}$. More downstream, gain or loss of function studies with JNK have been shown to affect hypertrophic growth. Activation of JNK induces increased cardiomyocyte size in vitro ${ }^{(255)}$ and gene transfer of inactive JNK prevents TAC-induced hypertrophy in rats ${ }^{(42)}$.

\section{Wnt Signaling and Heart Failure}

Heart failure is the vicious aftermath of several pathological cardiac conditions including hypertrophy and MI, especially when optimal pharmacological treatment is lacking. Ongoing improvements in revascularization therapy reduces mortality due to MI, but increase the population developing heart failure following $\mathrm{MI}^{(11)}$. Approximately $20 \%$ of the people that suffer from MI after 65 years of age develop heart failure ${ }^{(210)}$. In total, more than 26 million people are estimated to suffer from heart failure worldwide ${ }^{(8)}$ and the 5 -year mortality is almost $50 \%{ }^{(21)}$.

Current pharmacotherapeutic tools for heart failure target the renin-angiotensinaldosterone system (RAAS), $\beta$-adrenergic system, and reduce volume overload. Nevertheless, treatment with these tools does not cure heart failure but only delays the progression toward further deterioration. There is increasing evidence that Wnt signaling is involved in adverse cardiac remodeling and the progression to heart failure. Better insights of the implication of Wnt signaling in heart failure might identify new targets for heart failure prevention and/or treatment. 


\section{sFRPs in heart failure}

Schumann et al. were the first to find upregulated mRNA levels of the pro-apoptotic sFRP3 and sFRP4, but not sFRP1 and sFRP2 in human failing hearts ${ }^{(220)}$. This was associated with decreased $\beta$-catenin levels and might contribute to the induction of an apoptosis-susceptible myocyte phenotype. Increased mRNA levels of sFRP3 in the failing myocardium were confirmed in a recent study by Askevold et al. ${ }^{(12)}$. In addition, serum SFRP3 levels of heart failure patients were also significantly increased compared to controls ${ }^{(12)}$. In the latter study, tertiles of baseline SFRP3 levels were significantly associated with cardiovascular mortality in a follow-up study ${ }^{(12)}$, although sFRP3 lacked significant predictive accuracy for subsequent cardiovascular events in another study ${ }^{(175)}$.

Left ventricular assist device therapy in heart failure patients is an approach for mechanical unloading of the heart to allow recovery of the failing heart. The process of recovery was associated with reduced levels of SFRP3 and $1^{(12,67)}$, suggesting activated Wnt signaling during the process of recovery. The TO2 strain cardiomyopathic hamsters exhibit heart failure with marked fibrosis and increased expression of SFRP2 ${ }^{(154)}$. Antibody treatment against sFRP2, administered twice a week, increased cardiac ejection fraction compared to a further decline in the control group. Moreover, myocardial fibrosis was reduced by $\sim 50 \%$ and apoptosis by $\sim 65 \%$, whereas anterior wall thickness was enlarged by $\sim 75 \%{ }^{(154)}$.

\section{GSK3 $\beta$ in heart failure}

GSK3 $\beta$ overexpression during development of cardiac decompensation after TACinduced heart failure was shown to be detrimental for cardiac function and displays increased signs of heart failure ${ }^{(91)}$. This suggests that GSK3 $\beta$ inhibition would be favorable for heart failure treatment. In pacing-induced heart failure in dogs, cardiac recovery was allowed for 6 weeks after induction of heart failure ${ }^{(32)}$. Cardiac recovery was accompanied by increased Akt signaling, and caused increased downstream inhibition of GSK3 $\beta$ and increased levels of $\beta$-catenin. This supports the latter suggestion favoring GSK3 $\beta$ inhibition for heart failure treatment, although in human 
failing hearts GSK3 $\beta$ already is inhibited by increased activity of Akt compared to control and hypertrophied hearts, but there is no evidence whether this is beneficial or detrimental ${ }^{(85)}$. Kirk et al. demonstrated that cardiac resynchronization therapy following tachypacing-induced heart failure reactivated GSK3 $\beta^{(117)}$. This reactivation contributed to improved $\mathrm{Ca}^{2+}$ sensitivity in the myofilaments. Hence GSK3 $\beta$ is proposed as a new therapeutic target to enhance contractile function.

\section{Miscellaneous Wnt signaling factors in heart failure}

A few other members of Wnt signaling have been associated with heart failure. In volume overloaded rats, upregulation of WISP1 has been observed ${ }^{(162)}$. Cardiacspecific activation of the non-canonical signaling member JNK leads to contractile dysfunction and signs of congestive heart failure that resulted in death 7 weeks after birth of the mice ${ }^{(202)}$. However, there was no temporal control over JNK activation and thus primary effects cannot be differentiated from secondary effects of JNK-induced cardiomyopathy.

\section{Wnt Signaling and Arrhythmias}

Mechanisms for the onset of arrhythmias are generally divided into abnormalities in impulse initiation (automaticity and triggered activity) and abnormalities in impulse propagation (reentry) ${ }^{(92)}$. Disorders in electrical conductivity of the heart can be caused by a variety of genetic and environmental factors or can result from other cardiac diseases such as MI, hypertrophy, or heart failure.

The prerequisite for propagation of the cardiac action potential is the intercellular connection of cardiomyocytes by so-called intercalated disks (Fig. 8). These disks contain two different junctional complexes, the adhesion junctions and gap junctions. Adhesion junctions are important for mechanical coupling between cardiomyocytes. There are two main types of adhesion junctions, adherens junctions and desmosomes. Adherens junctions are made up of $\mathrm{N}$-cadherin, $\mathrm{a}$ - and $\beta$-catenin, and plakoglobin. The other is the desmosome that contains the desmosomal proteins desmoglein and desmocollin and the linker proteins of the plakin and catenin families 


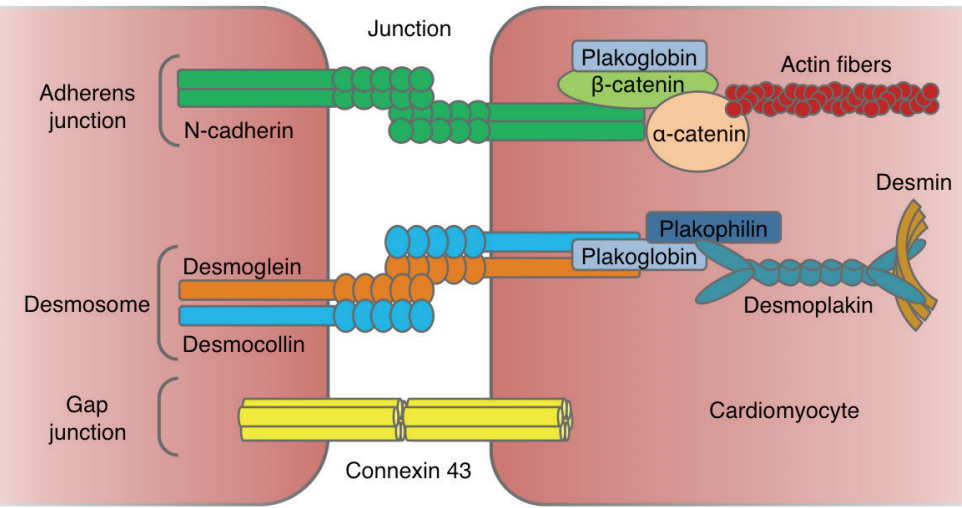

Figure 8 | A schematic representation of an intercalated disk between adjacent cardiomyocytes. Mechanical coupling of the cardiomyocytes is coordinated by adherens junctions and desmosomes. Gap junctions are necessary for rapid current propagation through the myocardium to induce cardiac contraction.

(desmoplakin, plakophilins, and plakoglobin). Besides this, adherens junctions play an essential role in gap junction formation and assembly ${ }^{(121)}$. Gap junctions are necessary for intercellular current flow and propagation of cardiac action potentials, and are made up from connexins. In the heart, three prominent isoforms of connexins are present. Connexin $43(\mathrm{C} \times 43)$ is the only connexin known to be present in the adult working myocardium whereas connexin 40 and 45 are present in the fast conducting structures such as the bundle of $\mathrm{His}^{(141)}$.

\section{Regulation of connexin 43 by Wnt signaling}

There is evidence that $\mathrm{Cx} 43$ is regulated by Wnt signaling. Rapid electrical stimulation of neonatal rat cardiomyocytes increases the expression level of $\beta$-catenin in the nucleus already after 10 minutes followed by increment in the total cell fraction after 30 minutes. After 1 hour of rapid electrical stimulation, Cx43 protein expression is also significantly increased ${ }^{(180)}$. The evidence that changes in $\beta$-catenin precede the modifications in Cx43 emphasizes that it might play an essential role in the formation and stability of gap junctions. Moreover, Cx43 mRNA and protein expression were notably induced by stimulation of Wnt signaling with $\mathrm{LiCl}$. This led to an accumulation of $\beta$-catenin in the cytosol and membrane fraction of neonatal rat cardiomyocytes ${ }^{(3)}$. 
A similar response was observed when these cardiomyocytes were co-cultured with rat fibroblasts or neuroblastoma cells that were overexpressing Wnt1. The accumulation of $\beta$-catenin resulted in $\beta$-catenin-mediated transcription and $\mathrm{C} x 43$ expression as well as its translocation to the junctional membrane where it colocalized with $\mathrm{Cx} 43^{(3)}$. On the contrary, in the existence of ventricular arrhythmias in vivo, Cx43 levels were significantly reduced which was associated with downregulation of $\beta$-catenin ${ }^{(3)}$. Granulocyte colony-stimulating factor (G-CSF) has been shown to bring about similar effects regarding the activation of Wnt signaling and Cx43 expression ${ }^{(125)}$. In addition, G-CSF increased the phosphorylation of Cx43 and restrained ventricular arrhythmias induced by $\mathrm{Ml}$ in rats compared to non-treated animals. MSCs have shown to mitigate the initiation of ventricular arrhythmias after $\mathrm{MI}^{(249)}$. A possible mechanism for this effect is Wnt secretion by MSCs that affects cardiomyocytes through paracrine signaling and thereby increases conduction velocity and Cx43 protein levels ${ }^{(177)}$.

These experiments clearly demonstrate a role for canonical Wnt signaling in the regulation of $\mathrm{Cx} 43$ expression and could thereby form an interesting target for treating arrhythmias.

\section{Wnt signaling and arrhythmogenic right ventricular cardiomyopathy}

Arrhythmogenic right ventricular cardiomyopathy (ARVC) is a genetic disease of the myocardium that predominantly affects the right ventricle but can also involve the left ventricle. It is characterized by replacement of the healthy myocardium by abnormal adipose and fibrous tissue. Clinical manifestations are defined by cardiac arrhythmias, heart failure and sudden cardiac death. Approximately $40 \%$ of patients with ARVC have one or more mutations in genes encoding desmosomal proteins ${ }^{(223)}$.

Suppression of canonical Wnt signaling has been linked with $A R V C^{(40)}$. Humaninduced pluripotent stem cells from ARVC patients that were differentiated to cardiomyocytes reveal a significant reduction in nuclear $\beta$-catenin compared to cells from non-ARVC patients ${ }^{(34)}$, suggesting reduced canonical Wnt signaling. Loss of desmoplakin leads to nuclear localization of plakoglobin, that competes with $\beta$ - 
catenin for binding to TCF/LEF, and a $50 \%$ reduction in canonical Wnt signaling through TCF/LEF ${ }^{(74)}$. Heterozygous desmoplakin-deficient mice are hallmarked by excess adipose tissue and fibrosis in the myocardium, myocyte apoptosis, cardiac dysfunction and arrhythmias, all being the notorious features of $A R V C^{(74)}$. Mice that have a cardiac-specific double knock-out for plakoglobin and $\beta$-catenin exhibit a comparable phenotype together with reduced $\mathrm{Cx} 43$ containing gap junctions and degenerating intercalated disks ${ }^{(231)}$. In human ARVC heart samples, reduced levels of desmoglein and desmocollin were observed although remarkably no difference in $\beta$ catenin levels was observed $^{(247)}$. Of note, the control group consisted of five ischemic, two dilated, and only one normal heart. Therefore, altered $\beta$-catenin levels due to other etiologies cannot be excluded.

\section{Wnt Signaling in Atherosclerosis}

Development of atherosclerosis is a complex process that involves numerous mechanisms that are still not completely understood. There are several pivotal steps toward the development of atherosclerosis. Endothelial activation and dysfunction are the primary events in atheroma development and can be induced by dyslipidemia followed by accumulation of oxidized low-density lipoproteins (LDLs) in the subendothelial space. These initial events are usually located at sites with low shear, but high oscillatory shear stress ${ }^{(181)}$. Subsequently, the inflammatory process is initiated due to elevated expression of chemokines and adhesion molecules. Many different immune cells are implicated in atherosclerotic pathogenesis. These include monocytes, neutrophils, dendritic cells, T-cells, and B-cells. Moreover, activated platelets also interact with inflammatory and endothelial cells, and can also secrete chemokines and induce cell adhesion molecule expression. This can sequentially engage other cell types and enhance the activation of other inflammatory cells ${ }^{(138)}$.

Maturation of the atherosclerotic plaque occurs when the plaque formation expands due to increased presence of foam cells that form a lipid core. In addition, persisting influx of different inflammatory cells and extracellular lipids results into formation of a core region that is separated from the arterial lumen by a fibrous cap. This fibrous cap 
is formed by recruited vascular smooth muscle cells (VSMCs) and deposited ECM. In expanding plaques, the lipid core can turn into a necrotic area due to apoptotic macrophages and other cells. Further maturation can lead to plaque destabilization due to matrix degrading proteases - secreted by primarily inflammatory cells - that decrease the thickness of the fibrotic cap. Finally, the plaque will rupture and display its remains to the arterial lumen, leading to thrombus formation and probably ischemia at the site of action. When occurring in the heart, this is better known as $M I^{(244,256)}$.

Indications for involvement of Wnt signaling in atherosclerosis are given by the presence of Wnt5a and DKK1 in murine and human lesions ${ }^{(43,240)}$. In addition, serum levels of DKK1 have been identified as an independent risk factor for the presence of calcification and atherosclerotic plaques in coronary arteries ${ }^{(115)}$. Patients with aortic stenosis demonstrate elevated circulating levels of SFRP3, WIF1 as well as DKK1 and can all - DKK1 in particular - predict long-term mortality in these patients ${ }^{(13)}$. Moreover, patients with acute ischemic stroke and stable cerebrovascular disease also display elevated levels of DKK1 in the circulation ${ }^{(221)}$. Recently, low levels of SFRP5 have also been associated with coronary artery disease ${ }^{(170)}$. These studies indicate altered levels of Wnt signaling components when atherosclerosis is present or has led to a cardiovascular event. However, there is also evidence that Wnt signaling is implicated in the consecutive events toward atherosclerotic plaque development. An overview of this is given in following subheadings.

\section{Wnt signaling in endothelial dysfunction and inflammation}

Activated endothelium expresses chemokines and adhesion molecules such as vascular cell adhesion molecule protein 1 and E-selectin, which creates a proinflammatory environment. It evokes leukocyte attraction and adherence and increases endothelial permeability and turnover, leading to endothelial dysfunction. Endothelial cells express a large array of Wnts (Wnt2, -2b, -3, -4, -5a, -5b, -7a, -8a, 9a, -9b, and -11) and Frizzleds (Fzd1-10 except Fzd3) as well as other components such as LRP5, LRP6, sFRP1, SFRP3, DKK1, and DKK3 ${ }^{(70)}$. 
Nuclear localization of $\beta$-catenin has been identified in endothelial cells in atheroprone regions of the aorta before and during lesion development ${ }^{(75)}$. Indeed, TCF/LEF transcriptional activity correlated anatomically with the nuclear localization of $\beta$-catenin ${ }^{(75)}$. This suggests a role for canonical Wnt signaling in the onset of endothelial activation/dysfunction at sites with altered shear stress and thereby contributing to atherogenesis. In addition, in vitro data demonstrated enhanced monocyte adhesion to endothelial cells by activation of the Wnt/ $\beta$-catenin pathway without altering expression levels of adhesion molecules ${ }^{(131)}$. Once in the intima, monocytes differentiate to macrophages. These macrophages have been suggested to secrete Wnt5a in the atherosclerotic lesion ${ }^{(43)}$. In endothelial cells, inflammatory genes are upregulated by stimulation with Wnt5a through activation of the noncanonical $\mathrm{Ca}^{2+} / \mathrm{PKC}$ pathway and downstream activation of $\mathrm{NF}-\mathrm{KB}^{(114)}$. Moreover, endothelial- and platelet-derived DKK1 enhances the expression of inflammatory genes in endothelial cells through inhibition of the canonical pathway and activation of $N F-k B^{(240)}$.

Collectively, this suggests that Wnt/ $\beta$-catenin signaling plays a role in the early onset of endothelial activation and dysfunction whereas non-canonical signaling is involved in the sequential inflammatory phase.

\section{Wnt signaling and proliferation and migration of VSMCs}

The pro-inflammatory environment in the atherosclerotic lesion together with the altered crosstalk between endothelial cells and VSMCs causes a phenotypic switch of VSMCs toward the so-called "synthetic phenotype"(195). These quiescent cells become activated, start to proliferate, and migrate into the intima and contribute to intimal thickening. VSMCs have a maladaptive role in the lesion development and progression by producing inflammatory cytokines and ECM deposition. On the other hand, they likely play a beneficial role in the later stages of atherosclerosis by formation of the fibrous cap where they proliferate and produce ECM to stabilize the plaque $^{(142)}$. 
There is evidence that Wnt signaling is involved in VSMC proliferation. $\beta$ Catenin/TCF-mediated transcription has been shown to inhibit apoptosis and induce proliferation of rat aortic VSMCs ${ }^{(254)}$ and is induced by Wnt1/LRP6 signaling ${ }^{(253)}$. Moreover, VSMC proliferation is also induced by Wnt4/Fzd1-mediated canonical signaling during intimal thickening ${ }^{(238)}$. Increased levels of inactivated GSK3 $\beta$ have been observed in pulmonary aortic VSMCs of pulmonary hypertensive rats, suggesting increased $\beta$-catenin signaling contributing to VSMC proliferation ${ }^{(227)}$. Inflammatory factors in the pro-inflammatory milieu of the atherosclerotic lesion have also been suggested to induce VSMC proliferation. Interleukin (IL)-18, a proinflammatory cytokine associated with the development and progression of atherosclerosis $^{(135)}$, is such a factor that induces proliferation through activation of Wnt signaling. IL-18 initiates VSCM proliferation through GSK3 $\beta$ inactivation, $\beta-$ catenin nuclear translocation, and subsequent TCF/LEF activation and WISP1 induction $^{(206)}$. In vitro treatment with Wnt1 or Wnt3 in aging VSMCs from rats (8 months old) resulted in activation of canonical signaling but did not provoke proliferation, whereas it did in young cells $(6 \text { weeks old })^{(151)}$. Non-canonical signaling has not been extensively studied for its role in VSMC proliferation. However, there is indirect evidence that it could be involved, since downstream components such as CaMKII and JNK have been demonstrated to promote VSMC proliferation ${ }^{(45,93)}$.

Migration of VSMC is also suggested to be mediated by Wnt signaling. Wnt3a is able to enhance the migration and adhesion of VSMCs through increment of integrinlinked kinase expression and thereby augment the $\beta 1$-integrin activity ${ }^{(264)}$. Migration is also dependent on activation of CaMKII, a non-canonical component of the Wnt pathway ${ }^{(199)}$. In addition, tissue factor promotes VSMC migration by signaling through Wnt pathways ${ }^{(200)}$.

This demonstrates that VSMC proliferation and migration is regulated by Wnt signaling but also by many other mechanisms, indicating that its control is complex. 


\section{Wnt signaling in the process of vascular calcification}

Vascular calcification is a risk factor for cardiovascular morbidity and mortality and is a key feature of atherosclerosis. The degree of calcification in atherosclerotic lesions is positively correlated with plaque size and the risk of $\mathrm{MI}^{(99)}$. Vascular calcification is a process that has similarities with bone formation and is promoted by BMP2. Activated endothelium produces BMP2 in response to pathogenic stimuli such as tumor necrosis factor-a and oxidized $\mathrm{LDL}^{(51)}$. BMP2 is indicated to regulate vascular calcification through a mechanism that involves Wnt signaling ${ }^{(224)}$. This is mediated by Msx2, which is an osteogenic transcription factor that is upregulated by BMP2. In LDL receptor knock-out mice, BMP2 and Msx2 are upregulated in the aorta at locations with calcifications ${ }^{(225)}$. Conditioned medium from Msx2 overexpressing cells is proosteogenic and is able to stimulate Wnt-dependent TCF/LEF transcription. Moreover, these cells upregulate Wnt3a, Wnt7a, and augment nuclear translocation of $\beta$-catenin, whereas DKK1 is downregulated. These alterations in expression patterns were confirmed in vivo in mice overexpressing Msx2. Notably, treatment with the canonical antagonist DKK1 was able to reverse the osteogenic features of Msx2 in vitro ${ }^{(225)}$. Another recent study confirms that inhibition of Wnt/ $\beta$-catenin signaling by magnesium can reverse the calcification of VSMCs ${ }^{(171)}$.

\section{LRP receptors and the development of atherosclerosis}

LRP5 and - 6 are co-receptors of the canonical Wnt signaling pathway but are also involved in cholesterol homeostasis and protection against atherosclerosis ${ }^{(77)}$. Indeed, LRP6 mutations in humans are associated with accelerated development of atherosclerosis $^{(148,215)}$. The trait of hyperlipidemia associated with these mutations is rescued by administration of Wnt3a in mice by altering the expression levels of hepatic lipogenic enzymes ${ }^{(78)}$. It was confirmed in vitro that signaling through the mutant LRP6 was recovered with higher concentrations of Wnt3a compared to control cells. This implies that Wnt signaling is participating in the regulation of lipid 
homeostasis. Furthermore, human macrophages exposed to LDL have increased levels of LRP5 and canonical Wnt signaling as demonstrated by higher levels of $\beta$ catenin, LEF1 and target genes such as cyclin D1, c-jun, and BMP2 ${ }^{(30)}$. This reaction was abolished when macrophages were treated with siRNA against LRP5, something that also negatively affected their migration capacity. In mice, a hypercholesterolemic diet causes increased expression of LRP5 in the aortic wall and mild atherosclerotic lesions, whereas LRP5 knock-out mice developed larger atherosclerotic lesions ${ }^{(29)}$. Moreover, supplementation of cholesterol lowering agents reduced the expression LRP5 in hyperlipidemic wild-type mice.

Taken together, this demonstrates a clear role for LRP5 and 6 as well as canonical signaling in halting the atherosclerotic development. However, LRP5 also promotes the formation of macrophage derived foam cells by internalization of intimal LDL and, therefore, also contributes to the advancement of atherosclerosis ${ }^{(30)}$.

\section{Conclusion}

Over the last decades, our knowledge of the different components and pathways involved in Wnt signaling has increased considerably, giving rise to a picture of a very complex network of molecular interactions. In parallel, the contribution of Wnt signaling to many diseases has been discovered. In this review, we have described a wide range of cardiac conditions in which the involvement of Wnt signaling has been described or where interventions in Wnt signaling - either genetic or pharmacologic in nature - have been shown to have a modulatory effect on the disease process. In many cases, we have included studies that show inconsistent outcomes as to whether Wnt signaling should be activated or inhibited. Since Wnt signaling is known to be involved in many disease mechanisms like hypertrophy, inflammation, fibrosis, and angiogenesis, it becomes clear that in cardiac diseases, where often a mixture of these disease mechanisms and cell types is involved, the results from different studies can lead to alternative conclusions. To add an additional layer of complexity, Wnt signaling does not operate in isolation but acts in concert with many other signaling pathways which can further fine-tune the outcomes of a study. Moreover, 
the vast majority of the studies have been performed in animal models of cardiac disease which can respond to interventions with considerable variation, depending on gender, genetic background, and method of disease induction. To make the switch toward clinical applicability of the large amount of experimental data that has been produced on this subject, we will have to move toward more clinically relevant materials such as blood, biopsies from patients, and post-mortem materials.

The widespread involvement of Wnt signaling in many cardiac pathologies may give rise to questions regarding its therapeutic applicability, as this implies multiple (and potentially) adverse effects of interventions in this pathway. In this respect, the involvement of Wnt signaling in many cardiac conditions and disease mechanisms shares some analogy with a well-established cardiovascular control system, the RAAS. The unraveling of the involvement of the RAAS in diverse cardiovascular pathologies and disease mechanisms has led to the development of one of the most successful families of drugs for the treatment of cardiovascular diseases to date. Although the experimental evidence that is currently available is not sufficient to predict a similar success for interventions in Wnt signaling, this example illustrates that interventions in a signaling pathway involved in multiple mechanisms of disease is not a dead end by definition but can be very successful. However, to achieve such a goal, we will first have to develop better drugs to target the Wnt signaling pathway at different levels. This will help us to identify the nodal points in the signaling pathway that are critical for the control or restoration of cardiovascular homeostasis under different conditions. Combined with an in-depth analysis of the molecular mechanisms underlying the diverse cardiovascular pathologies, this should lead to rigorous testing of the merits of interventions in Wnt signaling as a tool in the battle against cardiovascular diseases.

\section{Acknowledgements}

Kevin CM Hermans is funded by the Dutch Heart Foundation (2010B196). 


\section{References}

1. Ahmad F, Lal H, Zhou J, Vagnozzi RJ, Yu JE, Shang X, Woodgett JR, Gao E, and Force T. Cardiomyocyte-specific deletion of gsk3alpha mitigates post-myocardial infarction remodeling, contractile dysfunction, and heart failure. Journal of the American College of Cardiology 64: 696706, 2014.

2. Ai D, Fu X, Wang J, Lu MF, Chen L, Baldini A, Klein WH, and Martin JF. Canonical Wnt signaling functions in second heart field to promote right ventricular growth. Proc Natl Acad Sci U S A 104: 9319-9324, 2007.

3. Ai Z, Fischer A, Spray DC, Brown AM, and Fishman GI. Wnt-1 regulation of connexin43 in cardiac myocytes. J Clin Invest 105: 161-171, 2000.

4. Aicher A, Kollet O, Heeschen C, Liebner S, Urbich C, Ihling C, Orlandi A, Lapidot T, Zeiher AM, and Dimmeler S. The Wnt antagonist Dickkopf-1 mobilizes vasculogenic progenitor cells via activation of the bone marrow endosteal stem cell niche. Circ Res 103: 796-803, 2008.

5. Aisagbonhi O, Rai M, Ryzhov S, Atria N, Feoktistov I, and Hatzopoulos AK. Experimental myocardial infarction triggers canonical Wnt signaling and endothelial-to-mesenchymal transition. Dis Model Mech 4: 469-483, 2011.

6. Alfaro MP, Pagni M, Vincent A, Atkinson J, Hill MF, Cates J, Davidson JM, Rottman J, Lee E, and Young PP. The Wnt modulator sFRP2 enhances mesenchymal stem cell engraftment, granulation tissue formation and myocardial repair. Proc Natl Acad Sci U S A 105: 18366-18371, 2008.

7. Alfaro MP, Vincent A, Saraswati S, Thorne CA, Hong CC, Lee E, and Young PP. sFRP2 suppression of bone morphogenic protein (BMP) and Wnt signaling mediates mesenchymal stem cell (MSC) self-renewal promoting engraftment and myocardial repair. The Journal of biological chemistry 285: 35645-35653, 2010.

8. Ambrosy AP, Fonarow GC, Butler J, Chioncel O, Greene SJ, Vaduganathan M, Nodari S, Lam CS, Sato N, Shah AN, and Gheorghiade M. The global health and economic burden of hospitalizations for heart failure: lessons learned from hospitalized heart failure registries. Journal of the American College of Cardiology 63: 1123-1133, 2014.

9. Angers $\mathrm{S}$ and Moon RT. Proximal events in Wnt signal transduction. Nature reviews Molecular cell biology 10: 468-477, 2009.

10. Antos CL, McKinsey TA, Frey N, Kutschke W, McAnally J, Shelton JM, Richardson JA, Hill JA, and Olson EN. Activated glycogen synthase-3 beta suppresses cardiac hypertrophy in vivo. Proc Natl Acad Sci U S A 99: 907-912, 2002.

11. Armstrong PW and Committee WS. A comparison of pharmacologic therapy with/without timely coronary intervention vs. primary percutaneous intervention early after ST-elevation myocardial infarction: the WEST (Which Early ST-elevation myocardial infarction Therapy) study. European heart journal 27: 1530-1538, 2006.

12. Askevold ET, Aukrust P, Nymo SH, Lunde IG, Kaasboll OJ, Aakhus S, Florholmen G, Ohm IK, Strand ME, Attramadal H, Fiane A, Dahl CP, Finsen AV, Vinge LE, Christensen G, Yndestad A, Gullestad L, Latini R, Masson S, Tavazzi L, Investigators G-H, and Ueland T. The cardiokine secreted Frizzledrelated protein 3, a modulator of Wnt signalling, in clinical and experimental heart failure. Journal of internal medicine 275: 621-630, 2014.

13. Askevold ET, Gullestad L, Aakhus S, Ranheim T, Tonnessen T, Solberg OG, Aukrust P, and Ueland T. Secreted Wnt modulators in symptomatic aortic stenosis. Journal of the American Heart Association 1: e002261, 2012.

14. Asuni AA, Hooper C, Reynolds $\mathrm{CH}$, Lovestone S, Anderton BH, and Killick R. GSK3alpha exhibits beta-catenin and tau directed kinase activities that are modulated by Wnt. The European journal of neuroscience 24: 3387-3392, 2006. 
15. Banziger C, Soldini D, Schutt C, Zipperlen P, Hausmann G, and Basler K. Wntless, a conserved membrane protein dedicated to the secretion of Wnt proteins from signaling cells. Cell 125: 509522, 2006.

16. Barandon L, Casassus F, Leroux L, Moreau C, Allieres C, Lamaziere JM, Dufourcq P, Couffinhal T, and Duplaa C. Secreted frizzled-related protein-1 improves postinfarction scar formation through a modulation of inflammatory response. Arterioscler Thromb Vasc Biol 31: e80-87, 2011.

17. Barandon L, Couffinhal T, Dufourcq P, Ezan J, Costet P, Daret D, Deville C, and Duplaa C. Frizzled A, a novel angiogenic factor: promises for cardiac repair. European journal of cardio-thoracic surgery : official journal of the European Association for Cardio-thoracic Surgery 25: 76-83, 2004.

18. Barandon L, Couffinhal T, Ezan J, Dufourcq P, Costet P, Alzieu P, Leroux L, Moreau C, Dare D, and Duplaa C. Reduction of infarct size and prevention of cardiac rupture in transgenic mice overexpressing FrzA. Circulation 108: 2282-2289, 2003.

19. Barandon L, Dufourcq P, Costet P, Moreau C, Allieres C, Daret D, Dos Santos P, Daniel Lamaziere JM, Couffinhal T, and Duplaa C. Involvement of FrzA/sFRP-1 and the Wnt/frizzled pathway in ischemic preconditioning. Circulation research 96: 1299-1306, 2005.

20. Barrott JJ, Cash GM, Smith AP, Barrow JR, and Murtaugh LC. Deletion of mouse Porcn blocks Wnt ligand secretion and reveals an ectodermal etiology of human focal dermal hypoplasia/Goltz syndrome. Proc Natl Acad Sci U S A 108: 12752-12757, 2011.

21. Barry SP and Townsend PA. What causes a broken heart--molecular insights into heart failure. International review of cell and molecular biology 284: 113-179, 2010.

22. Bartscherer K, Pelte N, Ingelfinger D, and Boutros M. Secretion of Wnt ligands requires Evi, a conserved transmembrane protein. Cell 125: 523-533, 2006.

23. Baurand A, Zelarayan L, Betney R, Gehrke C, Dunger S, Noack C, Busjahn A, Huelsken J, Taketo MM, Birchmeier W, Dietz R, and Bergmann MW. Beta-catenin downregulation is required for adaptive cardiac remodeling. Circulation research 100: 1353-1362, 2007.

24. Bhat R, Xue Y, Berg S, Hellberg S, Ormo M, Nilsson Y, Radesater AC, Jerning E, Markgren PO, Borgegard T, Nylof M, Gimenez-Cassina A, Hernandez F, Lucas JJ, Diaz-Nido J, and Avila J. Structural insights and biological effects of glycogen synthase kinase 3-specific inhibitor ARA014418. The Journal of biological chemistry 278: 45937-45945, 2003.

25. Blankesteijn WM, Essers-Janssen YP, Ulrich MM, and Smits JF. Increased expression of a homologue of drosophila tissue polarity gene "frizzled" in left ventricular hypertrophy in the rat, as identified by subtractive hybridization. Journal of molecular and cellular cardiology 28: 1187-1191, 1996.

26. Blankesteijn WM, Essers-Janssen YP, Verluyten MJ, Daemen MJ, and Smits JF. A homologue of Drosophila tissue polarity gene frizzled is expressed in migrating myofibroblasts in the infarcted rat heart. Nature medicine 3: 541-544, 1997.

27. Blankesteijn WM, van Gijn ME, Essers-Janssen YP, Daemen MJ, and Smits JF. Beta-catenin, an inducer of uncontrolled cell proliferation and migration in malignancies, is localized in the cytoplasm of vascular endothelium during neovascularization after myocardial infarction. The American journal of pathology 157: 877-883, 2000.

28. Bond J, Sedmera D, Jourdan J, Zhang Y, Eisenberg CA, Eisenberg LM, and Gourdie RG. Wnt11 and Wnt7a are up-regulated in association with differentiation of cardiac conduction cells in vitro and in vivo. Developmental dynamics : an official publication of the American Association of Anatomists 227: 536-543, 2003.

29. Borrell-Pages M, Romero JC, and Badimon L. Cholesterol modulates LRP5 expression in the vessel wall. Atherosclerosis 235: 363-370, 2014.

30. Borrell-Pages M, Romero JC, Juan-Babot O, and Badimon L. Wnt pathway activation, cell migration, and lipid uptake is regulated by low-density lipoprotein receptor-related protein 5 in human macrophages. European heart journal 32: 2841-2850, 2011. 
31. Brade T, Manner J, and Kuhl M. The role of Wnt signalling in cardiac development and tissue remodelling in the mature heart. Cardiovascular research 72: 198-209, 2006.

32. Braz JC, Gill RM, Corbly AK, Jones BD, Jin N, Vlahos CJ, Wu Q, and Shen W. Selective activation of $\mathrm{PI3Kalpha/Akt/GSK-3beta} \mathrm{signalling} \mathrm{and} \mathrm{cardiac} \mathrm{compensatory} \mathrm{hypertrophy} \mathrm{during} \mathrm{recovery} \mathrm{from}$ heart failure. European journal of heart failure 11: 739-748, 2009.

33. Buckingham M, Meilhac S, and Zaffran S. Building the mammalian heart from two sources of myocardial cells. Nature reviews Genetics 6: 826-835, 2005.

34. Caspi O, Huber I, Gepstein A, Arbel G, Maizels L, Boulos M, and Gepstein L. Modeling of arrhythmogenic right ventricular cardiomyopathy with human induced pluripotent stem cells. Circulation Cardiovascular genetics 6: 557-568, 2013.

35. Cattelino A, Liebner S, Gallini R, Zanetti A, Balconi G, Corsi A, Bianco P, Wolburg H, Moore R, Oreda $B$, Kemler R, and Dejana $E$. The conditional inactivation of the beta-catenin gene in endothelial cells causes a defective vascular pattern and increased vascular fragility. The Journal of cell biology 162 : 1111-1122, 2003.

36. Cerutti C, Kurdi M, Bricca G, Hodroj W, Paultre C, Randon J, and Gustin MP. Transcriptional alterations in the left ventricle of three hypertensive rat models. Physiological genomics 27: 295308, 2006.

37. Chen B, Dodge ME, Tang W, Lu J, Ma Z, Fan CW, Wei S, Hao W, Kilgore J, Williams NS, Roth MG, Amatruda JF, Chen C, and Lum L. Small molecule-mediated disruption of Wnt-dependent signaling in tissue regeneration and cancer. Nature chemical biology 5: 100-107, 2009.

38. Chen DM, Cai X, Kwik-Uribe CL, Zeng R, and Zhu XZ. Inhibitory effects of procyanidin B(2) dimer on lipid-laden macrophage formation. Journal of cardiovascular pharmacology 48: 54-70, 2006.

39. Chen L, Wu Q, Guo F, Xia B, and Zuo J. Expression of Dishevelled-1 in wound healing after acute myocardial infarction: possible involvement in myofibroblast proliferation and migration. J Cell Mol Med 8: 257-264, 2004.

40. Chen SN, Gurha P, Lombardi R, Ruggiero A, Willerson JT, and Marian AJ. The hippo pathway is activated and is a causal mechanism for adipogenesis in arrhythmogenic cardiomyopathy. Circulation research 114: 454-468, 2014.

41. Cho J, Zhai P, Maejima Y, and Sadoshima J. Myocardial injection with GSK-3beta-overexpressing bone marrow-derived mesenchymal stem cells attenuates cardiac dysfunction after myocardial infarction. Circulation research 108: 478-489, 2011.

42. Choukroun G, Hajjar R, Fry S, del Monte F, Haq S, Guerrero JL, Picard M, Rosenzweig A, and Force T. Regulation of cardiac hypertrophy in vivo by the stress-activated protein kinases/c-Jun $\mathrm{NH}(2)$ terminal kinases. J Clin Invest 104: 391-398, 1999.

43. Christman MA, 2nd, Goetz DJ, Dickerson E, McCall KD, Lewis CJ, Benencia F, Silver MJ, Kohn LD, and Malgor R. Wnt5a is expressed in murine and human atherosclerotic lesions. Am J Physiol Heart Circ Physiol 294: H2864-2870, 2008.

44. Chu ML, Ahn VE, Choi HJ, Daniels DL, Nusse R, and Weis WI. structural Studies of Wnts and identification of an LRP6 binding site. Structure 21: 1235-1242, 2013.

45. Cipolletta E, Monaco S, Maione AS, Vitiello L, Campiglia P, Pastore L, Franchini C, Novellino E, Limongelli V, Bayer KU, Means AR, Rossi G, Trimarco B, laccarino G, and Illario M. Calmodulindependent kinase II mediates vascular smooth muscle cell proliferation and is potentiated by extracellular signal regulated kinase. Endocrinology 151: 2747-2759, 2010.

46. Cleutjens JP, Blankesteijn WM, Daemen MJ, and Smits JF. The infarcted myocardium: simply dead tissue, or a lively target for therapeutic interventions. Cardiovascular research 44: 232-241, 1999.

47. Clevers H. Wnt/beta-catenin signaling in development and disease. Cell 127: 469-480, 2006.

48. Cliffe A, Hamada F, and Bienz M. A role of Dishevelled in relocating Axin to the plasma membrane during wingless signaling. Current biology : CB 13: 960-966, 2003. 
49. Coghlan MP, Culbert AA, Cross DA, Corcoran SL, Yates JW, Pearce NJ, Rausch OL, Murphy GJ, Carter PS, Roxbee Cox L, Mills D, Brown MJ, Haigh D, Ward RW, Smith DG, Murray KJ, Reith AD, and Holder JC. Selective small molecule inhibitors of glycogen synthase kinase-3 modulate glycogen metabolism and gene transcription. Chemistry \& biology 7: 793-803, 2000.

50. Cohen ED, Wang Z, Lepore JJ, Lu MM, Taketo MM, Epstein DJ, and Morrisey EE. Wnt/beta-catenin signaling promotes expansion of Isl-1-positive cardiac progenitor cells through regulation of FGF signaling. J Clin Invest 117: 1794-1804, 2007.

51. Cola C, Almeida M, Li D, Romeo F, and Mehta JL. Regulatory role of endothelium in the expression of genes affecting arterial calcification. Biochemical and biophysical research communications 320 : 424-427, 2004.

52. Colston JT, de la Rosa SD, Koehler M, Gonzales K, Mestril R, Freeman GL, Bailey SR, and Chandrasekar B. Wnt-induced secreted protein-1 is a prohypertrophic and profibrotic growth factor. Am J Physiol Heart Circ Physiol 293: H1839-1846, 2007.

53. Cong F, Schweizer L, and Varmus H. Wnt signals across the plasma membrane to activate the beta-catenin pathway by forming oligomers containing its receptors, Frizzled and LRP. Development 131: 5103-5115, 2004.

54. Corada M, Morini MF, and Dejana E. Signaling Pathways in the Specification of Arteries and Veins. Arterioscler Thromb Vasc Biol, 2014.

55. Corada M, Nyqvist D, Orsenigo F, Caprini A, Giampietro C, Taketo MM, Iruela-Arispe ML, Adams $\mathrm{RH}$, and Dejana $\mathrm{E}$. The Wnt/beta-catenin pathway modulates vascular remodeling and specification by upregulating DII4/Notch signaling. Developmental cell 18: 938-949, 2010.

56. Courtwright A, Siamakpour-Reihani S, Arbiser JL, Banet N, Hilliard E, Fried L, Livasy C, Ketelsen D, Nepal DB, Perou CM, Patterson C, and Klauber-Demore N. Secreted frizzle-related protein 2 stimulates angiogenesis via a calcineurin/NFAT signaling pathway. Canc Res 69: 4621-4628, 2009.

57. Crompton M. Mitochondrial intermembrane junctional complexes and their role in cell death. The Journal of physiology 529 Pt 1: 11-21, 2000.

58. Cruciat CM and Niehrs C. Secreted and transmembrane wnt inhibitors and activators. Cold Spring Harbor perspectives in biology 5: a015081, 2013.

59. Daskalopoulos EP, Janssen BJ, and Blankesteijn WM. Myofibroblasts in the infarct area: concepts and challenges. Microscopy and microanalysis : the official journal of Microscopy Society of America, Microbeam Analysis Society, Microscopical Society of Canada 18: 35-49, 2012.

60. Dejana E. The role of wnt signaling in physiological and pathological angiogenesis. Circ Res 107: 943-952, 2010.

61. Dejmek J, Safholm A, Kamp Nielsen C, Andersson T, and Leandersson K. Wnt-5a/Ca2+-induced NFAT activity is counteracted by Wnt-5a/Yes-Cdc42-casein kinase 1alpha signaling in human mammary epithelial cells. Molecular and cellular biology 26: 6024-6036, 2006.

62. Dorn GW, 2nd. The fuzzy logic of physiological cardiac hypertrophy. Hypertension 49: 962-970, 2007.

63. Duan J, Gherghe C, Liu D, Hamlett E, Srikantha L, Rodgers L, Regan JN, Rojas M, Willis M, Leask A, Majesky $M$, and Deb $A$. Wnt1/betacatenin injury response activates the epicardium and cardiac fibroblasts to promote cardiac repair. Embo J 31: 429-442, 2012.

64. Eisenberg CA, Gourdie RG, and Eisenberg LM. Wnt-11 is expressed in early avian mesoderm and required for the differentiation of the quail mesoderm cell line QCE-6. Development 124: 525-536, 1997.

65. Eisenberg LM and Eisenberg CA. Evaluating the role of Wnt signal transduction in promoting the development of the heart. TheScientificWorldJournal 7: 161-176, 2007.

66. Emami KH, Nguyen C, Ma H, Kim DH, Jeong KW, Eguchi M, Moon RT, Teo JL, Kim HY, Moon SH, Ha $\mathrm{JR}$, and Kahn M. A small molecule inhibitor of beta-catenin/CREB-binding protein transcription [corrected]. Proc Natl Acad Sci U S A 101: 12682-12687, 2004. 
67. Felkin LE, Lara-Pezzi EA, Hall JL, Birks EJ, and Barton PJ. Reverse remodelling and recovery from heart failure are associated with complex patterns of gene expression. Journal of cardiovascular translational research 4: 321-331, 2011.

68. Foord SM, Bonner TI, Neubig RR, Rosser EM, Pin JP, Davenport AP, Spedding M, and Harmar AJ. International Union of Pharmacology. XLVI. G protein-coupled receptor list. Pharmacological reviews 57: 279-288, 2005.

69. Forrester WC, Dell M, Perens E, and Garriga G. A C. elegans Ror receptor tyrosine kinase regulates cell motility and asymmetric cell division. Nature 400: 881-885, 1999.

70. Franco CA, Liebner S, and Gerhardt H. Vascular morphogenesis: a Wnt for every vessel? Current opinion in genetics \& development 19: 476-483, 2009.

71. Fujio Y, Matsuda T, Oshima Y, Maeda M, Mohri T, Ito T, Takatani T, Hirata M, Nakaoka Y, Kimura R, Kishimoto T, and Azuma J. Signals through gp130 upregulate Wnt5a and contribute to cell adhesion in cardiac myocytes. FEBS letters 573: 202-206, 2004.

72. Fukuda $\mathrm{K}$ and Yuasa $\mathrm{S}$. Stem cells as a source of regenerative cardiomyocytes. Circulation research 98: 1002-1013, 2006.

73. Gale NW, Dominguez MG, Noguera I, Pan L, Hughes V, Valenzuela DM, Murphy AJ, Adams NC, Lin HC, Holash J, Thurston G, and Yancopoulos GD. Haploinsufficiency of delta-like 4 ligand results in embryonic lethality due to major defects in arterial and vascular development. Proc Natl Acad Sci U S A 101: 15949-15954, 2004.

74. Garcia-Gras E, Lombardi R, Giocondo MJ, Willerson JT, Schneider MD, Khoury DS, and Marian AJ. Suppression of canonical Wnt/beta-catenin signaling by nuclear plakoglobin recapitulates phenotype of arrhythmogenic right ventricular cardiomyopathy. J Clin Invest 116: 2012-2021, 2006.

75. Gelfand BD, Meller J, Pryor AW, Kahn M, Bortz PD, Wamhoff BR, and Blackman BR. Hemodynamic activation of beta-catenin and T-cell-specific transcription factor signaling in vascular endothelium regulates fibronectin expression. Arterioscler Thromb Vasc Biol 31: 1625-1633, 2011.

76. Gessert $\mathrm{S}$ and Kuhl M. The multiple phases and faces of wnt signaling during cardiac differentiation and development. Circulation research 107: 186-199, 2010.

77. Go GW and Mani A. Low-density lipoprotein receptor (LDLR) family orchestrates cholesterol homeostasis. Yale J Biol Med 85: 19-28, 2012.

78. Go GW, Srivastava R, Hernandez-Ono A, Gang G, Smith SB, Booth CJ, Ginsberg HN, and Mani A. The combined hyperlipidemia caused by impaired Wnt-LRP6 signaling is reversed by Wnt3a rescue. Cell Metab 19: 209-220, 2014.

79. Goodwin AM, Sullivan KM, and D'Amore PA. Cultured endothelial cells display endogenous activation of the canonical Wnt signaling pathway and express multiple ligands, receptors, and secreted modulators of Wnt signaling. Dev Dyn 235: 3110-3120, 2006.

80. Grigoryan T, Wend P, Klaus A, and Birchmeier W. Deciphering the function of canonical Wnt signals in development and disease: conditional loss- and gain-of-function mutations of beta-catenin in mice. Genes \& development 22: 2308-2341, 2008.

81. Hagenmueller M, Riffel JH, Bernhold E, Fan J, Katus HA, and Hardt SE. Dapper-1 is essential for Wnt5a induced cardiomyocyte hypertrophy by regulating the Wnt/PCP pathway. FEBS letters 588 : 2230-2237, 2014.

82. Hagenmueller M, Riffel JH, Bernhold E, Fan J, Zhang M, Ochs M, Steinbeisser H, Katus HA, and Hardt SE. Dapper-1 induces myocardial remodeling through activation of canonical Wnt signaling in cardiomyocytes. Hypertension 61: 1177-1183, 2013.

83. Hahn JY, Cho HJ, Bae JW, Yuk HS, Kim KI, Park KW, Koo BK, Chae IH, Shin CS, Oh BH, Choi YS, Park YB, and Kim HS. Beta-catenin overexpression reduces myocardial infarct size through differential effects on cardiomyocytes and cardiac fibroblasts. The Journal of biological chemistry 281: 3097930989, 2006. 
84. Haq S, Choukroun G, Kang ZB, Ranu H, Matsui T, Rosenzweig A, Molkentin JD, Alessandrini A, Woodgett J, Hajjar R, Michael A, and Force T. Glycogen synthase kinase-3beta is a negative regulator of cardiomyocyte hypertrophy. The Journal of cell biology 151: 117-130, 2000.

85. Haq S, Choukroun G, Lim H, Tymitz KM, del Monte F, Gwathmey J, Grazette L, Michael A, Hajjar R, Force $\mathrm{T}$, and Molkentin JD. Differential activation of signal transduction pathways in human hearts with hypertrophy versus advanced heart failure. Circulation 103: 670-677, 2001.

86. Haq S, Michael A, Andreucci M, Bhattacharya K, Dotto P, Walters B, Woodgett J, Kilter H, and Force T. Stabilization of beta-catenin by a Wnt-independent mechanism regulates cardiomyocyte growth. Proc Natl Acad Sci U S A 100: 4610-4615, 2003.

87. Harris TJ and Peifer M. Decisions, decisions: beta-catenin chooses between adhesion and transcription. Trends in cell biology 15: 234-237, 2005.

88. Hassler C, Cruciat CM, Huang YL, Kuriyama S, Mayor R, and Niehrs C. Kremen is required for neural crest induction in Xenopus and promotes LRP6-mediated Wnt signaling. Development 134: 42554263, 2007.

89. He W, Zhang L, Ni A, Zhang Z, Mirotsou M, Mao L, Pratt RE, and Dzau VJ. Exogenously administered secreted frizzled related protein 2 (Sfrp2) reduces fibrosis and improves cardiac function in a rat model of myocardial infarction. Proc Natl Acad Sci U S A 107: 21110-21115, 2010.

90. Herr $\mathrm{P}$ and Basler K. Porcupine-mediated lipidation is required for Wnt recognition by Wls. Developmental biology 361: 392-402, 2012.

91. Hirotani S, Zhai P, Tomita H, Galeotti J, Marquez JP, Gao S, Hong C, Yatani A, Avila J, and Sadoshima J. Inhibition of glycogen synthase kinase 3 beta during heart failure is protective. Circulation research 101: 1164-1174, 2007.

92. Hoffman BF and Rosen MR. Cellular mechanisms for cardiac arrhythmias. Circulation research 49: 1-15, 1981.

93. Hu Y, Cheng L, Hochleitner BW, and Xu Q. Activation of mitogen-activated protein kinases (ERK/JNK) and AP-1 transcription factor in rat carotid arteries after balloon injury. Arterioscler Thromb Vasc Biol 17: 2808-2816, 1997.

94. Huang SM, Mishina YM, Liu S, Cheung A, Stegmeier F, Michaud GA, Charlat O, Wiellette E, Zhang Y, Wiessner S, Hild M, Shi X, Wilson CJ, Mickanin C, Myer V, Fazal A, Tomlinson R, Serluca F, Shao W, Cheng H, Shultz M, Rau C, Schirle M, Schlegl J, Ghidelli S, Fawell S, Lu C, Curtis D, Kirschner MW, Lengauer C, Finan PM, Tallarico JA, Bouwmeester T, Porter JA, Bauer A, and Cong F. Tankyrase inhibition stabilizes axin and antagonizes Wnt signalling. Nature 461: 614-620, 2009.

95. Huber $\mathrm{AH}$, Nelson WJ, and Weis WI. Three-dimensional structure of the armadillo repeat region of beta-catenin. Cell 90: 871-882, 1997.

96. Hudson J, Titmarsh D, Hidalgo A, Wolvetang E, and Cooper-White J. Primitive cardiac cells from human embryonic stem cells. Stem cells and development 21: 1513-1523, 2012.

97. Huelsken J, Vogel R, Brinkmann V, Erdmann B, Birchmeier C, and Birchmeier W. Requirement for beta-catenin in anterior-posterior axis formation in mice. The Journal of cell biology 148: 567-578, 2000.

98. Hurlstone AF, Haramis AP, Wienholds E, Begthel H, Korving J, Van Eeden F, Cuppen E, Zivkovic D, Plasterk $\mathrm{RH}$, and Clevers $\mathrm{H}$. The $\mathrm{Wnt} /$ beta-catenin pathway regulates cardiac valve formation. Nature 425: 633-637, 2003.

99. Iribarren C, Sidney S, Sternfeld B, and Browner WS. Calcification of the aortic arch: risk factors and association with coronary heart disease, stroke, and peripheral vascular disease. JAMA : the journal of the American Medical Association 283: 2810-2815, 2000.

100. Ishikawa T, Tamai Y, Zorn AM, Yoshida H, Seldin MF, Nishikawa T, and Taketo MM. Mouse wnt receptor gene Fzd5 is essential for yolk sac and placental angiogenesis. Development 128: 25-33, 2001. 
101. Janda CY, Waghray D, Levin AM, Thomas C, and Garcia KC. Structural basis of Wnt recognition by Frizzled. Science 337: 59-64, 2012.

102. Javadov $\mathrm{S}$ and Karmazyn M. Mitochondrial permeability transition pore opening as an endpoint to initiate cell death and as a putative target for cardioprotection. Cellular physiology and biochemistry : international journal of experimental cellular physiology, biochemistry, and pharmacology 20: 1-22, 2007.

103. Jho EH, Zhang T, Domon C, Joo CK, Freund JN, and Costantini F. Wnt/beta-catenin/Tcf signaling induces the transcription of Axin2, a negative regulator of the signaling pathway. Molecular and cellular biology 22: 1172-1183, 2002.

104. Juhaszova M, Zorov DB, Kim SH, Pepe S, Fu Q, Fishbein KW, Ziman BD, Wang S, Ytrehus K, Antos $\mathrm{CL}$, Olson EN, and Sollott SJ. Glycogen synthase kinase-3beta mediates convergence of protection signaling to inhibit the mitochondrial permeability transition pore. J Clin Invest 113: 1535-1549, 2004.

105. Kaidanovich-Beilin O and Woodgett JR. GSK-3: Functional Insights from Cell Biology and Animal Models. Frontiers in molecular neuroscience 4: 40, 2011.

106. Karakikes I, Senyei GD, Hansen J, Kong CW, Azeloglu EU, Stillitano F, Lieu DK, Wang J, Ren L, Hulot JS, lyengar R, Li RA, and Hajjar RJ. Small molecule-mediated directed differentiation of human embryonic stem cells toward ventricular cardiomyocytes. Stem cells translational medicine 3: 1831, 2014.

107. Kawamura M, Miyagawa S, Miki K, Saito A, Fukushima S, Higuchi T, Kawamura T, Kuratani T, Daimon T, Shimizu T, Okano T, and Sawa Y. Feasibility, safety, and therapeutic efficacy of human induced pluripotent stem cell-derived cardiomyocyte sheets in a porcine ischemic cardiomyopathy model. Circulation 126: S29-37, 2012.

108. Kawano Y and Kypta R. Secreted antagonists of the Wnt signalling pathway. Journal of cell science 116: 2627-2634, 2003.

109. Kaykas A, Yang-Snyder J, Heroux M, Shah KV, Bouvier M, and Moon RT. Mutant Frizzled 4 associated with vitreoretinopathy traps wild-type Frizzled in the endoplasmic reticulum by oligomerization. Nat Cell Biol 6: 52-58, 2004.

110. Kerkela R, Kockeritz L, Macaulay K, Zhou J, Doble BW, Beahm C, Greytak S, Woulfe K, Trivedi CM, Woodgett JR, Epstein JA, Force T, and Huggins GS. Deletion of GSK-3beta in mice leads to hypertrophic cardiomyopathy secondary to cardiomyoblast hyperproliferation. J Clin Invest 118: 3609-3618, 2008.

111. Kerkela R, Woulfe K, and Force T. Glycogen synthase kinase-3beta -- actively inhibiting hypertrophy. Trends in cardiovascular medicine 17: 91-96, 2007.

112. Kikuchi A. Regulation of beta-catenin signaling in the Wnt pathway. Biochemical and biophysical research communications 268: 243-248, 2000.

113. Kikuchi A, Yamamoto H, and Kishida S. Multiplicity of the interactions of Wnt proteins and their receptors. Cellular signalling 19: 659-671, 2007.

114. Kim J, Kim J, Kim DW, Ha Y, Ihm MH, Kim H, Song K, and Lee I. Wnt5a induces endothelial inflammation via beta-catenin-independent signaling. Journal of immunology 185: 1274-1282, 2010.

115. Kim KI, Park KU, Chun EJ, Choi SI, Cho YS, Youn TJ, Cho GY, Chae IH, Song J, Choi DJ, and Kim CH. A novel biomarker of coronary atherosclerosis: serum DKK1 concentration correlates with coronary artery calcification and atherosclerotic plaques. J Korean Med Sci 26: 1178-1184, 2011.

116. Kimelman $\mathrm{D}$ and $\mathrm{Xu} \mathrm{W}$. beta-catenin destruction complex: insights and questions from a structural perspective. Oncogene 25: 7482-7491, 2006.

117. Kirk JA, Holewinski RJ, Kooij V, Agnetti G, Tunin RS, Witayavanitkul N, de Tombe PP, Gao WD, Van Eyk J, and Kass DA. Cardiac resynchronization sensitizes the sarcomere to calcium by reactivating GSK-3beta. J Clin Invest 124: 129-138, 2014. 
118. Klaus A, Saga Y, Taketo MM, Tzahor E, and Birchmeier W. Distinct roles of Wnt/beta-catenin and Bmp signaling during early cardiogenesis. Proc Natl Acad Sci U S A 104: 18531-18536, 2007.

119. Klein PS and Melton DA. A molecular mechanism for the effect of lithium on development. Proc Natl Acad Sci U S A 93: 8455-8459, 1996.

120. Kobayashi K, Luo M, Zhang Y, Wilkes DC, Ge G, Grieskamp T, Yamada C, Liu TC, Huang G, Basson CT, Kispert A, Greenspan DS, and Sato TN. Secreted Frizzled-related protein 2 is a procollagen C proteinase enhancer with a role in fibrosis associated with myocardial infarction. Nat Cell Biol 11: 46-55, 2009.

121. Kostin S, Hein S, Bauer EP, and Schaper J. Spatiotemporal development and distribution of intercellular junctions in adult rat cardiomyocytes in culture. Circulation research 85: 154-167, 1999.

122. Koyanagi M, Haendeler J, Badorff C, Brandes RP, Hoffmann J, Pandur P, Zeiher AM, Kuhl M, and Dimmeler S. Non-canonical Wnt signaling enhances differentiation of human circulating progenitor cells to cardiomyogenic cells. The Journal of biological chemistry 280: 16838-16842, 2005.

123. Koyanagi M, Iwasaki M, Haendeler J, Leitges M, Zeiher AM, and Dimmeler S. Wnt5a increases cardiac gene expressions of cultured human circulating progenitor cells via a PKC delta activation. PloS one 4: e5765, 2009.

124. Kumar S, Zigman M, Patel TR, Trageser B, Gross JC, Rahm K, Boutros M, Gradl D, Steinbeisser H, Holstein T, Stetefeld J, and Ozbek S. Molecular dissection of Wnt3a-Frizzled8 interaction reveals essential and modulatory determinants of Wnt signaling activity. BMC biology 12: 44, 2014.

125. Kuwabara M, Kakinuma Y, Katare RG, Ando M, Yamasaki F, Doi Y, and Sato T. Granulocyte colonystimulating factor activates Wnt signal to sustain gap junction function through recruitment of beta-catenin and cadherin. FEBS letters 581: 4821-4830, 2007.

126. Kuwahara K and Nakao K. New molecular mechanisms for cardiovascular disease:transcriptional pathways and novel therapeutic targets in heart failure. Journal of pharmacological sciences 116 : 337-342, 2011.

127. Kwon C, Arnold J, Hsiao EC, Taketo MM, Conklin BR, and Srivastava D. Canonical Wnt signaling is a positive regulator of mammalian cardiac progenitors. Proc Natl Acad Sci U S A 104: 10894-10899, 2007.

128. Laeremans H, Hackeng TM, van Zandvoort MA, Thijssen VL, Janssen BJ, Ottenheijm HC, Smits JF, and Blankesteijn WM. Blocking of frizzled signaling with a homologous peptide fragment of wnt3a/wnt5a reduces infarct expansion and prevents the development of heart failure after myocardial infarction. Circulation 124: 1626-1635, 2011.

129. LaFramboise WA, Bombach KL, Dhir RJ, Muha N, Cullen RF, Pogozelski AR, Turk D, George JD, Guthrie RD, and Magovern JA. Molecular dynamics of the compensatory response to myocardial infarct. Journal of molecular and cellular cardiology 38: 103-117, 2005.

130. Lal H, Zhou J, Ahmad F, Zaka R, Vagnozzi RJ, Decaul M, Woodgett J, Gao E, and Force T. Glycogen synthase kinase-3alpha limits ischemic injury, cardiac rupture, post-myocardial infarction remodeling and death. Circulation 125: 65-75, 2012.

131. Lee DK, Nathan Grantham R, Trachte AL, Mannion JD, and Wilson CL. Activation of the canonical Wnt/beta-catenin pathway enhances monocyte adhesion to endothelial cells. Biochemical and biophysical research communications 347: 109-116, 2006.

132. Lepourcelet M, Chen YN, France DS, Wang H, Crews P, Petersen F, Bruseo C, Wood AW, and Shivdasani RA. Small-molecule antagonists of the oncogenic Tcf/beta-catenin protein complex. Cancer cell 5: 91-102, 2004.

133. Leung JY, Kolligs FT, Wu R, Zhai Y, Kuick R, Hanash S, Cho KR, and Fearon ER. Activation of AXIN2 expression by beta-catenin-T cell factor. A feedback repressor pathway regulating Wnt signaling. The Journal of biological chemistry 277: 21657-21665, 2002. 
134. Li J, Xuan W, Yan R, Tropak MB, Jean-St-Michel E, Liang W, Gladstone R, Backx PH, Kharbanda RK, and Redington AN. Remote preconditioning provides potent cardioprotection via PI3K/Akt activation and is associated with nuclear accumulation of beta-catenin. Clinical science 120: 451462, 2011.

135. Li JM, Eslami MH, Rohrer MJ, Dargon P, Joris I, Hendricks G, Baker S, and Cutler BS. Interleukin 18 binding protein (IL18-BP) inhibits neointimal hyperplasia after balloon injury in an atherosclerotic rabbit model. Journal of vascular surgery 47: 1048-1057, 2008.

136. Lian X, Hsiao C, Wilson G, Zhu K, Hazeltine LB, Azarin SM, Raval KK, Zhang J, Kamp TJ, and Palecek SP. Robust cardiomyocyte differentiation from human pluripotent stem cells via temporal modulation of canonical Wnt signaling. Proc Natl Acad Sci U S A 109: E1848-1857, 2012.

137. Liebner S, Corada M, Bangsow T, Babbage J, Taddei A, Czupalla CJ, Reis M, Felici A, Wolburg H, Fruttiger M, Taketo MM, von Melchner H, Plate $\mathrm{KH}$, Gerhardt H, and Dejana E. Wnt/beta-catenin signaling controls development of the blood-brain barrier. The Journal of cell biology 183: 409417, 2008.

138. Lievens D and von Hundelshausen P. Platelets in atherosclerosis. Thrombosis and haemostasis 106: 827-838, 2011.

139. Lin L, Cui L, Zhou W, Dufort D, Zhang X, Cai CL, Bu L, Yang L, Martin J, Kemler R, Rosenfeld MG, Chen J, and Evans SM. Beta-catenin directly regulates Islet1 expression in cardiovascular progenitors and is required for multiple aspects of cardiogenesis. Proc Natl Acad Sci U S A 104: 9313-9318, 2007.

140. Liu P, Wakamiya M, Shea MJ, Albrecht U, Behringer RR, and Bradley A. Requirement for Wnt3 in vertebrate axis formation. Nature genetics 22: 361-365, 1999.

141. Lo CW. Role of gap junctions in cardiac conduction and development: insights from the connexin knockout mice. Circulation research 87: 346-348, 2000.

142. Louis SF and Zahradka P. Vascular smooth muscle cell motility: From migration to invasion. Experimental and clinical cardiology 15: e75-85, 2010.

143. Lu W, Yamamoto V, Ortega B, and Baltimore D. Mammalian Ryk is a Wnt coreceptor required for stimulation of neurite outgrowth. Cell 119: 97-108, 2004.

144. Luckey SW, Mansoori J, Fair K, Antos CL, Olson EN, and Leinwand LA. Blocking cardiac growth in hypertrophic cardiomyopathy induces cardiac dysfunction and decreased survival only in males. Am J Physiol Heart Circ Physiol 292: H838-845, 2007.

145. MacDonald BT, Hien A, Zhang X, Iranloye O, Virshup DM, Waterman ML, and He X. Disulfide bond requirements for active wnt ligands. The Journal of biological chemistry 289: 18122-18136, 2014.

146. MacDonnell SM, Weisser-Thomas J, Kubo H, Hanscome M, Liu Q, Jaleel N, Berretta R, Chen X, Brown JH, Sabri AK, Molkentin JD, and Houser SR. CaMKII negatively regulates calcineurin-NFAT signaling in cardiac myocytes. Circulation research 105: 316-325, 2009.

147. Malekar P, Hagenmueller M, Anyanwu A, Buss S, Streit MR, Weiss CS, Wolf D, Riffel J, Bauer A, Katus HA, and Hardt SE. Wnt signaling is critical for maladaptive cardiac hypertrophy and accelerates myocardial remodeling. Hypertension 55: 939-945, 2010.

148. Mani A, Radhakrishnan J, Wang H, Mani MA, Nelson-Williams C, Carew KS, Mane S, Najmabadi H, Wu D, and Lifton RP. LRP6 mutation in a family with early coronary disease and metabolic risk factors. Science 315: 1278-1282, 2007.

149. Mao B, Wu W, Davidson G, Marhold J, Li M, Mechler BM, Delius H, Hoppe D, Stannek P, Walter C, Glinka A, and Niehrs C. Kremen proteins are Dickkopf receptors that regulate Wnt/beta-catenin signalling. Nature 417: 664-667, 2002.

150. Marcelo KL, Goldie LC, and Hirschi KK. Regulation of endothelial cell differentiation and specification. Circ Res 112: 1272-1287, 2013. 
151. Marchand A, Atassi F, Gaaya A, Leprince P, Le Feuvre C, Soubrier F, Lompre AM, and Nadaud S. The Wnt/beta-catenin pathway is activated during advanced arterial aging in humans. Aging cell 10: 220-232, 2011.

152. Martinez A, Alonso M, Castro A, Perez C, and Moreno FJ. First non-ATP competitive glycogen synthase kinase 3 beta (GSK-3beta) inhibitors: thiadiazolidinones (TDZD) as potential drugs for the treatment of Alzheimer's disease. Journal of medicinal chemistry 45: 1292-1299, 2002.

153. Marvin MJ, Di Rocco G, Gardiner A, Bush SM, and Lassar AB. Inhibition of Wnt activity induces heart formation from posterior mesoderm. Genes \& development 15: 316-327, 2001.

154. Mastri M, Shah Z, Hsieh K, Wang X, Wooldridge B, Martin S, Suzuki G, and Lee T. Secreted Frizzledrelated protein 2 as a target in antifibrotic therapeutic intervention. American journal of physiology Cell physiology 306: C531-539, 2014.

155. Masuelli L, Bei R, Sacchetti P, Scappaticci I, Francalanci P, Albonici L, Coletti A, Palumbo C, Minieri M, Fiaccavento R, Carotenuto F, Fantini C, Carosella L, Modesti A, and Di Nardo P. Beta-catenin accumulates in intercalated disks of hypertrophic cardiomyopathic hearts. Cardiovascular research 60: 376-387, 2003.

156. Matsushima K, Suyama T, Takenaka C, Nishishita N, Ikeda K, Ikada Y, Sawa Y, Jakt LM, Mori H, and Kawamata S. Secreted frizzled related protein 4 reduces fibrosis scar size and ameliorates cardiac function after ischemic injury. Tissue engineering Part A 16: 3329-3341, 2010.

157. Maye P, Zheng J, Li L, and Wu D. Multiple mechanisms for Wnt11-mediated repression of the canonical Wnt signaling pathway. The Journal of biological chemistry 279: 24659-24665, 2004.

158. McKinsey TA and Kass DA. Small-molecule therapies for cardiac hypertrophy: moving beneath the cell surface. Nature reviews Drug discovery 6: 617-635, 2007.

159. McMurray JJ, Packer M, Desai AS, Gong J, Lefkowitz MP, Rizkala AR, Rouleau JL, Shi VC, Solomon SD, Swedberg K, Zile MR, Investigators P-H, and Committees. Angiotensin-neprilysin inhibition versus enalapril in heart failure. The New England journal of medicine 371: 993-1004, 2014.

160. Mechoulam $\mathrm{H}$ and Pierce EA. Retinopathy of prematurity: molecular pathology and therapeutic strategies. Am J Pharmacogenomics 3: 261-277, 2003.

161. Meijer L, Skaltsounis AL, Magiatis P, Polychronopoulos P, Knockaert M, Leost M, Ryan XP, Vonica CA, Brivanlou A, Dajani R, Crovace C, Tarricone C, Musacchio A, Roe SM, Pearl L, and Greengard P. GSK-3-selective inhibitors derived from Tyrian purple indirubins. Chemistry \& biology 10: 12551266, 2003.

162. Melenovsky V, Benes J, Skaroupkova P, Sedmera D, Strnad H, Kolar M, Vlcek C, Petrak J, Benes J, Jr., Papousek F, Oliyarnyk O, Kazdova L, and Cervenka L. Metabolic characterization of volume overload heart failure due to aorto-caval fistula in rats. Molecular and cellular biochemistry 354 : 83-96, 2011.

163. Mi K and Johnson GV. Role of the intracellular domains of LRP5 and LRP6 in activating the Wnt canonical pathway. Journal of cellular biochemistry 95: 328-338, 2005.

164. Michael A, Haq S, Chen X, Hsich E, Cui L, Walters B, Shao Z, Bhattacharya K, Kilter H, Huggins G, Andreucci M, Periasamy M, Solomon RN, Liao R, Patten R, Molkentin JD, and Force T. Glycogen synthase kinase-3beta regulates growth, calcium homeostasis, and diastolic function in the heart. The Journal of biological chemistry 279: 21383-21393, 2004.

165. Mikels AJ and Nusse R. Purified Wnt5a protein activates or inhibits beta-catenin-TCF signaling depending on receptor context. PLoS biology 4: e115, 2006.

166. Miller JR. The Wnts. Genome biology 3: REVIEWS3001, 2002.

167. Min JK, Park H, Choi HJ, Kim Y, Pyun BJ, Agrawal V, Song BW, Jeon J, Maeng YS, Rho SS, Shim S, Chai JH, Koo BK, Hong HJ, Yun CO, Choi C, Kim YM, Hwang KC, and Kwon YG. The WNT antagonist Dickkopf2 promotes angiogenesis in rodent and human endothelial cells. J Clin Invest 121: 18821893, 2011. 
168. Minami I, Yamada K, Otsuji TG, Yamamoto T, Shen Y, Otsuka S, Kadota S, Morone N, Barve M, Asai Y, Tenkova-Heuser T, Heuser JE, Uesugi M, Aiba K, and Nakatsuji N. A small molecule that promotes cardiac differentiation of human pluripotent stem cells under defined, cytokine- and xeno-free conditions. Cell reports 2: 1448-1460, 2012.

169. Mirotsou M, Zhang Z, Deb A, Zhang L, Gnecchi M, Noiseux N, Mu H, Pachori A, and Dzau V. Secreted frizzled related protein 2 (Sfrp2) is the key Akt-mesenchymal stem cell-released paracrine factor mediating myocardial survival and repair. Proc Natl Acad Sci U S A 104: 1643-1648, 2007.

170. Miyoshi T, Doi M, Usui S, Iwamoto M, Kajiya M, Takeda K, Nosaka K, Nakayama R, Okawa K, Takagi W, Nakamura K, Hirohata S, and Ito $\mathrm{H}$. Low serum level of secreted frizzled-related protein 5 , an anti-inflammatory adipokine, is associated with coronary artery disease. Atherosclerosis 233: 454459, 2014.

171. Montes de Oca A, Guerrero F, Martinez-Moreno JM, Madueno JA, Herencia C, Peralta A, Almaden Y, Lopez I, Aguilera-Tejero E, Gundlach K, Buchel J, Peter ME, Passlick-Deetjen J, Rodriguez M, and Munoz-Castaneda JR. Magnesium inhibits Wnt/beta-catenin activity and reverses the osteogenic transformation of vascular smooth muscle cells. PloS one 9: e89525, 2014.

172. Morini MF and Dejana E. Transcriptional regulation of arterial differentiation via Wnt, Sox and Notch. Curr Opin Hematol 21: 229-234, 2014.

173. Morisco C, Zebrowski D, Condorelli G, Tsichlis P, Vatner SF, and Sadoshima J. The Akt-glycogen synthase kinase 3 beta pathway regulates transcription of atrial natriuretic factor induced by betaadrenergic receptor stimulation in cardiac myocytes. The Journal of biological chemistry 275: 14466-14475, 2000.

174. Morris AJ and Malbon CC. Physiological regulation of G protein-linked signaling. Physiological reviews 79: 1373-1430, 1999.

175. Motiwala SR, Szymonifka J, Belcher A, Weiner RB, Baggish AL, Gaggin HK, Bhardwaj A, and Januzzi $\mathrm{JL}$, Jr. Measurement of novel biomarkers to predict chronic heart failure outcomes and left ventricular remodeling. Journal of cardiovascular translational research 7: 250-261, 2014.

176. Mulligan KA, Fuerer C, Ching W, Fish M, Willert K, and Nusse R. Secreted Wingless-interacting molecule (Swim) promotes long-range signaling by maintaining Wingless solubility. Proc Natl Acad SciU S A 109: 370-377, 2012.

177. Mureli S, Gans CP, Bare DJ, Geenen DL, Kumar NM, and Banach K. Mesenchymal stem cells improve cardiac conduction by upregulation of connexin 43 through paracrine signaling. Am J Physiol Heart Circ Physiol 304: H600-609, 2013.

178. Murry CE, Jennings RB, and Reimer KA. Preconditioning with ischemia: a delay of lethal cell injury in ischemic myocardium. Circulation 74: 1124-1136, 1986.

179. Nakamura T, Sano M, Songyang Z, and Schneider MD. A Wnt- and beta -catenin-dependent pathway for mammalian cardiac myogenesis. Proc Natl Acad Sci U S A 100: 5834-5839, 2003.

180. Nakashima T, Ohkusa T, Okamoto Y, Yoshida M, Lee JK, Mizukami Y, and Yano M. Rapid electrical stimulation causes alterations in cardiac intercellular junction proteins of cardiomyocytes. Am J Physiol Heart Circ Physiol 306: H1324-1333, 2014.

181. Nakashima Y, Raines EW, Plump AS, Breslow JL, and Ross R. Upregulation of VCAM-1 and ICAM-1 at atherosclerosis-prone sites on the endothelium in the ApoE-deficient mouse. Arterioscler Thromb Vasc Biol 18: 842-851, 1998.

182. Nimmagadda S, Geetha-Loganathan P, Scaal M, Christ B, and Huang R. FGFs, Wnts and BMPs mediate induction of VEGFR-2 (Quek-1) expression during avian somite development. Dev Biol 305: 421-429, 2007.

183. Nishino Y, Webb IG, Davidson SM, Ahmed Al, Clark JE, Jacquet S, Shah AM, Miura T, Yellon DM, Avkiran M, and Marber MS. Glycogen synthase kinase-3 inactivation is not required for ischemic preconditioning or postconditioning in the mouse. Circulation research 103: 307-314, 2008. 
184. Nishita M, Yoo SK, Nomachi A, Kani S, Sougawa N, Ohta Y, Takada S, Kikuchi A, and Minami Y. Filopodia formation mediated by receptor tyrosine kinase Ror2 is required for Wnt5a-induced cell migration. The Journal of cell biology 175: 555-562, 2006.

185. Nusse R, Brown A, Papkoff J, Scambler P, Shackleford G, McMahon A, Moon R, and Varmus H. A new nomenclature for int-1 and related genes: the Wnt gene family. Cell 64: 231, 1991.

186. Nusse R and Varmus HE. Many tumors induced by the mouse mammary tumor virus contain a provirus integrated in the same region of the host genome. Cell 31: 99-109, 1982.

187. Obermeier B, Daneman R, and Ransohoff RM. Development, maintenance and disruption of the blood-brain barrier. Nature Med 19: 1584-1596, 2013.

188. Oerlemans MI, Goumans MJ, van Middelaar B, Clevers H, Doevendans PA, and Sluijter JP. Active Wnt signaling in response to cardiac injury. Basic Res Cardiol 105: 631-641, 2010.

189. Oikonomopoulos A, Sereti KI, Conyers F, Bauer M, Liao A, Guan J, Crapps D, Han JK, Dong H, Bayomy AF, Fine GC, Westerman K, Biechele TL, Moon RT, Force T, and Liao R. Wnt signaling exerts an antiproliferative effect on adult cardiac progenitor cells through IGFBP3. Circulation research 109: 1363-1374, 2011.

190. Oishi I, Suzuki H, Onishi N, Takada R, Kani S, Ohkawara B, Koshida I, Suzuki K, Yamada G, Schwabe GC, Mundlos S, Shibuya H, Takada S, and Minami Y. The receptor tyrosine kinase Ror2 is involved in non-canonical Wnt5a/JNK signalling pathway. Genes to cells : devoted to molecular \& cellular mechanisms 8: 645-654, 2003.

191. Oka T, Xu J, and Molkentin JD. Re-employment of developmental transcription factors in adult heart disease. Seminars in cell \& developmental biology 18: 117-131, 2007.

192. Oon CE and Harris AL. New pathways and mechanisms regulating and responding to Delta-like ligand 4-Notch signalling in tumour angiogenesis. Biochem Soc Trans 39: 1612-1618, 2011.

193. Opie LH, Commerford PJ, Gersh BJ, and Pfeffer MA. Controversies in ventricular remodelling. Lancet 367: 356-367, 2006.

194. Ostrom RS. A new molecular target for blunting organ fibrosis. Focus on "Secreted Frizzled-related protein 2 as a target in antifibrotic therapeutic intervention". American journal of physiology Cell physiology 306: C527-528, 2014.

195. Owens GK, Kumar MS, and Wamhoff BR. Molecular regulation of vascular smooth muscle cell differentiation in development and disease. Physiological reviews 84: 767-801, 2004.

196. Panakova D, Sprong H, Marois E, Thiele C, and Eaton S. Lipoprotein particles are required for Hedgehog and Wingless signalling. Nature 435: 58-65, 2005.

197. Pandur P, Lasche M, Eisenberg LM, and Kuhl M. Wnt-11 activation of a non-canonical Wnt signalling pathway is required for cardiogenesis. Nature 418: 636-641, 2002.

198. Patthy L. The WIF module. Trends in biochemical sciences 25: 12-13, 2000.

199. Pauly RR, Bilato C, Sollott SJ, Monticone R, Kelly PT, Lakatta EG, and Crow MT. Role of calcium/calmodulin-dependent protein kinase II in the regulation of vascular smooth muscle cell migration. Circulation 91: 1107-1115, 1995.

200. Pena E, Arderiu G, and Badimon L. Tissue factor induces human coronary artery smooth muscle cell motility through Wnt-signalling. J Thromb Haemost 11: 1880-1891, 2013.

201. Pennica D, Swanson TA, Welsh JW, Roy MA, Lawrence DA, Lee J, Brush J, Taneyhill LA, Deuel B, Lew M, Watanabe C, Cohen RL, Melhem MF, Finley GG, Quirke P, Goddard AD, Hillan KJ, Gurney AL, Botstein D, and Levine AJ. WISP genes are members of the connective tissue growth factor family that are up-regulated in wnt-1-transformed cells and aberrantly expressed in human colon tumors. Proc Natl Acad Sci U S A 95: 14717-14722, 1998.

202. Petrich BG, Eloff BC, Lerner DL, Kovacs A, Saffitz JE, Rosenbaum DS, and Wang Y. Targeted activation of c-Jun $\mathrm{N}$-terminal kinase in vivo induces restrictive cardiomyopathy and conduction defects. The Journal of biological chemistry 279: 15330-15338, 2004. 
203. Povelones $M$ and Nusse R. The role of the cysteine-rich domain of Frizzled in Wingless-Armadillo signaling. Embo J 24: 3493-3503, 2005.

204. Qu J, Zhou J, Yi XP, Dong B, Zheng H, Miller LM, Wang X, Schneider MD, and Li F. Cardiac-specific haploinsufficiency of beta-catenin attenuates cardiac hypertrophy but enhances fetal gene expression in response to aortic constriction. Journal of molecular and cellular cardiology 43: 319326, 2007.

205. Radice GL, Rayburn H, Matsunami H, Knudsen KA, Takeichi M, and Hynes RO. Developmental defects in mouse embryos lacking N-cadherin. Developmental biology 181: 64-78, 1997.

206. Reddy VS, Valente AJ, Delafontaine P, and Chandrasekar B. Interleukin-18/WNT1-inducible signaling pathway protein-1 signaling mediates human saphenous vein smooth muscle cell proliferation. Journal of cellular physiology 226: 3303-3315, 2011.

207. Ribatti D and Crivellato E. "Sprouting angiogenesis", a reappraisal. Dev Biol 372: 157-165, 2012.

208. Ring DB, Johnson KW, Henriksen EJ, Nuss JM, Goff D, Kinnick TR, Ma ST, Reeder JW, Samuels I, Slabiak T, Wagman AS, Hammond ME, and Harrison SD. Selective glycogen synthase kinase 3 inhibitors potentiate insulin activation of glucose transport and utilization in vitro and in vivo. Diabetes 52: 588-595, 2003.

209. Robitaille J, MacDonald ML, Kaykas A, Sheldahl LC, Zeisler J, Dube MP, Zhang LH, Singaraja RR, Guernsey DL, Zheng B, Siebert LF, Hoskin-Mott A, Trese MT, Pimstone SN, Shastry BS, Moon RT, Hayden MR, Goldberg YP, and Samuels ME. Mutant frizzled-4 disrupts retinal angiogenesis in familial exudative vitreoretinopathy. Nature Genet 32: 326-330, 2002.

210. Roger VL, Go AS, Lloyd-Jones DM, Benjamin EJ, Berry JD, Borden WB, Bravata DM, Dai S, Ford ES, Fox CS, Fullerton HJ, Gillespie C, Hailpern SM, Heit JA, Howard VJ, Kissela BM, Kittner SJ, Lackland DT, Lichtman JH, Lisabeth LD, Makuc DM, Marcus GM, Marelli A, Matchar DB, Moy CS, Mozaffarian D, Mussolino ME, Nichol G, Paynter NP, Soliman EZ, Sorlie PD, Sotoodehnia N, Turan TN, Virani SS, Wong ND, Woo D, Turner MB, American Heart Association Statistics C, and Stroke Statistics S. Heart disease and stroke statistics--2012 update: a report from the American Heart Association. Circulation 125: e2-e220, 2012.

211. Rohini A, Agrawal N, Koyani CN, and Singh R. Molecular targets and regulators of cardiac hypertrophy. Pharmacol Res 61: 269-280, 2010.

212. Samarzija I, Sini P, Schlange T, Macdonald G, and Hynes NE. Wnt3a regulates proliferation and migration of HUVEC via canonical and non-canonical Wnt signaling pathways. Biochem Biophys Res Comm 386: 449-454, 2009.

213. Sanbe A, Gulick J, Hanks MC, Liang Q, Osinska H, and Robbins J. Reengineering inducible cardiacspecific transgenesis with an attenuated myosin heavy chain promoter. Circulation research 92: 609-616, 2003.

214. Saraswati S, Alfaro MP, Thorne CA, Atkinson J, Lee E, and Young PP. Pyrvinium, a potent small molecule Wnt inhibitor, promotes wound repair and post-MI cardiac remodeling. PloS one 5: e15521, 2010.

215. Sarzani R, Salvi F, Bordicchia M, Guerra F, Battistoni I, Pagliariccio G, Carbonari L, Dessi-Fulgheri P, and Rappelli A. Carotid artery atherosclerosis in hypertensive patients with a functional LDL receptor-related protein 6 gene variant. Nutrition, metabolism, and cardiovascular diseases : NMCD 21: 150-156, 2011.

216. Sasaki T, Hwang H, Nguyen C, Kloner RA, and Kahn M. The small molecule Wnt signaling modulator ICG-001 improves contractile function in chronically infarcted rat myocardium. PloS one 8: e75010, 2013.

217. Schelbert EB, Fonarow GC, Bonow RO, Butler J, and Gheorghiade M. Therapeutic targets in heart failure: refocusing on the myocardial interstitium. J Am Coll Cardiol 63: 2188-2198, 2014.

218. Schneider VA and Mercola M. Wnt antagonism initiates cardiogenesis in Xenopus laevis. Genes \& development 15: 304-315, 2001. 
219. Schulte $G$ and Bryja V. The Frizzled family of unconventional G-protein-coupled receptors. Trends in pharmacological sciences 28: 518-525, 2007.

220. Schumann H, Holtz J, Zerkowski HR, and Hatzfeld M. Expression of secreted frizzled related proteins 3 and 4 in human ventricular myocardium correlates with apoptosis related gene expression. Cardiovascular research 45: 720-728, 2000.

221. Seifert-Held T, Pekar T, Gattringer T, Simmet NE, Scharnagl H, Stojakovic T, Fazekas F, and Storch MK. Circulating Dickkopf-1 in acute ischemic stroke and clinically stable cerebrovascular disease. Atherosclerosis 218: 233-237, 2011.

222. Seimi SK, Seinosuke K, Tsuyoshi S, Tomomi U, Tetsuaki H, Miki K, Ryuji T, Kenji I, and Mitsuhiro Y. Glycogen synthase kinase-3beta is involved in the process of myocardial hypertrophy stimulated by insulin-like growth factor-1. Circulation journal : official journal of the Japanese Circulation Society 68: 247-253, 2004.

223. Sen-Chowdhry S, Syrris P, and McKenna WJ. Genetics of right ventricular cardiomyopathy. Journal of cardiovascular electrophysiology 16: 927-935, 2005.

224. Shao JS, Aly ZA, Lai CF, Cheng SL, Cai J, Huang E, Behrmann A, and Towler DA. Vascular Bmp Msx2 Wnt signaling and oxidative stress in arterial calcification. Annals of the New York Academy of Sciences 1117: 40-50, 2007.

225. Shao JS, Cheng SL, Pingsterhaus JM, Charlton-Kachigian N, Loewy AP, and Towler DA. Msx2 promotes cardiovascular calcification by activating paracrine Wnt signals. J Clin Invest 115: 12101220, 2005.

226. Simons $M$ and Mlodzik $M$. Planar cell polarity signaling: from fly development to human disease. Annual review of genetics 42: 517-540, 2008.

227. Sklepkiewicz P, Schermuly RT, Tian X, Ghofrani HA, Weissmann N, Sedding D, Kashour T, Seeger W, Grimminger F, and Pullamsetti SS. Glycogen synthase kinase 3 beta contributes to proliferation of arterial smooth muscle cells in pulmonary hypertension. PloS one 6: e18883, 2011.

228. Srivastava D. Making or breaking the heart: from lineage determination to morphogenesis. Cell 126: 1037-1048, 2006.

229. Stenman JM, Rajagopal J, Carroll TJ, Ishibashi M, McMahon J, and McMahon AP. Canonical Wnt signaling regulates organ-specific assembly and differentiation of CNS vasculature. Science 322: 1247-1250, 2008.

230. Sugden PH, Fuller SJ, Weiss SC, and Clerk A. Glycogen synthase kinase 3 (GSK3) in the heart: a point of integration in hypertrophic signalling and a therapeutic target? A critical analysis. British journal of pharmacology 153 Suppl 1: S137-153, 2008.

231. Swope D, Cheng L, Gao E, Li J, and Radice GL. Loss of cadherin-binding proteins beta-catenin and plakoglobin in the heart leads to gap junction remodeling and arrhythmogenesis. Molecular and cellular biology 32: 1056-1067, 2012.

232. Takada R, Satomi Y, Kurata T, Ueno N, Norioka S, Kondoh H, Takao T, and Takada S. Monounsaturated fatty acid modification of Wnt protein: its role in Wnt secretion. Developmental cell 11: 791-801, 2006.

233. Tateishi A, Matsushita M, Asai T, Masuda Z, Kuriyama M, Kanki K, Ishino K, Kawada M, Sano S, and Matsui $\mathrm{H}$. Effect of inhibition of glycogen synthase kinase-3 on cardiac hypertrophy during acute pressure overload. General thoracic and cardiovascular surgery 58: 265-270, 2010.

234. Temple IK, MacDowall P, Baraitser M, and Atherton DJ. Focal dermal hypoplasia (Goltz syndrome). Journal of medical genetics 27: 180-187, 1990.

235. Thorne CA, Hanson AJ, Schneider J, Tahinci E, Orton D, Cselenyi CS, Jernigan KK, Meyers KC, Hang BI, Waterson AG, Kim K, Melancon B, Ghidu VP, Sulikowski GA, LaFleur B, Salic A, Lee LA, Miller DM, 3rd, and Lee E. Small-molecule inhibition of Wnt signaling through activation of casein kinase 1alpha. Nature chemical biology 6: 829-836, 2010. 
236. Tong H, Imahashi K, Steenbergen C, and Murphy E. Phosphorylation of glycogen synthase kinase3beta during preconditioning through a phosphatidylinositol-3-kinase--dependent pathway is cardioprotective. Circulation research 90: 377-379, 2002.

237. Toyofuku T, Hong Z, Kuzuya T, Tada M, and Hori M. Wnt/frizzled-2 signaling induces aggregation and adhesion among cardiac myocytes by increased cadherin-beta-catenin complex. The Journal of cell biology 150: 225-241, 2000.

238. Tsaousi A, Williams H, Lyon CA, Taylor V, Swain A, Johnson JL, and George SJ. Wnt4/beta-catenin signaling induces VSMC proliferation and is associated with intimal thickening. Circulation research 108: 427-436, 2011.

239. Tzahor E. Wnt/beta-catenin signaling and cardiogenesis: timing does matter. Developmental cell 13: 10-13, 2007.

240. Ueland T, Otterdal K, Lekva T, Halvorsen B, Gabrielsen A, Sandberg WJ, Paulsson-Berne G, Pedersen TM, Folkersen L, Gullestad L, Oie E, Hansson GK, and Aukrust P. Dickkopf-1 enhances inflammatory interaction between platelets and endothelial cells and shows increased expression in atherosclerosis. Arterioscler Thromb Vasc Biol 29: 1228-1234, 2009.

241. Ueno S, Weidinger G, Osugi T, Kohn AD, Golob JL, Pabon L, Reinecke H, Moon RT, and Murry CE. Biphasic role for Wnt/beta-catenin signaling in cardiac specification in zebrafish and embryonic stem cells. Proc Natl Acad Sci U S A 104: 9685-9690, 2007.

242. Vaduganathan M, Greene SJ, Ambrosy AP, Gheorghiade M, and Butler J. The disconnect between phase II and phase III trials of drugs for heart failure. Nature reviews Cardiology 10: 85-97, 2013.

243. van de Schans VA, van den Borne SW, Strzelecka AE, Janssen BJ, van der Velden JL, Langen RC, Wynshaw-Boris A, Smits JF, and Blankesteijn WM. Interruption of Wnt signaling attenuates the onset of pressure overload-induced cardiac hypertrophy. Hypertension 49: 473-480, 2007.

244. van der Wal AC and Becker AE. Atherosclerotic plaque rupture--pathologic basis of plaque stability and instability. Cardiovascular research 41: 334-344, 1999.

245. Verma V, Purnamawati K, Manasi, and Shim W. Steering signal transduction pathway towards cardiac lineage from human pluripotent stem cells: a review. Cellular signalling 25: 1096-1107, 2013.

246. Vigneron F, Dos Santos P, Lemoine S, Bonnet M, Tariosse L, Couffinhal T, Duplaa C, and JaspardVinassa B. GSK-3beta at the crossroads in the signalling of heart preconditioning: implication of mTOR and Wnt pathways. Cardiovascular research 90: 49-56, 2011.

247. Vite A, Gandjbakhch E, Prost C, Fressart V, Fouret P, Neyroud N, Gary F, Donal E, Varnous S, Fontaine G, Fornes P, Hidden-Lucet F, Komajda M, Charron P, and Villard E. Desmosomal cadherins are decreased in explanted arrhythmogenic right ventricular dysplasia/cardiomyopathy patient hearts. PloS one 8: e75082, 2013.

248. Wallingford JB and Habas R. The developmental biology of Dishevelled: an enigmatic protein governing cell fate and cell polarity. Development 132: 4421-4436, 2005.

249. Wang D, Zhang F, Shen W, Chen M, Yang B, Zhang Y, and Cao K. Mesenchymal stem cell injection ameliorates the inducibility of ventricular arrhythmias after myocardial infarction in rats. International journal of cardiology 152: 314-320, 2011.

250. Wang H, Charles PC, Wu Y, Ren R, Pi X, Moser M, Barshishat-Kupper M, Rubin JS, Perou C, Bautch V, and Patterson C. Gene expression profile signatures indicate a role for Wnt signaling in endothelial commitment from embryonic stem cells. Circ Res 98: 1331-1339, 2006.

251. Wang H, Hao J, and Hong CC. Cardiac induction of embryonic stem cells by a small molecule inhibitor of Wnt/beta-catenin signaling. ACS chemical biology 6: 192-197, 2011.

252. Wang HY, Liu T, and Malbon CC. Structure-function analysis of Frizzleds. Cellular signalling 18: 934-941, 2006. 
253. Wang X, Adhikari N, Li Q, and Hall JL. LDL receptor-related protein LRP6 regulates proliferation and survival through the Wnt cascade in vascular smooth muscle cells. Am J Physiol Heart Circ Physiol 287: H2376-2383, 2004.

254. Wang X, Xiao Y, Mou Y, Zhao Y, Blankesteijn WM, and Hall JL. A role for the beta-catenin/T-cell factor signaling cascade in vascular remodeling. Circulation research 90: 340-347, 2002.

255. Wang Y, Su B, Sah VP, Brown JH, Han J, and Chien KR. Cardiac hypertrophy induced by mitogenactivated protein kinase kinase 7, a specific activator for c-Jun $\mathrm{NH2}$-terminal kinase in ventricular muscle cells. The Journal of biological chemistry 273: 5423-5426, 1998.

256. Weber C, Zernecke A, and Libby P. The multifaceted contributions of leukocyte subsets to atherosclerosis: lessons from mouse models. Nature reviews Immunology 8: 802-815, 2008.

257. Weidinger G and Moon RT. When Wnts antagonize Wnts. The Journal of cell biology 162: 753-755, 2003.

258. White HD and Chew DP. Acute myocardial infarction. Lancet 372: 570-584, 2008.

259. Willert K, Brown JD, Danenberg E, Duncan AW, Weissman IL, Reya T, Yates JR, 3rd, and Nusse R. Wnt proteins are lipid-modified and can act as stem cell growth factors. Nature 423: 448-452, 2003.

260. Willert $\mathrm{KH}$. Isolation and application of bioactive Wnt proteins. Methods in molecular biology 468: 17-29, 2008.

261. Wouda RR, Bansraj MR, de Jong AW, Noordermeer JN, and Fradkin LG. Src family kinases are required for WNT5 signaling through the Derailed/RYK receptor in the Drosophila embryonic central nervous system. Development 135: 2277-2287, 2008.

262. Woulfe KC, Gao E, Lal H, Harris D, Fan Q, Vagnozzi R, DeCaul M, Shang X, Patel S, Woodgett JR, Force $\mathrm{T}$, and Zhou J. Glycogen synthase kinase-3beta regulates post-myocardial infarction remodeling and stress-induced cardiomyocyte proliferation in vivo. Circulation research 106: 1635-1645, 2010.

263. Wu JC, Wang SM, and Tseng YZ. The involvement of PKC in N-cadherin-mediated adherens junction assembly in cultured cardiomyocytes. Biochemical and biophysical research communications 225: 733-739, 1996.

264. Wu X, Wang J, Jiang H, Hu Q, Chen J, Zhang J, Zhu R, Liu W, and Li B. Wnt3a activates beta1integrin and regulates migration and adhesion of vascular smooth muscle cells. Mol Med Rep 9: 1159-1164, 2014.

265. Xiang G, Yang Q, Wang B, Sekiya N, Mu X, Tang Y, Chen CW, Okada M, Cummins J, Gharaibeh B, and Huard J. Lentivirus-mediated Wnt11 gene transfer enhances Cardiomyogenic differentiation of skeletal muscle-derived stem cells. Mol Ther 19: 790-796, 2011.

266. Yadav HN, Singh M, and Sharma PL. Involvement of GSK-3beta in attenuation of the cardioprotective effect of ischemic preconditioning in diabetic rat heart. Molecular and cellular biochemistry 343: 75-81, 2010.

267. Yamamoto H, Sakane H, Yamamoto H, Michiue T, and Kikuchi A. Wnt3a and Dkk1 regulate distinct internalization pathways of LRP6 to tune the activation of beta-catenin signaling. Developmental cell 15: 37-48, 2008.

268. Yang DH, Yoon JY, Lee SH, Bryja V, Andersson ER, Arenas E, Kwon YG, and Choi KY. Wnt5a is required for endothelial differentiation of embryonic stem cells and vascularization via pathways involving both Wnt/beta-catenin and protein kinase Calpha. Circ Res 104: 372-379, 2009.

269. You LR, Lin FJ, Lee CT, DeMayo FJ, Tsai MJ, and Tsai SY. Suppression of Notch signalling by the COUP-TFII transcription factor regulates vein identity. Nature 435: 98-104, 2005.

270. Zelarayan LC, Noack C, Sekkali B, Kmecova J, Gehrke C, Renger A, Zafiriou MP, van der Nagel R, Dietz R, de Windt LJ, Balligand JL, and Bergmann MW. Beta-Catenin downregulation attenuates ischemic cardiac remodeling through enhanced resident precursor cell differentiation. Proc Natl Acad Sci U S A 105: 19762-19767, 2008. 
271. Zerlin M, Julius MA, and Kitajewski J. Wnt/Frizzled signaling in angiogenesis. Angiogenesis 11: 63$69,2008$.

272. Zhang CG, Jia ZQ, Li BH, Zhang H, Liu YN, Chen P, Ma KT, and Zhou CY. beta-Catenin/TCF/LEF1 can directly regulate phenylephrine-induced cell hypertrophy and Anf transcription in cardiomyocytes. Biochemical and biophysical research communications 390: 258-262, 2009.

273. Zheng Q, Chen P, Xu Z, Li F, and Yi XP. Expression and redistribution of beta-catenin in the cardiac myocytes of left ventricle of spontaneously hypertensive rat. Journal of molecular histology 44: 565-573, 2013.

274. Zhou J, Freeman TA, Ahmad F, Shang X, Mangano E, Gao E, Farber J, Wang Y, Ma XL, Woodgett J, Vagnozzi RJ, Lal H, and Force T. GSK-3alpha is a central regulator of age-related pathologies in mice. J Clin Invest 123: 1821-1832, 2013.

275. Zhou X, Hu X, Xie J, Xu C, Xu W, and Jiang H. Exogenous high-mobility group box 1 protein injection improves cardiac function after myocardial infarction: involvement of Wht signaling activation. J Biomed Biotechnol 2012: 743879, 2012.

276. Zhou Y, Wang Y, Tischfield M, Williams J, Smallwood PM, Rattner A, Taketo MM, and Nathans J. Canonical WNT signaling components in vascular development and barrier formation. The Journal of clinical investigation 124: 3825-3846, 2014.

277. Zuo S, Jones WK, Li H, He Z, Pasha Z, Yang Y, Wang Y, Fan GC, Ashraf M, and Xu M. Paracrine effect of Wnt11-overexpressing mesenchymal stem cells on ischemic injury. Stem cells and development 21: 598-608, 2012. 



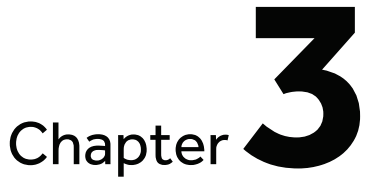

\section{Expression of Wnt/Frizzled signaling components following myocardial infarction in mice and humans}

Kevin C.M. Hermans, Tari Sips, Evangelos P. Daskalopoulos, Jacques J.M. Debets, Helena T.M. Vervoort-Peters, Bart de Vries and W. Matthijs Blankesteijn 


\section{Abstract}

Myocardial infarction (MI) results in a complex wound healing process involving several cell types and ultimately leads to the formation of a rigid scar, made of extracellular matrix components, to replace the affected myocardium. Previously, our lab has demonstrated that the genetic background of mice is a strong determinant for the wound healing process following MI. In addition, there is cumulating evidence that Wnt/Frizzled signaling is involved in this process. This generated the hypothesis that differences in the wound healing processes between mouse strains are attributed to distinct expression of Wnt/Frizzled signaling components in the infarcted myocardium. To make this more clinically relevant, human post mortem myocardial material from different stages post-MI was analyzed for expression patterns of Wnt/Frizzled signaling components. In this study, four mouse strains (BALB/c, C57BL/6, FVB and Swiss) were subjected to $\mathrm{MI}$ and were either sacrificed at one or four weeks afterwards. Echocardiography revealed no differences in ejection fraction and cardiac volumes between one and four weeks post-MI. Gene expression analysis by qPCR showed an upregulation of Frizzled mRNA at one week and Wht ligands at four weeks post-Ml in the infarcted myocardium when compared to remote areas, yet a significant difference between strains was only noted for Wnt1, -3a and -8a. These genes were upregulated in the C57BL/6 and FVB strains and also correlated negatively with cardiac volumes in these mice, suggesting increased Wnt signaling to be favorable for prevention of cardiac dilatation. Analysis of human post-mortem infarct samples demonstrated a gene expression pattern that resembles the cellularity of the infarcted myocardium over time. However, expression levels of the analyzed genes were very low and variable, which was likely due to the nature of the formalin-fixed tissue. Overall, the findings in this study illustrate the involvement of Wnt signaling post-MI but in only two out of four strains this could be correlated to cardiac remodeling. 


\section{Introduction}

Myocardial infarction (MI) is the result of interrupted blood flow in the affected myocardium. Prolonged ischemia can cause cardiomyocyte death. These dead cells are replaced with scar tissue by a process referred to as wound healing. This process is initiated immediately following cardiomyocyte death and can be further divided in three different phases ${ }^{(1,2)}$. Twelve to 16 hours following the ischemic event, the inflammatory phase (phase I) is initiated in which infiltrated inflammatory cells remove dead cellular and matrix debris. The second phase is characterized by the formation of granulation tissue starting two to three days after MI. During this phase, the inflammatory response is suppressed whereas fibroblasts and endothelial cells start to proliferate. Fibroblasts deposit extracellular matrix (ECM) components $^{(3)}$ and can differentiate into myofibroblasts under influence of mechanical tension and transforming growth factor (TGF) $\beta 1^{(4,5)}$. Myofibroblasts contribute to the formation of new ECM components and also express alpha smooth muscle actin (aSMA) that condenses the scar tissue, thereby preventing the dilatation of the infarct ${ }^{(5)}$. Another key feature of this phase is the formation of small blood vessels to restore blood flow in the infarcted area ${ }^{(6)}$. During the final phase (phase III), cells present in the infarcted myocardium start to disappear from the wound, with the exception of the myofibroblasts. This phase is further characterized by the collagens that become cross-linked and the consecutive formation of scar tissue ${ }^{(3)}$.

Maintenance of the scar tissue by an accurate balance between ECM deposition and degradation is important for preservation of an adequate cardiac function following MI. Excessive degradation of the ECM in the infarct area can lead to rupture (within one week after $\mathrm{MI}$ ) or dilatation of the ventricle due to thinning of the wall ${ }^{(1,7)}$. Furthermore, dilatation and remodeling of the remote myocardium can lead to decreased ventricular function and eventually the development of heart failure ${ }^{(8)}$. In mice, the genetic background has been shown to be an important factor for infarct healing following $\mathrm{MI}$ and can have decisive influences in the outcome of the remodeling process. Five mouse strains, exposed to experimental MI, demonstrated 
substantial differences in frequency of infarct rupture, thinning of the infarct area, preservation of cardiac function and heart failure incidence ${ }^{(9)}$.

Wnt/Frizzled signaling is involved in many developmental processes including cardiogenesis and vasculogenesis but is generally silent in healthy adult tissues (Chapter 2). However, reactivation of Wnt/Frizzled signaling is a common observation upon the development of a pathological condition. The involvement of Wnt/Frizzled signaling following $\mathrm{MI}$ and its implication on the wound healing process has been demonstrated before ${ }^{(10,11)}$, although the exact mechanisms are still unclear due to the complex nature of the signaling pathway. Myofibroblasts upregulate Frizzled (Fzd) -2 when migrating to the infarcted myocardium ${ }^{(12)}$ and their numbers are inversely correlated with LV dilatation $^{(9)}$. This implies that the substantial discrepancies in infarct healing in different mice strains can possibly be attributed to divergent regulation of Wnt signaling. Therefore, the aim of this study was to unravel the relationship between genetic background and the activity of the Wnt/Frizzled signaling pathway and correlate them to parameters that can indicate (the development of) heart failure. Furthermore, the expression profile of Wnt/Frizzled pathway components in post-mortem human infarct samples was quantified at different time points post-MI to investigate whether aberrant Wnt/Frizzled signaling is also present in human infarct remodeling.

\section{Materials \& Methods}

\section{Animal study}

\section{Animal surgery}

Male mice, 10-12 weeks of age, were purchased from Charles River, Leiden, The Netherlands. The following strains were included: BALB/c, C57BL/6, FVB and Swiss. The mice were divided in two different groups, which were either sacrificed at one week or four weeks post-MI. As analgesia, $0.1 \mathrm{mg} / \mathrm{kg}$ buprenorphine was administered by subcutaneous injection 30-60 minutes before the surgery. Mice were anesthetized by isoflurane and were placed in supine position. The trachea was intubated with a steel tube connected to a small animal respirator (Hugo Sachs, 
MiniVent, tidal volume: $180-250 \mu$, rate: $200-250$ breaths/min, depending on the strain). Body temperature was monitored by a rectal probe and maintained at $37^{\circ} \mathrm{C}$ by a heating pad and lamp. MI was induced under isoflurane gas anesthesia $(2.0-3.0 \%)$ using a stereomicroscope (Leica MZ FL III, Leica Switzerland). After thoracotomy through the left fourth intercostal space, the lateral branch of the left coronary artery was ligated with a 6-0 prolene suture just proximal to the main bifurcation. Absence of coronary blood flow to the distal area was confirmed by discoloration of the myocardium and disturbed ECG signal. Chest and skin were closed in layers using 5-0 polysorb sutures. Animals were gradually weaned from the respirator and recovered overnight in an incubator $\left(28^{\circ} \mathrm{C}\right)$. By the end of the day of operation and at the end of the two following days, buprenorphine $(0.05$ to $0.1 \mathrm{mg} / \mathrm{kg})$ was administered. All interventions were performed by the same technician to minimize the variations in the procedures. All experimental procedures were approved by the Committee for Animal Research of Maastricht University and were in accordance with the Guide for the Care and Use of Laboratory Animals (NIH Publication No. 85-23, revised 1996).

\section{Echocardiography}

All animals were subjected to echocardiography under isoflurane anesthesia for the assessment of left ventricular (LV) dimensions and function. Recordings were taken prior to surgical procedures (baseline) and at the end of the protocol (1 or 4 weeks). Transthoracic echocardiographic B-mode recordings were made in midpapillary short-axis and parasternal long-axis of the LV using a Vevo2100 imaging platform (VisualSonics, Toronto, Canada) with a MS-400 30 MHz MicroScan transducer. The LV area (LVA) and LV length (LVL) of the lumen were determined from the long-axis images in end-diastole and end-systole from at least three different cycles. With these parameters, the end-diastolic volume (EDV) and end-systolic volume (ESV) were calculated as $\left(8 \times L V A^{2}\right) /(3 \pi \times L V L)$. Ejection fraction was calculated as $100 \times((E D V-E S V) / E D V)$ (Description adapted from $\left.^{(13)}\right)$ 


\section{Tissue collection}

At the end of the experiment, hearts and lungs were excised and weighed. Hearts were divided in right ventricle, septum, left ventricle and infarct. These parts were snap-frozen in liquid nitrogen and stored at $-80^{\circ} \mathrm{C}$ until further use.

\section{Real-time PCR}

Cryopreserved heart tissue was homogenized and RNA was isolated using the RNeasy ${ }^{\circledR}$ Fibrous Tissue Mini Kit (Qiagen, Hilden, Germany) according to the manufacturer's protocol. In brief, tissue was homogenized in isolation buffer and was further digested by incubation with proteinase K. Samples were loaded to a spin column and washed with washing buffer. RNA was further purified by removal of genomic DNA followed by additional washing steps. Subsequently, RNA was collected and assessed for concentration and purity $\left(A_{260} / A_{280}\right.$ ratio) with a NanoDrop spectrophotometer (Thermo Fischer Scientific, USA). cDNA was synthesized by reverse transcription of the RNA, using a iScript cDNA synthesis kit (Bio-Rad, Hercules, CA, USA). Real-time (RT) PCR Primers were designed using Primer-BLAST (NCBI, Bethesda, MD, USA). RT-PCR of the samples was performed in duplicate on the CFX96 Real-Time System (Bio-Rad) and CDNA was detected using iQ SYBR ${ }^{\circledR}$

Table 1 | Primer sequences for mouse genes and annealing temperatures used in the RT-PCR

\begin{tabular}{llll}
\hline Gene & Forward primer & Reverse primer & Ta $\left({ }^{\circ} \mathbf{C}\right)$ \\
\hline Wnt1 & CTGTGCGAGAGTGCAAATGG & ACGATCTTGCCGAAGAGGTG & 63 \\
Wnt3a & CTCGCATGGCATAGATGGGT & ACAGTGGCATTTCTCCCTCC & 61 \\
Wnt5a & CAACTGGCGGGACTTTCTCAAA & CATCTCCGATGCCGGAACT & 62 \\
Wnt8a & TTGGGACATCACAGGGTTGG & GATCATCCATCTACCCCGCC & 64 \\
Fzd1 & TATCGCCGGCTTTCTGTTG & CCCCGTCCTCTGCAAACTT & 60 \\
Fzd2 & CCTCAAGGTGCCGTCCTATC & CAACACCGACCATGTGAGGA & 63 \\
Fzd7 & ACCCTACTGCTCCCTACCTG & AGAAGGGGAAAGACAAGCGG & 61 \\
Axin2 & CCTGACCAAACAGACGACGA & CACCTCTGCTGCCACAAAAC & 62 \\
CyclinD1 & CATTCCCTTGACTGCCGAGA & TTGTTCTCATCCGCCTCTGG & 63 \\
B-Actin & CAGCAAGCAGGAGTACGATG & AGGGTGTAAAACGCAGCTC & 61 \\
\hline
\end{tabular}

$\mathrm{Fzd}=$ frizzled; $\mathrm{Ta}=$ Annealing temperature 
Green Supermix (Bio-Rad). mRNA expression was assessed of the genes listed in

Table 1. Gene expression was normalized to the housekeeping gene $\beta$-actin and further quantified using the comparative $\mathrm{Ct}(\Delta \mathrm{Ct})$ method.

\section{Human study}

\section{Sample collection}

Samples were obtained from the Maastricht Pathology Tissue Collection (MPTC). Collection, storage and use of tissue and patient data were performed in agreement with the "Human Tissue and Medical Research: Code of conduct for responsible use (2011)". Post-mortem, formalin fixed and paraffin embedded human LV sections were microscopically analyzed for the presence of myocardial infarction, which covered at least $50 \%$ of the section. They were divided into four categories, according to the infarct age. This was established by histological analysis of a haematoxylin and eosin stain according to the previously described criteria ${ }^{(3)}$. Group A included samples from 0-1 week post-MI, group B; 1-3 weeks post-MI, group C; 3-6 weeks post-MI and group D; >6 weeks post-MI. A total of 40 samples with presence of myocardial infarction were selected and were divided over the groups as followed; group A: 11, group B: 10, group C: 4, group D: 15. Paraffin-embedded tissues from both the infarcted and non-infarcted area of the LV were collected from all patients.

\section{RNA isolation}

RNA was isolated from formalin fixed paraffin embedded heart tissue using the RecoverAll ${ }^{\mathrm{TM}}$ Total Nucleic Acid Isolation Kit (Life Technologies, Carlsbad, CA, USA) according to the manufacturer's protocol. In short, eight $10 \mu \mathrm{m}$ sections were cut from paraffin blocks containing the heart tissue. The paraffin was removed by addition of xylol and heating of the sample. Xylol was decanted and ethanol was added to remove residual xylol. The tissue was digested at $50^{\circ} \mathrm{C}$ with addition of a protease. Subsequently, isolation additive and ethanol were added to the samples followed by loading onto a filter column. The column was then centrifuged and washed with washing buffers. DNase was applied to the filter column for removal of genomic DNA followed by additional washing steps. Finally, the RNA was eluted from the column 
and assessed for concentration and purity $\left(\mathrm{A}_{260} / \mathrm{A}_{280}\right.$ ratio) with a NanoDrop spectrophotometer (Thermo Fischer Scientific, Waltham, MA, USA).

\section{Real-time PCR}

cDNA was synthesized as described in the previous paragraphs as well as the primer design. RT-PCR of the samples was performed in duplicate as described before. mRNA expression was assessed of the genes listed in Table 2. Gene expression was normalized to the housekeeping gene cyclophilin and further quantified using the comparative $\mathrm{Ct}(\Delta \mathrm{Ct})$ method.

\section{Statistics}

All data are presented as mean \pm SEM. Echocardiographic measurements between strains were compared using one-way ANOVA with Bonferroni post-hoc tests. Statistical analysis of both the mouse and humans gene expression was performed using two-way ANOVA and Bonferroni post-hoc analysis. Correlations between gene expression and cardiac dimensions or organ weights were established by a Pearson correlation test. For all analyses, a $\mathrm{P}$-value of $<0.05$ was considered statistically significant.

Table 2 | Primer sequences for human genes and annealing temperatures used in the RT-PCR

\begin{tabular}{llll}
\hline Gene & Forward primer & Reverse primer & Ta $\left({ }^{\circ} \mathbf{C}\right)$ \\
\hline Wnt1 & ATGGTGTCATTCTGCCTGCT & GACTTAGGAGGACCCGGAGA & 61 \\
Wnt3a & CCCTGGAGCTAGTGTCTCCTCT & CCAGGGAGAAGCCAACGCA & 63 \\
Wnt5a & GTCAACAGCCGCTTCAACTC & CATTGCGCACGCAGTAGTC & 60 \\
Wnt8a & CAGTTTGCTTGGGAACGCTG & ACTTCTCAGCTGTTGTGGG & 60 \\
Fzd1 & TGAGCCGACCAAGGTGTATG & CACAGCACTGACCAAATGCC & 64 \\
Fzd2 & CTTCTCACAGGAGGAGACGC & TGAAGAAGGTGGAAGCGCAG & 64 \\
Fzd7 & CGCCTCTGTTCGTCTACCTC & TGATGGTGCGGATACGGAAG & 64 \\
Axin2 & AAGCGATGAGTTTGCCTGTG & CCCAGAATCCGGCCTTCAT & 61 \\
Cyclophilin & AGACAAGGTCCCAAAGAC & ACCACCCTGACACATAAA & 60 \\
\hline
\end{tabular}

$\mathrm{Fzd}=$ frizzled; $\mathrm{Ta}=$ Annealing temperature 


\section{Results}

\section{Cause of death and organ- and body weights of the different mouse strains}

Body weights for BALB/C, C57BL/6 and FVB mice did not differ significantly from each other, while Swiss mice had a significant higher body weight compared to all other strains. This is not unusual since Swiss mice are relatively large mice. No differences were observed for heart and lung weights, when corrected for body weight, at 7 and 28 days post-MI. In addition, body, heart and lung weights did not change significantly between 7 and 28 days post-MI (Table 3).

Overall, $86 \%$ of the animals survived in the one-week protocol, whereas only $70 \%$ survived the four week protocol. The highest post-infarct mortality was observed for the FVB strain (38\%) when the two time points were combined (Figure 1). In addition, this strain had the highest infarct rupture incidence $(42 \%)$ in the four-week protocol whereas the overall infarct rupture incidence was only $14 \%$. Death due to (onset of) heart failure was only seen for the FVB and Swiss strain and occurred in only $7 \%$ of all the animals.

\section{Cardiac dimensions of the different mouse strains post-MI}

At baseline $(t=0)$ there were already significant differences in cardiac volumes (ESV and EDV) and EF between the strains as measured by echocardiography (Figure 2). Swiss mice had the largest EDV and ESV whereas FVB had the smallest cardiac

Table 3 | Heart, lung and body weights of the different mouse strains

\begin{tabular}{llllll}
\hline Parameter & Time & BALB/C & C57BL/6 & FVB & Swiss \\
\hline BW $(g)$ & Baseline & $27.00 \pm 0.32$ & $25.81 \pm 0.30$ & $26.71 \pm 0.42$ & $41.75 \pm 0.75^{* * *}$ \\
& 7 days & $25.33 \pm 0.50$ & $25.67 \pm 0.58$ & $25.56 \pm 1.00$ & $38.78 \pm 1.18^{* * *}$ \\
& 28 days & $28.67 \pm 0.49$ & $27.44 \pm 0.67$ & $29.20 \pm 0.58$ & $41.45 \pm 1.11^{* * *}$ \\
HW/BW (\%) & 7 days & $0.63 \pm 0.04$ & $0.69 \pm 0.04$ & $0.55 \pm 0.06$ & $0.55 \pm 0.03$ \\
& 28 days & $0.64 \pm 0.08$ & $0.61 \pm 0.03$ & $0.43 \pm 0.02$ & $0.52 \pm 0.05$ \\
LW/BW (\%) & 7 days & $0.95 \pm 0.16$ & $0.70 \pm 0.05$ & $0.66 \pm 0.04$ & $0.69 \pm 0.06$ \\
& 28 days & $0.81 \pm 0.20$ & $0.55 \pm 0.04$ & $0.68 \pm 0.10$ & $0.54 \pm 0.05$
\end{tabular}

BW: body weight, HW: heart weight, LW: lung weight. Data are presented as mean $\pm \mathrm{SEM} ;{ }^{* * *} \mathrm{p}<0.001 \mathrm{vs}$. all other strains 
Post-infarct animals

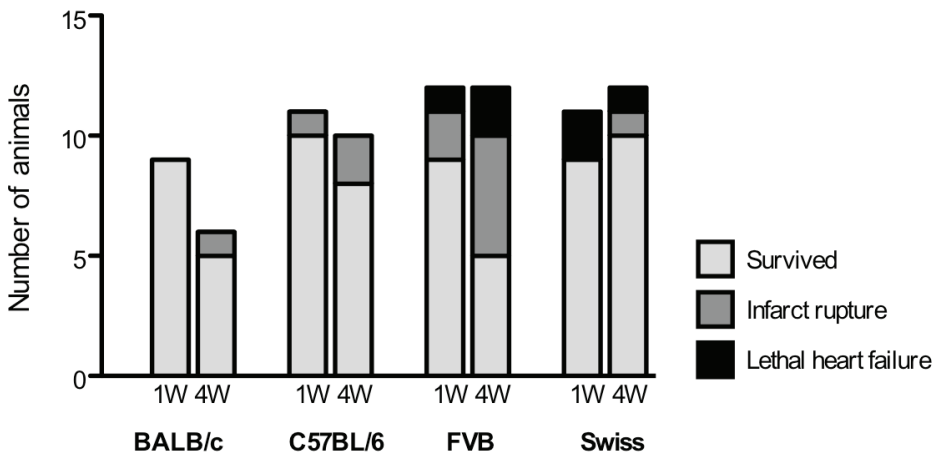

Figure 1 | Post-infarct survival differences between strains.

$\mathrm{BALB} / \mathrm{c}$ mice had the highest survival rate post-MI, with only one death out of 16 animals due to infarct rupture. The FVB strain had the lowest survival rate, which could mainly be attributed to the high infarct rupture incidence. $1 \mathrm{~W}$ : animals sacrificed at one week post-MI, $4 \mathrm{~W}$ : animals sacrificed at four weeks postMI.

volumes. EF was significantly higher at baseline in both C57BL/6 and FVB mice compared to the other strains. Following MI, ESV, EDV and EF changed significantly in all strains but no difference could be observed between one $(t=7)$ and four $(t=28)$ weeks post-MI. One week post-MI, ESV and EDV were shown to be significantly higher for C57BL/6 compared to FVB mice. Furthermore, Swiss mice had significantly higher EDV and ESV values compared to all other strains. When looking at 4 weeks post-MI, ESV and EDV were only different for the Swiss strain compared to the other strains. EF was not significantly different between strains at one as well as four weeks post-MI.

\section{Gene expression of the infarcted and remote area post MI}

Gene expression of components of the Wnt/Frizzled pathway at one and four weeks post-MI was both analyzed for the infarcted and non-infarcted areas of the myocardium in the four strains that were investigated. Gene expression for every gene was normalized to the expression of BALB/C remote one week following MI; this value was set at $1.0 \pm$ SEM. 

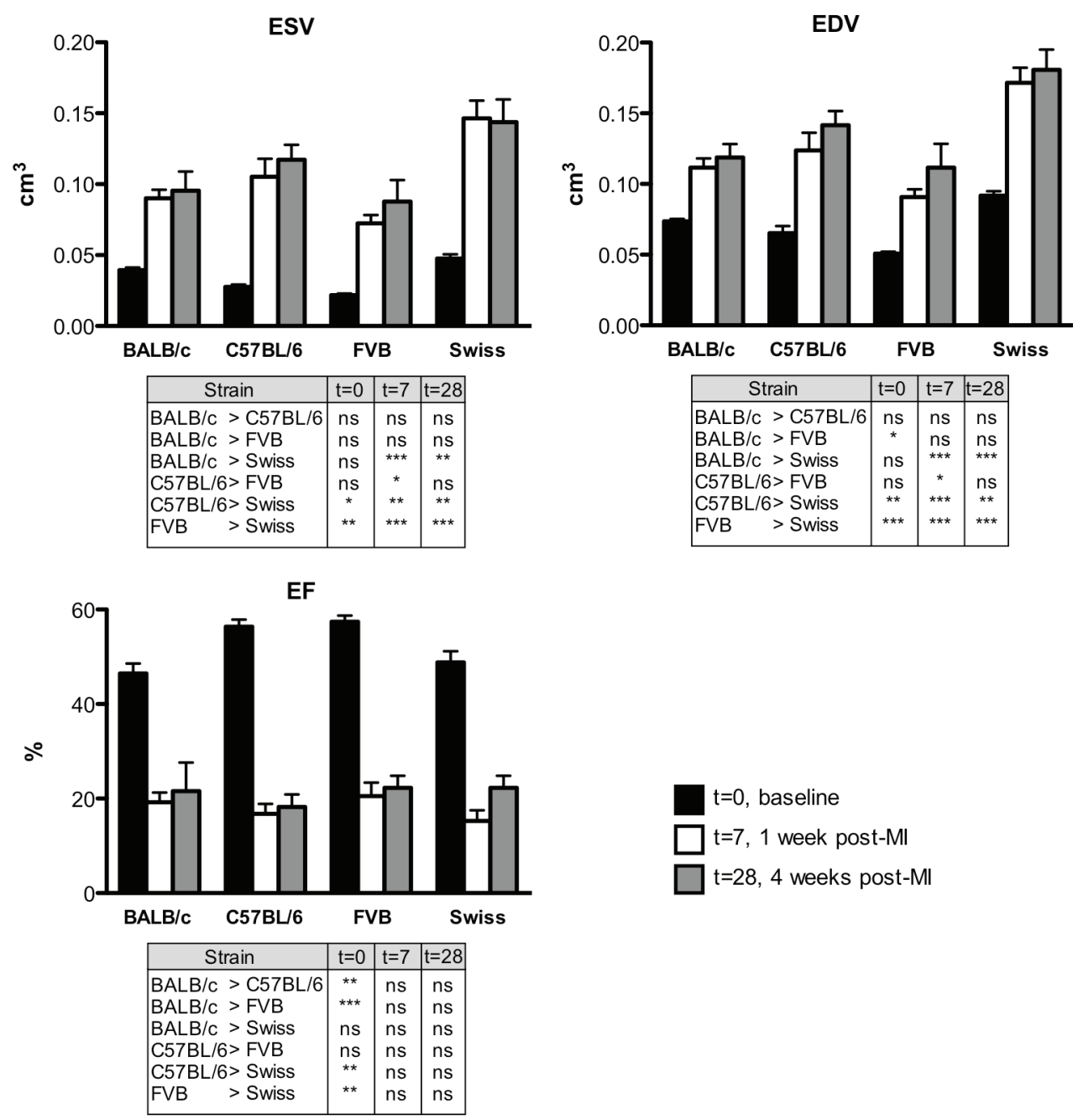

Figure $\mathbf{2}$ | Cardiac characteristics by means of echocardiography.

At baseline $(t=0)$ some strains showed significant differences for ESV, EDV and EF. Following MI, ESV and EDV significantly increased and EF significantly decreased in all strains, although no difference was observed between one $(t=7)$ and four weeks $(t=28)$ following MI. At one and four weeks post-MI, Swiss mice had significantly higher ESV, EDV and EF compared to all other strains. Data are presented as mean \pm SEM $* p<0.05,{ }^{* *} p<0.01,{ }^{* * *} p<0.001$.

Fzd2 expression was upregulated in the infarct area compared to the remote area one and four weeks post-MI, although not significant in all strains (Figure 3). In the infarcted myocardium, Fzd1 and -7 were significantly upregulated compared to the 
Fzd1

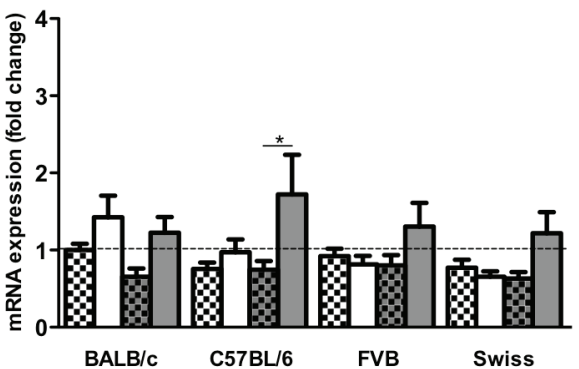

Fzd7
Fzd2

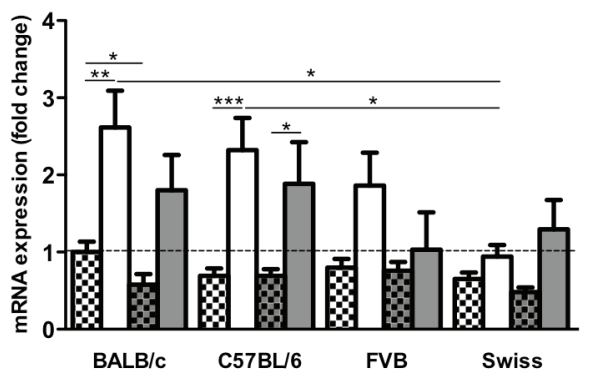

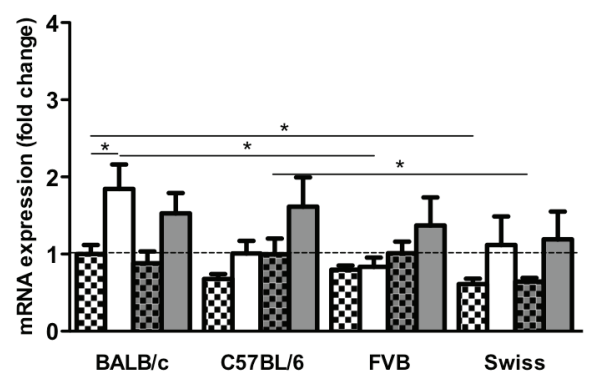

Dremote area 1 week post-MI

멸 remote area 4 weeks post-MI

$\square$ infarcted area 1 week post-MI
$\square$ infarcted area 4 weeks post-Ml

Figure 3 | Upregulated Frizzled expression in the infarct area following MI .

Fzd2 and to a lesser extent, Fzd1 and -7, were upregulated in the infarcted area in several strains. All values were normalized to 1 week remote which was set at 1.0 . Data are presented as mean \pm SEM. ${ }^{*} p<0.05, * *$ $p<0.01, * * * p<0.001$.

remote area post-MI in only a few conditions (Figure 3 ) but there was a trend towards an upregulated expression in most of the strains, especially at four weeks after MI. In general, Swiss mice demonstrated a trend towards lower Fzd expression levels compared to other strains, which was significant in a few conditions. The remote areas did not demonstrate different expression patterns between one and four weeks following MI.

Expression of Wnt genes was also altered post-MI (Figure 4). In contrast to Fzd genes, Wnt genes were not yet upregulated in the infarcted area one week after MI, but rather demonstrated a trend towards decreased mRNA expression levels when compared to the remote region. At four weeks post-MI however, Wnt1, $-3 a$ and $-8 a$ were significantly upregulated ( $\sim 5$ to $\sim 8$-fold) in C57BL/6 and FVB in the infarcted 
Wnt1

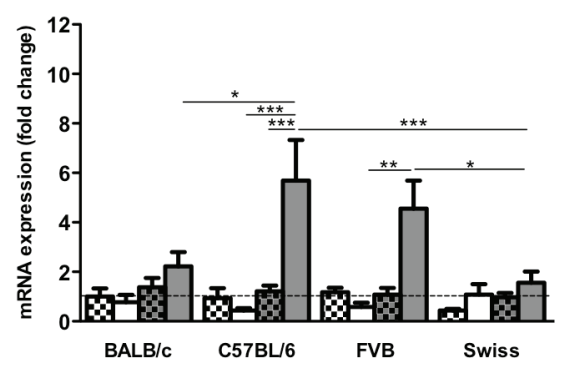

Wnt5a

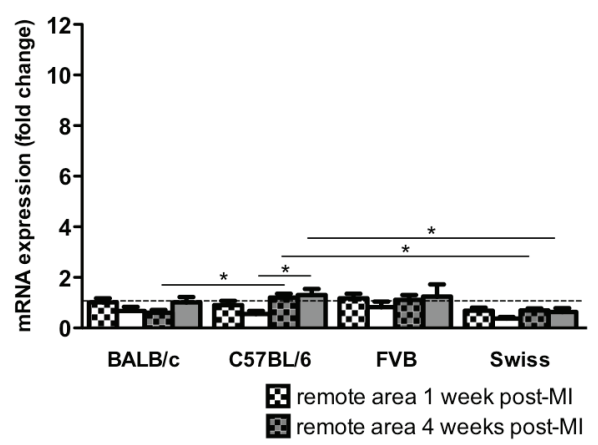

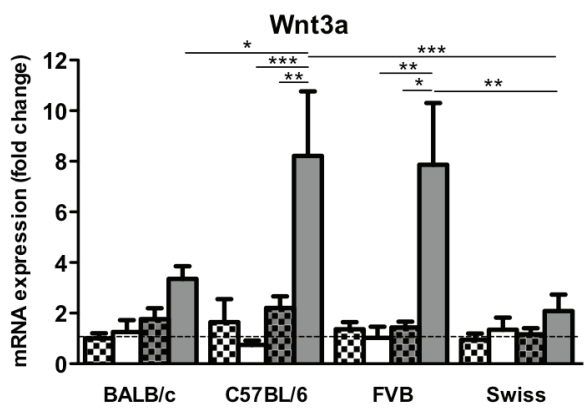

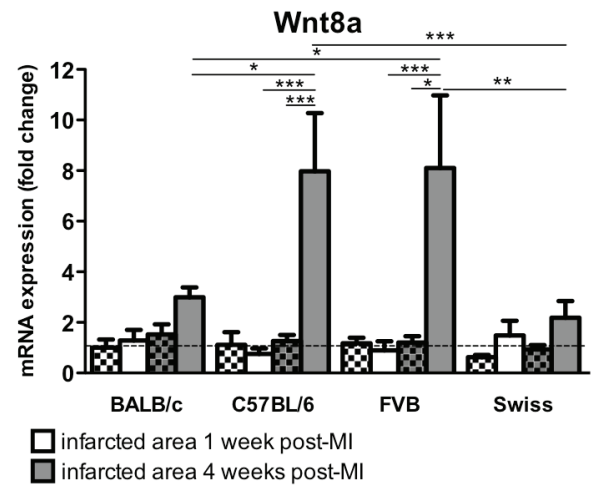

Figure 4 | Increased mRNA expression of several Wnt genes at for week post-MI.

Wnt $1,-3 a$ and -8 a, but not Wnt5a, were significantly upregulated in the infarcted myocardium four weeks post-MI compared to the remote area. All values were normalized to 1 week remote, which was set at 1.0. Data are presented as mean \pm SEM. ${ }^{*} p<0.05,{ }^{* *} p<0.01,{ }^{* * *} p<0.001$.

myocardium, whereas Wnt5a was not upregulated in such a way. In addition, BALB/c and Swiss mice were also shown to have a trend towards an increased expression of Wnt1, -3a and -8a in the infarcted myocardium at four weeks post-MI when compared to one week but gene expression was significantly lower compared to the C57BL/6 and FVB strains.

Axin2 and CyclinD1, target genes of the canonical Wnt/Frizzled pathway, did not demonstrate a clear expression pattern following MI (Figure 5). However, when comparing the two genes, the expression patterns are analogous within the strain. Again, Swiss mice seem to have lower expression levels, or diminished activation of the Wnt/Frizzled pathway. 

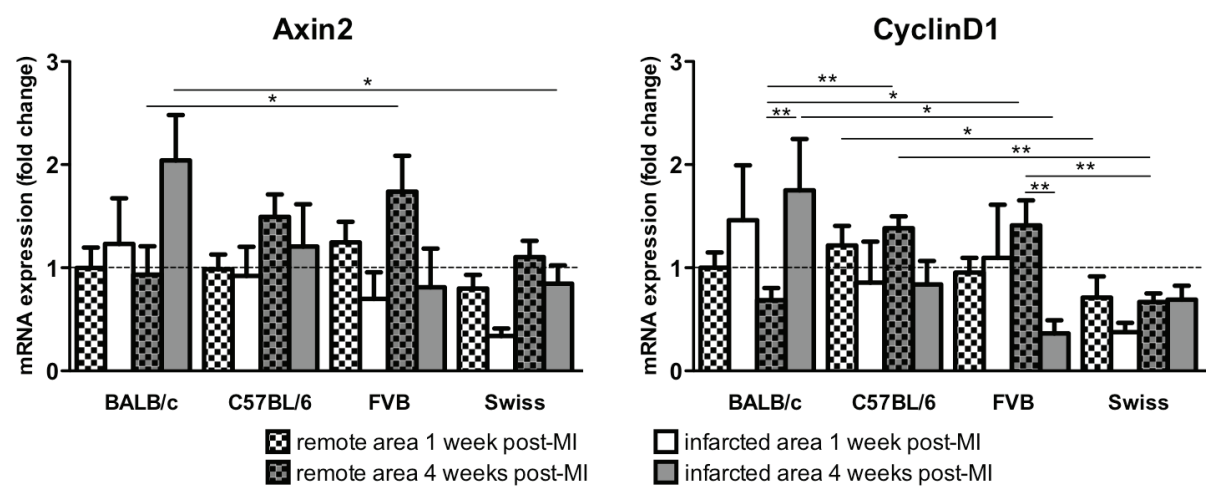

Figure $\mathbf{5}$ | No distinct expression pattern of canonical Wnt/Frizzled target genes post-MI.

No identical gene expression pattern was observed between the strains for Axin2 and CyclinD1. Comparison of the two genes however demonstrated a related pattern. All values were normalized to 1 week remote, which was set at 1.0. Data are presented as mean \pm SEM. ${ }^{*} p<0.05,{ }^{* *} p<0.01$.

\section{Correlation of gene expression with LV volumes and lung and heart weights}

EDV is a measure of the dilation of the ventricle and thus the development of LV dilatation, which frequently results in heart failure. To investigate whether gene expression in each strain was linearly related to the EDV, gene expression of the infarcted area was plotted against the EDV for every individual mouse (Figure 6) followed by calculation of the correlation coefficient. One week after MI, no significant correlation was observed between EDV and gene expression for any of the genes investigated (Table 4). Four weeks post-MI, there was a significant negative correlation between EDV and Wnt1, $-3 a$ and -8a for the C57BL/ 6 and FVB strains but not in de BALB/c and Swiss mice. In contrast, no correlation between EDV and any of the Frizzleds or the target genes was observed (Figure 6). Similar results were observed when correlated to ESV (Table 4). A more direct sign for the development of heart failure is an increase in lung weight. When gene expression of the infarcted myocardium was plotted against the corresponding lung weights, significant correlations were only observed for Axin2 and CylcinD1 in Swiss mice at four weeks after MI (Table 4). In addition, heart weight correlated only with Fzd7 (1 week), Wnt3a (4 weeks) and Wnt8a (4 weeks) in the FVB strain. 
Fzd1

Fzd2

Fzd7
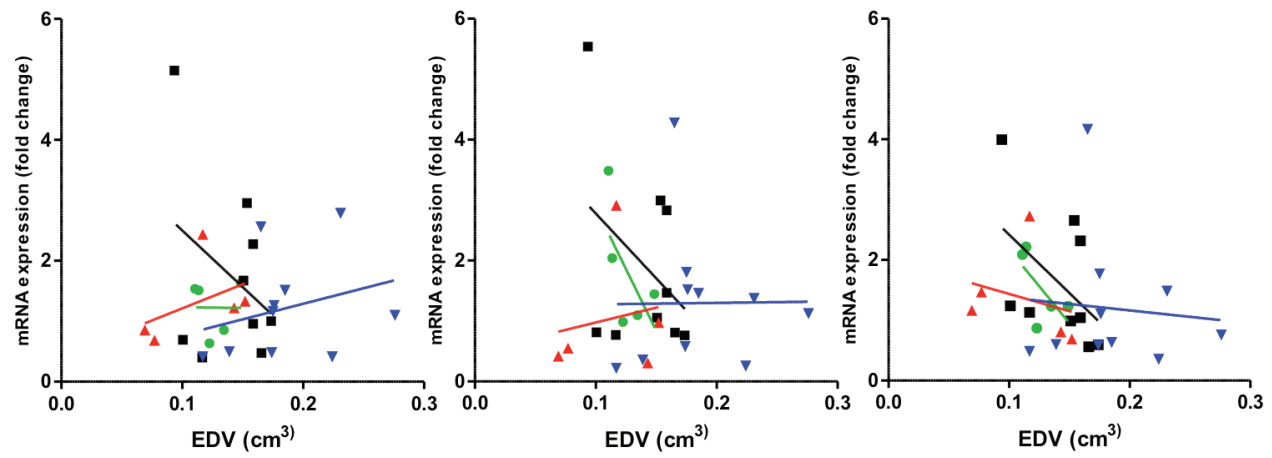

Wnt1

Wnt3a

Wnt5a

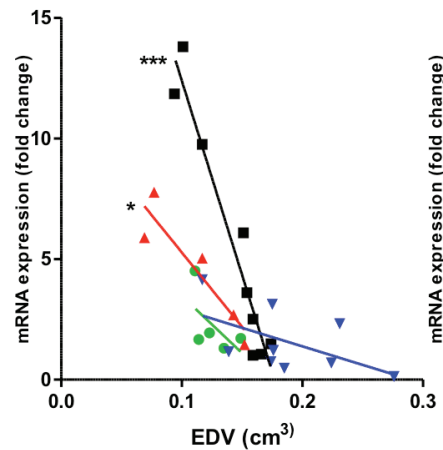

Wnt8a

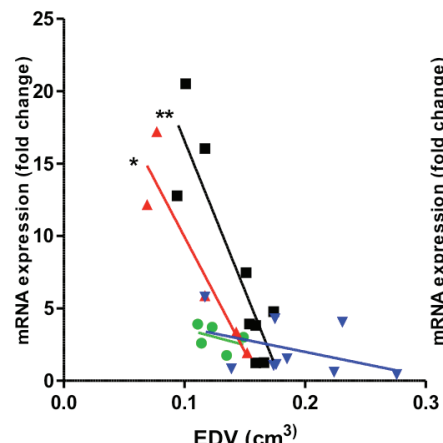

- BALB/c

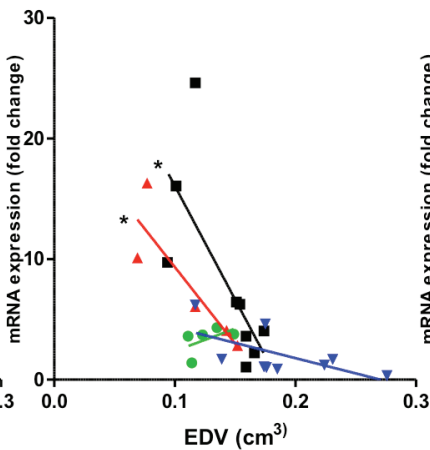

Axin2

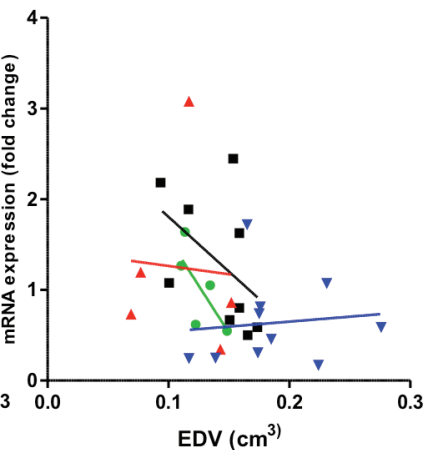

CyclinD1
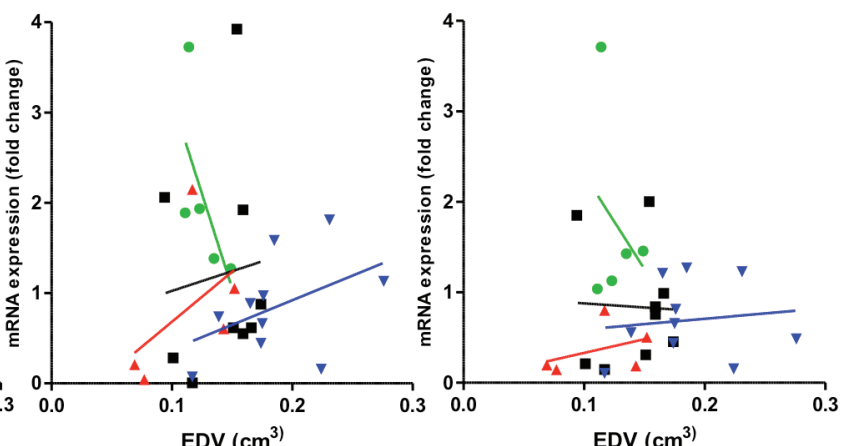

$\operatorname{EDV}\left(\mathrm{cm}^{3}\right)$

$\operatorname{EDV}\left(\mathbf{c m}^{3}\right)$

C57BL/6 6 FVB $\rightarrow$ Swiss

Figure 6 | Individual gene expression of the infarcted myocardium 4 weeks post-MI was plotted against the EDVs of corresponding mice. A Pearson correlation coefficient was calculated to identify a linear relationship of the two variables. A significant correlation was observed for three out of four Wnt genes in the C57BL/ 6 and FVB strains but not for other genes. ${ }^{*} p<0.05 ; * * p<0.01 ; * * * p<0.001$. 


\begin{tabular}{|c|c|c|c|c|c|c|c|c|c|c|c|c|c|c|c|c|}
\hline 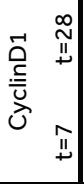 & $\begin{array}{l}\text { P } \\
\text { ị } \\
1 \\
\circ \\
\stackrel{0}{0} \\
\stackrel{0}{1}\end{array}$ & $\begin{array}{l}0 \\
0 \\
0 \\
1 \\
n \\
n \\
0 \\
0 \\
1\end{array}$ & $\begin{array}{l}\stackrel{9}{q} \\
0\end{array}$ & $\begin{array}{l}\underset{T}{\mathbb{S}} \\
\stackrel{i}{1}\end{array}$ & 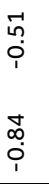 & \begin{tabular}{l}
$\overrightarrow{7}$ \\
\multicolumn{1}{c}{} \\
1 \\
1 \\
$\infty$ \\
0 \\
0 \\
1
\end{tabular} & $\begin{array}{l}\text { q̊ } \\
\circ\end{array}$ & $\begin{array}{l}0 \\
\mathscr{j} \\
i \\
1\end{array}$ & $\underset{\sim}{\stackrel{J}{0}}$ & $\begin{array}{l}\tilde{0} \\
0 \\
0 \\
0 \\
\dddot{1} \\
\stackrel{1}{1}\end{array}$ & 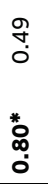 & 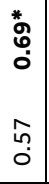 & $\begin{array}{l}\stackrel{\infty}{0} \\
\stackrel{\leftrightarrow}{0}\end{array}$ & $\begin{array}{l}\tilde{N} \\
0 \\
0 \\
\tilde{O} \\
\dot{i} \\
1\end{array}$ & $\begin{array}{l}\stackrel{0}{\circ} \\
\stackrel{0}{0} \\
\\
\stackrel{\infty}{0} \\
0 \\
0\end{array}$ & ?ֶ \\
\hline 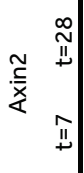 & $\begin{array}{l}0 \\
0 \\
i \\
0 \\
0 \\
0 \\
i\end{array}$ & $\begin{array}{l}0 \\
? \\
0 \\
1 \\
0 \\
0 \\
0 \\
1 \\
1\end{array}$ & $\begin{array}{l}\text { Mo } \\
\text { Oे }\end{array}$ & $\begin{array}{l}\infty \\
0 \\
0 \\
i\end{array}$ & $\begin{array}{l}0 \\
\stackrel{0}{0} \\
\stackrel{1}{1}\end{array}$ & $\begin{array}{l}\vec{N} \\
\stackrel{i}{i}\end{array}$ & 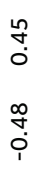 & $\begin{array}{l}\text { Mo } \\
0 \\
\dot{i}\end{array}$ & $\stackrel{\vec{N}}{\stackrel{i}{i}}$ & $\begin{array}{l}\text { à } \\
\text { í }\end{array}$ & $\begin{array}{l}\overrightarrow{7} \\
0 \\
\tilde{0} \\
\tilde{m} \\
o \\
i\end{array}$ & $\begin{array}{c}\vdots \\
\vdots \\
0 \\
0 \\
0 \\
\vec{N} \\
\vdots \\
0\end{array}$ & 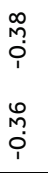 & 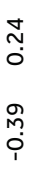 & 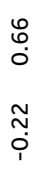 & $\approx$ \\
\hline 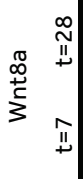 & $\begin{array}{l}\text { ㅁ } \\
\stackrel{0}{0} \\
1 \\
0 \\
\text { m. } \\
\stackrel{1}{1}\end{array}$ & 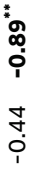 & 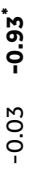 & $\begin{array}{l}0 \\
0 \\
\grave{1}\end{array}$ & $\begin{array}{l}1 \\
0 \\
0 \\
0 \\
0 \\
0 \\
0 \\
0\end{array}$ & 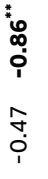 & $\begin{array}{l}\text { के } \\
\text { هo }\end{array}$ & $\begin{array}{l}\hat{n} \\
0 \\
i \\
1 \\
0 \\
\stackrel{1}{1} \\
i\end{array}$ & $\begin{array}{l}\text { ने } \\
\text { o } \\
1 \\
0 \\
0 \\
0\end{array}$ & 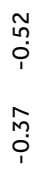 & $\begin{array}{l}\vec{b} \\
\dot{0} \\
1 \\
0 \\
m \\
0.0\end{array}$ & $\begin{array}{l}0 \\
0 \\
0 \\
ت \\
\stackrel{-}{0}\end{array}$ & 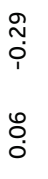 & $\begin{array}{l}0 \\
0 \\
i \\
i \\
0 \\
0 \\
m \\
i \\
i\end{array}$ & $\begin{array}{l}01 \\
0 \\
0 \\
1 \\
0 \\
0 \\
0\end{array}$ & f \\
\hline 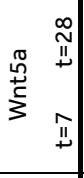 & $\begin{array}{l}N \\
\hat{0} \\
i \\
M \\
m \\
i \\
i\end{array}$ & 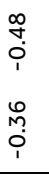 & $\begin{array}{l}0 \\
0 \\
i \\
i\end{array}$ & $\begin{array}{l}\text { ¿o } \\
\text { ì }\end{array}$ & 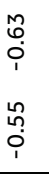 & 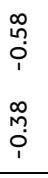 & $\begin{array}{l}0 \\
0 \\
0 \\
1 \\
0 \\
0 \\
0 \\
1\end{array}$ & $\begin{array}{l}\text { ने } \\
\text { o } \\
1\end{array}$ & $\begin{array}{l}n \\
m \\
\text { on } \\
i\end{array}$ & $\begin{array}{l}0 \\
\stackrel{0}{0} \\
\text { i. }\end{array}$ & 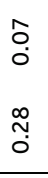 & 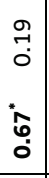 & 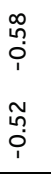 & 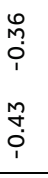 & $\begin{array}{l}\stackrel{J}{1} \\
\stackrel{0}{ } \\
\vec{m} \\
0\end{array}$ & $\underset{F}{*}$ \\
\hline 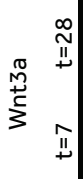 & $\begin{array}{l}\tilde{n} \\
0 \\
0 \\
\overrightarrow{+} \\
i \\
i\end{array}$ & $\begin{array}{l}\text { in } \\
\text { in } \\
i \\
i \\
0 \\
0 \\
0 \\
i\end{array}$ & 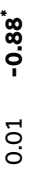 & 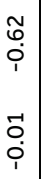 & 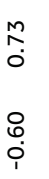 & 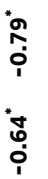 & 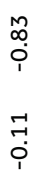 & 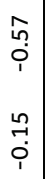 & 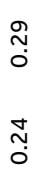 & 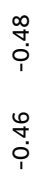 & $\begin{array}{l}\text { nn } \\
\text { on } \\
1 \\
m \\
0 \\
0\end{array}$ & 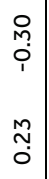 & $\begin{array}{l}\text { ने } \\
0 \\
\hat{n} \\
0\end{array}$ & 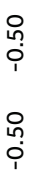 & $\begin{array}{l}\text { ing } \\
\text { ì } \\
\text { in } \\
\text { o } \\
\dot{0}\end{array}$ & 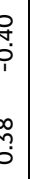 \\
\hline 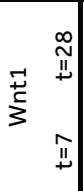 & 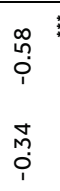 & $\begin{array}{l}\vdots \\
\vdots \\
0 \\
0 \\
1 \\
\infty \\
0 \\
0 \\
1\end{array}$ & "ָׁ & $\begin{array}{l}\text { 垈 } \\
\text { in }\end{array}$ & 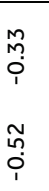 & 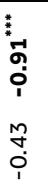 & 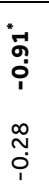 & 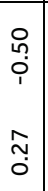 & $\begin{array}{l}\text { ma } \\
\stackrel{0}{0} \\
1 \\
m \\
m \\
0\end{array}$ & $\begin{array}{l}\stackrel{0}{0} \\
\stackrel{i}{1} \\
\text { M } \\
\stackrel{N}{i} \\
i\end{array}$ & $\begin{array}{l}\infty \\
0 \\
0 \\
1 \\
0 \\
0 \\
m \\
0\end{array}$ & 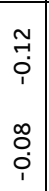 & 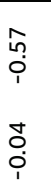 & 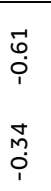 & $\begin{array}{l}\hat{\infty} \\
\stackrel{0}{0} \\
1 \\
\\
\stackrel{\infty}{0} \\
\stackrel{0}{0}\end{array}$ & $\sigma$ \\
\hline 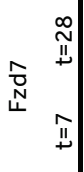 & $\begin{array}{l}n 0 \\
0 \\
i \\
1 \\
\stackrel{0}{0} \\
\stackrel{0}{0}\end{array}$ & 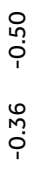 & 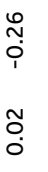 & $\begin{array}{l}\text { ò } \\
\text { i. }\end{array}$ & 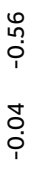 & 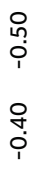 & $\begin{array}{l}\vec{m} \\
0 \\
i \\
0 \\
0 \\
0 \\
0\end{array}$ & 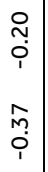 & 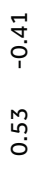 & 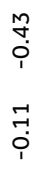 & $\begin{array}{l}\vec{N} \\
\stackrel{0}{1} \\
\\
\stackrel{0}{0} \\
\stackrel{0}{0}\end{array}$ & 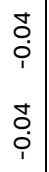 & 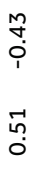 & 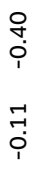 & $\begin{array}{l}\circ \\
\stackrel{0}{0} \\
1 \\
1 \\
0 \\
0 \\
0 \\
0 \\
0\end{array}$ & 1 \\
\hline 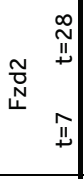 & $\begin{array}{l}m \\
0 \\
0 \\
1 \\
m \\
? \\
0 \\
1\end{array}$ & 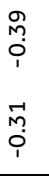 & $\begin{array}{l}\text { ㄱ. } \\
0 \\
0 \\
0 \\
0 \\
0 \\
1\end{array}$ & $\begin{array}{l}\text { o } \\
\text { ì }\end{array}$ & 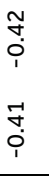 & 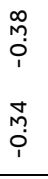 & $\begin{array}{l}\stackrel{J}{~} \\
\stackrel{0}{0} \\
\hat{0} \\
0\end{array}$ & $\begin{array}{c}\overrightarrow{-} \\
\overrightarrow{0} \\
1 \\
-1 \\
\overrightarrow{0} \\
\dot{0}\end{array}$ & $\begin{array}{l}\hat{m} \\
0 \\
1 \\
0 \\
0 \\
0 \\
1\end{array}$ & $\begin{array}{l}\tilde{N} \\
0 \\
i \\
\tilde{n} \\
\tilde{N} \\
1\end{array}$ & $\begin{array}{l}\stackrel{d}{N} \\
0 \\
m \\
m \\
0\end{array}$ & $\begin{array}{l}20 \\
0 \\
0 \\
\hat{0} \\
0\end{array}$ & 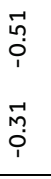 & 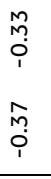 & 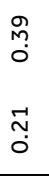 & \\
\hline 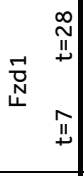 & 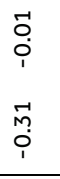 & 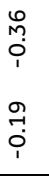 & 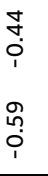 & 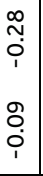 & 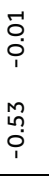 & 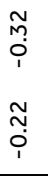 & 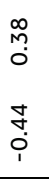 & \begin{tabular}{l}
$\stackrel{\sim}{N}$ \\
$\stackrel{0}{ }$ \\
\multirow{N}{*}{} \\
$\stackrel{0}{1}$
\end{tabular} & $\begin{array}{l}\stackrel{n}{n} \\
\text { o. } \\
\\
\vec{N} \\
\stackrel{1}{1}\end{array}$ & 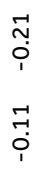 & $\underset{\text { Nิ }}{\text { Oे }}$ & $\begin{array}{l}\circ \\
\stackrel{\circ}{\circ}\end{array}$ & $\begin{array}{l}\stackrel{\infty}{N} \\
0 \\
n \\
n \\
m \\
0 \\
1\end{array}$ & $\begin{array}{l}\stackrel{0}{0} \\
\stackrel{0}{0} \\
1 \\
\infty \\
m \\
0 \\
1\end{array}$ & 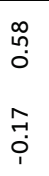 & \\
\hline & 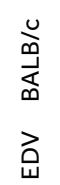 & 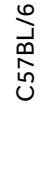 & & $\sum_{n}^{n}$ & 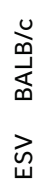 & 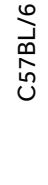 & & $\stackrel{\substack{n \\
\vdots \\
n}}{n}$ & $\begin{array}{l}\frac{u}{\infty} \\
\frac{1}{\infty} \\
3\end{array}$ & 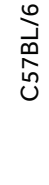 & $\sum_{L}^{\infty}$ & $\begin{array}{c}\tilde{w} \\
\vdots \\
w\end{array}$ & 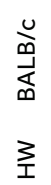 & 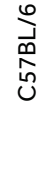 & & \\
\hline
\end{tabular}




\section{Wnt/Frizzled signaling expression in post-mortem human MI samples}

To evaluate whether Wnt/Frizzled signaling genes have a changed expression pattern following $\mathrm{Ml}$ in humans, a retrospective study was conducted with formalin fixed post-mortem myocardial samples. Tissue samples were histologically checked for the presence of an infarction and were divided into four categories according to the established infarct age. Together with each infarcted sample, a non-infarcted sample from the same heart was also analyzed for its gene expression. Since not all samples demonstrated detectable mRNA expression for each gene, the actual number of samples in each group was variable and is displayed in Figure 7.

As can be seen in Figure 7, a general expression pattern could be observed for all genes that were analyzed: in group B there is an increased in expression, which decreases again in group C, followed by a slight increase in group D. However, significant difference in expression in the infarcted myocardium was only detected for Wnt1 and Fzd7 between group A and B. In addition, Fzd7 was differently expressed in the remote area between group A-B and B-D. Differences in the expression over time were not observed for other genes that were measured. No significant differences could be observed between remote and infarcted myocardium. Large variations in expression levels were observed between different samples, even within a single patient, hampering the determination of significant differences between the groups

\section{Discussion}

Previously, our lab has demonstrated that the genetic background of mice is a strong determinant for the infarct healing process post-MI. Induction of MI in five mouse strains demonstrated substantial differences in frequency of infarct rupture, thinning of the infarct area, preservation of cardiac function and heart failure incidence ${ }^{(9)}$. To find a link between Wnt signaling and the difference in infarct healing between mice strains, we provide an overview of the expression of several genes from the Wnt/Frizzled signaling cascade following experimental $\mathrm{MI}$ in four different mouse strains, together with their cardiac dimensions assessed by echocardiography. In 


10mote myocardium
A: 0-1 week post-MI
C: 3-6 weeks post-M $\square$ infarcted myocardium
B: 1-3 weeks post-Ml
D: $>6$ weeks post-MI

Figure 7 | Wnt/Frizzled signaling gene expression in post-mortem human MI samples.

Only Fzd7 and Wnt1 demonstrated significant differences in the infarcted myocardium between group $A$ and B. All values were normalized to group A: remote myocardium, which was set at 1.0. Data are presented as mean \pm SEM, ${ }^{*} p<0.05$. 
addition, we present data on the expression of these genes in post-mortem human MI samples.

Several Wnt ligands and Fzd receptors were upregulated in the infarcted area compared to the remote region in mice following MI, although the target genes for canonical Wnt signaling were not upregulated accordingly. The upregulation of Wnt and Fzd family members following experimental $\mathrm{MI}$ in mice (C57BL/6) has been demonstrated before by several research groups ${ }^{(14,15)}$, but then compared to shamoperated or unmanipulated control animals. The expression pattern of Fzd1, -2 and 7 in C57BL/ 6 mice between the infarcted and remote area at one week post-MI was similar to the study from Barandon et al. where one week post-MI and baseline animals were compared ${ }^{(15)}$. The upregulated expression of Fzd2 one week post-MI has also been observed before in the infarcted rat myocardium when compared to sham operated animals ${ }^{(12)}$, confirming the results of this study.

The expression of Wnt ligands presented in this manuscript was not significantly altered between the infarcted and remote area one week post-MI, which is in accordance with the previously mentioned study ${ }^{(15)}$. This is also supported by a study where expression of Wnts was investigated five days following MI compared to sham animals: Wnt1, $-3 a,-5 a$ and $-8 a$ expression was not significantly altered in these mice following $\mathrm{MI}^{(14)}$. Remarkably, we found a significant increase of Wnt1, $-3 a$ and $-8 \mathrm{a}$ in the C57BL/6 and FVB strains at four weeks following induction of MI. To our knowledge there are no other data available that provide information on the expression of Wnts four weeks post-MI although canonical Wnt signaling has been shown to be upregulated in the myocardium up until at least three weeks post-MI ${ }^{(16)}$.

The expression of target genes Axin2 and CyclinD1 was not significantly altered between the remote and infarcted area within strains, although one would expect an upregulation in the infarcted area, since Fzd receptors and Wnt ligands were significantly upregulated. A study with Axin2 reporter mice demonstrated increased expression of Axin2 following MI throughout the entire myocardium (16). This could explain the absence of differential expression of the target genes between remote 
and infarcted myocardium in our study. Non-canonical Wnt signaling (See Chapter 2) can also be activated, although direct evidence is lacking since target genes of this signaling pathway were not studied. However, Wnt5a (a non-canonical Wnt ligand ${ }^{(17)}$ ) expression does not point in this direction, since there is no upregulation of this gene in the infarcted area.

Correlation of gene expression with the parameters EDV, ESV, LW and HW demonstrated contrasting results. Wnt1, $-3 a$ and $-8 a$ expression levels were negatively correlated with ESV and EDV in C57BL/6 and FVB mice, whereas a significant correlation was absent for LW and HW at four weeks post-MI. This suggests that in a later stage of wound healing post-MI, increased Wnt expression is beneficial for preserving EDV and ESV whereas reduced expression will likely lead to dilatation of the ventricle. A presumable consequence of increased Wnt expression would be an increased Wnt signaling activity, although this was not reflected by a comparable expression of the canonical target genes Axin2 and CyclinD1. Since Wnt1, $-3 a$ and $-8 a$ are canonical Wnt ligands ${ }^{(18)}$ it is also not likely that these would activate non-canonical signaling.

In contrast to van den Borne et al. ${ }^{(9)}$, we did not observe a difference in EF between strains at one and four weeks post-MI. The EF for all strains remained around $20 \%$ whereas EFs of less than $10 \%$ were reported previously for the BALB/c and Swiss strains four weeks following MI. In addition, dilatation of the infarct between one and four weeks post-MI in Swiss mice was not observed in this study, whereas this did occur previously between two and four weeks ${ }^{(9)}$. Death due to presence of heart failure was completely absent in the BALB/C and C57BL/6 mice whereas a few animals died ( $10 \%$ and $8 \%$ respectively) due to this in the aforementioned study. Also lung to body weight ratio was not significantly different in this study. Especially Swiss mice had a low lung to body weight ratio compared to the previous study (9). BALB/C and Swiss mice have previously been proposed as good models to study heart failure post-MI since these mice clearly demonstrated a reduced cardiac performance, dilatation of the infarct and increases in lung weight ${ }^{(9)}$. All these characteristics were 
not observed in the present study for these strains, which suggests the absence of overt heart failure development with a consequence that mice remain in a compensated state. The wound healing process following $\mathrm{MI}$ comprises an extensive inflammatory response in the myocardium ${ }^{(19)}$, which will contribute to development of heart failure. Our mice were housed in individually ventilated cages (IVC), which reduces the exposure to pro-inflammatory stimuli and results in a diminished grade of basal inflammation in mice. A plausible explanation for the absence of the heart failure phenotype in these mice, is a reduced exposure to inflammatory stimuli due to these housing conditions (see chapter 5).

The data on the expression profile of Wnt/Frizzled signaling components in human post-mortem MI samples demonstrated a pattern of gene expression in time for most of the genes, namely; an upregulation one to three weeks following MI, followed by a downregulation three to six weeks after $\mathrm{Ml}$ and finally the gene expression changed back to baseline levels in group $\mathrm{D}$. This pattern is in parallel with the cellularity of an infarcted area of the myocardium in which cell numbers increase during the period of granulation tissue formation and decrease again in the remodeling phase ${ }^{(3)}$. Nevertheless, several factors can influence the outcome of this study. The material used for RNA isolation was formalin fixed which means that the ECM in this tissue is tightly-crosslinked. This crosslinking is increased in fibrous tissues such as muscle and infarct tissue, which impedes the RNA isolation process. In addition, location and duration of storage of these samples affects the quality of RNA in terms of lower yields and smaller RNA fragments. Another factor that strongly affects the quality of RNA is the time between death and autopsy, which is also a variable factor in this study. Endogenous RNAses will degrade intact RNA molecules to small fragments, which will negatively influence the efficiency of the RT-PCR reaction. In contrast to experimental $\mathrm{Ml}$ in mice, the zone of the infarcted area in patients is more scattered. This means that also RNA of viable myocardium or border zone tissue is present and will contaminate the gene expression pattern in the infarcted area. Other determinants that can seriously affect gene expression are disease state of the patients in general and the medication that is taken by them. 
When the variance of all these factors between samples is high, this can hamper statistical analysis and thus no firm conclusions can be drawn.

A limitation of this study is the absence of overt heart failure development, especially in the Swiss and BALB/C strains, which might be the result of different housing conditions compared to the previous study from our lab (Chapter 5).

\section{Conclusion}

This study provides an overview of the Wnt/Frizzled gene expression regulation following experimental $\mathrm{MI}$ in four different mouse strains, known to have different wound healing processes following MI. An increased gene expression of Wht ligands and Frizzled receptors was a general observation in most of the strains following $\mathrm{MI}$. However, gene expression of several Wnt ligands was significantly increased at four weeks post-MI in two out of four strains and correlated very well with cardiac volumes but not with lung and heart weights, which are more direct signs of heart failure development. These observations suggested that increased Wnt signaling is favorable for prevention of LV dilatation. Marked differences in gene expression between strains was only present for several Wnt ligands but not for Frizzled receptors or target genes. However, it must be noted that Wnt/Frizzled gene expression was the lowest in Swiss mice compared to other strains. The absence of overt heart failure development is a limitation of the study and could interfere with the gene expression patterns observed in the present study. Besides a recurrent gene expression pattern over time for the human Wnt/Frizzled genes, matching the cellularity of the tissue, no other useful information could be extracted from these data, which might be the result of large variations between the patients.

Taken together, this study illustrates the need for more research with human material to really identify differentially regulated components in the signaling pathway and to translate results from animal experiments to a clinical situation. Snap frozen material that is collected immediately following death of the patient would be ideal for this purpose. In addition it would be of interest to identify the individual cell 
types that express these genes to increase our understanding of the contribution of Wnt signaling to the wound healing process following MI. 


\section{References}

1. Blankesteijn WM, Creemers E, Lutgens E, Cleutjens JP, Daemen MJ, Smits JF. Dynamics of cardiac wound healing following myocardial infarction: observations in genetically altered mice. Acta physiologica Scandinavica. 2001;173(1):75-82.

2. Frangogiannis NG. The mechanistic basis of infarct healing. Antioxidants \& redox signaling. 2006;8(11-12):1907-39.

3. Cleutjens JP, Blankesteijn WM, Daemen MJ, Smits JF. The infarcted myocardium: simply dead tissue, or a lively target for therapeutic interventions. Cardiovascular research. 1999;44(2):232-41.

4. Dobaczewski M, Chen W, Frangogiannis NG. Transforming growth factor (TGF)-beta signaling in cardiac remodeling. Journal of molecular and cellular cardiology. 2011;51(4):600-6.

5. Daskalopoulos EP, Janssen BJ, Blankesteijn WM. Myofibroblasts in the infarct area: concepts and challenges. Microscopy and microanalysis : the official journal of Microscopy Society of America, Microbeam Analysis Society, Microscopical Society of Canada. 2012;18(1):35-49.

6. Nelissen-Vrancken HJ, Debets JJ, Snoeckx LH, Daemen MJ, Smits JF. Time-related normalization of maximal coronary flow in isolated perfused hearts of rats with myocardial infarction. Circulation. 1996;93(2):349-55.

7. van den Borne SW, Cleutjens JP, Hanemaaijer R, Creemers EE, Smits JF, Daemen MJ, et al. Increased matrix metalloproteinase- 8 and -9 activity in patients with infarct rupture after myocardial infarction. Cardiovascular pathology : the official journal of the Society for Cardiovascular Pathology. 2009;18(1):37-43.

8. Pfeffer MA, Braunwald E. Ventricular remodeling after myocardial infarction. Experimental observations and clinical implications. Circulation. 1990;81(4):1161-72.

9. van den Borne SW, van de Schans VA, Strzelecka AE, Vervoort-Peters HT, Lijnen PM, Cleutjens JP, et al. Mouse strain determines the outcome of wound healing after myocardial infarction. Cardiovascular research. 2009;84(2):273-82.

10. Hermans KC, Blankesteijn WM. Wnt Signaling in Cardiac Disease. Comprehensive Physiology. 2015;5(3):1183-11209.

11. Hermans KC, Daskalopoulos EP, Blankesteijn WM. Interventions in Wnt signaling as a novel therapeutic approach to improve myocardial infarct healing. Fibrogenesis \& tissue repair. 2012;5(1):16.

12. Blankesteijn WM, Essers-Janssen YP, Verluyten MJ, Daemen MJ, Smits JF. A homologue of Drosophila tissue polarity gene frizzled is expressed in migrating myofibroblasts in the infarcted rat heart. Nature medicine. 1997;3(5):541-4.

13. Heijnen BF, Pelkmans LP, Danser AH, Garrelds IM, Mullins JJ, De Mey JG, et al. Cardiac remodeling during and after renin-angiotensin system stimulation in Cyp1a1-Ren2 transgenic rats. J Renin Angiotensin Aldosterone Syst. 2014;15(1):69-81.

14. Aisagbonhi O, Rai M, Ryzhov S, Atria N, Feoktistov I, Hatzopoulos AK. Experimental myocardial infarction triggers canonical Wnt signaling and endothelial-to-mesenchymal transition. Dis Model Mech. 2011;4(4):469-83.

15. Barandon L, Couffinhal T, Ezan J, Dufourcq P, Costet P, Alzieu P, et al. Reduction of infarct size and prevention of cardiac rupture in transgenic mice overexpressing FrzA. Circulation. 2003;108(18):2282-9.

16. Oerlemans MI, Goumans MJ, van Middelaar B, Clevers H, Doevendans PA, Sluijter JP. Active Wnt signaling in response to cardiac injury. Basic Res Cardiol. 2010;105(5):631-41.

17. Grumolato L, Liu G, Mong P, Mudbhary R, Biswas R, Arroyave R, et al. Canonical and noncanonical Wnts use a common mechanism to activate completely unrelated coreceptors. Genes \& development. 2010;24(22):2517-30. 
18. Siar $\mathrm{CH}$, Nagatsuka H, Han PP, Buery RR, Tsujigiwa H, Nakano K, et al. Differential expression of canonical and non-canonical Wnt ligands in ameloblastoma. Journal of oral pathology \& medicine : official publication of the International Association of Oral Pathologists and the American Academy of Oral Pathology. 2012;41(4):332-9.

19. Frangogiannis NG. Regulation of the inflammatory response in cardiac repair. Circulation research. 2012;110(1):159-73. 



\section{Chapter

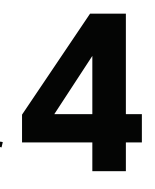

\section{UM206, a selective Frizzled antagonist, attenuates adverse remodeling after myocardial infarction in swine}

André Uitterdijk ${ }^{*}$, Kevin C.M. Hermans", Daphne P.M. de Wijs-Meijler, Evangelos P. Daskalopoulos, Irwin K. Reiss, Dirk J. Duncker, W. Matthijs Blankesteijn and Daphne Merkus Laboratory Investigation 2016, 96:168-176 *Authors contributed equally to this work 


\section{Abstract}

Modulation of Wnt/Frizzled signaling with UM206 reduced infarct expansion and prevented heart failure development in mice, an effect that was accompanied by increased myofibroblast presence in the infarct, suggesting that Wnt/Frizzled signaling has a key role in cardiac remodeling following myocardial infarction (MI). This study investigated the effects of modulation of Wnt/Frizzled signaling with UM206 in a swine model of reperfused MI. For this purpose, seven swine with MI were treated with continuous infusion of UM206 for 5 weeks. Six control swine were treated with vehicle. Another eight swine were sham-operated. Cardiac function was determined by echo in awake swine. Infarct mass was estimated at baseline by heart-specific fatty acid-binding protein ELISA and at follow-up using planimetry. Components of Wnt/Frizzled signaling, myofibroblast presence, and extracellular matrix were measured at follow-up with qPCR and/or histology. Results show that UM206 treatment resulted in a significant decrease in infarct mass compared with baseline $(-41 \pm 10 \%)$, whereas infarct mass remained stable in the Control-MI group $(+3 \pm$ $17 \%)$. Progressive dilation of the left ventricle occurred in the Control-MI group between 3 and 5 weeks after MI, while adverse remodeling was halted in the UM206treated group. mRNA expression for Frizzled-4 and the Frizzled co-receptor LRP5 was increased in UM206-treated swine as compared with Control-MI swine. Myofibroblast presence was significantly lower in infarcted tissue of the UM206treated animals $(1.53 \pm 0.43 \%$ vs. $3.38 \pm 0.61 \%)$ at 5 weeks follow-up. This study demonstrates that UM206 treatment attenuates adverse remodeling in a swine model of reperfused MI, indicating that Wnt/Frizzled signaling is a promising target to improve infarct healing and limit post-MI remodeling. 


\section{Introduction}

Although left ventricular (LV) remodeling after myocardial infarction (MI) is aimed at maintaining cardiac pump function, initial infarct size, and the subsequent progressive expansion and thinning of the infarcted area constitute the main risk factors for the development of post-MI heart failure ${ }^{(1)}$. Several strategies that influence either the infarct size and/or the ensuing process of LV remodeling have been proposed as potential therapies to halt the development and progression of LV dysfunction $^{(2,3)}$.

Cardiac fibroblasts, which account for up to $70 \%$ of the cells present in the myocardium, regulate extracellular matrix (ECM) turnover, and have an essential role in cardiac homeostasis. Fibroblasts are more resistant to ischemia than cardiomyocytes $^{4-6}$, and prolonged myocardial ischemia results in death of particularly the cardiomyocytes, whereas the fibroblasts survive. Fibroblasts have therefore been proposed to be a therapeutic target to influence the healing process of the infarcted myocardium $^{(1,5,7-9)}$. In addition to these resident fibroblasts, fibroblasts enter the infarcted tissue by migration. When present in the infarcted area, the fibroblasts gradually differentiate into their more contractile and synthetic myofibroblast phenotype. These (myo)fibroblasts have key roles both in the initial inflammatory phase as well as in the subsequent proliferative phase of the post-infarction response, which together lead to the formation of a stable, collagen-rich scar ${ }^{(4)}$. Thus, increasing myofibroblast presence shortly after $\mathrm{MI}$ has been proposed to promote scar contraction and limit LV dilation ${ }^{(1,4,10)}$. Fibroblast migration is inhibited by Wnt/Frizzled (Fzd) signaling. Targeting the Wnt signaling pathway by modulating its ligand, the Fzd receptors, through UM206, an antagonist of Fzd1 and Fzd2, has been shown to promote fibroblast migration, limit infarct size, and attenuate adverse remodeling after infarction induced by permanent ligation of the coronary artery in mice ${ }^{(11,12)}$. A potential pitfall of altering fibroblast presence is that in the remote noninfarcted myocardium, local fibroblasts may remain activated in response to volume and pressure overload and promote interstitial fibrosis ${ }^{(1,13)}$. 
In light of these considerations, the present study was designed to investigate whether UM206 is capable of limiting adverse LV remodeling after MI in a preclinical setting, that is, when tested in a large translational swine model of reperfused $\mathrm{MI}$. Moreover, we aimed to elucidate the molecular mechanism of a potential beneficial effect of UM206 on remodeling of the infarct area as well as the remote myocardium. For this purpose, swine were subjected to $2 \mathrm{~h}$ of coronary artery occlusion followed by reperfusion. After one day, cardiac function was assessed with echocardiography and UM206 or saline was continuously infused intra-arterially throughout the 5-week follow-up period. At follow-up, cardiac function was reassessed and myocardial tissue was analyzed to elucidate underlying mechanisms and signaling pathways.

\section{Materials \& Methods}

Animal experiments were performed in accordance with the Guide for the Care and Use of Laboratory Animals (NIH Publication No. 85-23, revised 1996) and with approval of the Erasmus Medical Center Animal Care Committee. Twenty-two preadolescent (2-3 months old) Yorkshire $\times$ Landrace swine $(21 \pm 1 \mathrm{~kg})$ of either sex were used.

\section{Surgery}

Swine were sedated with ketamine $(20 \mathrm{mg} / \mathrm{kg}$, intramuscularly) and midazolam $(0.5$ $\mathrm{mg} / \mathrm{kg}$, intramuscularly), anesthetized with thiopental (10 mg/kg, intravenously), intubated and ventilated with $02 / \mathrm{N} 2(1 / 3(\mathrm{v} / \mathrm{v}))$, and anesthetized with fentanyl (20 $\mu \mathrm{g} / \mathrm{kg} / \mathrm{h})^{(14,15)}$. Following a thoracotomy through the fourth left intercostal space, a polyvinyl catheter was inserted into the aorta. The heart was exposed via a small pericardial incision, the proximal left circumflex artery was dissected, and a suture was placed around it. Subsequently, a polyvinyl catheter was inserted into the left atrium. Baseline blood samples were taken. Following administration of heparin (5000 IU intravenously), the proximal left circumflex artery was occluded for $2 \mathrm{~h}$ by ligation of the suture followed by reperfusion. Administration of heparin was repeated after 1 $\mathrm{h}$ of occlusion. Then following reperfusion, catheters were tunneled to the back, filled 
with heparin solution to prevent clotting, and the pericardium and the chest were closed. Blood samples were taken after 50 min of reperfusion. One animal died during reperfusion because of recurrent fibrillation. Eight weight-matched swine that underwent a thoracotomy with placement of a catheter in the aorta, but without ischemia-reperfusion, served as sham-operated animals. All animals were allowed to recover, receiving analgesia ( $0.3 \mathrm{mg}$ buprenorphine intramuscularly) for 2 days and antibiotic prophylaxis ( $25 \mathrm{mg} / \mathrm{kg}$ amoxicillin and $5 \mathrm{mg} / \mathrm{kg}$ gentamicin intravenously) for 5 days.

\section{Echocardiography, hemodynamic measurements and follow-up}

One day after surgery, (awake) animals underwent echocardiography for the determination of LV end-diastolic cross-sectional area (EDA) and end-systolic crosssectional area $(E S A)^{(16,17)}$. 2D ejection fraction was calculated as ((EDA - ESA)/EDA) $\times$ $100 \%$. Also, blood samples were taken from the aorta and collected in EDTA anticoagulation tubes, centrifuged, and plasma was stored at $-80{ }^{\circ} \mathrm{C}$ until further analysis. Blood pressure was recorded immediately following echographic measurements using the CODAS software and analyzed using a custom written program in Matlab.

Subsequently, animals were randomly assigned to the UM206 group (seven swine) or the Control-MI group (six swine). UM206 (target dose $0.6 \mu \mathrm{g} / \mathrm{kg}$ per day via the left atrium) was continuously infused at a rate of $1 \mathrm{ml} / \mathrm{h}$, using a balloon pump (Easypump, BBraun, filled with $240 \mathrm{ml}$ saline, heparin (100 IU/ml), $0.001 \mathrm{~g}$ EDTA, and $240 \mu \mathrm{g}$ UM206). In the Control-MI group, swine received an identical balloon pump but without UM206. Echographic and hemodynamic measurements, as well as blood sampling, were repeated after 3 and 5 weeks, and the balloon pump was refilled when necessary over the course of 5 weeks.

\section{Extensive hemodynamic measurements under anesthesia and tissue harvesting}

Five weeks after initial surgery, swine were reanesthetized with pentobarbital (10-15 $\mathrm{mg} / \mathrm{kg} / \mathrm{h}$, intravenously) and intubated and ventilated with a mixture of oxygen and 
nitrogen. A Swan-Ganz catheter was inserted via the femoral vein and advanced under fluoroscopic guidance into the pulmonary artery for the measurement of pulmonary artery pressure and cardiac output (thermodilution). A Millar catheter was inserted into the left carotid artery and advanced into the left ventricle for the measurement of LV pressure and its first derivative (dP/dt). After completion of all measurements, animals underwent a sternotomy, the heart was arrested by electrical fibrillation, and immediately excised. The left ventricle was sectioned into transversal slices of $\sim 1-2 \mathrm{~cm}$, which were first weighed and photographed. Subsequently, tissues from the anterior wall and infarct tissue were taken and further subdivided for storage in liquid nitrogen, isopentane, and buffered formaldehyde (3.5-4\%) for further histological and molecular assessment.

\section{Infarct mass measurements}

\section{Infarct mass at baseline}

To assess infarct mass at baseline, heart-specific fatty acid-binding protein (hFABP) was determined with ELISA from the plasma samples obtained at $50 \mathrm{~min}$ of reperfusion according to the manufacturer's description (Life Diagnostics, West Chester, PA, USA). Baseline infarct mass (IMbaseline) was estimated using the relationship between $\mathrm{hFABP}$ and infarct size obtained in a previous study from our laboratory ${ }^{(18)}$.

\section{Infarct mass at follow-up}

Infarct mass at follow-up was determined using the pictures of the individual rings of the heart by an experienced technician (blinded to treatment of the animals) using planimetry. Infarct area on basal and apical side of each ring, expressed as the percentage of total area of the ring, was averaged and multiplied by weight of the ring. Total infarct mass at follow-up (IMFu) was calculated as the sum of the weights of the infarcts in the individual rings. 


\section{ELISA, histology, and molecular studies}

\section{Longitudinal circulating markers for collagen turnover}

Blood samples taken at pre-infarction baseline, $24 \mathrm{~h}$ post-infarction, and every week until 5-week follow-up were quantified for swine MMP-9 and TIMP-1 using ELISA according to the manufacturer's instructions (Cusabio, Huissen, The Netherlands).

\section{Histology}

To quantify myofibroblast numbers in the infarct area, paraffin-embedded sections of $4 \mu \mathrm{m}$ were stained for $\mathrm{a}-\mathrm{smooth}$ muscle actin (a-SMA) as described before ${ }^{(19)}$ (a-SMA monoclonal antibody; Sigma, Zwijndrecht, The Netherlands). Next, the infarcted area was planimetrically quantified for myofibroblast area in a blinded matter with vessels excluded (Qwin, Leica, Rijswijk, The Netherlands). Data were expressed as myofibroblast area/total infarct area (\%).

\section{$R T-q P C R$}

Cryopreserved infarct tissue was homogenized and RNA was isolated using the RNeasy Fibrous Tissue Mini Kit (Qiagen, Hilden, Germany) according to the manufacturer's instructions. Isolated RNA was assessed for concentration and purity $\left(A_{260} / A_{280}\right.$ ratio) with a NanoDrop spectrophotometer (Thermo Fischer Scientific, USA). Next, RNA was reverse transcribed into cDNA, using the iScript cDNA Synthesis Kit (Bio-Rad, USA). Temperature gradient optimization studies were performed with pooled samples from non-infarct tissue cDNA $(n=12)$. IQ SYBR Green Supermix (Bio-Rad) was used for the detection of cDNA levels. Quantification of gene expression of genes related to either myofibroblast presence, regulation, or differentiation were quantified, as well as genes involved in ECM turnover and Wnt/Fzd signaling was performed using the comparative $\mathrm{Ct}(\Delta \mathrm{Ct})$ method, and results are expressed as ratios to the housekeeping gene cyclophilin and normalized to the average of sham-operated animals. See Supplementary Table S1 for primer details. 


\section{Statistical Analysis}

Statistical analysis was performed in SPSS. Expression data were first compared between sham, Control-MI remote, and UM206-treated remote myocardium using ANOVA. Subsequently, as infarct mass variation at baseline was considerable, ranging from 9.6 to $23.5 \mathrm{~g}$, ANCOVA with UM206 as a factor and infarct size determined by plasma hFABP as a covariate was used. When hFABP was not related to expression, an ANOVA for repeated measures was used with area (infarct vs. remote) as within-subject factor and UM206 treatment as between-subject factor. Hemodynamic and echographic data were analyzed using ANOVA or ANCOVA (with infarct size as covariate) for repeated measures with time as within-subject factor and group as between-subject factor. Data are given as mean \pm s.e.m. $\mathrm{P}<0.05$ was considered statistically significant.

\section{Results}

Occlusion of the proximal left circumflex artery resulted in infarction of the lateral wall of the left ventricle as evidenced by marked changes in the ECG (not shown) and $\mathrm{hFABP}$ release. Although plasma hFABP concentrations at $50 \mathrm{~min}$ of reperfusion varied considerably between the individual animals, overall plasma hFABP concentrations were similar in the Control-MI group and the UM206 group (Table 1). Estimated IM baseline was therefore also similar between groups.

Table 1 | Infarct mass at baseline and follow-up

\begin{tabular}{|c|c|c|c|}
\hline & Sham & Control-MI & UM206 \\
\hline $\mathrm{hFABP}(\mathrm{ng} / \mathrm{ml})$ & - & $141 \pm 34$ & $155 \pm 22$ \\
\hline IM baseline (g) & - & $14.5 \pm 1.5$ & $17.7 \pm 1.9$ \\
\hline $\mathrm{IM}_{\mathrm{FU}}(g)$ & - & $14.2 \pm 2.3$ & $11.2 \pm 2.2^{\dagger}$ \\
\hline Infarct Size $F u(\% L V)$ & - & $10.6 \pm 1.7$ & $8.7 \pm 1.6$ \\
\hline LVM/BM (g/kg) & $2.31 \pm 0.10$ & $3.35 \pm 0.21 *$ & $3.14 \pm 0.39 *$ \\
\hline RVM/BM (g/kg) & $0.75 \pm 0.04$ & $1.11 \pm 0.06 *$ & $1.13 \pm 0.09 *$ \\
\hline
\end{tabular}

BM, body mass; FU, follow-up; hFABP, heart-specific fatty acid-binding protein; IM, infarct mass; LVM, left ventricular mass; $\mathrm{MI}$, myocardial infarction; RVM, right ventricular mass. Data are expressed as mean \pm s.e.m. ${ }^{*} \mathrm{P}<0.05$ vs. sham; ${ }^{\dagger} \mathrm{P}<0.05$ vs. corresponding baseline. 
Treatment with UM206 for 5 weeks resulted in a significant decrease in IM, whereas IM remained unchanged in the Control-MI group (Figures 1a-c and Table 1). The alterations in infarct remodeling were accompanied by changes in LV geometry as measured with echo in awake swine. After 3 weeks follow-up, LV dilation occurred as evidenced by the larger increase in LV-EDA in both Control-MI and UM206-treated swine as compared with sham-operated animals (Figures $1 \mathrm{~d}-\mathrm{f}$ and Table 2). This increase in LV-EDA was progressive between 3 and 5 weeks after $\mathrm{MI}$ in the ControlMI group, whereas LV-EDA remained constant in the UM206 group (Table 2), resulting in a significant reduction in dilation of the LV by UM206 treatment 5 weeks
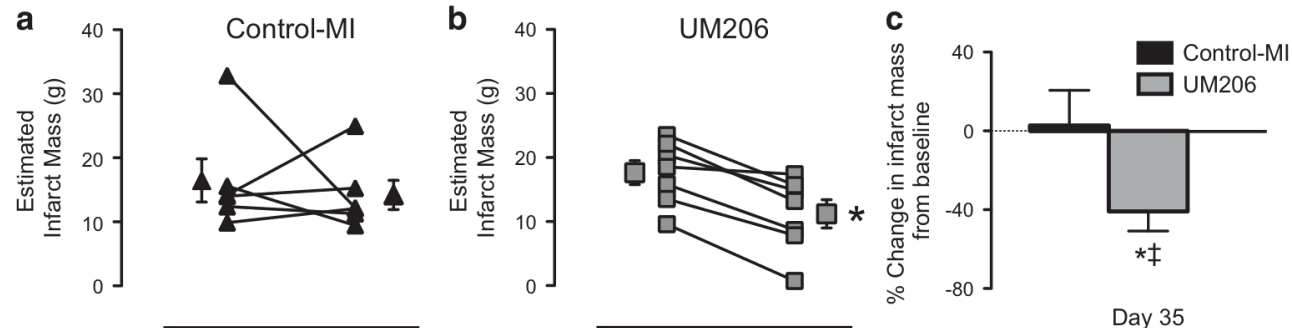

Baseline Follow-up
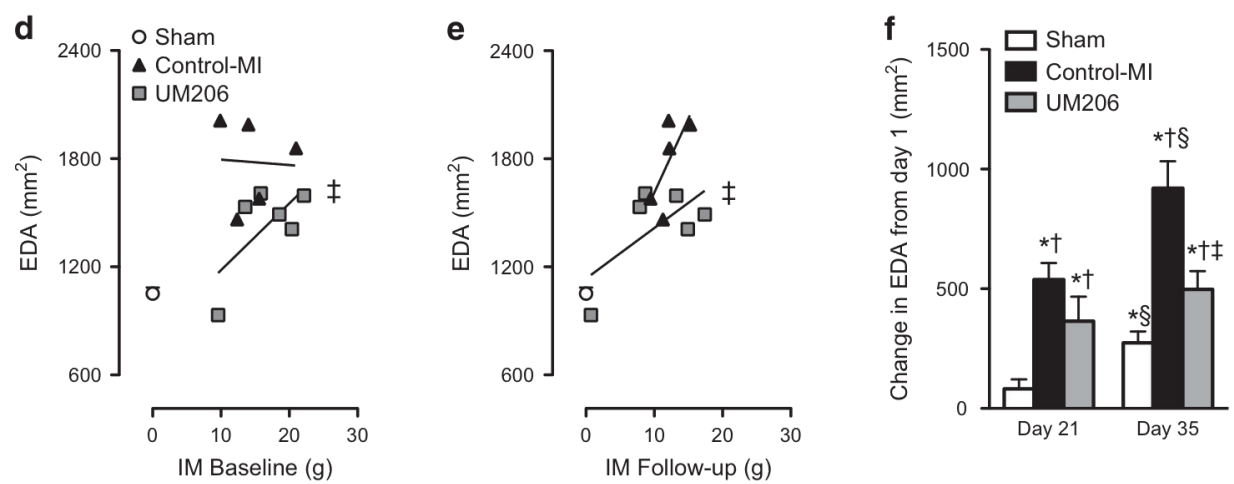

Figure 1 | Effect of UM206 treatment on infarct size and left ventricular dilatation.

Infarct mass as estimated by heart-specific fatty acid-binding protein (hFABP) at baseline and with planimetry at follow-up was not different in Control-myocardial infarction (MI) swine (a) but decreased significantly in UM206-treated swine (b). The relative change in infarct mass was significantly higher in UM206-treated swine as compared with Control-MI (c). The reduction in infarct mass was accompanied by a reduced left ventricular end-diastolic area (EDA) as measured with echocardiography both when related to infarct mass (IM) at baseline (d) and at follow-up (e). This reduced dilation occurred particularly between 3 and 5 weeks after MI, when EDA increased further in Control-MI, but not in UM206-treated swine. ${ }^{*} P<0.05$, vs. baseline (b and $\mathbf{c}$ ) or day 1 post-MI (f), ${ }^{\dagger} \mathrm{P}<0.05$ vs. sham, ${ }^{\ddagger} \mathrm{P}<0.05$ UM206 treatment vs. Control-MI, ${ }^{\varsigma} \mathrm{P}<0.05$ day 35 vs. day 21 . 
after MI (Table 2 and Figure 1f). This reduction in LV dilation induced by UM206 was further supported by a rotation of the relation between LV-EDA and both IM baseline (Figure 1d) and IMFU 5 weeks after MI (Figure 1e). MI resulted in a significant decrease in ejection fraction at 3 and 5 weeks follow-up, but there was no overall difference in ejection fraction between UM206-treated and Control-MI swine (Table 2), due to the large variation in IM. However, IMFU was linearly related to LV ejection fraction (not shown), which may suggest that the IM reduction by UM206 could result in improved LV function. Hemodynamics, as measured under anesthesia, were similar between groups (Table 3), although heart rate was slightly lower in vehicle-treated swine. This was most likely the result of anesthesia, as awake heart rates were not different between groups (not shown).

In agreement with previous observations in mice, MI resulted in the occurrence of myofibroblasts in the infarct area, activation of the Wnt/Fzd pathway, inflammation, and increased expression of ECM proteins in the infarct area. Interestingly, this occurred not only in the infarcted myocardium but also in the remote myocardium.

Table 2 | Echocardiographic parameters

\begin{tabular}{lccc}
\hline Days post-MI & Sham & Control-MI & UM206 \\
\hline Day 1 & & & \\
EDA $\left(\mathrm{mm}^{2}\right)$ & $778 \pm 49$ & $851 \pm 75$ & $902 \pm 84$ \\
ESA $\left(\mathrm{mm}^{2}\right)$ & $359 \pm 22$ & $448 \pm 86$ & $456 \pm 60$ \\
EF $(\%)$ & $53 \pm 2$ & $49 \pm 6$ & $50 \pm 3$
\end{tabular}

Day 21

$\begin{array}{lcrr}\mathrm{EDA}\left(\mathrm{mm}^{2}\right) & 860 \pm 50 & 1389 \pm 76^{*} & 1266 \pm 81^{*} \\ \mathrm{ESA}\left(\mathrm{mm}^{2}\right) & 360 \pm 41 & 843 \pm 67^{*} & 693 \pm 61^{*} \\ \mathrm{EF}(\%) & 58 \pm 4 & 39 \pm 4^{*} & 45 \pm 4^{*}\end{array}$

Day 35

$\begin{array}{lccc}\text { EDA }\left(\mathrm{mm}^{2}\right) & 1052 \pm 33 & 1781 \pm 110^{*} & 1428 \pm 103^{* \dagger} \\ \text { ESA }\left(\mathrm{mm}^{2}\right) & 471 \pm 53 & 1010 \pm 95^{*} & 789 \pm 113^{*} \\ \text { EF }(\%) & 56 \pm 4 & 44 \pm 3^{*} & 45 \pm 5\end{array}$

EDA, end diastolic area; EF, ejection fraction; ESA, end systolic area; MI, myocardial infarction. Data are expressed as mean \pm s.e.m. ${ }^{*} \mathrm{P}<0.05$ vs. sham; ${ }^{\dagger} \mathrm{P}<0.05$ vs. Control-MI. 
Table 3 | Hemodynamic parameters under anesthesia

\begin{tabular}{lccc}
\hline & Sham & Control-MI & UM206 \\
\hline Heart rate (b.p.m) & $99 \pm 3$ & $83 \pm 7^{*}$ & $103 \pm 7$ \\
Aorta pressure $(\mathrm{mm} \mathrm{Hg})$ & $92 \pm 5$ & $103 \pm 7$ & $103 \pm 2$ \\
$\mathrm{LVSP}(\mathrm{mm} \mathrm{Hg})$ & $103 \pm 4$ & $118 \pm 8$ & $115 \pm 2$ \\
$\mathrm{LVEDP}(\mathrm{mm} \mathrm{Hg})$ & $13 \pm 2$ & $15 \pm 3$ & $13 \pm 2$ \\
$\mathrm{dP} / \mathrm{dt}_{\max }(\mathrm{mm} \mathrm{Hg} / \mathrm{s})$ & $1620 \pm 140$ & $1690 \pm 180$ & $1590 \pm 160$ \\
$\mathrm{dP} / \mathrm{dt}_{\min }(\mathrm{mm} \mathrm{Hg} / \mathrm{s})$ & $-1600 \pm 140$ & $-2100 \pm 140$ & $-2100 \pm 170$ \\
$\mathrm{CO}(\mathrm{I} / \mathrm{min})$ & $3.9 \pm 0.3$ & $3.4 \pm 0.5$ & $4.2 \pm 0.3$ \\
\hline
\end{tabular}

$\mathrm{CO}$, cardiac output; $\mathrm{dP} / \mathrm{dtmax}$, maximal rate of rise of left ventricular pressure; $\mathrm{dP} / \mathrm{dtmin}$, maximal rate of decrease in left ventricular pressure; LVEDP, left ventricular end diastolic pressure; LVSP, left ventricular systolic pressure; MI, myocardial infarction. Data are expressed as mean \pm s.e.m. ${ }^{*} P<0.05$ vs. sham.

mRNA for Wnt3a was reduced in the remote, non-infarcted myocardium as compared with sham-operated swine, and was increased in the infarcted area as compared with the remote area (Table 4). mRNA for both Fzd2 and Fzd4 was increased in remote non-infarcted myocardium as compared with sham, and while expression of Fzd2 tended to be more increased $(P=0.06)$ in the infarcted area, Fzd4 mRNA expression was less in infarcted as compared with the remote area (Table 4). mRNA expression of the Fzd co-receptor LRP5 was increased, whereas mRNA expression of the coreceptor LRP6 was decreased in remote as well as in infarcted myocardium as compared with sham-operated animals. TGF- $\beta 1$ and collagen-3 were increased in remote and infarcted myocardium of swine with $\mathrm{MI}$, whereas collagen-1 was slightly lower in remote myocardium of swine with $\mathrm{MI}$ as compared with sham-operated animals, but was increased in the infarcted myocardium in comparison with remote myocardium (Table 4). Moreover, LOX, one of the enzymes responsible for collagencrosslinking, as well as tenascin-C, a glycoprotein that is expressed in the ECM following injury, were increased in the infarcted myocardium as compared with remote tissue. In the downstream part of the Wnt/Fzd signaling pathway, axin and APC were unaltered in either remote or infarcted myocardium, whereas $\beta$-catenin was increased in remote and infarcted myocardium of both Control-MI swine and swine treated with UM206 as compared with sham-operated swine. 


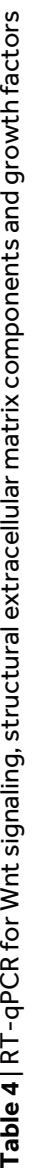

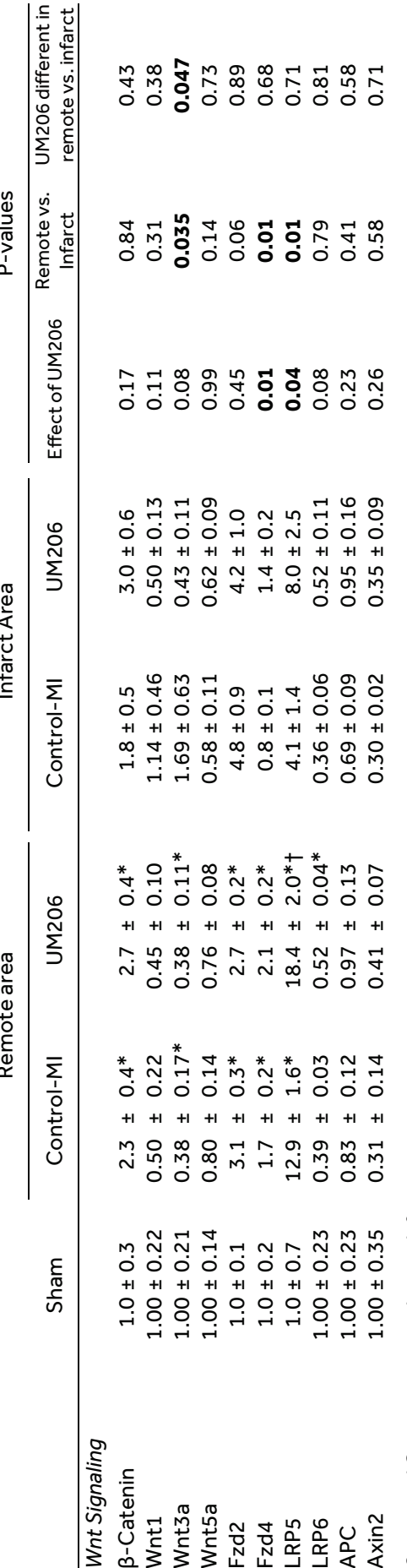

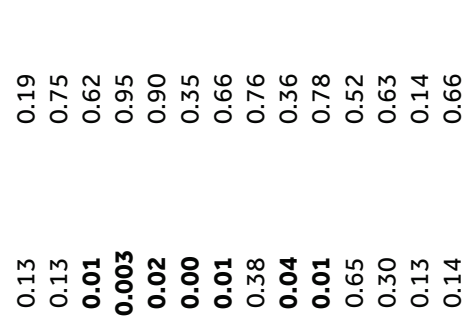

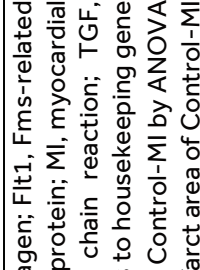

元

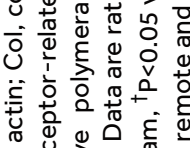

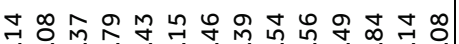

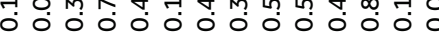

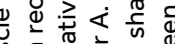

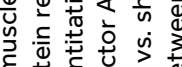
c

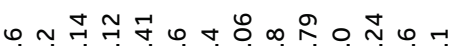

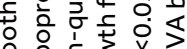

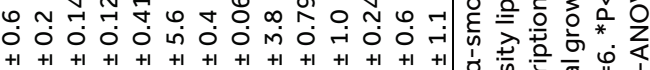

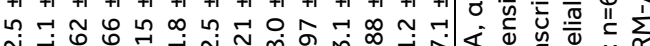
N

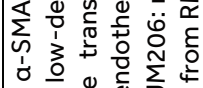

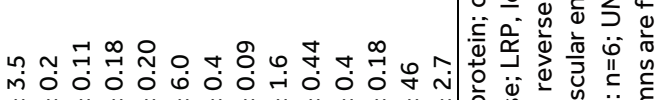

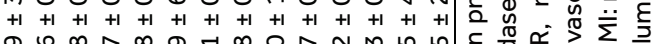
ดุ

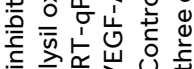

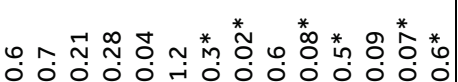
品 $\overline{0}$ is

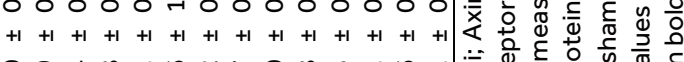

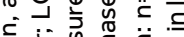
욱

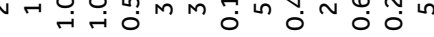

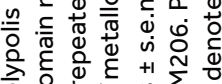

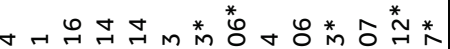

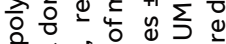
范

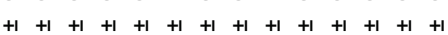
N 䓠

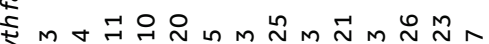

秀

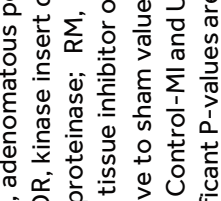

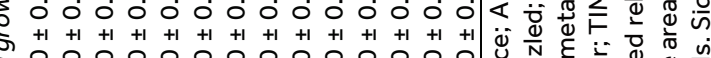

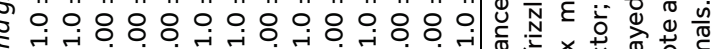
离

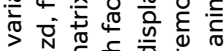
虫 计

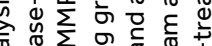

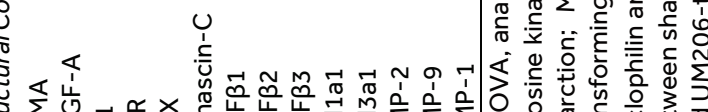

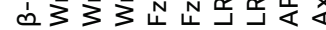


The infarct reduction by UM206 was accompanied by changes in infarct composition and expression of genes involved in ECM remodeling and Wnt/Fzd signaling. Histological assessment of a-SMA-positive cells in the infarcted myocardium revealed a significantly lower presence of myofibroblasts in the UM206 group (Figure 2a), which when also corrected for infarct mass at baseline was corroborated by a trend towards a reduction in a-SMA mRNA expression $(P=0.076)$. Interestingly, the amount of myofibroblasts present correlated very well with the change in IM over time in the Control-MI group, but not in the UM206-treated group (Figure 2b). In accordance with their role in ECM turnover, the reduced presence of myofibroblasts resulted in a decrease in TIMP-1 (Figure 2c) and a trend towards a decrease in MMP-9 mRNA ( $P=0.085$; Figure $2 \mathrm{~d}$ ) in the UM206-treated group as compared with the Control-MI group 5 weeks after induction of MI. The effects of UM206 treatment on local TIMP-1 and MMP-9 expression were not reflected in significant changes in MMP9 and TIMP-1 in circulating plasma. TIMP-1 levels were below the detection limit of the assay in most plasma samples and were not different between Control-MI and UM206-treated swine. MI resulted in a significant increase in plasma MMP-9 one day post-MI before the start of UM206 treatment $(15 \pm 5 \mathrm{ng} / \mathrm{ml}$ at day $1 \mathrm{vs.} 8 \pm 4 \mathrm{ng} / \mathrm{ml}$ just before initiation of $\mathrm{MI}$ ) but was not different between groups. This increase in plasma MMP-9 tended to wane over time, being $6 \pm 1 \mathrm{ng} / \mathrm{ml}$ at 5 weeks follow-up $(\mathrm{P}=$ 0.10 vs. day 1 ), but serial assessment of plasma MMP-9 did not show any differences between Control-MI and UM206-treated swine.

Interestingly, mRNA expression of Fzd4 was significantly higher in the infarcted myocardium of the UM206-treated animals (Table 4). This higher expression of Fzd4, a receptor thought to be involved in angiogenesis, was accompanied by a tendency towards a higher expression of VEGF in the infarcted myocardium of UM206-treated animals as compared with Control-MI, whereas expression of the VEGF receptors Flt1 and KDR was reduced in infarcted area as compared with remote myocardium, but not further affected by UM206 treatment. 

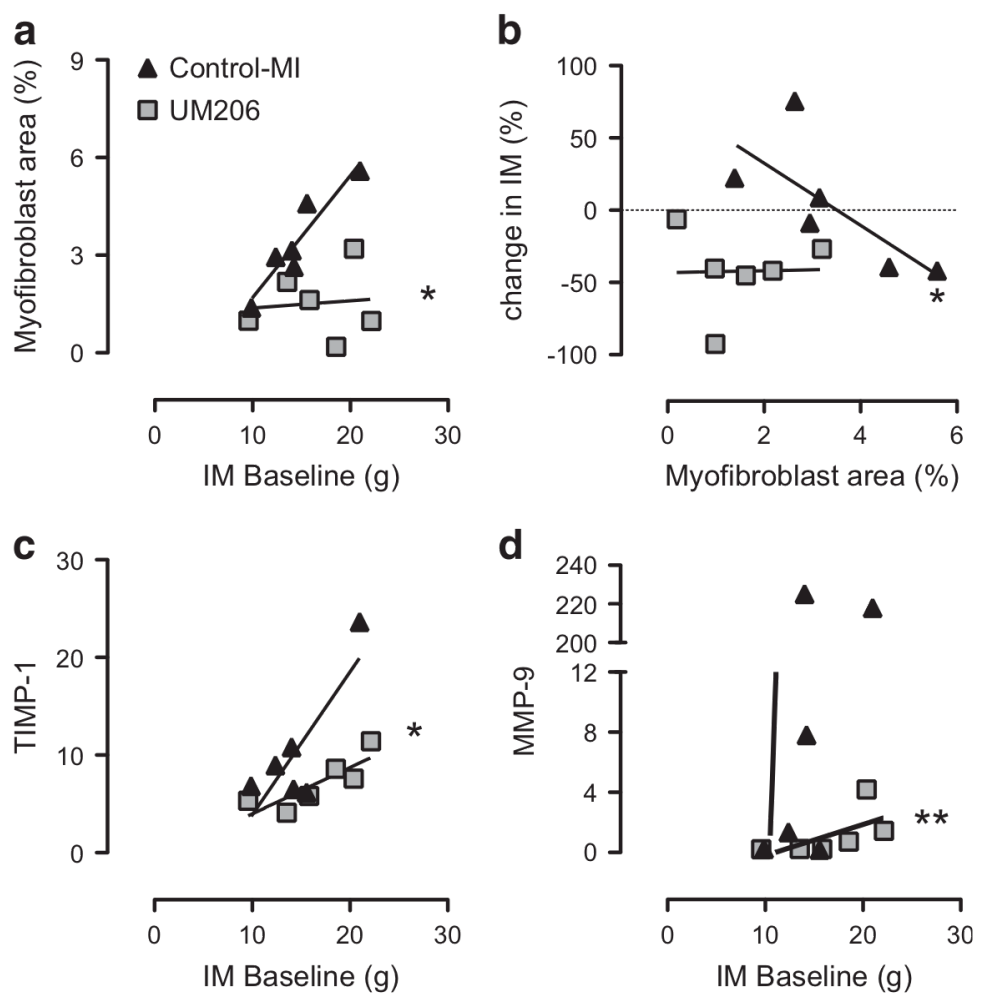

Figure 2 | Effect of UM206 treatment on infarct remodeling and expression of markers for myofibroblast presence and extracellular matrix remodeling.

UM206 reduced myofibroblast presence as assessed with immunohistochemistry in the infarcted area (a, $1.53 \pm 0.43 \%$ in UM206 vs. $3.38 \pm 0.61 \%$ in Control-myocardial infarction (MI)). Myofibroblast presence correlated with the change in infarct mass (IM) over time, with higher myofibroblast presence being associated with a larger reduction in IM in Control-MI swine (b). The lower myofibroblast presence in UM206-treated swine suggests that myofibroblast-induced IM reduction was already completed in this group. The reduced presence of myofibroblasts was associated with a decrease in tissue inhibitor of metalloproteinase-1 (TIMP-1) (c) and a trend towards a reduction in matrix metalloproteinase-9 (MMP-9) (d). ${ }^{*} \mathrm{P}<0.05,{ }^{* * P}<0.10$ UM206 treatment vs. Control-MI.

mRNA for the Fzd co-receptors LRP5 $(P=0.06)$ and LRP6 $(P<0.05)$ was higher in the remote myocardium of UM206-treated animals as compared with Control-MI (Table 4), which was accompanied by a trend towards a lower TIMP-1 expression $(P=0.07)$, suggesting that UM206 treatment may directly affect remodeling of the remote myocardium as well. 


\section{Discussion}

In the present study, the effect of UM206, a modulator of Wnt/Fzd signaling, was investigated on infarct remodeling and LV function in a clinically relevant large animal model. The most important findings in the present study are that treatment with UM206 for 5 weeks after acute MI, resulted in (I) IM reductions and (II) reduced dilation of the LV, which was accompanied by (III) changes in the expression of genes involved in ECM remodeling and Wnt/Fzd signaling. The implications of these findings will be discussed below.

\section{Myofibroblasts and $L V$ remodeling after $M I$}

MI results in dilation and remodeling of the left ventricle. Although this process is aimed at maintaining pump function, dilation of the left ventricle has been shown to be an initiating factor in the process leading to heart failure. Infarct size and composition of the scar tissue, replacing the infarcted myocardium, are important determinants of the outcome of the LV remodeling process. To assess accurately the effect of treatment, in a study with relatively few animals, it is important to not only measure infarct size at the end of the study but also at baseline, and to correlate findings at the end of the study to the factor that initiated the remodeling process. In a recent study, we found that $\mathrm{hFABP}$, when measured in blood at $50 \mathrm{~min}$ of reperfusion, correlated linearly with infarct mass as determined by TTC staining following killing of the animals ${ }^{(18)}$. In the present study, hFABP correlated well with the clinical marker high-sensitive troponin I ( $r=0.72)$, further confirming the validity of our estimation of infarct mass at baseline. IMbaseline, estimated by measuring hFABP, did vary between individual animals, but overall was similar between Control-MI and UM206-treated groups.

Infarct healing occurs in three partly overlapping phases: an initial inflammatory phase, followed by a proliferative phase and maturation of the scar. (Myo)fibroblasts have different roles in the different phases ${ }^{(4,10)}$. In the initial phase, the fibroblasts act as local immune modulators and are the main effectors of fibrogenesis ${ }^{(1,4-6,20)}$. In the subsequent proliferative phase of healing, fibroblasts further differentiate into 
myofibroblasts that not only have an augmented matrix-synthetic phenotype but also express the contractile protein a-SMA. Both the increased ECM production and the contractile properties of the myofibroblasts have been proposed to be key factors in strengthening the infarct and limiting infarct expansion, thereby reducing LV dilation ${ }^{(1,4,9,21)}$ and therefore constitute a target to modulate infarct remodeling. Administration of UM206 promotes migration of fibroblasts to the infarcted area by inhibition of Wnt/Fzd signaling, and thereby modulates the scar formation in the infarcted area ${ }^{(11)}$. In accordance with our recent study in mice ${ }^{(11)}$, we found in the present study that treatment with UM206 for 5 weeks reduced infarct mass as compared with its baseline measurement. This reduction in infarct mass was accompanied by a decreased LV dilation, as measured in awake animals with echocardiography, between 3 and 5 weeks after MI in swine treated with UM206. Interestingly, IMFU correlated very well with ejection fraction measured at 5 weeks follow-up, which may suggest that, although there was no overall difference in ejection fraction between Control-MI and UM206-treated swine because of variation in infarct size, by promoting infarct reduction, UM206 treatment may improve cardiac function.

In both the canine $\mathrm{e}^{(22)}$ and the porcine ${ }^{(10)}$ heart, myofibroblast presence peaks between 5 and 21 days after MI, after which myofibroblast numbers gradually decline. This has led to the concept that during the phase of infarct maturation, when the infarct is filled with matrix, myofibroblast proliferation is suppressed, and myofibroblasts become quiescent and undergo apoptosis ${ }^{(4)}$. In the present study, we found that the presence of myofibroblasts, as indicated by immunohistochemistry (in which we excluded blood vessels) as well as mRNA expression (that may in part reflect a-SMA from blood vessels) for a-SMA, was higher in the infarcted tissue as compared with remote tissue and correlated not only with $\mathrm{IM}_{\text {baseline }}$ but also with the estimated change in IM over time in the Control-MI group, suggesting that, indeed, myofibroblasts contribute to infarct contraction. In contrast to our previous study in mice, in which UM206 treatment increased myofibroblast presence in the infarcted area $^{(11)}$, myofibroblast presence was lower in the infarcted myocardium of UM206- 
treated swine as compared with Control-MI, particularly in swine with a large MI, despite the observation that the reduction in IM was larger. It should be noted, however, that infarct size as a percentage of the left ventricle in mice is much larger than the infarct size in swine in the present study, and therefore mechanical stress within the murine infarcts is expected to be larger. As myofibroblast differentiation is promoted by mechanical stress ${ }^{(23)}$, it is likely that the UM206-induced infarct remodeling earlier after $\mathrm{Ml}$ attenuated mechanical stress 5 weeks after $\mathrm{MI}$, and thereby reduced myofibroblast presence. This is in accordance with a recent study in swine showing that, in control infarcts myofibroblasts presence increased between 7 and 21 days of infarct, whereas treatment with a biocomposite material resulted in an increased myofibroblast presence 7 days after $\mathrm{MI}$, while myofibroblasts were lower at 21 days, at a time when LV dilation was reduced compared with control infarcts ${ }^{(10)}$. Importantly, it has been suggested that persistent myofibroblast presence in the injured heart, particularly in the remote non-infarcted myocardium, may be detrimental as it may lead to excessive fibrosis and contribute to heart failure ${ }^{(1,24)}$. It is therefore important to also evaluate changes in the remote myocardium. MMP-9 was decreased while TIMP-1 and collagen-3 were increased in the remote myocardium after MI, which is suggestive of increased interstitial fibrosis ${ }^{(1,13)}$, but UM206 treatment did not modulate this expression.

In humans, LV dilation was shown to correlate with circulating MMP-9 levels ${ }^{(25,26)}$. In our study, however, biological activity of early myofibroblast presence was not reflected in circulating levels of MMP-9 and TIMP-1, typical markers for collagen turnover. It is possible that the surgical trauma in combination with the chronic instrumentation of our animals evoked inflammatory and reparative processes that influenced the plasma levels of MMP-9, which may have masked the effect of the MI. Moreover, plasma levels of MMP-9 do not only reflect the increased expression of MMP-9 in the infarcted area but are also influenced by the decreased expression of MMP-9 in the remote-non-infarcted myocardium. Thus, it is likely that local measures for wound healing more accurately assess the wound-healing process as compared with circulating ones. Indeed, in contrast to the unaltered circulating plasma levels of 
MMP-9, MMP-9 mRNA tended to be higher in the infarcted myocardium of Control-MI as compared with UM206-treated swine 5 weeks after MI and correlated with infarct size, which is in accordance with the increased presence of myofibroblasts, and their role in modulation of the ECM. In combination with our observation that expression of collagens 1 and 3 was unaltered by UM206, the increased levels of MMP-9 in the Control-MI swine may have resulted in enhanced degradation of the ECM, which could have contributed to the LV dilation that occurred between 3 and 5 weeks after MI.

Almost all Fzd members have been identified in the healthy heart tissue but signaling in the adults is silent ${ }^{(20,24)}$. The Wnt/Fzd signaling pathway is activated in wound healing after $\mathrm{MI}^{(21,27)}$. In the present study, Wnt3a as well as Fzd receptor expression patterns were indeed different in remote vs. infarcted myocardium. Most of our findings regarding changes in activation of Wnt/Fzd signaling are in accordance with a recently published study in swine in which gene expression was evaluated using microarrays ${ }^{(28)}$. Thus, Fzd2 was increased, whereas Fzd4 was decreased in infarcted myocardium as compared with remote myocardium. Wnt3a was upregulated in the infarcted myocardium in the present study but downregulated in this previous study at 3 weeks after $\mathrm{MI}^{(28)}$, whereas unchanged at 6 weeks after $\mathrm{Ml}^{(28)}$. Also, downstream targets in the Wnt/Fzd signaling cascade were similarly affected by MI; Axin2 was decreased, whereas APC was unaltered ${ }^{(28)}$. UM206 treatment reduced the upregulation of Wnt3a in the infarcted tissue. As Wnt3a promotes myofibroblast differentiation ${ }^{(29)}$, this observation is in accordance with the presence of myofibroblasts that is reduced in UM206-treated as compared with Control-MI swine.

Although, in the present study, we focused on the effect of altering Wnt/Fzd signaling in myofibroblasts, it is possible that altering signaling in other cell types within the myocardium may have contributed to the beneficial effects of UM206. Wnt signaling has also been related to inflammation and angiogenesis ${ }^{(7)}$, and expression of Fzd4, a receptor that has been shown to be involved in stabilization of microvessels, was 
higher in animals treated with UM206 as compared with Control-MI. As microvessel stabilization is protective against microvascular regression in the maturation phase of $\mathrm{MI}$, the increased expression of Fzd4 may have contributed to the improved infarct healing.

\section{Conclusion}

Administration of the peptide fragment UM206 attenuates the dilation of the left ventricle after $\mathrm{Ml}$ in a translationally relevant swine model of ischemia-reperfusion. From this observation, we conclude that inhibition of Wnt/Fzd signaling has a beneficial effect on the wound healing after $\mathrm{MI}$, resulting in reduced adverse remodeling of the heart. Although the effects on cardiac function were limited at the 5-week time point, it is attractive to speculate that prolonged administration of UM206 will prevent the deterioration of the cardiac performance that is frequently observed after infarction.

\section{Acknowledgements}

We gratefully acknowledge technical assistance of A. Verzijl, S. Sneep, M. te Lintel Hekkert, L. Vervoort-Peters and L.A. Blonden. This study was partially supported by a grant from the Dutch Heart Foundation (2010B196), Den Haag, The Netherlands, Cyttron II (FES0908), and CTMM-TRIUMPH.

\section{Disclosure/Conflict of interest}

The authors declare no conflict of interest. 


\section{Supplementary Material}

Table S1 | Primer sequences and annealing temperatures used in the RT-qPCR

\begin{tabular}{|c|c|c|c|}
\hline $\begin{array}{l}\text { Sus Scrofa } \\
\text { gene }\end{array}$ & Forward primer & Reverse primer & $\begin{array}{l}\text { Annealing } \\
\text { Temperature } \\
\text { used }\left({ }^{\circ} \mathrm{C}\right)\end{array}$ \\
\hline$\beta$-Catenin & ATTGAAGCTGAGGGAGCCAC & ACTCCTAAAGGATGATTTACAGGTC & 62 \\
\hline Fzd2 & ATAGGCACGTCCTTCCTCCT & GACGGGTGTAGAACTTCСTCC & 62 \\
\hline Fzd4 & ACATGGGGCATTTCCAGGAG & TACAAGTCGCCTGGGTGAAC & 65 \\
\hline LRP5 & ACGTGATCGAGTTTGGCCTT & TGTTGTGCATGCAGTCGTTG & 65 \\
\hline LRP6 & CGTGCCAGTTGGAGGTTTTG & TCCGAAGGCTGTGGATAGGA & 62 \\
\hline APC & ACAAAACTGGAAACTGAGGCAT & CGGAGGGACATTTTTGACCG & 63 \\
\hline AXIN2 & CAAACCCATGCСTGTCTCСТ & CGGAAGAGATAAGCCCCGTC & 65.5 \\
\hline a SMA & GGACCCTGTGAAGCACCAG & GGGCAACACGAAGCTCATTG & 66.4 \\
\hline VEGF-A & GACCAGAAACCCCACGAAGT & AAATGCTTTCTCCGCTCCGA & 58 \\
\hline LOX & TCCAAGCTGGCTATTCGACG & AGGATTGTACGGGTCATCGC & 65 \\
\hline Tenascin-C & CACCCCGGTACTTGTTCCAT & CCTCGAAGGTGACAGTTGCT & 57 \\
\hline TGF $\beta 1$ & GTGGAAAGCGGCAACCAAAT & CACTGAGGCGAAAACCCTCT & 65 \\
\hline TGF $\beta 2$ & TGCCTGCGTCCACTTTACAT & AGCTGAGAACCCTGCTATGC & 62 \\
\hline TGF $\beta 3$ & ATGGAGAAGAAACCCAGAGCTT & TCCGACTCGGTGTTTTCCTG & 63.5 \\
\hline Col1a1 & AGACATCCCACCAGTCACCT & TCACGTCATCGCACAACACA & 62 \\
\hline Col3a1 & GCTCCCATCTTGGTCAGTCC & CCATCATTACCTCGAGCCCC & 63.5 \\
\hline MMP-2 & GCAGTGATGGCAAGTTGTGG & TTGACATCGTCGTGGGACAG & 65 \\
\hline MMP-9 & ACTTCGGAAACGCAAAAGGC & AAGAGTCTCTCGCTAGGGCA & 62 \\
\hline TIMP-1 & CTGGTCATCAGGGCCAAGTT & GGTCTGTCCACAAGCAGTGA & 63.5 \\
\hline Cyclophilin & AGACAGCAGAAAACTTCCGTG & AAGATGCCAGGACCCGTATG & 63.5 \\
\hline
\end{tabular}




\section{References}

1. Daskalopoulos EP, Hermans KC, Blankesteijn WM. Cardiac (myo)fibroblast: Novel strategies for its targeting following myocardial infarction. Current pharmaceutical design 2014;20(12):1987-2002.

2. Kloner RA, Jennings RB. Consequences of brief ischemia: stunning, preconditioning, and their clinical implications: part 1. Circulation 2001;104(24):2981-2989.

3. Kloner RA, Jennings RB. Consequences of brief ischemia: stunning, preconditioning, and their clinical implications: part 2. Circulation 2001;104(25):3158-3167.

4. Chen W, Frangogiannis NG. Fibroblasts in post-infarction inflammation and cardiac repair. Biochimica et biophysica acta 2013;1833(4):945-953.

5. Ma Y, de Castro Bras LE, Toba H, et al. Myofibroblasts and the extracellular matrix network in postmyocardial infarction cardiac remodeling. Pflugers Archiv : European journal of physiology 2014;466(6):1113-1127.

6. Turner NA, Porter KE. Function and fate of myofibroblasts after myocardial infarction. Fibrogenesis \& tissue repair 2013;6(1):5.

7. Hermans KC, Daskalopoulos EP, Blankesteijn WM. Interventions in Wnt signaling as a novel therapeutic approach to improve myocardial infarct healing. Fibrogenesis \& tissue repair 2012;5(1):16.

8. Porter KE, Turner NA. Cardiac fibroblasts: at the heart of myocardial remodeling. Pharmacology \& therapeutics 2009;123(2):255-278.

9. Hermans KC, Blankesteijn WM. Wnt Signaling in Cardiac Disease. Comprehensive Physiology 2015;5(3):1183-11209.

10. McGarvey JR, Pettaway S, Shuman JA, et al. Targeted injection of a biocomposite material alters macrophage and fibroblast phenotype and function following myocardial infarction: relation to left ventricular remodeling. The Journal of pharmacology and experimental therapeutics 2014;350(3):701-709.

11. Laeremans $\mathrm{H}$, Hackeng TM, van Zandvoort MA, et al. Blocking of frizzled signaling with a homologous peptide fragment of wnt3a/wnt5a reduces infarct expansion and prevents the development of heart failure after myocardial infarction. Circulation 2011;124(15):1626-1635.

12. Hermans KC DE, Janssen BJ and Blankesteijn W. Matthijs. UM206, a frizzled-receptor antagonist attenuates adverse remodeling and cardiac function deterioration following myocardial infarction. The FASEB Journal 2014;28(1 Supplement):652.610.

13. Shinde AV, Frangogiannis NG. Fibroblasts in myocardial infarction: a role in inflammation and repair. Journal of molecular and cellular cardiology 2014;70:74-82.

14. Boontje NM, Merkus D, Zaremba R, et al. Enhanced myofilament responsiveness upon betaadrenergic stimulation in post-infarct remodeled myocardium. Journal of Molecular and Cellular Cardiology 2011;50(3):487-499.

15. Zhou ZC, de Wijs-Meijler D, Lankhuizen I, et al. Blunted coronary vasodilator response to uridine adenosine tetraphosphate in post-infarct remodeled myocardium is due to reduced P1 receptor activation. Pharmacological Research 2013;77:22-29.

16. Kuster DWD, Merkus D, Kremer A, et al. Left ventricular remodeling in swine after myocardial infarction: a transcriptional genomics approach. Basic Research in Cardiology 2011;106(6):12691281.

17. van der Velden J, Merkus D, Klarenbeek BR, et al. Alterations in myofilament function contribute to left ventricular dysfunction in pigs early after myocardial infarction. Circulation research 2004;95(11):e85-95.

18. Uitterdijk A, Sneep S, van Duin RW, et al. Serial measurement of hFABP and high-sensitivity troponin I post-PCI in STEMI: how fast and accurate can myocardial infarct size and no-reflow be predicted? Am J Physiol Heart Circ Physiol 2013;305(7):H1104-1110.

19. van den Borne SW, van de Schans VA, Strzelecka AE, et al. Mouse strain determines the outcome of wound healing after myocardial infarction. Cardiovasc Res 2009;84(2):273-282. 
20. Daskalopoulos EP, Janssen BJ, Blankesteijn WM. Myofibroblasts in the infarct area: concepts and challenges. Microscopy and microanalysis : the official journal of Microscopy Society of America, Microbeam Analysis Society, Microscopical Society of Canada 2012;18(1):35-49.

21. Daskalopoulos EP, Janssen BJ, Blankesteijn WM. Targeting Wnt signaling to improve wound healing after myocardial infarction. Methods in molecular biology 2013;1037:355-380.

22. Frangogiannis NG, Michael LH, Entman ML. Myofibroblasts in reperfused myocardial infarcts express the embryonic form of smooth muscle myosin heavy chain (SMemb). Cardiovasc Res 2000;48(1):89-100.

23. Hinz B, Gabbiani G. Mechanisms of force generation and transmission by myofibroblasts. Current opinion in biotechnology 2003;14(5):538-546.

24. Lajiness JD, Conway SJ. Origin, development, and differentiation of cardiac fibroblasts. Journal of molecular and cellular cardiology 2014;70:2-8.

25. Kelly D, Cockerill G, Ng LL, et al. Plasma matrix metalloproteinase-9 and left ventricular remodelling after acute myocardial infarction in man: a prospective cohort study. European heart journal 2007;28(6):711-718.

26. Squire IB, Evans J, Ng LL, et al. Plasma MMP-9 and MMP-2 following acute myocardial infarction in man: correlation with echocardiographic and neurohumoral parameters of left ventricular dysfunction. Journal of cardiac failure 2004;10(4):328-333.

27. Daskalopoulos EP, Hermans KC, Janssen BJ, et al. Targeting the Wnt/frizzled signaling pathway after myocardial infarction: a new tool in the therapeutic toolbox? Trends Cardiovasc Med 2013;23(4):121-127.

28. Prat-Vidal C, Galvez-Monton C, Nonell L, et al. Identification of temporal and region-specific myocardial gene expression patterns in response to infarction in swine. PloS one 2013;8(1):e54785.

29. Carthy JM, Garmaroudi FS, Luo Z, et al. Wnt3a induces myofibroblast differentiation by upregulating TGF-beta signaling through SMAD2 in a beta-catenin-dependent manner. PloS one 2011;6(5):e19809. 


Chapter 5

\section{Variable effects of UM206 on the wound healing after myocardial infarction}

Kevin C.M. Hermans, Evangelos P. Daskalopoulos, Hilde Laeremans, Jacques J.M. Debets, Agnieszka E. Strzelecka, Peter J.A. Leenders, Helena T.M. Vervoort-Peters, Ben J.A. Janssen and W. Matthijs Blankesteijn 


\section{Abstract}

An inadequate wound healing following myocardial infarction (MI) is one of the main causes of heart failure. Therefore, interventions aimed at improving this process may help in preserving cardiac function after MI. In this overview, we compared the results of eight studies in which the effect of administration of a peptide fragment of Wnt5a, UM206, on infarct healing was investigated in a mouse model of MI. In the first two studies, beneficial effects on cardiac dimensions, ejection fraction and lung weight were observed in UM206-treated mice when compared to saline treatment. However, in the following studies no differences between UM206- and saline-treated mice could be detected for these parameters. Variations in dose of UM206, genetic background of the mice and the manufacturer of UM206 did not result in a restoration of the phenotype. An in-depth analysis of the data sets revealed that the absence of a protective effect of UM206 could be attributed to a lack of adverse cardiac remodeling and heart failure development in all experimental groups, including the saline-treated mice. This change in the phenotype of the MI model appeared to coincide with a transition of the housing of the mice from open cages to individually ventilated cages (IVC). This was likely to result in a lower exposure of the mice to inflammatory stimuli, because the exchange of micro-organisms between the cages and the environment was eliminated. There is increasing evidence that low-grade inflammation is a strong determinant of the outcome of many cardiovascular diseases, including MI. Therefore, the change in housing conditions is the most likely explanation for the disappearance of the heart failure phenotype in the MI model, thereby eliminating the potential for UM206 to show its beneficial effect on adverse cardiac remodeling. This conclusion is further supported by the beneficial effects observed for UM206 in a swine model of ischemia/reperfusion (Chapter 4 of this thesis) where the animals were housed under traditional housing conditions, similar to the first two mouse studies. 


\section{Introduction}

Heart failure is a devastating condition that frequently results from myocardial infarction (MI). The development of heart failure is generally thought to be the consequence of adverse cardiac remodeling ${ }^{(1)}$. Although the initial remodeling of the infarct area after $\mathrm{MI}$ is generally considered to be advantageous, excessive remodeling leads to dilatation of the entire left ventricle, having a negative effect on cardiac function ${ }^{(2)}$. This has resulted in the concept that interventions during / targeting wound healing after MI can be beneficial for cardiac function.

In the past decades, massive efforts have been made to study the wound healing process after MI, in order to identify novel therapeutic targets. Several pathways have been identified and tested in animal models ${ }^{(2)}$. Our lab has a longstanding interest in the role of Wnt signaling in cardiac remodeling following $\mathrm{MI}$ and the potential of this pathway for interventions to improve the wound healing. Following the initial description of the activation of Wnt signaling after $\mathrm{MI}^{(3)}$, several studies from other research groups and ourselves have shown beneficial effects of Wnt signaling-related interventions on the wound healing post- $\mathrm{MI}^{(4)}$, please refer also to Chapter 2 of this thesis. Our group has published data on an intervention with a peptide fragment of Wnt5a named UM206 in a mouse MI model ${ }^{(5)}$. In this study, subcutaneous administration of the peptide via an osmotic minipump resulted in smaller infarcts and higher myofibroblast numbers in the infarct area, when compared to saline infusion. This resulted in smaller end-diastolic volumes, improved cardiac function and decreased lung weights, all indicating that heart failure development was prevented in this relatively large group of animals.

Following this successful study, we decided to test variations in the dosage regimen and thus gain more insight into the cellular target(s) of UM206 and the phase(s) of the wound healing where the compound displays the most activity in order to shed more light on the exact mechanism. As described in this manuscript, we initially observed that interventions with UM206 starting at 2 weeks post-MI were almost as successful as administration of UM206 for five weeks following MI. However, after two positive 
studies the beneficial effect of UM206 appeared to be lost. In this manuscript we provide an overview of all available experimental data regarding the variable effects of UM206 on infarct healing. In the Discussion section, we address the possible causes of the loss of the phenotype of UM206 and provide recommendations for future experiments.

\section{Materials \& Methods}

\section{Materials}

UM206 was produced either by ChemPep Inc., Miami FL, USA (study A-D, G) or by Pepscan, Lelystad, The Netherlands (study E, F, H). UM206 is a 13 amino acid long peptide derived from an area of high homology between multiple Wnt molecules. It has a molecular weight of $1427 \mathrm{Da}$ and the following sequence: AcCNKTSEGMDGCEL-NH $\mathrm{NH}_{2}$. In previous experiments, this peptide was found to inhibit the Fzd-1 and -2 mediated canonical Wnt signaling induced by Wnt3a in vitro ${ }^{(5)}$. As can be deduced from this sequence, the two Cys residues present at position 1 and 11 can form a disulfide bond under oxidative conditions. This so-called 'circular' UM206 was found to have no inhibitory effect on the Fzd-1 and -2 mediated canonical Wnt signaling.

\section{Animal surgery and administration of UM206}

An overview of the executed studies can be found in Figure 1. Male Swiss mice were used (10-12 weeks of age at the start of the study) in all studies with the exception of study $\mathrm{F}$ where male BALB/C mice were used. The animals were supplied by Charles River, Leiden, The Netherlands, but in study D Swiss mice from Charles River and Harlan (Horst, The Netherlands) were compared to each other. Animals had free access to food and water. The UM206 compound was administrated via an osmotic minipump (Alzet 2002 or 2006 for 2 or 5 weeks of treatment, respectively; Durect, Cupertino, CA, USA). MI was induced, under isoflurane gas anesthesia (2.0-3.0\%) using a stereomicroscope (Leica MZ FL III, Leica Switzerland). For this purpose, animals were placed on a heating pad in supine position, endotracheal intubation was 
performed under direct laryngoscopy and mechanical ventilation was maintained with a small animal respirator (Hugo Sachs, MiniVent, tidal volume: 180-250 $\mu$, rate: 200250 breaths/min, depending on the strain). After thoracotomy, the lateral branch of LCA was ligated with a 6-0 prolene just proximal to the main bifurcation. Successful ligation was verified by visual inspection of the LV apex for myocardial blanching indicating interruption of the coronary blood flow. The chest cavity and skin were closed in layers with 5-0 polysorb sutures. Animals were gradually weaned from the respirator. All experimental procedures were approved by the Committee for Animal Research for Maastricht University.

\section{Echocardiography}

Left ventricular (LV) dimensions and function were assessed under isoflurane anesthesia. B-mode echocardiographic recordings were made in midpapillary shortaxis and parasternal long-axis using a Vevo2100 imaging platform (Visualsonics, Toronto, Canada). Data were derived from images in end diastole and peak systole and average values over at least three different cycles were used. From the long-axis images LV area (LVA), as well as the length of the LV lumen from base to apex (LVL) were determined. The end-diastolic volume (EDV) and end-systolic volume (ESV) were calculated from the area and length measurements as $\left(8 \times L V A^{2}\right) /(3 \pi \times L V L)$ in diastole and systole, respectively. Furthermore, ejection fraction (EF) was calculated as $100 \times((E D V-E S V) / E D V)$ (Description adapted from $\left.{ }^{(6)}\right)$.

\section{Hemodynamics}

Hemodynamic measurements were performed as described previously ${ }^{(7)}$. Briefly, mice underwent urethane anesthesia ( $2.5 \mathrm{mg} / \mathrm{kg}$ i.p.), then a high-fidelity catheter tip micromanometer (Mikro-tip 1.4F; SPR-671, Millar Instruments, Houston, TX, USA) was inserted through the right carotid artery into the left ventricular cavity. The heart was then stimulated by an i.v. ramp infusion of dobutamine (Sigma Aldrich, Saint Louis, MO, USA) using a microinjection pump (model 200 Series, Kd Scientific, Boston, MA, USA). Every 2 min the infusion rate of dobutamine was increased by 2.5 $\mathrm{ng} \times(\mathrm{g} \text { body weight })^{-1} \mathrm{~min}^{-1}$ up to $20 \mathrm{ng} \times(\text { g body weight })^{-1} \mathrm{~min}^{-1}$. 


\section{Histological analysis}

Histological analysis of the infarcted hearts was performed as previously described ${ }^{(8)}$. Briefly, the mouse hearts were longitudinally cut in half perpendicular to the septum, fixed in $4 \%$ paraformaldehyde solution for $24 \mathrm{hrs}$ and embedded in paraffin. Sections $(4 \mu \mathrm{m})$ were cut and stained with the AZAN technique. Infarct size (percentage of the left ventricular length) was measured using a computerized morphometry system (Qwin, Leica). Alpha smooth muscle actin (aSMA) monoclonal antibody (Sigma, dilution 1:1000) was used to identify myofibroblasts in the infarct area. The relative myofibroblast area was determined using the Qwin morphometry system with manual exclusion of vascular smooth muscle cells and expressed as myofibroblast area/total tissue area (\%).

\section{Statistical analysis}

Data are represented as mean \pm SEM. For comparisons of individual groups, Student's t-test was used. A P-value $<0.05$ (two-sided) was considered to be statistically significant. Comparisons of multiple groups were performed using oneway ANOVA with Dunnett's post-hoc test. Again, P-values $<0.05$ (two-sided) were considered to be statistically significant. All statistical analyses were performed using GraphPad software (version 5).

\section{Results}

\section{Overview of the studies}

In this overview, we present the results from eight different studies in which the effect of UM206 on infarct healing was assessed. UM206 was administered subcutaneously via an osmotic minipump at a dose of $6 \mu \mathrm{g} / \mathrm{kg}$ day, with the exception of study $\mathrm{H}$ where a higher dose was used. The dose of $6 \mu \mathrm{g} / \mathrm{kg}$ day was calculated by means of the half-life of $84 \pm 2$ minutes, determined previously in mice ${ }^{(5)}$. In all studies except for study $F$, Swiss mice were used as they show a strong tendency to develop LV dilatation and heart failure after $\mathrm{MI}^{(8)}$. In all studies, the administration of UM206 started either directly or after a specified period following the induction of MI. The 
dosage regimens are graphically represented in Fig. 1 where the UM206-treatment periods are shown in grey bars and the saline-treatment periods in light blue bars. In study A, infarct healing was followed for 5 weeks and UM206 was administered either for this entire period or during the first 2 or last 3 weeks. In study B and C, infarct healing was followed for 8 weeks with UM206 administered for the final 5 weeks (first 3 weeks were treatment-free). In study D, Swiss mice from two different suppliers (Charles River and Harlan) were subjected to a 5 week UM206 treatment (starting shortly after MI induction). In study E, the oxidized (circular) form of UM206 was administered whereas in all other studies the linear (reduced) form was applied. In study $F$, the influence of the genetic background was explored by using BALB/c rather than Swiss mice. Because UM206 obtained from different sources was used in the previous studies, UM206 from the supplier of study A and B (ChemPep) was used in study G. Finally, in study H UM206 was administered at a maximally soluble concentration of $150 \mu \mathrm{g} / \mathrm{kg} /$ day.

\begin{tabular}{|c|c|c|c|c|c|c|c|c|c|c|c|}
\hline $\begin{array}{l}\text { Week } \\
\text { Study }\end{array}$ & 1 & 2 & 3 & 4 & 5 & 6 & 7 & 8 & Date of experiment & Subject & $\begin{array}{c}\text { Source of } \\
\text { UM206 }\end{array}$ \\
\hline A & & & & & & & & & Mar 2009 - Feb 2010 & Original study & Chempep \\
\hline B & & & & & & & & & Sep 2011 - Mar 2012 & Effect of UM206 on infarct & Chempep \\
\hline \multirow{2}{*}{ c } & & & & & & & & & \multirow{2}{*}{ Apr 2013 - Jun 2013} & Effect of UM206 on infarct & \multirow{2}{*}{ Chempep } \\
\hline & & & & & & & & & & regression & \\
\hline \multirow{2}{*}{ D } & & & & & & & & & \multirow{2}{*}{ Sep 2012 - May 2013} & Comparison Swiss mice & \multirow{2}{*}{ Chempep } \\
\hline & & & & & & & & & & Charles River and Harlan & \\
\hline E & & & & & & & & & Jul 2013 - Aug 2013 & Test UM206 from Pepscan & Pepscan \\
\hline $\mathbf{F}$ & & & & & & & & & Jan 2014 - Apr 2014 & $\mathrm{BALB} / \mathrm{c}$ mice & Pepscan \\
\hline G & & & & & & & & & Jun 2014 - Jul 2014 & $\begin{array}{l}\text { UM206 from original } \\
\text { Chempep vial (study A) }\end{array}$ & Chempep \\
\hline H & & & & & & & & & Feb 2015 - Mar 2015 & High dose experiment & Pepscan \\
\hline
\end{tabular}

No treatment Saline UM206

End of study

Figure 1 | Schematic overview of the included studies.

This illustrates the treatment protocols with either UM206 (orange bars) or saline (blue bars). Periods where no treatment is administered are represented by grey bars. In total, data from 8 different studies were included in this overview. The dates of the studies, the specific subject of each study and the source of UM206 are indicated in the respective columns. 


\section{Effects of UM206 treatment on mortality and biometrical characteristics}

One of the most remarkable effects of the UM206-treatment in study A was the complete prevention of mortality post-MI. In Swiss mice, mortality due to heart failure is typically around $30 \%$ after 5 weeks $^{(8)}$, a figure that was confirmed in the saline-treated group in study A. An overview of the survival of the mice in all eight studies is provided in Table 1.

Heart and lung weight are two important indicators of the development of heart failure: An increased heart weight is an indicator for cardiac hypertrophy whereas an increased lung weight is the result of fluid retention in the lungs, a sign for a decreased pumping capacity of the heart. As shown in Fig. 2, a small but statistically significant decrease in heart weight was observed in the UM206-treated group compared to saline-treated controls in study A. However, this difference was only observed in the continuously treated animals, whereas both early and late treatment groups did not show this difference. In studies B-H, however, no differences in heart weight were observed. UM206 treatment also yielded significant reductions in lung weight in studies $A$ and $B$, albeit that these differences were only observed in the full 5-week treatment group in study A. Remarkably, in studies $\mathrm{C}-\mathrm{H}$ the weights of hearts and lungs in the saline-treated groups were significantly lower than those observed in study A, often even lower than the values observed in the UM206-treated animals in

Table 1 | Overview of the mortality of mice in all eight studies

\begin{tabular}{|c|c|c|c|c|c|c|}
\hline \multirow{3}{*}{$\begin{array}{r}\text { Study } \\
\text { A } \\
\text { B }\end{array}$} & \multicolumn{2}{|c|}{$\begin{array}{c}\text { \% Saline treated } \\
\text { (dead/total) }\end{array}$} & \multicolumn{2}{|c|}{$\begin{array}{l}\text { \% UM206 treated } \\
\text { (dead/total) }\end{array}$} & \multirow{2}{*}{\multicolumn{2}{|c|}{$\begin{array}{c}\text { \% Before treatment } \\
\text { (dead/total) }\end{array}$}} \\
\hline & $35 \%$ & $(6 / 17)$ & $0 \%$ & $(0 / 26)$ & & \\
\hline & $0 \%$ & $(0 / 6)$ & $0 \%$ & $(0 / 9)$ & $44 \%$ & $(11 / 25)$ \\
\hline C & $0 \%$ & $(0 / 6)$ & $14 \%$ & $(2 / 14)$ & $9 \%$ & $(2 / 22)$ \\
\hline$D$ & \multicolumn{2}{|c|}{ NA } & $5 \%$ & $(1 / 20)$ & \multicolumn{2}{|c|}{ NA } \\
\hline $\mathrm{E}$ & $0 \%$ & $(0 / 10)$ & $13 \%$ & $(1 / 8)$ & \multicolumn{2}{|c|}{ NA } \\
\hline $\mathrm{F}$ & $15 \%$ & $(2 / 13)$ & $0 \%$ & $(0 / 13)$ & \multicolumn{2}{|c|}{ NA } \\
\hline G & $0 \%$ & $(0 / 7)$ & $0 \%$ & $(0 / 4)$ & \multicolumn{2}{|c|}{ NA } \\
\hline $\mathrm{H}$ & $0 \%$ & $(0 / 6)$ & $0 \%$ & $(0 / 8)$ & $18 \%$ & $(3 / 17)$ \\
\hline
\end{tabular}

NA: Not applicable 
A

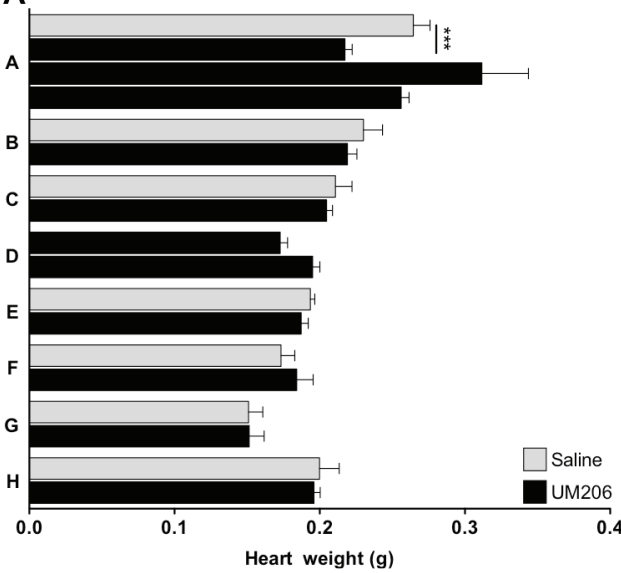

B

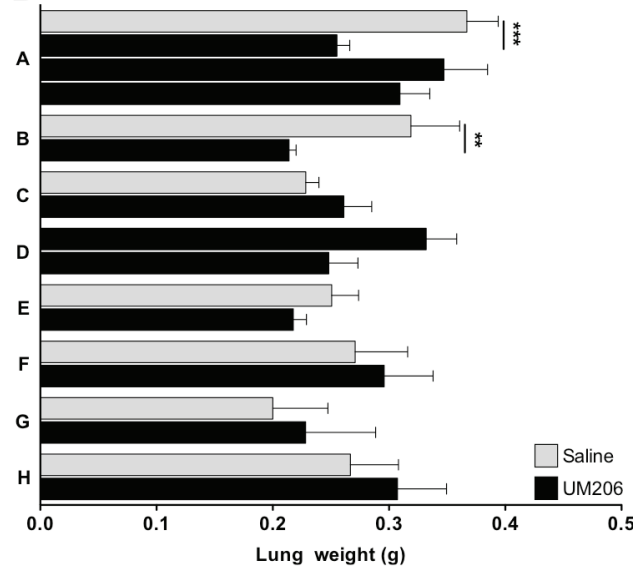

Figure $\mathbf{2}$ | Overview of the heart weights (A) and lung weights (B) observed in the different studies.

Data are presented as mean \pm SEM. In study A, UM206 only induced a significant reduction in heart and lung weight when administered for the entire duration of the protocol ( 5 weeks). A significant decrease in lung weight, but not in heart weight, was also observed in study B. Similar differences were observed when the organ weight was corrected for body weight. *: $\mathrm{P}<0.05 ;{ }^{* *}$ : $\mathrm{P}<0.01 ;{ }^{* * *}$ : $\mathrm{P}<0.001$. Please note the gradual decline of heart and lung weight in the saline groups over time (one-way ANOVA: $P<0.01$ )

studies A and B. Similar results were obtained when heart and lung weight were corrected for the body mass of the animals (data not shown). This suggests that only the animals in studies $A$ and $B$ showed overt heart failure development, whereas the other animals (studies $\mathrm{C}-\mathrm{F}$ ) remained in a compensated state during the course of the experiment.

\section{Overview of the echocardiographic data}

In all of the studies, 2D echocardiography was used to determine end-diastolic and end-systolic volumes (EDV and ESV, respectively) as well as the ejection fraction (EF). An overview of all the experimental data is provided in Fig. 3. In study A, a significantly reduced ESV and EDV was observed in animals treated either for the full 5 weeks or the last 3 weeks following MI, whereas administration at the first two weeks after MI did not result in significant improvements. A similar statistically significant beneficial effect of UM206 treatment on ESV, EDV and EF was observed in study B. In study C, however, the values for EDV and ESV in the saline-treated group were close to the UM206-treated values in study A and B. In studies D-H, EDV and ESV were similar to 



Figure 3 | Echocardiographic analysis of the left ventricular ESV and EDV.

In study $A$ and B, UM206 treatment induced significant reductions in both ESV (A) and EDV (B) whereas the ejection fractions (EF) were significantly increased (C). Unexpectedly, the EF in study $C$ showed the opposite pattern, whereas in studies $\mathrm{D}-\mathrm{H}$ no significant differences were observed in any of the parameters. *: $\mathrm{P}<0.05$; **: $\mathrm{P}<0.01 ; * * *: \mathrm{P}<0.001$.

the levels observed in the UM206-treated animals in study A in both saline and UM206-treated groups.

Significant improvement of the EF was observed in UM206-treated animals in studies $A$ and $B$. To our surprise, the EF was even significantly higher in the saline-treated group than in the UM206-treated group in study C. In studies D-H, no significant effects of UM206 were observed when compared to saline treatment.

\section{Hemodynamic measurements}

In all experiments, an assessment of the hemodynamic characteristics was performed at the end of the study, just before sacrificing the animals. Hemodynamic 

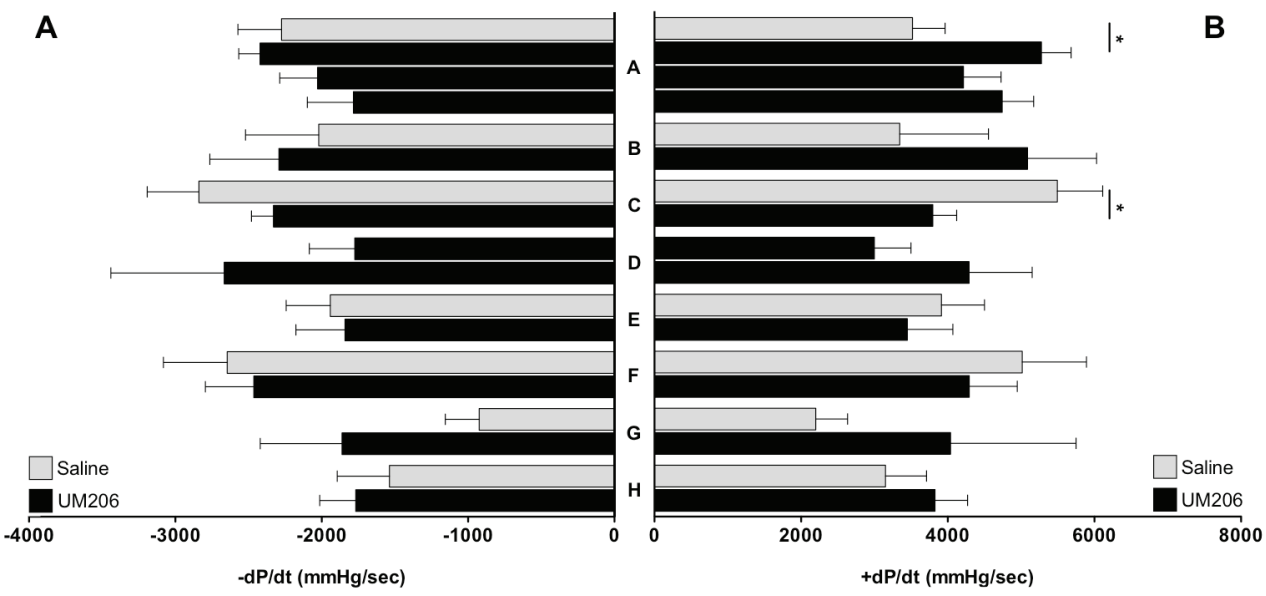

Figure 4 | Hemodynamic characteristics of the mice, maximally stimulated with dobutamine.

The bars represent the effect of dobutamine on the $\mathrm{dP} / \mathrm{dt}$ corrected for the baseline value $(\mathrm{dP} / \mathrm{dt}$ max $\mathrm{dP} / \mathrm{dt}$ baseline) of the $-\mathrm{dP} / \mathrm{dt}(\mathbf{A})$ and $+\mathrm{dP} / \mathrm{dt}$ (B). Please note that UM206 treatment only resulted in a significant increase in $+d P / d t$ in study $A$, whereas in study $C$ the opposite effect was observed. ${ }^{*}: P<0.05$.

characteristics were determined under baseline conditions ( $\mathrm{dP} / \mathrm{dt}$ baseline) and in the presence of increasing concentrations of dobutamine ( $\mathrm{dP} / \mathrm{dt}$ max), the maximal change in these parameters due to dobutamine administration is shown in Fig. 4. A significant improvement was observed for the change in +dP/dt max in the UM206treated group in study A, whereas study C showed the opposite effect. No significant differences were observed in the $-\mathrm{dP} / \mathrm{dt}$ values in any of the studies.

\section{Infarct characteristics}

For all animals included in this manuscript the infarct length was determined histologically and expressed as a percentage of the total ventricle area or circumference, respectively (Fig. 5). In none of the studies a difference in the \% infarct area was observed between UM206- and saline-treated animals. However, \% infarct length was smaller in the full UM206 treatment group in study A, indicating a reduced dilatation of the infarct. This observation could not be confirmed in any of the other studies. In study A, the smaller \% infarct length was accompanied by a $\sim 4-$ fold increase in the relative myofibroblast count (in the infarct area) in the group treated with UM206 for the full 5 weeks. Significant increases in this parameter were 

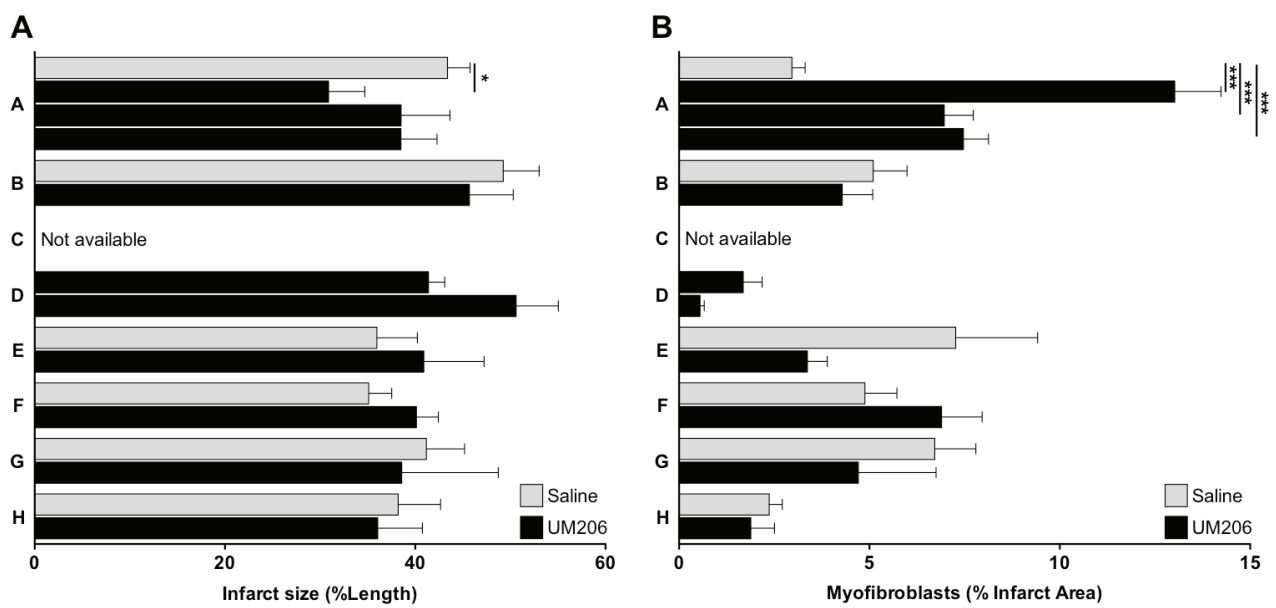

Figure 5 | Effect of UM206 treatment on the histological characteristics of the infarcts. In study A, UM206 treatment resulted in a significant decrease in infarct length (A), paralleled by a profound increase in the \% myofibroblasts in the infarct area (B). These results could not be confirmed in the other studies. *: $\mathrm{P}<0.05$.

found in the groups that were treated for the first two or the last three weeks in study A, albeit the increases in this parameter were relatively small compared to the full 5week treatment. The relative myofibroblast area was also determined in studies B and $\mathrm{D}-\mathrm{H}$ but in none of these studies significant differences were observed for this parameter between UM206- and saline-treated animals.

\section{Discussion}

In this manuscript we provide an overview of eight consecutive studies on the effects of UM206 on the wound healing after MI, performed in our laboratory. In the first study (study A), a strong protective effect of this treatment was observed on adverse cardiac remodeling, as illustrated by less dilatation of the left ventricle, improved cardiac function and lower lung weights as well as improved survival ${ }^{(5)}$. This beneficial effect of UM206 treatment on infarct healing could be confirmed in study B, although the increase in myofibroblast numbers could not be reproduced. From study $C$ on, no significant differences have been observed in the infarct healing UM206-treated groups compared to saline-treated controls. In this context, it is of interest to note that both in rat (unpublished observations) and porcine models of myocardial 
infarction, beneficial effects on infarct size and geometry have been observed; the results obtained in the porcine $\mathrm{MI}$ model are presented in Chapter 4 of this thesis.

In the original data set from study A, 6 out of 26 animals that received the full 5 week UM206 treatment did not show macroscopic signs of myocardial damage at sacrifice. At that time, we attributed this to the effect of the intervention with UM206 on infarct healing, because all of the 13 saline-treated controls did show macroscopically visible infarcts. Therefore, the data of these 6 animals were included in the statistical analysis of the effects of UM206 treatment on echocardiographic and hemodynamic parameters are shown in Fig 2-4. A re-evaluation of the dataset from which these 6 animals are excluded revealed that a significant effect of UM206 treatment was still observed for heart weight, lung weight, EF, ESV and EDV; however, exclusion of these data resulted in loss of statistical significance for positive and negative $\mathrm{dP} / \mathrm{dt}$.

Irreproducibility of experimental data is a major issue in biomedical sciences. Researchers from the pharmaceutical companies Bayer and Amgen have systematically investigated this issue and found that the results of $75-91 \%$ of published experimental studies could not be reproduced in their own laboratories ${ }^{(9,10)}$. This illustrates that we are dealing with a considerable number of variables that are difficult to control, but that are of paramount importance for the outcome of an experiment. It is quite evident that when one is confronted with a discrepancy between subsequent studies, a scrutinous comparison of the experimental conditions is executed to identify potential differences. First of all, the surgical team that performed the operations is highly experienced and has not changed over the years so this is an unlikely factor. Originally, the Swiss mice were obtained from Charles River, but in order to exclude a possible effect of the genetic background we also tested Swiss mice from Harlan (study D) as well as BALB/c mice (study F), with similar results. This excludes the animals and the surgery as a plausible source of the variation in the effects of UM206.

Another variable that we addressed was the source of UM206. In studies A-D and G, we made use of UM206 produced by ChemPep (Miami, FL, USA) but we also tried 
UM206 produced by Pepscan (Lelystad, the Netherlands) in studies E, F and $\mathrm{H}$. No consistent differences in effects were observed between the peptides produced by these two companies, which is in agreement with the identical analytical data sheets provided with the compounds.

Since UM206 is a peptide of 13 amino acids with two Cys residues located at positions 1 and 11 , the peptide can form an internal disulfide bond when it is placed under oxidative conditions. Alternatively, dimeric or even multimeric complexes can also be - theoretically - formed, although this obviously is more likely when the compound is dissolved at a high concentration. Given the low concentration of UM206 in the minipumps, the formation of multimers is unlikely. In vitro incubation of UM206 in osmotic minipumps under oxidative conditions revealed that virtually all of the UM206 will have formed disulfide bonds, mostly the internal variant, within 24 hours (personal communication Dr. Nicolas Dailly and Dr. Peter Timmerman, Pepscan Lelystad). In previous in vitro studies, we have found the oxidized form of UM206 to be inactive as an antagonist, so this could explain the lack of effect observed in studies $\mathrm{C}-\mathrm{H}$. However, then the question remains unanswered how the compound was administered in the active form in studies $A$ and $B$ as well as in the rat and swine studies, but in the inactive form in studies $\mathrm{C}-\mathrm{H}$.

A third issue is the position of the UM206 peptide in the Wnt/frizzled complex. The crystal structure of the XWnt8/Fzd8 cysteine-rich domain was published recently ${ }^{(11)}$, showing that it is unlikely that the loop of the Wnt protein where UM206 is derived from is in direct physical contact with the frizzled protein (fig. 1 in Chapter 2 of this thesis for details). This finding obscures the pharmacological mechanism of action of this peptide. In the meantime, several researchers have provided evidence that Wnt and frizzled interact in a complex with other proteins, including the co-receptor LRP5 $/ 6^{(12)}$, and it is quite likely that UM206 interferes somehow with this complex formation. We cannot exclude that variations in the components involved in the formation of this complex determine the effectiveness of UM206, but it is unclear how this could have changed over time. 
A remarkable observation in the current set of experimental data is that the lung weights in the saline-treated animals in studies $A$ and $B$ are considerably higher than the lung weights in studies $\mathrm{C}-\mathrm{H}$, despite similar infarct lengths (see Fig. 5a). This suggests that overt heart failure induced by myocardial infarction was only present in the first two studies, but that the cardiac remodeling was less severe in the latter six ones. It is quite obvious that a therapy aiming at preventing adverse cardiac remodeling is ineffective when this adverse remodeling does not take place. This raises the question whether there have been any changes in the experimental conditions between the first two and the latter six studies that could explain these deviating outcomes. In this respect, the transition from housing of the mice in open cages to housing in individually ventilated cages (IVC) that took place between study $B$ and $C$ could be of relevance. IVC housing of rats was shown to reduce the exposure to ammonia and $\mathrm{CO}_{2}$ and to improve the integrity of the airway epithelium ${ }^{(13)}$. When translated to our experimental situation, this change in housing conditions may mean that exposure to pro-inflammatory stimuli is reduced under IVC conditions. It is generally accepted that cardiac ischemia invokes an inflammatory response in the infarct area ${ }^{(14)}$. Toll-like receptors can recognize the presence of pathogens in the body, but also play an essential role in the sterile inflammatory response following cardiac injury $^{(15)}$, suggesting an amplifying effect of exposure to external pathogens on adverse cardiac remodeling after MI. Recent studies have confirmed that the lowgrade inflammation present in e.g. periodontal disease has a marked adverse effect on the cardiac remodeling after $\mathrm{MI}^{(16,17)}$. This may imply that the reduced exposure to pro-inflammatory stimuli of IVC-housed mice attenuated the development of heart failure post-MI, thereby eliminating the potential therapeutic gain that could be obtained with UM206. In this context it is relevant to note that the housing conditions of the rat and swine studies that showed beneficial effects of UM206 best resembled the open cage housing conditions used in the first mouse studies. Due to the institutional policy of our Animal Facility, repeating the experiment in open cages can be performed no more. 
Alterations in phenotypes of animal models due to changes in housing conditions have been reported by other authors. Ventilated caging systems have been shown to reduce the ambient oxygen concentration for up to $0.5 \%$, which is associated with alterations in blood cell composition that is indicative for chronic exposure to hypoxia $^{(18)}$. Effects on mouse social behavior have also been reported and demonstrate that IVC housing increases anxiety related behavior ${ }^{(19,20)}$. In addition, severity of the anxiety related behavior seems to be variable across different IVC systems, depending on the amount of air changes per hour ${ }^{(21)}$. These observations underscore the importance of the housing conditions on the phenotype of animal models and that it can cause a serious bias in research data between different studies.

In conclusion, the most plausible explanation for the discrepancies in effectiveness of UM206 between the different studies included in this overview is that a change in the housing conditions has modified the characteristics of the animal model that was used to investigate the therapeutic benefit of this compound. This raises the fundamental question how one should choose the conditions for animal experiments in order to be predictive for human disease. Standardization with respect to age, gender, genetic background and housing was generally believed to reduce experimental 'noise' and improve reproducibility. However, it has now become increasingly clear that the translation of data from such standardized studies to the heterogeneous - clinical practice may be complex or even impossible. This has induced a counter-movement towards more variation in animal models to provide much higher relevance for clinical practice ${ }^{(22)}$. In this respect, the trend of animal facilities towards an as-low-as-possible and strongly standardized pathogen status should be monitored with caution as this deviates more and more from the daily clinical practice that the animal models aim to reflect. 


\section{References}

1. McMurray JJ, Pfeffer MA. Heart failure. Lancet. 2005;365(9474):1877-89.

2. Daskalopoulos EP, Hermans KC, Blankesteijn WM. Cardiac (myo)fibroblast: Novel strategies for its targeting following myocardial infarction. Curr Pharm Des. 2014;20(12):1987-2002.

3. Blankesteijn WM, Essers-Janssen YPG, Verluyten MJA, Daemen MJAP, Smits JFM. A homologue of Drosophila tissue polarity gene frizzled is expressed in migrating myofibroblasts in the infarcted rat heart. Nature medicine. 1997;3:541-4.

4. Hermans KC, Blankesteijn WM. Wnt Signaling in Cardiac Disease. Compr Physiol. 2015;5(3):118311209.

5. Laeremans H, Hackeng TM, van Zandvoort MA, Thijssen VL, Janssen BJ, Ottenheijm HC, et al. Blocking of frizzled signaling with a homologous peptide fragment of wnt3a/wnt5a reduces infarct expansion and prevents the development of heart failure after myocardial infarction. Circulation. 2011;124(15):1626-35.

6. Heijnen BF, Pelkmans LP, Danser AH, Garrelds IM, Mullins JJ, De Mey JG, et al. Cardiac remodeling during and after renin-angiotensin system stimulation in Cyp1a1-Ren2 transgenic rats. J Renin Angiotensin Aldosterone Syst. 2014;15(1):69-81.

7. De Celle T, Vanrobaeys F, Lijnen P, Blankesteijn WM, Heeneman S, Van Beeumen J, et al. Alterations in mouse cardiac proteome after in vivo myocardial infarction: permanent ischaemia versus ischaemia-reperfusion. Exp Physiol. 2005;90(4):593-606.

8. van den Borne SW, van de Schans VA, Strzelecka AE, Vervoort-Peters HT, Lijnen PM, Cleutjens JP, et al. Mouse strain determines the outcome of wound healing after myocardial infarction. Cardiovascular research. 2009;84(2):273-82.

9. Prinz F, Schlange T, Asadullah K. Believe it or not: how much can we rely on published data on potential drug targets? Nature reviews Drug discovery. 2011;10(9):712.

10. Begley CG, Ellis LM. Drug development: Raise standards for preclinical cancer research. Nature. 2012;483(7391):531-3.

11. Janda CY, Waghray D, Levin AM, Thomas C, Garcia KC. Structural basis of Wnt recognition by Frizzled. Science. 2012;337(6090):59-64.

12. Joiner DM, Ke J, Zhong Z, Xu HE, Williams BO. LRP5 and LRP6 in development and disease. Trends Endocrinol Metab. 2013;24(1):31-9.

13. Teixeira MA, Chaguri LC, Carissimi AS, Souza NL, Mori CM, Saldiva PH, et al. Effects of an individually ventilated cage system on the airway integrity of rats (Rattus norvegicus) in a laboratory in Brazil. Lab Anim. 2006;40(4):419-31.

14. Frangogiannis NG. Regulation of the inflammatory response in cardiac repair. Circ Res. 2012;110(1):159-73.

15. Hofmann U, Ertl G, Frantz S. Toll-like receptors as potential therapeutic targets in cardiac dysfunction. Expert Opin Ther Targets. 2011;15(6):753-65.

16. DeLeon-Pennell KY, de Castro Bras LE, lyer RP, Bratton DR, Jin YF, Ripplinger CM, et al. P. gingivalis lipopolysaccharide intensifies inflammation post-myocardial infarction through matrix metalloproteinase-9. Journal of molecular and cellular cardiology. 2014;76:218-26.

17. Hanatani T, Suzuki J, Ogawa M, Aoyama N, Kobayashi N, Hirata Y, et al. The periodontal pathogen Aggregatibacter actinomycetemcomitans deteriorates ventricular remodeling after myocardial infarction in mice. Int Heart J. 2012;53(4):253-6.

18. York JM, McDaniel AW, Blevins NA, Guillet RR, Allison SO, Cengel KA, et al. Individually ventilated cages cause chronic low-grade hypoxia impacting mice hematologically and behaviorally. Brain, behavior, and immunity. 2012;26(6):951-8.

19. Logge W, Kingham J, Karl T. Behavioural consequences of IVC cages on male and female C57BL/6J mice. Neuroscience. 2013;237:285-93. 
20. Mineur YS, Crusio WE. Behavioral effects of ventilated micro-environment housing in three inbred mouse strains. Physiology \& behavior. 2009;97(3-4):334-40.

21. Burman O, Buccarello L, Redaelli V, Cervo L. The effect of two different Individually Ventilated Cage systems on anxiety-related behaviour and welfare in two strains of laboratory mouse. Physiology \& behavior. 2014;124:92-9.

22. Richter SH, Garner JP, Wurbel H. Environmental standardization: cure or cause of poor reproducibility in animal experiments? Nat Methods. 2009;6(4):257-61. 




\section{Chapter}

\section{Multiple-constrained peptide mimetics of Wnt inhibit canonical Wnt signaling}

Kevin C.M. Hermans, Ana I. Fernández-Llamazares, Nicole Kriek, Nicolas Dailly, W. Matthijs Blankesteijn and Peter Timmerman 


\section{Abstract}

Wnt signaling is involved in various developmental processes but is usually silent in healthy adult tissues. However, a reactivation of this signaling pathway is generally observed during pathological conditions such as cardiovascular diseases or cancer. Compounds that can interfere between Wnt and its receptor Frizzled (Fzd) are potential therapeutics to treat such diseases. The crystal structure of Xenopus Wnt8 in complex with the cysteine rich domain (CRD) of Fzd8 demonstrates that Wnt contacts the Fzd CRD at two opposing sites via its $\beta$-loop extensions also known as the thumb (which is palmitoylated at the tip) and index finger. These $\beta$-loop extensions are stabilized by several intra-loop disulfide bonds between conserved cysteines. Based on this knowledge, a library of peptides, derived from the native human Wnt3a and Wnt5a sequences, was synthetically produced and cyclized via a CLIPS scaffold to mimic these $\beta$-loop extensions. Peptide mimics of both thumb and index finger were able to inhibit Wnt3a induced Wnt/Fzd signaling in an in vitro reporter assay with an $\mathrm{IC}_{50}$ in the micromolar range. The sequence length of the peptide as well as palmitoylation of the thumb fragment on the native $\mathrm{Ser}^{209}$ position (in Wnt3a) and finally the presence of a synthetic CLIPS scaffold all influenced the antagonistic potency of these peptides. Mutation of the conserved cysteines also affected the antagonistic capacity in a positive or negative way. In an attempt to improve the antagonistic effect, thumb and index finger peptides were administered simultaneously; this only resulted in an additive rather than a synergistic effect. These findings demonstrate that peptides derived from the Wnt-sequences that are known to interact with the Fzd CRD can form the basis for antagonists to inhibit Wnt/Fzd signaling. 


\section{Introduction}

Wnt signaling is involved in many processes, such as control of cell division, tissue patterning and cell fate specification during embryonic development ${ }^{(1)}$. It is mainly silent in healthy adult tissues, but a reactivation of Wnt signaling is often observed during pathological conditions. Signaling is commonly activated by binding of Wnt to Frizzled (Fzd), which initiates multiple (complex) downstream signaling pathways. At least three different Wnt signaling pathways have been described, i.e. the calcium, the Rho/c-jun N-terminal kinase, and the - best studied - $\beta$-catenin pathway, which is also known as the canonical pathway and uses $\beta$-catenin as second messenger (see Chapter 2 for further details). Wnts are 350-400 amino acids in size and have a conserved pattern of 22-24 cysteines. They are post-translationally palmitoylated on a serine residue at the $\mathrm{N}$-terminal side that makes them hydrophobic. This modification is critical for both the secretion and signaling activity of the protein ${ }^{(2-4)}$. The crystal structure of Xenopus Wnt8 in complex with the cysteine-rich domain (CRD) of Fzd8 demonstrates an exceptional architecture of the Wnt protein, in which disulfide bonds between the conserved cysteines play an important role (Figure 1). The structure of Wnt resembles the outline of a hand with a thumb and index finger grasping the Fzd CRD at two opposing sites. This unusual three-dimensional structure is unknown for any other ligand-receptor interaction. The thumb at the $\mathrm{N}$-terminal site contains a palmitic or palmitoleic acid at the tip that engages a groove on the CRD. The index finger at the $\mathrm{C}$-terminal domain is characterized by a 38 amino acid long $\beta$-strand hairpin, which is stabilized by several disulfide bonds between conserved cysteines, including a vicinal disulfide bond at the tip of the finger. The index finger forms a strong hydrophobic contact with a groove on the opposite side of the CRD ${ }^{(2)}$. This interaction between Wnt and the CRD of Fzd leaves a gap with conformational plasticity in the center of the complex that could be involved in dimerization of Fzd proteins or binding to the LRP co- 
receptors and therefore might be important for the activation of Wnt/Fzd signaling as well ${ }^{(5,6)}$.

To date several compounds have been identified to target Wnt/Fzd signaling at different levels of the pathway ${ }^{(7,8)}$, although to our knowledge no substance has been described that interferes with the interaction between Wnt and Fzd. Previously, our lab has developed a peptide fragment of Wnt5a, named UM206, that was able to block Fzd-1 and -2 signaling both in an in vitro and in vivo model ${ }^{(9)}$. However, aligning this peptide sequence with the crystal structure of Wnt demonstrates that Wnt does not interact with Fzd at this site (Figure 1), and therefore its exact mechanism of action has not been established yet.

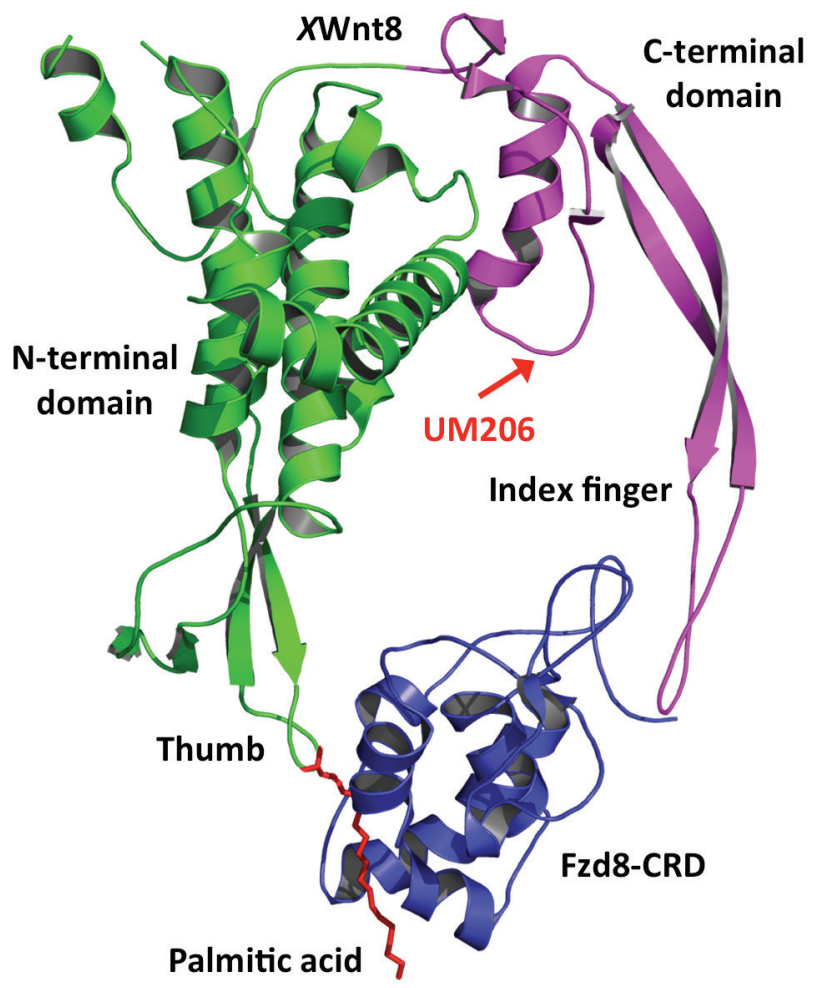

Figure 1 | Crystal structure of Xenopus Wnt8 bound to the cysteine rich domain (CRD) of Fzd8.

The shape of the Wnt protein mimics the palm of a hand with an index finger at the C-terminal domain and a thumb and the $\mathrm{N}$-terminal domain. The index finger and the palmitic acid both are in contact with the CRD. Aligning the sequence of UM206 with the native protein illustrates that it does not interact with the Fzd CRD. (Adapted from ${ }^{(2,10)}$ ) 
In search for new antagonists that can block the interaction between Wnt and

Fzd, we synthesized peptide loops mimicking the ends of the thumb and index finger of the Wnt3a/5a protein, with the rationale that these peptides can compete with the binding site of Wnt3a/5a on the CRD of Fzd-1/2. In the current study it was therefore hypothesized that these peptides can serve as antagonists of canonical Wnt signaling in vitro.

\section{Materials \& Methods}

\section{Synthesis of the Wnt mimicking peptides}

\section{Abbreviations}

ACN: acetonitrile; Acm: acetamidomethyl; CLIPS: chemical linkage of peptides onto a scaffold; Dap: 2,3-diaminopropionic acid; DMF: N,N-dimethylformamide; DMSO: dimethylsulfoxide; DTT: 1,4-dithiothreitol; Fmoc/tBu: 9-fluorenylmethoxycarbonyl/ tert-butyl; HPLC: high performance liquid chromatography; SS-bond: disulfide bond; TFA: trifluoroacetic acid; TCEP: tris(2-carboxyethyl)phosphine; UPLC-MS: ultra performance liquid chromatography coupled to mass spectrometry.

\section{General}

The peptides (Table 1) were synthesized at Pepscan Therapeutics B.V. in Lelystad, The Netherlands. Every peptide was characterized by its molecular weight and its reverse-phase UPLC retention time. The molecular weights of the peptides were determined by Electro Spray lonization Mass Spectrometry (ESI-MS), and does not include the associated TFA counter-ions.

\section{Synthetic approach}

For the synthesis of the SS-folded CLIPS-cyclized Wnt3a- and Wnt5a-derived peptides, a non-regioselective approach was followed. In this approach, the Acm group was employed to protect those Cys to be connected via an SS-bond. The approach involved 3 steps. First, the linear precursor of the target peptide was prepared by automated Fmoc/tBu solid-phase peptide synthesis. Next, this linear 
precursor was cyclized via Cys-attachment onto the bivalent CLIPS scaffold. Finally, the Acm groups were removed under oxidative conditions $\left(I_{2}\right)$. In this last synthetic step, all the SS-bonds of the peptide are formed concomitantly, which can offer several SS-bond isomers of unknown SS-bond pattern. For every target peptide, the SS-bond isomeric products formed were isolated to be tested separately.

\section{Instrumental methods}

UPLC-MS analysis was performed on a Waters instrument comprising a reversephase C18 column (50x2.1 $\mathrm{mm} 1.7 \mu \mathrm{m}$ particle size), an automatic injector, a separation module, a photodiode array detector, and an ESI mass detector. Typically, the sample to be analyzed was dissolved in either $\mathrm{DMSO}, \mathrm{H}_{2} \mathrm{O}, \mathrm{ACN}$, or any possible mixture of these solvents, and injected into the machine. A linear gradient of ACN $(+0.05 \%$ TFA $)$ into $\mathrm{H}_{2} \mathrm{O}(+0.05 \%$ TFA) was run with an $0.1 \mathrm{~mL} / \mathrm{min}$ flow rate, starting at $5 \% \mathrm{ACN}$ and with an increase of $25 \% \mathrm{ACN} / \mathrm{min}$. Such linear gradient was run for 2 or 3 min. UV detection was performed at $215 \mathrm{~nm}$. MS data was acquired using the positive ion mode. Data were managed with Waters MassLynx software. Preparative HPLC purification was performed on a Waters' instrument comprising a reverse-phase C18 column, a manual injector, a separation module, a UV detector, and a potentiometric recorder. Depending on the amount of crude peptide to be purified, a smaller $(150 \times 20$ $\mathrm{mm})$ or a larger $(120 \times 40 \mathrm{~mm}) \mathrm{C} 18$ column was used. The smaller C18 column was used for purifying crude products in less than $100 \mathrm{mg}$ amount, whereas the larger C18 column was used for purifying crude products in more than $100 \mathrm{mg}$ amount. Typically, the sample to be purified was dissolved in DMSO, in $\mathrm{H}_{2} \mathrm{O}$, or in a DMSO/ $\mathrm{H}_{2} \mathrm{O}$ mixture, and injected into the apparatus. A linear gradient of ACN (+0.05\% TFA) into $\mathrm{H}_{2} \mathrm{O}$ $(+0.05 \%$ TFA) was run at a of 30 or $60 \mathrm{~mL} / \mathrm{min}$ flow rate (depending on the column used). Such linear gradient was run for $20 \mathrm{~min}$, and the $\% \mathrm{ACN}$ was increased at a rate of $25 \% \mathrm{ACN} / \mathrm{min}$. UV detection was performed at $215 \mathrm{~nm}$. The collected fractions were analyzed by UPLC-MS, and those of interest were lyophilized. Lyophilized fractions were pooled together (depending on their purity), and lyophilized again. 


\section{Synthetic procedures}

Synthesis of the bivalent CLIPS scaffold was performed as described previously ${ }^{(11)}$. General procedure for cyclizing the peptide onto the bivalent CLIPS scaffold. The linear peptide (1.0 equiv.) was dissolved in $\mathrm{ACN} / \mathrm{H}_{2} \mathrm{O} 1: 3$ at a $0.5 \mathrm{mM}$ concentration. The resulting solution was sonicated for $10 \mathrm{~min}$. Then, the bivalent CLIPS scaffold (1.25 equiv., withdrawn from a $0.1 \mathrm{M}$ solution in $\mathrm{ACN} / \mathrm{H}_{2} \mathrm{O} 1: 1$ ) was added, followed by $\mathrm{NH}_{4} \mathrm{HCO}_{3}$ (300 equiv.,). The $\mathrm{pH}$ of the resulting mixture was checked to be above 7.8. After stirring for $1 \mathrm{~h}$ at room temperature, the mixture was analyzed by UPLC-MS. If starting material was still present, TCEP (1.0 equivalent), and an additional 1.0 equivalent of bivalent CLIPS scaffold were added, and the mixture was stirred for another $1 \mathrm{~h}$. Once the reaction was complete (UPLC-MS), it was quenched by adding $10 \%$ TFA until $\mathrm{pH}<4$. The mixture was frozen and lyophilized. The crude product was purified by preparative HPLC. [Note: For certain linear peptides that were not soluble in $\mathrm{ACN} / \mathrm{H}_{2} \mathrm{O}$ mixtures, the reaction was performed in $\mathrm{DMF} / \mathrm{H}_{2} \mathrm{O}$ ].

General procedure for Cys(Acm)-removal with concomitant SS-bond formation. The peptide (1.0 equiv.) was dissolved in DMSO at $10 \mathrm{mM}$ concentration, and 8 volumes of $\mathrm{MeOH}$ were added (affording a $1.1 \mathrm{mM}$ peptide solution in $\mathrm{DMSO} / \mathrm{MeOH} 1: 8$ ). To this solution, $\mathrm{I}_{2}$ (1.3 equiv., withdrawn from a $34 \mathrm{mg} / \mathrm{mL} \mathrm{I}$ solution in $\mathrm{MeOH}$ ) was added, and the $\mathrm{pH}$ of the mixture was checked to be $<6$. The reaction was allowed to proceed at room temperature. To monitor the reaction by UPLC-MS, an aliquot of the reaction mixture was taken, DTT (withdrawn from a $7.2 \mathrm{mg} / \mathrm{mL}$ DTT aqueous solution) was added until the solution became colorless, excess of a $200 \mathrm{mM} \mathrm{NH}_{4} \mathrm{HCO}_{3}$ solution was added, and the resulting solution was analyzed. Upon completion, the reaction was quenched as described above. The solvent was removed under reduced pressure, and the resulting residue was purified by preparative HPLC. The main SS-bond isomeric products formed were separated by prep. HPLC and all isolated in order to be tested separately. 
Table 1 | Peptide Library

\begin{tabular}{|c|c|c|c|c|}
\hline & $\#$ & Wnt3a & \# & Wnt5a \\
\hline \multirow{15}{*}{ 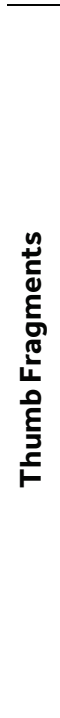 } & $\mathbf{N}$ & ${ }^{199}$ MHLKCKCHGLSGSCEVKTCWWSQ ${ }^{221}$ & $\mathbf{N}$ & ${ }^{234}$ ADVACKCHGVSGSCSLKTCWLQL ${ }^{256}$ \\
\hline & $\mathrm{T} 1$ & AC-CHLKCKCHGL2GSCEVKTCWWSC-NH & $\mathrm{T} 15$ & AC-CDVACKCHGV2GSCSLKTCWLQC-NH \\
\hline & $\mathrm{T} 2$ & AC-CHLKCKCHGLSGSCEVKTCWWSC-NH & T16 & AC-CDVACKCHGVSGSCSLKTCWLQC-NH \\
\hline & T3 & Ac-CLKCKCHGL2GSCEVKTCWWC-NH 2 & T17 & Ac-CVACKCHGV2GSCSLKTCWLC-NH 2 \\
\hline & T4 & Ac-CKCKCHGL2GSCEVKTCWC-NH 2 & T18 & Ac-CACKCHGV2GSCSLKTCWC-NH 2 \\
\hline & T5 & AC-CKAKCHGL2GSCELKTAWC-NH 2 & T19 & Ac-CCKCHGV2GSCSLKTCC-NH 2 \\
\hline & T6 & Ac-CKCKAHGL2GSAELKTCWC-NH & $\mathrm{T} 20$ & Ac-CKCHGV2GSCSLKTC-NH \\
\hline & T7 & Ac-CKSKSHGL2GSSEVKTSWC-NH & $\mathrm{T} 21$ & Ac-CKCHGVSGSCSLKTC-NH \\
\hline & T8 & Ac-CKSKSHGL2GSSEVKTSWC-NH & $\mathrm{T} 22$ & Ac-CKCHGV2GSCSLKTC-NH \\
\hline & T9 & AC-CKCHGL2GSCEVKTCC-NH 2 & & \\
\hline & T10 & Ac-CKCHGL2GSCEVKTC-NH 2 & & \\
\hline & T11 & AC-CKCHGLSGSCEVKTC-NH 2 & & \\
\hline & T12 & AC-CKCHGL2GSCEVKTC-NH 2 & & \\
\hline & T13 & Ac-CLCKEH2TGCVSKGC-NH 2 & & \\
\hline & T14 & Ac-CLC2KEHTGCVSKGC-NH ${ }_{2}$ & & \\
\hline \multirow{11}{*}{ 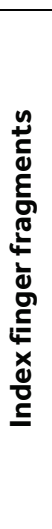 } & $\mathbf{N}$ & ${ }^{324}$ REKCRCVFHWCCYVSCQECT ${ }^{343}$ & $\mathbf{N}$ & ${ }^{349}$ TVQTERCHCKFHWCCYVKCKKCTEIV 374 \\
\hline & I1 & AC-CEKCRCVFHWCCYVSCQECC-NH 2 & 111 & Ac-CVQTERCHCKFHWCCYVKCKKCTEIC-NH \\
\hline & 12 & AC-CARCVFHWCCYVSCQEC-NH ${ }_{2}{ }^{*}$ & 112 & AC-CQTERCHCKFHWCCYVKCKKCTEC-NH \\
\hline & 13 & AC-CRCVFHWCCYVSCQC-NH $\mathrm{H}_{2}$ & 113 & Ac-CTERCHCKFHWCCYVKCKKCTC-NH \\
\hline & 14 & AC-CRAVFHWCCYVSAQC-NH ${ }_{2}$ & 114 & AC-CERCHCKFHWCCYVKCKKCC-NH 2 \\
\hline & 15 & AC-CRCVFHWAAYVSCQC-NH 2 & 115 & Ac-CAHCKFHWCCYVKCKKC-NH ${ }_{2}{ }^{*}$ \\
\hline & 16 & Ac-CRSVFHWSSYVSSQC-NH ${ }_{2}$ & 116 & Ac-CHCKFHWCCYVKCKC-NH 2 \\
\hline & 17 & Ac-CRSVFHWSSYVSSQC-NH 2 & 117 & Ac-CCKFHWCCYVKCC-NH 2 \\
\hline & 18 & Ac-CCVFHWCCYVSCC-NH ${ }_{2}$ & 118 & Ac-CKFHWCCYVKC-NH 2 \\
\hline & 19 & Ac-CVFHWCCYVSC-NH 2 & 119 & Ac-CKFHWCCYVKC-NH $\mathrm{N}_{2}$ \\
\hline & 110 & Ac-CVFHWCCYVSC-NH ${ }_{2}$ & & \\
\hline
\end{tabular}

\# = Peptide number is indicated by either a 'T' or 'I', referring to the thumb or index finger respectively; $\mathbf{N}=$ human native sequence; $\mathbf{S}=$ Palmitoylated Serine; 2 = Palmitoylated Dap; $\mathbf{C}=$ Cysteine connected via CLIPS; C = Cysteine connected via an SS-bond; $\mathbf{C}=$ Blocked Cysteine; $\mathbf{S}=$ Serine instead of cysteine; $\mathbf{A}=\mathbf{C}$ replaced by alanine; ${ }^{*}=$ Shortening of the peptides resulted in a free cysteine. This was replaced by an alanine in order to prevent interaction with another peptide. 


\section{Wnt Reporter Assay \\ $3 T 3$ mouse fibroblast cell line}

An engineered $3 T 3$ mouse fibroblast cell line (Leading Light ${ }^{\circledR}$ Wnt Reporter Assay, Enzo Life Sciences, Farmingdale, NY, USA) was used to test the Wnt pathway modulating capacities of the peptides. These cells express the firefly luciferase reporter gene under the control of Wnt-responsive promoters (TCF/LEF). Cells were cultured in $75 \mathrm{~cm}^{2}$ culture flasks (Corning, New York, NY, USA) in Dulbecco's modified essential medium supplemented with high glucose, GlutaMAXTM, HEPES (Life Technologies, Carlsbad CA, USA), 12\% growth medium concentrate (Enzo Life Sciences) and 1\% Penicillin-Streptomycin (Life Technologies). Cells were plated in 48-wells plates (Corning) at a density of 25.000 cells per well. After 24 hours, canonical Wnt signaling was induced by stimulation with Wnt3a conditioned medium (Wnt3aCM), obtained from Wnt3a producing L-cells (ATCC, Manassas, VA, USA). Simultaneously, the synthesized peptides were administered at different concentrations. As a control for Wnt/Fzd signaling inhibition, mouse Dickkopf-1 (DKK1) (R\&D Systems, Minneapolis MN, USA) was added to Wnt3a stimulated cells at a concentration of $250 \mathrm{ng} / \mathrm{ml}$. 24 Hours after stimulation the cells were lysed and firefly luciferase activity was measured with the use of a luciferase assay system (Promega, Madison WI, USA) according to manufacturer's protocol. All individual experiments were performed in duplicate.

\section{Human Embryonic Kidney (HEK) 293 cell line}

Cells were cultured in $75 \mathrm{~cm}^{2}$ culture flasks (Corning) in Dulbecco's modified essential medium supplemented with high glucose, GlutaMAXTM, HEPES (Life Technologies), 10\% Fetal Bovine Serum (Sigma Aldrich, Saint Louis, MO, USA) and 1\% PenicillinStreptomycin (Life Technologies). HEK293 cells were transiently transfected with a TCF/LEF-responsive firefly luciferase construct, constitutively expressing renilla luciferase (Cignal TCF/LEF Reporter (luc) Kit, Qiagen, Hilden, Germany) and pcDNA3.1 hFzd1, according to the manufacturer's protocol. In brief, cells were plated in 96 wells plates (Corning) at a density of 40.000 cells per well and were concurrently 
transfected (reverse transfection) with the aforementioned constructs. 24 Hours after transfection, the subsequent protocol was similar to the Leading Light cell line described above, with the exception that besides firefly luciferase, renilla luciferase was measured as well with the use of the Dual-Glo luciferase assay system (Promega).

\section{Statistical Analysis}

All values are shown as mean \pm SEM. Statistical analysis was executed with the use of GraphPad Prism software (version 5.02). Differences between experimental conditions were tested for significance with one-way ANOVA and Bonferroni posthoc analysis. A p-value $<0.05$ was considered to be statistically significant.

\section{Results}

\section{Reference experiments with Wnt3aCM}

To activate canonical Wnt signaling the 3 T3 mouse fibroblast cells were stimulated with Wnt3a conditioned medium (Wnt3aCM) obtained from Wnt3a producing L-cells in a 1:1 dilution with ENZO culture medium. Typical absolute values for luciferase in these experiments were around $3 \times 10^{6}$ light units when stimulated with Wnt3aCM, a 10-fold increase compared to untreated cells (Figure 2). This maximum response is normalized to 1.0 in all experiments. The natural canonical antagonist Dickkopf1 (DKK1) that interacts with the low-density lipoprotein receptor-related protein (LRP) (see chapter 2 for further details) was able to inhibit this signaling to baseline levels.

Figure 2 | Induction of canonical Wnt signaling by Wnt3aCM. Wnt signaling is $\sim 10$-fold upregulated in the 3 T3 mouse fibroblast cell-line by addition of Wnt3aCM compared to untreated cells. DKK1 (250 $\mathrm{ng} / \mathrm{ml}$ ) was able to inhibit signaling to baseline levels. Data are presented as mean \pm SEM $(n=3) . * * * p<0.001$ compared to Wnt3aCM stimulated cells. Addition of Wnt3aCM or DKK1 is indicated by a black box.

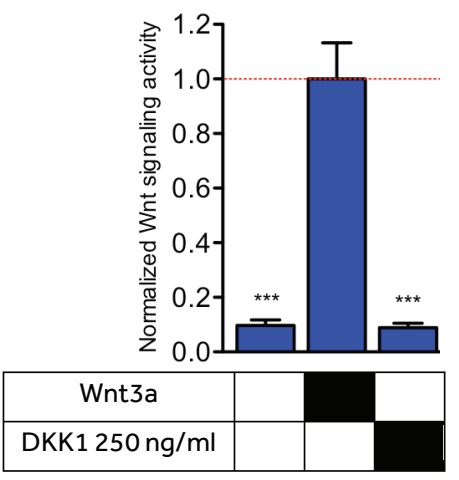




\section{Fixing the 3D-conformation of the index finger and thumb peptides}

To address the question whether Wnt signaling can be inhibited with peptide fragments of Wnt proteins, a library of peptides was synthesized (Table 1) that either resembled the thumb or index finger. Since in the native Wnt protein these parts are looped structures, peptides were cyclized using a bivalent CLIPS scaffold that connects two cysteines placed at the outer ends of the peptide in order to fix their three-dimensional conformation in a native fashion (Figure 3). Similar to the native protein, these loops were stabilized by formation of disulfide (SS)-bonds between the conserved cysteines (Figure 3). Equivalent to the native Wnt protein, the thumb fragment-derived peptides contain also a palmitoylation at the tip of the loop in addition to two conserved SS-bonds (Figure 3). However, in the native protein a serine residue is palmitoylated but due synthetic limitations the serine is substituted by a Dap in our peptides.

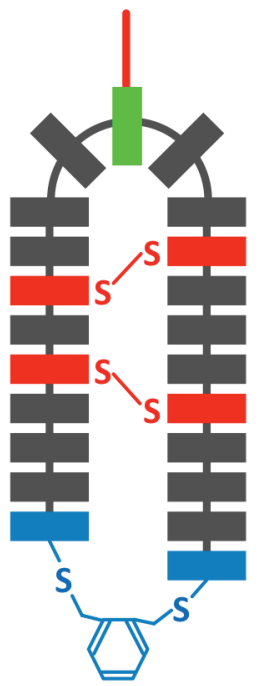

Thumb

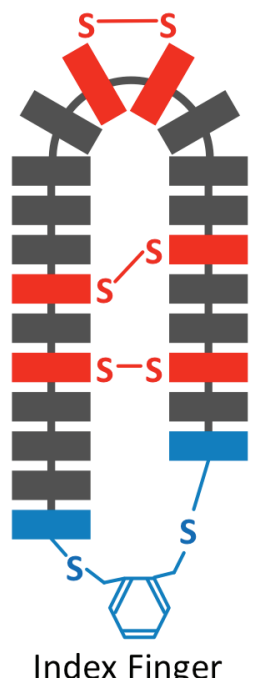

Index Finger
Cysteine connected via SS-bond

Cysteine connected via a CLIPS

Palmitoylated Dap

Amino acid

Figure 3 | Schematic representation of the peptide fragments.

The peptides are cyclized via a bivalent CLIPS scaffold and further stabilized by formation of native SSbonds between the conserved cysteines. On the left, an illustration of a thumb fragment with a palmitoylation at the tip. On the right, the index finger fragment with its conserved vicinal disulfide bond at the tip. 
A

Wnt3a sequence

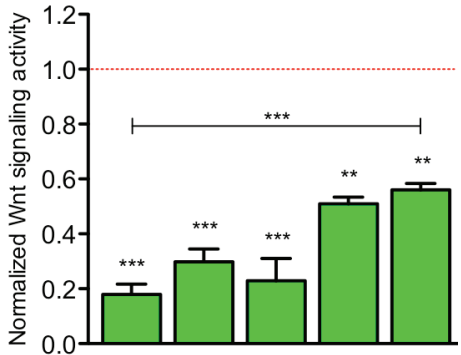

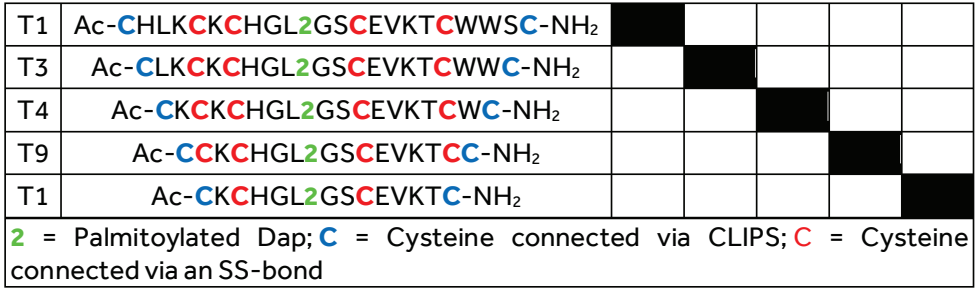

B

Wnt5a sequence

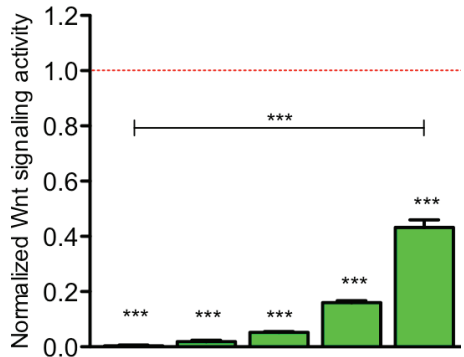

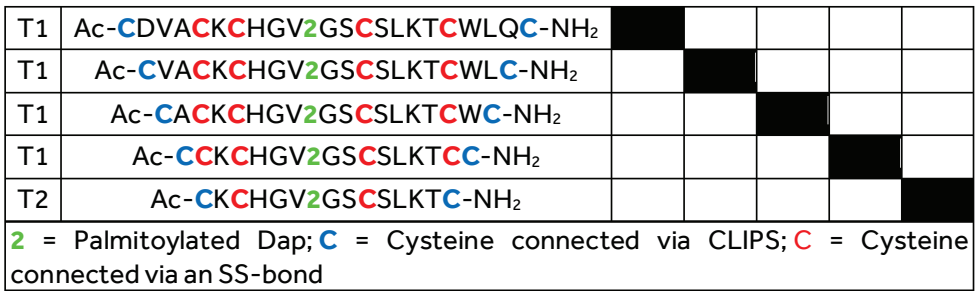

Figure 4 | Peptide length of the thumb-derived sequences affects antagonistic potency.

Both Wnt3a (A) and Wnt5a (B) thumb-derived sequences demonstrated inhibition of canonical Wnt signaling when administered at a concentration of $10 \mu \mathrm{M}$. Decreasing the length of the peptides decreased their antagonistic potency. Data are presented as mean $\pm \operatorname{SEM}(n=3) .{ }^{* *} p<0.01,{ }^{* * *} p<0.001$ compared to Wnt3aCM stimulated cells (1.0).

\section{Both thumb and index finger-derived peptides have antagonistic potencies}

In the in vitro assay, peptide fragments derived from the Wnt3a and Wnt5a thumb sequences (green) were found to possess significant antagonistic activities towards canonical Wnt signaling at a concentration of $\sim 10 \mu \mathrm{M}$ (Figure 4). Peptides containing 23 amino acids displayed the strongest antagonistic effect of all, with the Wnt5a- 
A

Wnt3a sequence

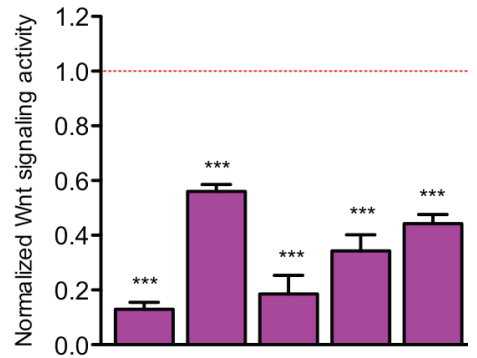

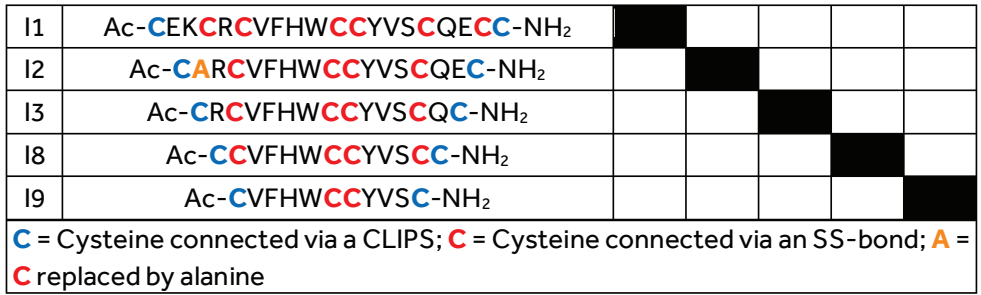

B

Wnt5a sequence

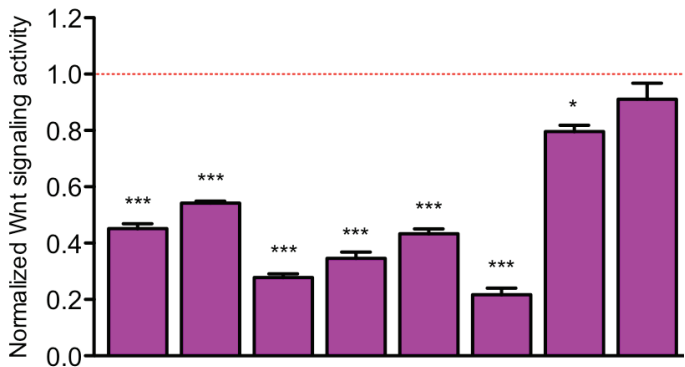

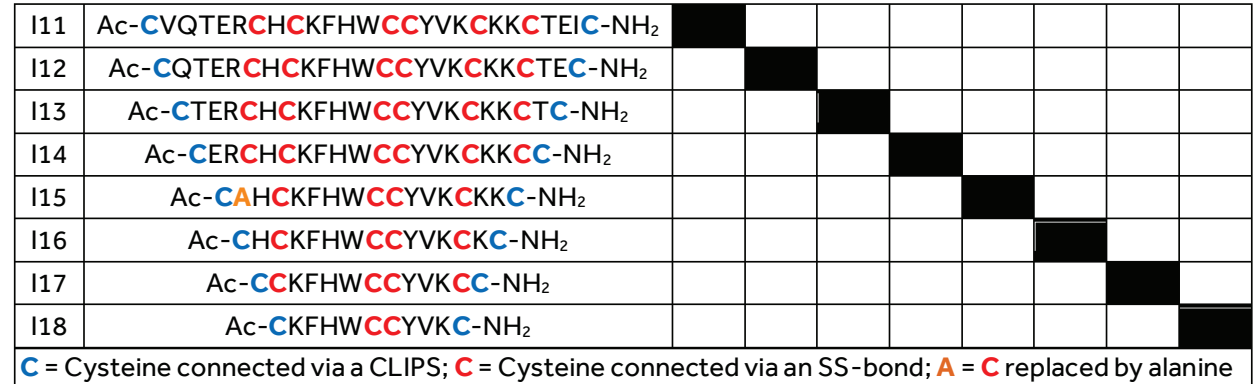

Figure 5 | Complex relationship between peptide length of the index finger and antagonistic activity.

Both Wnt3a (A) and Wnt5a (B) index finger derived sequences inhibited canonical Wnt signaling when administered at a concentration of $10 \mu \mathrm{M}$. Decreasing the length of the peptides decreased the antagonistic potency. Data are presented as mean $\pm \operatorname{SEM}(n=3) . * p<0.05, * * * p<0.001$ compared to Wnt3aCM stimulated cells (1.0).

derived peptide (T15) (Figure 4B) being more potent compared to the Wnt3a-derived peptide (T1) (Figure 4A). Decreasing the peptide length to 15 amino acids lowered the antagonistic potency by $\sim 40 \%$ at this concentration for both the Wnt3a (T12) and 
Wnt5a-derived (T20) fragments, demonstrating that peptide length of the thumbderived loop matters with regards to inhibition of Wnt signaling.

Similar to thumb-derived sequences of Wnt3a and Wnt5a, the index finger peptides (purple) also inhibited canonical Wnt signaling when administered at $10 \mu \mathrm{M}$ (Figure 5). Reducing the peptide length of the index finger affected the antagonistic potency in a negative way. However, there was a difference between Wnt3a- and Wnt5a-derived sequences. The shortest Wnt3a-derived (19) peptide containing 11 amino acids still demonstrated to be significantly active (Figure 5A), whereas its Wnt5a-derived counterpart (I18) lost its antagonistic effects completely (Figure 5B). We were not able to test peptides longer than 20 amino acids for the Wnt3a-derived sequence due to difficulties during the synthesis process. Nonetheless, Wnt5a peptides longer than 20 amino acids did not demonstrate a stronger antagonistic potential when administered at the same concentration. Overall, Wnt3a index finger-derived sequences were more active compared to their Wnt5a analogues at a concentration of $10 \mu \mathrm{M}$.

Dose response plots for both the thumb and index finger fragments of Wnt3a and Wnt5a demonstrated sigmoidal curves with $\mathrm{IC}_{50}$ values approximately ranging between 3 and $5 \mu \mathrm{M}$ (Figure 6).

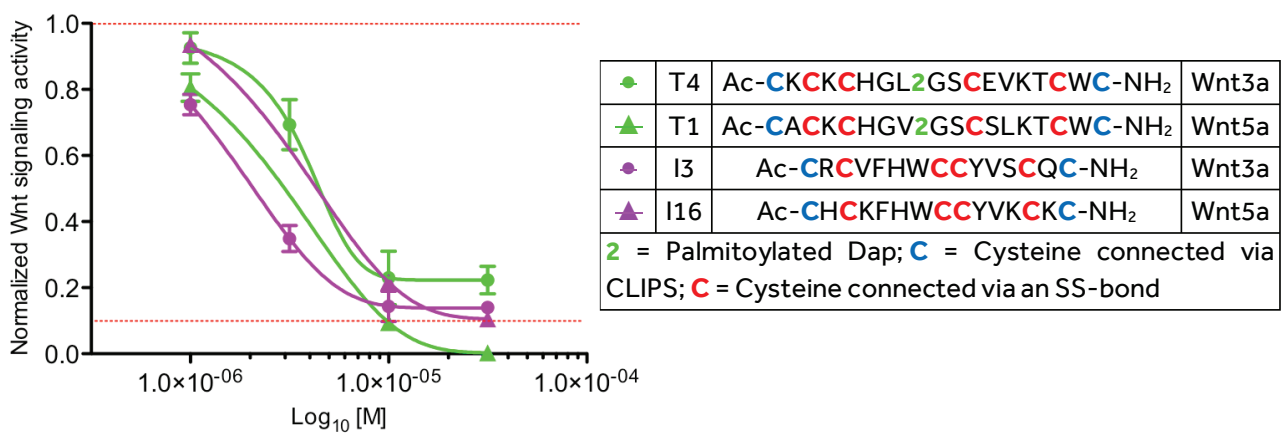

Figure 6 | Dose response relationship for thumb and index finger fragments on canonical Wnt signaling. Dose response curves for both the thumb (green) and index finger (purple) fragments administered at concentrations ranging from 1 to $30 \mu M$. Data are presented as mean $\pm \operatorname{SEM}(n=3)$. 
One striking observation was the inhibition of Wnt signaling below unstimulated baseline levels of \pm 0.1 normalized Wnt signaling activity with the longest Wnt5a derived thumb fragments (T15 \& T17). A closer look at the cells revealed cell detachment from the surface of the well and a loss of cells in these conditions. To address whether the reduced luciferase readouts were not only due to cell death but also the result of substantial Wnt signaling inhibition, the peptide offering the lowest readout (T15) was tested in another Wnt activity assay that corrects for cell viability. To this end, HEK293 cells were used that were transiently transfected with a TCF/LEF-responsive firefly luciferase construct and a constitutively expressed renilla luciferase. In addition, hFzd1 was co-transfected ensuring canonical Wnt signaling activity. Firefly luciferase readout values indicating Wnt signaling activity were divided by renilla luciferase values as a measure for cell viability. In this way, true Wnt signaling activity that is insensitive for cell loss is measured. In figure 7, it is demonstrated that in HEK293 cells canonical Wnt signaling was activated when Wnt3aCM was added. In concordance with the 3 T3 mouse fibroblast cell-line, Wnt signaling was significantly inhibited when DKK1 was co-administered at a concentration of $250 \mathrm{ng} / \mathrm{ml}$. Now,

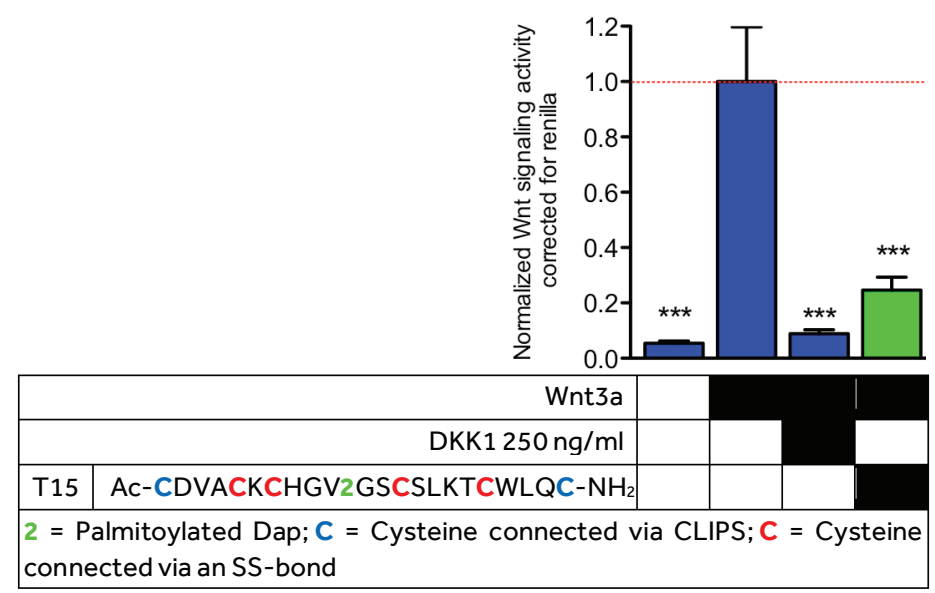

Figure 7 | Significant inhibition of Wnt signaling with thumb-derived peptides when normalized for cell viability in HEK293 cells.

HEK293 cells were transiently transfected with constructs for TCF/LEF-responsive firefly luciferase, a constitutively expressing renilla luciferase and hFzd1. Addition of the longest Wnt5a thumb fragment at a concentration of $10 \mu \mathrm{M}$ still inhibited Wnt signaling after correction for cell viability. Data are presented as mean $\pm \operatorname{SEM}(n=3) .{ }^{* * *} \mathrm{p}<0.001$ compared to Wnt3aCM stimulated cells (1.0). 
when peptide T15 was added at a concentration of $10 \mu \mathrm{M}$, a significant inhibition of $\pm 80 \%$ could still be observed, indicating that the inhibitory effect of this peptide is not solely due to cell loss. In contrast to the thumb-derived peptides, issues with cell viability were not observed at all for the index finger-derived peptides.

\section{Palmitoylation of the thumb fragment is essential for antagonistic activity}

Wnt proteins are post-translationally modified with a palmitoleic or palmitic acid attached to a serine residue at the tip of the thumb ${ }^{(2)}$. Due to limitations during synthesis, our peptides contain a palmitoylated Dap instead of a palmitoylated serine. Thumb fragments were shown to exert antagonistic effects when a palmitic acid was present (T1, $-10,-15$ and -20 in Figure 4). To demonstrate the importance of this modification at the tip of the thumb, the shortest and longest peptide fragments of both Wnt3a and Wnt5a derived sequences were synthesized without having a palmitic acid. As shown in figure 8A, non-palmitoylated analogues of both the Wnt3a and Wnt5a derived sequences completely lost the antagonistic activity, underscoring the importance of this modification. However, the palmitoyl group by itself did not exert any antagonistic activity, as shown by non-activity of two scrambled thumbderived peptides (T13 and T14) in figure 8B.

\section{Mutations in the peptides affect the inhibitory capacity}

To answer the question whether the SS-bonds between the conserved cysteines are a prerequisite for the activity of the peptides, mutated Wnt3a-derived peptides were synthesized in which each pair of SS-connected cysteines was replaced by either alanine or serine residues (orange color). As shown in Figure 9, inhibition of Wnt signaling was present when the native peptides (T4 and I3) were added, however both thumb (T7 and T8) and index finger $(16,17)$ peptides with cysteines mutated to serines, with either a CLIPS or not, did not show any inhibitory effect on canonical Wnt signaling. This suggests that either the presence of the bivalent CLIPS scaffold and the native SS-bonds between the conserved cysteines, or both, are necessary to inhibit canonical Wnt signaling activity. Mutation of the cysteines closest to the tip of the thumb to alanines (T6) did not decrease the inhibitory effect, but rather 
demonstrated a trend towards an improved inhibitory potency, whereas alanine mutation of the cysteines proximal to the CLIPS either reduced (thumb, T5) or eliminated (index finger, 14) the inhibition of Wnt signaling.

A

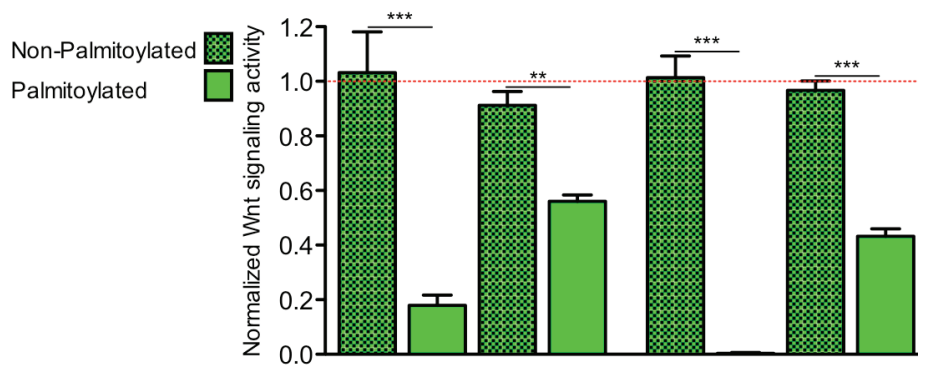

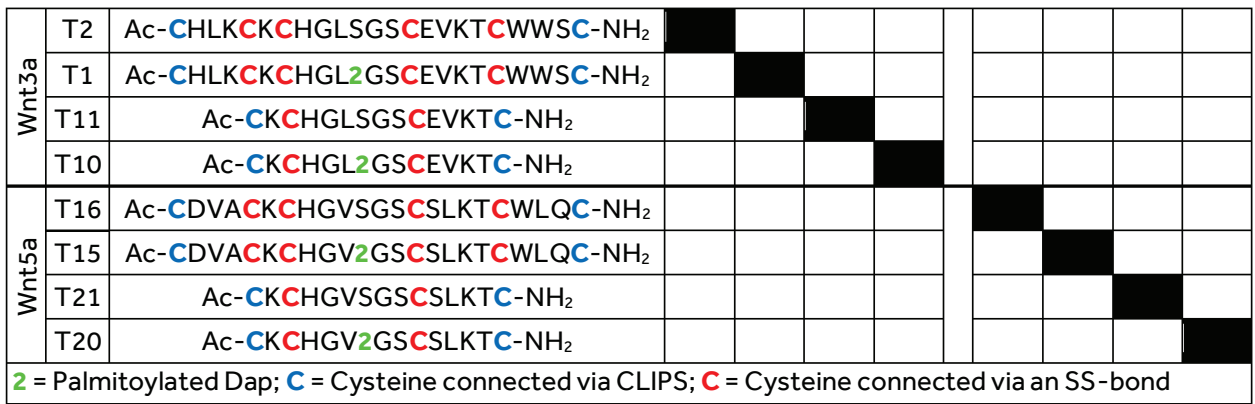

\section{B}

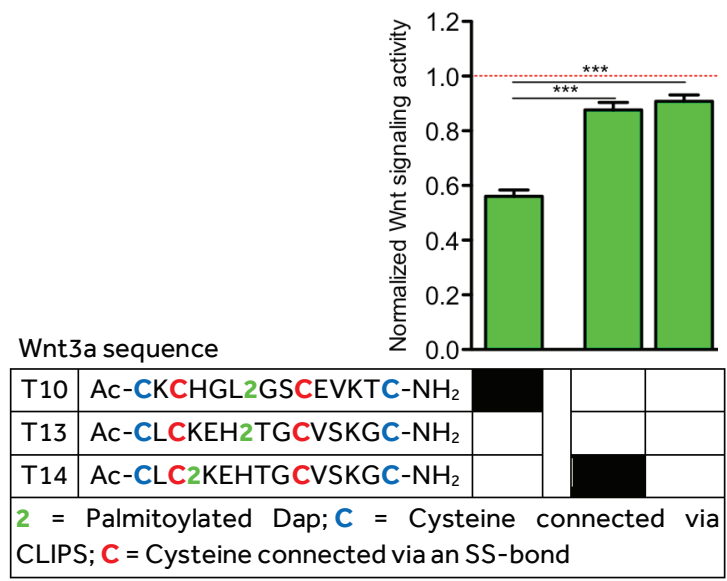

Figure 8 | Palmitoylation and native amino acid sequence are both essential for antagonistic activity of the thumb-derived peptides.

Non-palmitoylated (A) and scrambled (B) analogues of the thumb lost their antagonistic potency when administered at a concentration of $10 \mu \mathrm{M}$. Data are presented as mean $\pm \operatorname{SEM}(n=3),{ }^{* *} p<0.01,{ }^{* * *} p<0.001$. 


\section{The CLIPS scaffold significantly improved the antagonistic potency of the peptides}

The synthesized peptide fragments were cyclized by the means of a bivalent CLIPS scaffold as shown in Figure 3. To demonstrate that the presence of this scaffold improved the antagonistic potential, peptides lacking a bivalent CLIPS scaffold were synthesized as well. In Figure 10, it is shown that the presence of a scaffold significantly improved the antagonistic potency of both the thumb (T10, T20) and index finger (19) fragments. However, the Wnt5a index finger peptide I18 did not exhibit an improved antagonistic potency when the scaffold was present, although longer peptides did exert an antagonistic effect (Figure 5) indicating that this peptide (I18) is too short to act as an antagonist. This nicely illustrates that the CLIPS by itself does not have antagonistic properties but potentiated the antagonistic potential of the peptides by constraining their structure.

Wnt3a sequence

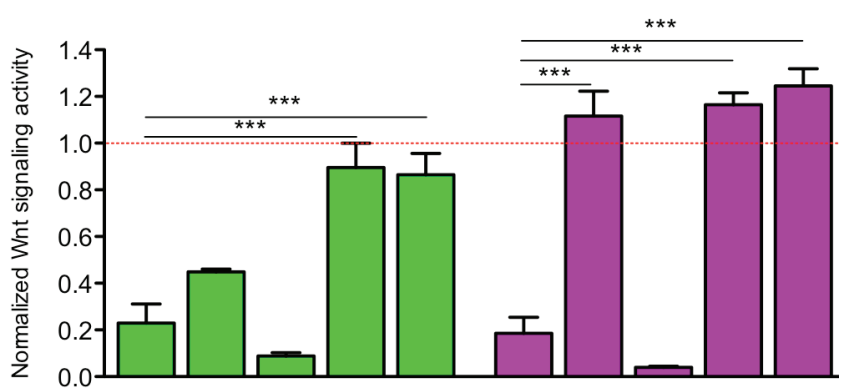

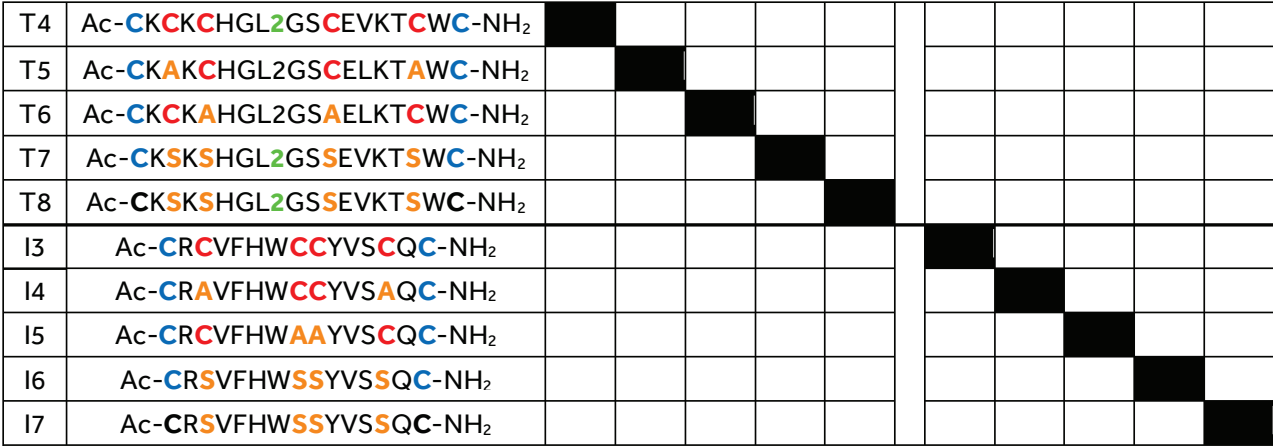

2 = Palmitoylated Dap; C = Cysteine connected via CLIPS; C = Cysteine connected via an SS-bond; $\mathrm{A}=\mathrm{C}$ replaced by Alanine; $\mathbf{S}=\mathrm{C}$ replaced by Serine; $\mathbf{C}=$ Blocked Cysteine

Figure 9 | Mutations of cysteines affect the inhibition of Wnt signaling.

In both Wnt3a thumb (green) and index finger (purple) peptides mutations of cyteines to alanines or serines significantly affects the inhibition of Wnt signaling. Peptides were administered at a concentration of 10 $\mu M$. Data are presented as mean $\pm \operatorname{SEM}(n=3),{ }^{* * *} p<0.001$. 
Effect on Wnt signaling upon simultaneous administration of thumb and index finger fragments

As shown in Figure 1, the native Wnt ligand has two extremities (thumb and index finger) that are involved in binding to the Fzd CRD. In all previous experiments, the effect of only a single mimicked extremity was assessed at a time. This brought up the idea that thumb and index finger fragments could work synergistically when added simultaneously. Since the peptides T4 and I3 both caused a strong inhibition when administered at $10 \mu \mathrm{M}$, the individual concentration in this experiment was set at $1 \mu \mathrm{M}$ to obtain a mild inhibition. This concentration did not result in a significant inhibition of Wnt signaling (Figure 11). However, when thumb and index finger fragments were added simultaneously, each at a concentration of $1 \mu \mathrm{M}$ (total concentration of $2 \mu \mathrm{M}$ ), a significant Wnt signaling inhibition was observed, albeit not in a synergistic fashion. When both fragments were added at $0.5 \mu \mathrm{M}$ each (total concentration $1 \mu \mathrm{M}$ ), significant inhibition of Wnt signaling could not be observed.

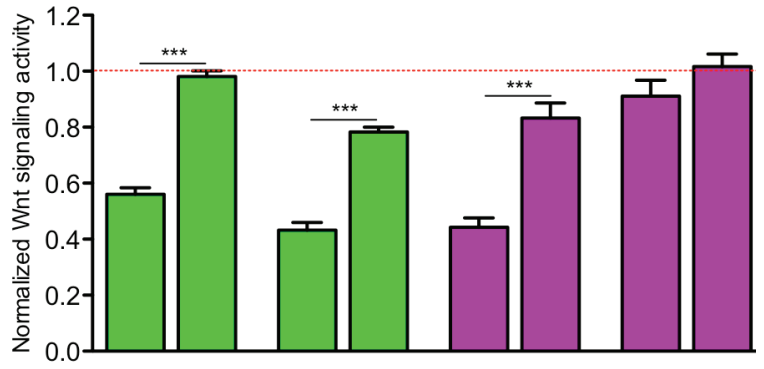

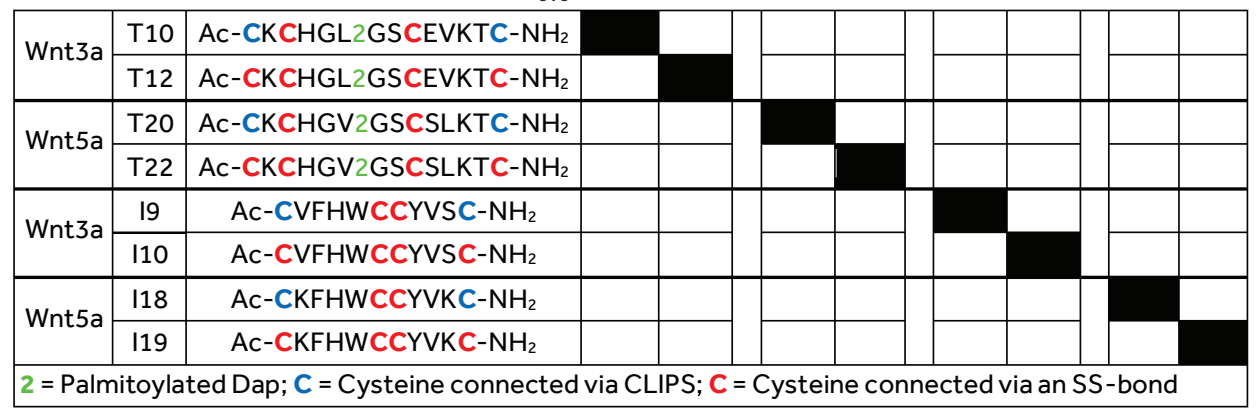

Figure 10 | Presence of a CLIPS scaffold increases the antagonistic potential of thumb and index fingerderived peptides.

Both thumb (green) and index finger (purple) peptides reveal an increased antagonistic potency when a CLIPS scaffold is present. Peptides were administered at a concentration of $10 \mu \mathrm{M}$. Data are presented as mean $\pm \operatorname{SEM}(n=3), * * * p<0.001$. 
This indicates that simultaneous addition of the two fragments does not act synergistically, but rather causes an additive effect on the inhibition of Wnt signaling.

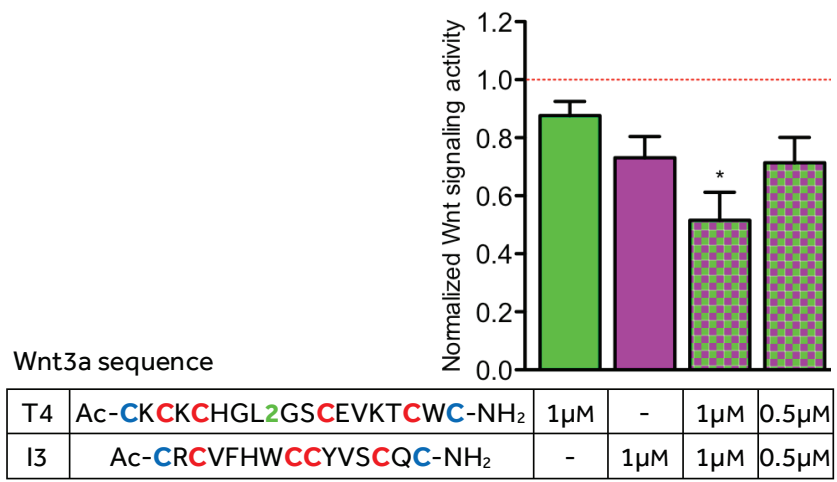

Figure 11 | Dual administration of both a thumb and index finger fragment displays an additive, but not a synergistic effect.

Thumb (green) and index finger (purple) peptides were administered at a dose of $1 \mu \mathrm{M}$. When added simultaneously (total concentration $2 \mu \mathrm{M}$; left mixed bar), a significant inhibition of Wnt signaling was observed. However, this did not create a synergistic effect, but rather an additive effect. Data are presented as mean $\pm \operatorname{SEM}(n=3),{ }^{*} p<0.05$ compared to Wnt3aCM stimulated cells (1.0).

\section{Discussion}

Wnt proteins interact with the Fzd CRD by means of two extensions also known as the thumb and index finger. We described for the first time the inhibition of canonical Wnt signaling in an in vitro assay by using thumb and index finger-derived peptides of Wnt3a/5a. We observed that the presence of multiple conformational constraints (both CLIPS-scaffold and at least one SS-bond) turned out to be crucial for activity as well as the presence of a palmitoylated serine residue in the thumb-derived fragments.

Wnt ligands are proteins containing highly conserved cysteines and a lipid group at the tip of the thumb ${ }^{(2)}$. This lipid group is post-translationally attached to a serine by porcupine acyl transferase. Reduced expression levels of porcupine results in diminished palmitoylation and secretion of Wnt protein ${ }^{(12)}$. Furthermore, targeted mutation of this serine to alanine, glycine or cysteine impairs secretion of the protein as well ${ }^{(13)}$, suggesting that a serine is required for palmitoylation at this residue. The impaired secretion is most likely the consequence of the lack of Wnt recognition by 
the transmembrane protein Wntless/Evi that is involved in trafficking of Wnt proteins $^{(14)}$. As these mutated forms of Wnt are not secreted, it is obvious that Wnt signaling is not activated when they are overexpressed ${ }^{(3)}$ and thus gives no resolution on their capability to activate Wnt signaling.

The vast amount of conserved cysteines in the Wnt protein are assumed to be pivotal for the disulfide bridges that embody the secondary structure of the protein ${ }^{(15)}$. Both the thumb and index finger-derived peptide fragments contain disulfide bonds between cysteines. For stimulation of Wnt signaling the importance of these disulfide bonds in the 'fingers' has been emphasized by the reduced or even vanished activation of Wnt signaling when individual or disulfide bond connected pairs of cysteines were mutated to alanines in these domains ${ }^{(13)}$. In our peptides, paired disulfide-bonding cysteines were mutated to either alanines or serines which resulted in a reduction or a complete loss of antagonistic potency in most of the peptides, suggesting a role of these paired cysteines in the positioning and maintenance of the hairpin structure of the peptides. A remarkable observation was the trend towards an improved antagonistic potency when the central pair of cysteines was substituted by alanines, in both thumb and index finger-derived peptides. First, substitution of cysteines by alanines will affect the tertiary structure of the peptides, which can have an effect of the interaction with the CRD. Second, cysteines and alanines both are hydrophobic amino acids, which could imply that the mutated peptides were still able to fit in the hydrophobic binding pockets and block the engagement of Wnt3a to Fzd and thereby inhibit signaling. Besides, cysteines are less hydrophobic and more related to alanine when bound via a disulfide bond ${ }^{(16)}$, which is the case in the thumb and index finger peptides. In contrast, serine is a polar amino acid with less hydrophobicity. This implies that peptides containing serine mutations are repelled from the hydrophobic binding pockets and thereby do not inhibit Wnt3a induced signaling.

Designing peptides that mimic functional domains of natural proteins can be very challenging since it can involve the folding of the protein in for example $\beta$-sheets, $\beta$ - 
turns or hairpins. The synthesized peptides in this manuscript adopt a hairpin-like structure, in which a bivalent CLIPS scaffold was used resulting in cyclization of the peptides $^{(17)}$. The presence of this scaffold in our peptides is favorable over a normal disulfide bond between two cysteine residues considering the significant increase in Wnt signaling inhibition. This indicates that cyclization via this scaffold generates better peptide mimics than traditional disulfide bonds, possibly by a superior constraint of the peptide due to the CLIPS scaffold and/or by an additional interaction with the target.

In order to find out whether palmitoylation is only needed for secretion of Wnt or also for the binding to its target, a recent study on Notum, an inhibitor of Wnt signaling for which the exact mechanism of action was recently discovered by Kakugawa et al. ${ }^{(18)}$, is of interest. Notum specifically cleaves the fatty acid from serine ${ }^{209}$ (located at the tip of the thumb) on hWnt3a and pretreatment of mWnt3a with recombinant Notum resulted in almost no activation of Wnt signaling by the residual $\mathrm{mWnt} 3 \mathrm{a}^{(18)}$. Although in the present study we are looking at inhibitory mechanisms, these data support our findings that non-palmitoylated thumb fragments do not exert antagonistic effects, which underscores the essence of this modification for interaction between Wht and the CRD of Fzd. In addition, we have demonstrated that the peptide sequence is also critical for activity of the peptide.

The Wnt signaling pathway regulates many key developmental processes such as cell division, differentiation, migration and survival ${ }^{(1,19)}$. Aberrant regulation of the Wnt signaling pathway by, for example, mutations in downstream genes such as APC, Axin and $\beta$-catenin, frequently results in tumorigenesis ${ }^{(20)}$. Furthermore, the expression of Fzd7 is increased in many different tumors compared to normal tissues and stimulates proliferation and progression of the tumor ${ }^{(21)}$. Targeting the Fzd7 receptor, either with siRNA or specific antibodies to block signaling, inhibits cell growth and induces apoptosis in cancer cells ${ }^{(22,23)}$. The reduced cell viability that we observed with the longest peptide fragments (T15 \& T17) can therefore be a physiological result of potent Wnt signaling inhibition that induces apoptotic signaling 
and ultimately loss of cells. However, we cannot affirm that this occurred by inhibition of Fzd7 or through other Fzd receptors involved.

The Wnt-inhibiting peptides described in this manuscript were all derived from either the human Wnt3a or Wnt5a native sequences. Wnt3a and Wnt5a share a sequence identity of $44 \%$ and are both known to have an effect on canonical Wnt signaling albeit that Wnt5a can act as an endogenous antagonist for Wnt3a and can stimulate canonical signaling depending on the receptor context ${ }^{(24)}$. The divergence in affinities of Wnt3a and Wnt5a proteins for Fzd CRDs has been reported recently by means of binding experiments. It turned out that Wnt3a had slightly lower $K_{D}$ values (in the $n M$ range) for the Fzd CRDs that were examined (Fzd1, -2, -4, -5, -7, -8) $)^{(25)}$. Both our thumb and index finger-derived fragments from Wnt3a and Wnt5a were able to inhibit canonical Wnt signaling, although the potency of inhibition was more profound for the Wnt5a thumb-derived peptides as compared to the equal-length Wnt3a thumb fragments, whereas for the index finger mimetics it appeared to be the other way around. The sequence identity between the Wnt3a and Wnt5a-derived peptides tested here is between $65 \%$ and $84 \%$, depending on the fragment. Peptide 18 (Wnt3aderived) and I19 (Wnt5a-derived) differ only two amino acids in their sequence, while there is a substantial difference in the inhibition of Wnt signaling. This confirms that minor differences in amino acid sequence between Wnt3a and Wnt5a peptides result in distinctly different antagonistic potencies.

Janda et al. have reported on the binding affinity of a 90 amino acids long 'mini-Wnt', that only contains the index finger domain, to Fzd CRDs ${ }^{(2)}$. The $K_{D}$ of this mini-Wnt for Fzd5 and Fzd8 was $3.65 \mu \mathrm{M}$ and $2.41 \mu \mathrm{M}$ respectively ${ }^{(2)}$. Although not entirely comparable, these values are in the same range as the $I_{50}$ values $(\approx 3$ to $5 \mu \mathrm{M})$ that could be deducted from the dose response curves presented in this manuscript. For in vitro research, these concentrations are reasonable to work with. However, when advancing to in vivo research, it will be necessary to increase further the antagonistic potencies of these peptides, preferably within the nanomolar range. To address this issue, thumb and index finger fragments were co-administered to investigate a 
potential synergistic effect. Unfortunately, this solely resulted in an additive effect on the inhibition of canonical Wnt signaling. Therefore, additional research is required in order to find other ways to decrease the $\mathrm{IC}_{50}$.

\section{Conclusions}

The development of Wnt signaling modulators is of importance as Wnt signaling is implicated in a wide array of diseases. In particular, cardiovascular diseases and cancer are two disease areas in which the role of Wnt signaling is progressively established. We systematically investigated the antagonistic characteristics of novel peptide fragments derived from human Wnt3a and Wnt5a sequences on canonical Wnt signaling. We evidently demonstrated that both thumb and index finger-derived peptides can antagonize Wnt3a-induced Wnt signaling. The length of the peptides as well as the presence of the bivalent CLIPS scaffold and also palmitoylation of the thumb fragment at the native $\mathrm{Ser}^{209}$ residue (Wnt3a) are all factors that significantly affect the antagonistic potency of the peptides. These novel peptide fragments can serve as a new tool to inhibit Wnt signaling in various diseases. Nevertheless, further studies are still needed to investigate the specificity of the peptides for the different Fzd receptors and to also improve their affinities and efficacies, before being able to advance towards in vivo studies. 


\section{References}

1. Clevers H. Wnt/beta-catenin signaling in development and disease. Cell. 2006;127(3):469-80.

2. Janda CY, Waghray D, Levin AM, Thomas C, Garcia KC. Structural basis of Wnt recognition by Frizzled. Science. 2012;337(6090):59-64.

3. Kumar S, Zigman M, Patel TR, Trageser B, Gross JC, Rahm K, et al. Molecular dissection of Wnt3aFrizzled8 interaction reveals essential and modulatory determinants of Wnt signaling activity. BMC biology. 2014;12:44.

4. Kuwabara M, Kakinuma Y, Katare RG, Ando M, Yamasaki F, Doi Y, et al. Granulocyte colonystimulating factor activates Wnt signal to sustain gap junction function through recruitment of beta-catenin and cadherin. FEBS letters. 2007;581(25):4821-30.

5. Chu ML, Ahn VE, Choi HJ, Daniels DL, Nusse R, Weis WI. structural Studies of Wnts and identification of an LRP6 binding site. Structure. 2013;21(7):1235-42.

6. Chen S, Bubeck D, MacDonald BT, Liang WX, Mao JH, Malinauskas T, et al. Structural and functional studies of LRP6 ectodomain reveal a platform for Wnt signaling. Developmental cell. 2011;21(5):848-61.

7. Kahn M. Can we safely target the WNT pathway? Nature reviews Drug discovery. 2014;13(7):51332.

8. Nencini A, Pratelli C, Quinn JM, Salerno M, Tunici P, De Robertis A, et al. Structure-activity relationship and properties optimization of a series of quinazoline-2,4-diones as inhibitors of the canonical Wnt pathway. European journal of medicinal chemistry. 2015;95:526-45.

9. Laeremans H, Hackeng TM, van Zandvoort MA, Thijssen VL, Janssen BJ, Ottenheijm HC, et al. Blocking of frizzled signaling with a homologous peptide fragment of wnt3a/wnt5a reduces infarct expansion and prevents the development of heart failure after myocardial infarction. Circulation. 2011;124(15):1626-35.

10. Hermans KC, Blankesteijn WM. Wnt Signaling in Cardiac Disease. Comprehensive Physiology. 2015;5(3):1183-11209.

11. Smeenk LE, Dailly N, Hiemstra H, van Maarseveen JH, Timmerman P. Synthesis of water-soluble scaffolds for peptide cyclization, labeling, and ligation. Organic letters. 2012;14(5):1194-7.

12. Takada R, Satomi Y, Kurata T, Ueno N, Norioka S, Kondoh H, et al. Monounsaturated fatty acid modification of Wnt protein: its role in Wnt secretion. Developmental cell. 2006;11(6):791-801.

13. MacDonald BT, Hien A, Zhang X, Iranloye O, Virshup DM, Waterman ML, et al. Disulfide bond requirements for active Wnt ligands. The Journal of biological chemistry. 2014;289(26):18122-36.

14. Herr P, Basler K. Porcupine-mediated lipidation is required for Wnt recognition by Wls. Developmental biology. 2012;361(2):392-402.

15. Willert K, Nusse R. Wnt proteins. Cold Spring Harbor perspectives in biology. 2012;4(9):a007864.

16. Nagano N, Ota M, Nishikawa K. Strong hydrophobic nature of cysteine residues in proteins. FEBS letters. 1999;458(1):69-71.

17. Timmerman P, Beld J, Puijk WC, Meloen RH. Rapid and quantitative cyclization of multiple peptide loops onto synthetic scaffolds for structural mimicry of protein surfaces. Chembiochem : a European journal of chemical biology. 2005;6(5):821-4.

18. Kakugawa S, Langton PF, Zebisch M, Howell SA, Chang TH, Liu Y, et al. Notum deacylates Wnt proteins to suppress signalling activity. Nature. 2015;519(7542):187-92.

19. Logan CY, Nusse R. The Wnt signaling pathway in development and disease. Annual review of cell and developmental biology. 2004;20:781-810.

20. Anastas JN, Moon RT. WNT signalling pathways as therapeutic targets in cancer. Nature reviews Cancer. 2013;13(1):11-26.

21. King TD, Zhang W, Suto MJ, Li Y. Frizzled7 as an emerging target for cancer therapy. Cellular signalling. 2012;24(4):846-51. 
22. Yang L, Wu X, Wang $\mathrm{Y}$, Zhang $\mathrm{K}$, Wu J, Yuan YC, et al. FZD7 has a critical role in cell proliferation in triple negative breast cancer. Oncogene. 2011;30(43):4437-46.

23. Pode-Shakked N, Harari-Steinberg O, Haberman-Ziv Y, Rom-Gross E, Bahar S, Omer D, et al. Resistance or sensitivity of Wilms' tumor to anti-FZD7 antibody highlights the Wnt pathway as a possible therapeutic target. Oncogene. 2011;30(14):1664-80.

24. Mikels AJ, Nusse R. Purified Wnt5a protein activates or inhibits beta-catenin-TCF signaling depending on receptor context. PLoS biology. 2006;4(4):e115.

25. Dijksterhuis JP, Baljinnyam B, Stanger K, Sercan HO, Ji Y, Andres O, et al. Systematic mapping of WNT-FZD protein interactions reveals functional selectivity by distinct WNT-FZD pairs. The Journal of biological chemistry. 2015;290(11):6789-98. 


Chapter 7

General Discussion 


\section{General Discussion}

Wnt/Frizzled signaling has gained an increasing amount of interest over the past decade and its implications in cardiovascular development and disease are becoming more and more evident. Despite this, the complex signaling pathways are still not unraveled into detail and many pieces of the puzzle are still missing to fully understand the signaling mechanisms. The aim of this thesis was to study the role of this pathway in the wound healing process after MI and to characterize the inhibitory potential of peptide fragments of Wnt proteins. To this end, we 1) characterized the expression of members of the Wnt/Frizzled signaling pathway in myocardial infarction (MI) in animal models and humans, 2) targeted this signaling pathway with the previously identified peptide UM206 in a mouse and swine model of MI in order to improve the wound healing and 3) identified new peptides that can antagonize canonical Wnt signaling.

As described in Chapter 2, Wnt signaling is involved in multiple cardiac conditions including myocardial infarction, cardiac hypertrophy and arrhythmias. Animal models of these diseases frequently show inconsistent results as to whether the pathway should be activated or inhibited. In order to identify the regulation of Wnt/Frizzled signaling following $\mathrm{MI}$, we provided a gene expression overview of Wnt/Frizzled signaling components in four different mouse strains in Chapter 3. Expression profiles of Frizzled receptors and Wnt ligands in the infarcted area were different between mouse strains. In particular, the expression of these genes was significantly increased in C57BL/6 and FVB, but this elevated expression was absent in Swiss mice. Moreover, we found an inverse relationship between Wht expression and end diastolic volumes (EDV) for two strains (C57BL/6 and FVB), suggesting that Wnt signaling contributes to the regulation of wound healing in these strains

Administration of UM206 (a peptide fragment derived from Wnt5a) was beneficial following $M I$ in mice ${ }^{(1)}$. In order to follow up on these experiments in mice, Wnt signaling was inhibited by UM206 following reperfused MI in a clinically relevant swine model, as demonstrated in Chapter 4 of this thesis. Adverse remodeling of the 
infarcted area was halted in the UM206-treated animals whereas a progressive dilation of the left ventricle was observed in the untreated swine between three and five weeks after MI. Effects on cardiac function were only minimal at five weeks following reperfusion, which may be attributed to the relatively small injury of the heart in all groups. However, it is tempting to speculate that UM206 administration for an extended duration will offer a superior cardiac function in treated swine compared to saline-treated swine. In Chapter 5 we demonstrated an overview of studies in which UM206 was administered to mice following experimental MI. Initial experiments demonstrated a beneficial effect of this peptide on cardiac function and wound healing. However, from a specific point in time this effect could not be reproduced anymore, which led to the initiation of a series of experiments aimed to uncover the cause of this phenomenon. Source of manufacturing and dosage of UM206 as well as changing to another mouse strain did not rescue the phenotype that we observed earlier. A lack of lung weight increase both in saline and UM206 groups after the turning point suggested absence of overt heart failure in these mice, thereby eliminating the potential therapeutic gain that could be obtained with UM206. This is likely the result of the transition of housing conditions from open cages to individually ventilated cages (IVC) at the turning point.

In Chapter 6 a systematically designed peptide library was screened for the ability to inhibit Wnt3a stimulated canonical Wnt signaling in vitro. This peptide library consisted of peptide fragments derived from Wnt3a or Wnt5a, which were selected based on the sites of interaction between Wnt and Frizzled as can be observed in the crystal structure of this complex. These peptide fragments were found to inhibit canonical Wnt signaling with an $\mathrm{IC}_{50}$ in the micromolar range. Variations in amino acid composition and tertiary structure defined the minimal requirements for frizzled CRD interaction. 
In summary these findings led to the following conclusions, which will be further discussed in the following sections:

1) Wnt/Frizzled signaling plays a modulatory role in the structural adaptation in the diseased heart and especially following MI.

2) Different animal models can be used to study the role of Wnt/Frizzled signaling although experimental conditions appear to be crucial for the phenotype in mice.

3) Molecular analysis of a ligand-receptor complex provides a good basis for development of peptidergic antagonists of the Wnt/Frizzled pathway.

\section{The importance of Wnt/Frizzled signaling following MI}

Wnt signaling plays a modulating role in several factors that influence adverse remodeling following MI. These factors include inflammation, angiogenesis and presence of myofibroblasts. Inflammation following $\mathrm{MI}$ is a complex process that is necessary for infarct healing but it also has adverse effects on the remodeling of the infarct depending on the type of inflammatory mediators. The involvement of Wnt signaling in the inflammatory response following $\mathrm{MI}$ was demonstrated by overexpression experiments. Overexpression of sFRP1 in mice reduces early leukocyte infiltration following $\mathrm{MI}^{(2)}$. When SFRP1 was conditionally overexpressed in cardiomyocytes or endothelial cells, this effect was not observed. However, transplanted bone marrow-derived cells overexpressing SFRP1 (to drive expression in leukocytes) reduced leukocyte infiltration following $\mathrm{MI}$, and resulted in improved infarct healing. This reduced infiltration was mainly achieved by altering the pro- and anti-inflammatory cytokine balance ${ }^{(3)}$. More recent evidence demonstrated deteriorated left ventricular function and infarct healing following knockout of Dickkopf-3 (DKK3), which was attributed by increased apoptosis and inflammation. The opposite phenotype was observed in DKK3 overexpressing mice ${ }^{(4)}$. SFRP1 and DKK3 are both inhibitors of Wnt signaling that, when overexpressed, reduce the inflammatory response following MI. This indicates that active Wnt signaling is proinflammatory and can therefore be targeted in order to reduce the inflammatory 
response in infarct healing. Moreover, these interventions apparently can target the negative aspects of inflammation after MI without affecting the positive aspects, implicating superiority of these interventions over general anti-inflammatory therapy.

Wnt signaling plays an important role in the embryonic development of the vascular system $^{(5,6)}$ but following $\mathrm{Ml}$ it is also implicated in formation of new vessels in adults. Previous work from our lab demonstrated Dvl1 and cytoplasmic $\beta$-catenin expression in endothelial cells of the newly formed blood vessels in the infarcted area following $\mathrm{MI}^{(7)}$. Overexpression of SFRP1 has been linked to increased capillary density in the infarcted $\operatorname{area}^{(8)}$. DKK2 administration in the infarcted heart results in similar effects ${ }^{(9)}$. Both DKK2 and sFRP1 are inhibitors of Wnt signaling suggesting increased vessel formation when Wnt signaling activity is reduced. This suggestion is supported by the increased amount of vessels in the infarcted area upon treatment with the Wnt signaling antagonist UM206 ${ }^{(1)}$. On the contrary, Wnt10b overexpression in cardiomyocytes robustly increased the vascular density in the infarcted zone leading to improved ventricular function ${ }^{(10)}$. As a Wnt ligand is regarded as an agonist, it is possible that Wnt10b targets another sub-pathway of Wnt than DKK2 and sFRP1, and thus explains these conflicting data on inhibition and stimulation of Wnt signaling. However, this calls for specificity of the inhibitory ligands, allowing to therapeutically intervene in one specific sub-part of the Wnt signaling pathway in order to achieve the desired effect.

Myofibroblasts in the infarcted heart fulfill an important role in optimizing the wound healing process following MI. By having both contractile and ECM producing capabilities myofibroblasts can prevent excessive left ventricular dilatation and stabilize the scar, respectively ${ }^{(11)}$. Presence of myofibroblasts is seen for many years after $\mathrm{Ml}$ in well-healed human infarct whereas these cells are lost in dilated infarcts ${ }^{(12)}$. This underscores the importance of these cells in maintaining left ventricular dimensions and function. Wnt signaling has been linked to differentiation of myofibroblasts in vitro and is influenced by different combinations of Wnt ligands and 
Frizzled receptors ${ }^{(13)}$. Following $\mathrm{MI}$, myofibroblasts show an upregulated Frizzled 2 expression $^{(14)}$ and active canonical Wnt signaling ${ }^{(15)}$. Strategies targeting Wnt signaling in vivo in order to increase myofibroblast content in the infarcted area are beneficial for the wound healing process and cardiac function. An active Wnt1/ $\beta$ catenin signaling pathway improves infarct healing by increased fibroblast proliferation and ECM production, whereas the opposite is observed when this specific pathway is inhibited ${ }^{(16)}$. Also in rats, the beneficial effect of an active $\beta$ catenin signaling pathway was confirmed as proven by increased fibroblast numbers and transdifferentiation to myofibroblasts, leading to an improved cardiac function and a suppressed infarct area ${ }^{(17)}$. UM206 (identified as a Frizzled antagonist) administration dramatically increased myofibroblast numbers in the infarct area in mice, which was identified to be the decisive factor for its cardio-protective effect following $\mathrm{MI}^{(1)}$. As shown, modulation of $\mathrm{Wnt}$ signaling can result in increased myofibroblast presence in the infarcted area, contributing to an improved cardiac function following MI. However, this can be achieved through different interventions in the signaling pathway proposed to be either stimulatory or inhibitory. This underscores the complexity of Wnt/Frizzled signaling in the induction of myofibroblast differentiation.

In Chapter 3 a significant difference in expression of Wnt signaling components between four mouse strains is described, although no marked differences were observed in cardiac dimensions and volumes. This creates a platform to study whether a certain intervention in Wnt/Frizzled signaling in either of these strains has different effects on cardiac remodeling, or that Wnt/Frizzled gene expression is not a suitable parameter to determine the nature of cardiac remodeling post-MI. The deviating expression levels between different mouse strains and the opposing results on whether to stimulate or inhibit Wnt signaling following MI, as described in Chapter 2 , raise the question whether the Wnt pathway is an appropriate target in order to improve wound healing following MI. Current therapies for heart failure target pathways such as the renin-angiotensin-aldosterone system (RAAS) or the adrenergic system ${ }^{(18)}$. During the development of heart failure, signaling activity 
through these pathways is upregulated due to increased presence of ligands rather than to increments in receptor density ${ }^{(19,20)}$. This is also in accordance with the perception of classical pharmacology where the concentration of drug is used as variable rather than the concentration of receptors. In Chapter 3, however, both ligands and receptors are upregulated following MI especially in the C57BL/6 and FVB strains. This might change at a later stage when heart failure is established but further investigation will be needed to confirm this.

In human heart failure patients, secreted frizzled related protein (sFRP) -3 and -4 were shown to be upregulated and tended to correlate negatively with cytoplasmic $\beta$ catenin levels in failing myocardium compared to control myocardium, although sFRP1, -2 and Frizzled 2 expression was not altered in these hearts ${ }^{(21)}$. Moreover, increased circulating SFRP3 levels have been associated with adverse outcome in heart failure ${ }^{(22)}$. It is known that SFRPs have other functions besides acting on Wnt signaling ${ }^{(23)}$ and thus do not necessarily reflect Wnt signaling inhibition. As described in Chapter 3, post-mortem human expression data in infarcted hearts demonstrated a trend towards increased expression of Wnt/Frizzled genes one to two three weeks post-MI. However, expression levels were very low and variable in these samples, which was likely due to the use of the formalin-fixed tissue in this study. Therefore, in view of development of drugs acting on Wnt signaling activity in humans, more research is needed to accurately determine whether Wnt signaling needs to be targeted and in which types of patients. Personalized medicine might be applicable here in the near future by identifying Wnt/Frizzled expression profiles and adapt treatment accordingly.

On the basis of these results it is clear that Wnt/Frizzled signaling plays a modulatory role in the process of adverse remodeling following MI. As described in Chapter 2 of this thesis, studies are inconsistent as to whether the Wnt/Frizzled pathway should be activated or inhibited following MI. This inconsistency can be the consequence of the use of various animal models and different treatment regimens. However, as 
described in Chapter 5, even when using identical models research outcome can be conflicting. This will be further discussed in the next section.

\section{Experimental conditions are crucial for the phenotype of mice following MI}

Reproducibility of preclinical experiments is a serious issue in biomedical sciences. Of the published studies, 51-89\% cannot be reproduced leading to delays and increasing costs of drug development ${ }^{(24)}$. In Chapter 5 we described the effects of UM206 in mice following $\mathrm{MI}$ that could not be reproduced anymore after a certain point. After deduction of the possible factors causing this irreproducibility it was concluded that the most plausible cause is the transition from open cages to individually ventilated cages (IVCs).

Air composition in IVCs is known to be different compared to open cages. IVC housing reduced exposure to ammonia and $\mathrm{CO}_{2}$ and improved the integrity of the airway epithelium ${ }^{(25)}$. This may in addition implicate that exposure to proinflammatory stimuli is reduced in IVCs, suggesting a reduced basal inflammatory state in mice housed in IVCs. Recent studies confirmed that low-grade inflammation, such as periodontal disease, has a considerable adverse effect on cardiac remodeling following $\mathrm{MI}^{(26,27)}$. The reduced inflammatory state of mice housed in IVCs suggests that development of heart failure post-MI is attenuated in these mice, thereby erasing the potential gain to be obtained with UM206 treatment. UM206 showed beneficial effects in rat (unpublished data) and swine (Chapter 4) models of MI performed with housing conditions that resemble the open cage housing of the initial mouse studies, thereby strengthening the hypothesis that the change in housing conditions is a crucial factor in the absence of heart failure development after MI. A possible method to bypass this reduced inflammatory state of mice would be to inject mice with minimal amounts of Porphyromonas gingivalis lipopolysaccharide (Pg-LPS) to induce low systemic inflammation ${ }^{(28)}$.

Current animal experiments are performed in healthy young mice under conditions that are as much standardized as possible. Standardization with regards to gender, genetic background, age and housing is believed to reduce variation and to create an 
optimal environment to provide a clear answer to a research question. Since the aim of this environment is to exclude factors that could affect the research outcome, translation of the results to the clinical practice is often complex due to the heterogeneity of the human population. More recently a trend has developed to use mice with comorbidities in the experimental setup to simulate a more real life situation of the patient. However, this type of experiments is extremely expensive and thus the majority of the experimental animal experiments are still executed in healthy young mice. This jeopardizes the predictability of these experiments for clinical practice and often leads to failure of early clinical trials. The observations described in this thesis emphasize the effect of housing conditions and standardization on the phenotype of animal models and can cause serious bias between different studies.

\section{Crystal structure of a ligand receptor complex serves as a good basis for the development of peptidergic antagonists}

Our lab was the first to describe a peptide derived from Wnt (UM206) that was aimed at interfering with the interaction between Wnt and frizzled. The amino acid sequence of UM206 was determined on the basis of regions of high homology between Wnt3a and Wnt5a. Further requirements were the presence of at least two cysteines and regions necessary for secretion or posttranslational modification were excluded. This yielded three peptides with UM206 having the highest affinity. However, back then the crystal structure of the Wnt ligand was not known and it now has turned out that the peptide loop of the native Wnt protein that represents UM206 is not in contact with the Frizzled cysteine rich domain (CRD) (Chapter 6, Figure 1) ${ }^{(29)}$.

The current knowledge on the location of UM206 in the native Wnt protein questions the working mechanism of UM206. As seen in Figure 1 in Chapter 6, the sequence is located in a loop stabilized by two cysteines, which suggests that it protrudes from the protein and is able to interact with another structure. Furthermore, it is appreciated that a gap is present between the receptor and the Wnt ligand that can harbor another protein or a complex of proteins. Frizzled CRDs can form dimers that 
can be important for binding of Wnt and initiation of the signaling pathway ${ }^{(30,31)}$. It is possible that UM206 acts on these CRD dimers and thereby prevent binding of Wnt and subsequent signaling activation. An interference of UM206 between the coreceptor LRP and the Wnt/Frizzled complex is unlikely since it was reported that the region where UM206 is derived from in the native Wnt protein, is not involved in binding to LRP6 ${ }^{(32)}$.

The presentation of the crystal structure has offered new insights in the binding sites of Wnt to $\mathrm{Fzd}^{(29)}$ and led to the development of looped/constrained peptide mimetics of Wnt as described in Chapter 6. These peptides were able to inhibit canonical Wnt/Frizzled signaling with an $\mathrm{IC}_{50}$ in the micromolar range. Length of the peptides as well as palmitoylation of the thumb fragment and finally the presence of a synthetic CLIPS scaffold all influenced the antagonistic potency of these peptides. These results demonstrate that crystal structures of ligand-receptor complexes offer highly valuable information on the targetable regions of a receptor. Regions of the ligand that interact with the receptor can be mimicked in order to target these interaction sites. Recently, low molecular weight compounds targeting the index finger site of Wnt/frizzled interaction have been described ${ }^{(33)}$. This underscores the importance of this binding pocket for activation of Frizzled by Wnt proteins.

The use of peptides as drugs is emerging in the area of drug development and offers advantages over the use of small non-peptidergic molecules, but is also associated with traditional disadvantages when considering peptides as a medicine. The main advantages are the high potency and selectivity, which result in fewer undesirable side effects. Disadvantages are rapid plasma clearance, poor membrane permeability and low oral bioavailability ${ }^{(34)}$. However, there are approaches that could potentially increase the in vivo half-life time of a peptide. Circulating albumin can serve as carrier protein for peptides and there are strategies that aim for binding to this protein in order to extend half-life of the peptide. Furthermore, enzymatic cleavage of the peptide can be reduced by substituting amino acids or by enhancing the secondary structure by for example clipping of the peptide ${ }^{(35)}$. Oral peptides often have low 
bioavailability due to acidic and enzymatic degradation in the gastrointestinal tract and when crossing the intestinal mucosa, therefore parenteral administration is commonly used. Increased bioavailability can be achieved by stabilizing the secondary structure by the afore mentioned method or stapling of peptides, Nmethylation and formation of intramolecular hydrogen bonds ${ }^{(35)}$. However, when such changes are introduced it can impact the in vivo effect of the peptide and reduce its specificity, thereby causing undesirable side effects. For that reason the inconvenience of daily injections should be outweighed with the severity of the disease that one is suffering from. When reflecting this to our peptides and its indication it can be said that a daily injection would be preferred over the development of heart failure.

\section{Future perspectives}

Up to recently, there were no pharmacological tools available that target the binding site of Wht on Frizzled. This made it difficult to specifically target the Frizzled receptor in order to modulate Wnt/Frizzled signaling. In experimental conditions, genetic interventions can be used to modulate Wnt/frizzled signaling, although this is more challenging in in vivo models. In this thesis, we have shown the beneficial effect of UM206 on wound healing after MI in different animal models. However, because both the site of interaction with the Wnt/frizzled complex and the exact therapeutic target(s) are not clear at present, more research will have to be carried out on these topics before this compound can be moved towards the direction of a therapeutic agent. The novel peptides that we have developed specifically target the sites of interaction between Wnt and frizzled, thereby offering a more predictable pharmacological working mechanism. However, the binding affinities of the current peptides are adequate for in vitro use, but are too low to be used in in vivo models of cardiovascular disease. Therefore, further peptide optimization is needed to improve the affinities. The use of these improved peptides can be envisioned as a therapeutic agent in in vivo models of cardiovascular diseases. However, since Wht signaling is implicated in a wide array of diseases the use of these peptides can be extended to 
many more applications such as treatment of cancer, correcting disorders of bone metabolism or inhibition of stem cell differentiation. In addition, when modified with an imaging marker they can be used as a diagnostic agent to visualize cells that express an elevated density of Frizzled receptors under pathological conditions. As there are 19 Wnt and 10 Frizzled members, these peptides can inhibit multiple signaling pathways at once which can be an undesired side effect in some cases. For this reason, the selectivity of these newly developed peptides for the different members of the Frizzled family will have to be determined. 


\section{References}

1. Laeremans H, Hackeng TM, van Zandvoort MA, Thijssen VL, Janssen BJ, Ottenheijm HC, et al. Blocking of frizzled signaling with a homologous peptide fragment of wnt3a/wnt5a reduces infarct expansion and prevents the development of heart failure after myocardial infarction. Circulation. 2011;124(15):1626-35.

2. Barandon L, Couffinhal T, Ezan J, Dufourcq P, Costet P, Alzieu P, et al. Reduction of infarct size and prevention of cardiac rupture in transgenic mice overexpressing FrzA. Circulation. 2003;108(18):2282-9.

3. Barandon L, Casassus F, Leroux L, Moreau C, Allieres C, Lamaziere JM, et al. Secreted frizzledrelated protein-1 improves postinfarction scar formation through a modulation of inflammatory response. Arterioscler Thromb Vasc Biol. 2011;31(11):e80-7.

4. Bao MW, Cai Z, Zhang XJ, Li L, Liu X, Wan N, et al. Dickkopf-3 protects against cardiac dysfunction and ventricular remodelling following myocardial infarction. Basic Res Cardiol. 2015;110(3):25.

5. Zerlin M, Julius MA, Kitajewski J. Wnt/Frizzled signaling in angiogenesis. Angiogenesis. 2008;11(1):63-9.

6. Hermans KC, Blankesteijn WM. Wnt Signaling in Cardiac Disease. Comprehensive Physiology. 2015;5(3):1183-209.

7. Blankesteijn WM, van Gijn ME, Essers-Janssen YP, Daemen MJ, Smits JF. Beta-catenin, an inducer of uncontrolled cell proliferation and migration in malignancies, is localized in the cytoplasm of vascular endothelium during neovascularization after myocardial infarction. The American journal of pathology. 2000;157(3):877-83.

8. Barandon L, Couffinhal T, Dufourcq P, Ezan J, Costet P, Daret D, et al. Frizzled A, a novel angiogenic factor: promises for cardiac repair. European journal of cardio-thoracic surgery : official journal of the European Association for Cardio-thoracic Surgery. 2004;25(1):76-83.

9. Min JK, Park H, Choi HJ, Kim Y, Pyun BJ, Agrawal V, et al. The WNT antagonist Dickkopf2 promotes angiogenesis in rodent and human endothelial cells. J Clin Invest. 2011;121(5):1882-93.

10. Paik DT, Rai M, Ryzhov S, Sanders LN, Aisagbonhi O, Funke MJ, et al. Wnt10b Gain-of-Function Improves Cardiac Repair by Arteriole Formation and Attenuation of Fibrosis. Circulation research. 2015;117(9):804-16.

11. van den Borne SW, Diez J, Blankesteijn WM, Verjans J, Hofstra L, Narula J. Myocardial remodeling after infarction: the role of myofibroblasts. Nature reviews Cardiology. 2010;7(1):30-7.

12. Willems IE, Havenith MG, De Mey JG, Daemen MJ. The alpha-smooth muscle actin-positive cells in healing human myocardial scars. The American journal of pathology. 1994;145(4):868-75.

13. Laeremans H, Rensen SS, Ottenheijm HC, Smits JF, Blankesteijn WM. Wnt/frizzled signalling modulates the migration and differentiation of immortalized cardiac fibroblasts. Cardiovascular research. 2010;87(3):514-23.

14. Blankesteijn WM, Essers-Janssen YP, Verluyten MJ, Daemen MJ, Smits JF. A homologue of Drosophila tissue polarity gene frizzled is expressed in migrating myofibroblasts in the infarcted rat heart. Nature medicine. 1997;3(5):541-4.

15. Aisagbonhi O, Rai M, Ryzhov S, Atria N, Feoktistov I, Hatzopoulos AK. Experimental myocardial infarction triggers canonical Wnt signaling and endothelial-to-mesenchymal transition. Dis Model Mech. 2011;4(4):469-83.

16. Duan J, Gherghe C, Liu D, Hamlett E, Srikantha L, Rodgers L, et al. Wnt1/betacatenin injury response activates the epicardium and cardiac fibroblasts to promote cardiac repair. Embo J. 2012;31(2):429-42.

17. Hahn JY, Cho HJ, Bae JW, Yuk HS, Kim KI, Park KW, et al. Beta-catenin overexpression reduces myocardial infarct size through differential effects on cardiomyocytes and cardiac fibroblasts. The Journal of biological chemistry. 2006;281(41):30979-89. 
18. Morrissey RP, Czer L, Shah PK. Chronic heart failure: current evidence, challenges to therapy, and future directions. American journal of cardiovascular drugs : drugs, devices, and other interventions. 2011;11(3):153-71.

19. Ahmed A. Myocardial beta-1 adrenoceptor down-regulation in aging and heart failure: implications for beta-blocker use in older adults with heart failure. European journal of heart failure. 2003;5(6):709-15.

20. Kurabayashi M, Yazaki Y. Downregulation of angiotensin II receptor type 1 in heart failure. A process of adaptation or deterioration? Circulation. 1997;95(5):1104-7.

21. Schumann H, Holtz J, Zerkowski HR, Hatzfeld M. Expression of secreted frizzled related proteins 3 and 4 in human ventricular myocardium correlates with apoptosis related gene expression. Cardiovascular research. 2000;45(3):720-8.

22. Askevold ET, Aukrust P, Nymo SH, Lunde IG, Kaasboll OJ, Aakhus S, et al. The cardiokine secreted Frizzled-related protein 3, a modulator of Wnt signalling, in clinical and experimental heart failure. Journal of internal medicine. 2014;275(6):621-30.

23. Ostrom RS. A new molecular target for blunting organ fibrosis. Focus on "Secreted Frizzled-related protein 2 as a target in antifibrotic therapeutic intervention". American journal of physiology Cell physiology. 2014;306(6):C527-8.

24. Freedman LP, Cockburn IM, Simcoe TS. The Economics of Reproducibility in Preclinical Research. PLoS biology. 2015;13(6):e1002165.

25. Teixeira MA, Chaguri LC, Carissimi AS, Souza NL, Mori CM, Saldiva PH, et al. Effects of an individually ventilated cage system on the airway integrity of rats (Rattus norvegicus) in a laboratory in Brazil. Lab Anim. 2006;40(4):419-31.

26. DeLeon-Pennell KY, de Castro Bras LE, lyer RP, Bratton DR, Jin YF, Ripplinger CM, et al. P. gingivalis lipopolysaccharide intensifies inflammation post-myocardial infarction through matrix metalloproteinase-9. Journal of molecular and cellular cardiology. 2014;76:218-26.

27. Hanatani T, Suzuki J, Ogawa M, Aoyama N, Kobayashi N, Hirata Y, et al. The periodontal pathogen Aggregatibacter actinomycetemcomitans deteriorates ventricular remodeling after myocardial infarction in mice. Int Heart J. 2012;53(4):253-6.

28. Deleon-Pennell KY, de Castro Bras LE, Lindsey ML. Circulating Porphyromonas gingivalis lipopolysaccharide resets cardiac homeostasis in mice through a matrix metalloproteinase-9dependent mechanism. Physiological reports. 2013;1(5):e00079.

29. Janda CY, Waghray D, Levin AM, Thomas C, Garcia KC. Structural basis of Wnt recognition by Frizzled. Science. 2012;337(6090):59-64.

30. Dann CE, Hsieh JC, Rattner A, Sharma D, Nathans J, Leahy DJ. Insights into Wnt binding and signalling from the structures of two Frizzled cysteine-rich domains. Nature. 2001;412(6842):8690.

31. Ain QU, Seemab U, Rashid S, Nawaz MS, Kamal MA. Prediction of structure of human WNT-CRD (FZD) complex for computational drug repurposing. PloS one. 2013;8(1):e54630.

32. Sahu I, Mishra S, Undi R, Kandi R, Gutti U, Gutti RK. Sequence and structural difference favors a distinct preference of Wnt3a binding with co-receptor LRP6. Journal of biomolecular structure \& dynamics. 2015;33(10):2133-44.

33. Lee HJ, Bao J, Miller A, Zhang C, Wu J, Baday YC, et al. Structure-based discovery of novel small molecule Wnt signaling inhibitors by targeting the cysteine rich domain of Frizzled. The Journal of biological chemistry. 2015.

34. Craik DJ, Fairlie DP, Liras S, Price D. The future of peptide-based drugs. Chemical biology \& drug design. 2013;81(1):136-47.

35. Fosgerau K, Hoffmann T. Peptide therapeutics: current status and future directions. Drug discovery today. 2015;20(1):122-8. 




\section{Chapter}

Summary Samenvatting

Valorisatie addendum Dankwoord Curriculum Vitae List of publications 


\section{Summary}

Myocardial infarction (MI) is a condition that affects many people worldwide. The lack of supply of oxygen and nutrients to parts of the vital myocardium leads to myocardial damage, evoking an inflammatory reaction. This is the start of the wound healing process, which is known as a very complex sequence of events. The quality of this process is important for maintaining the cardiac function as poor wound healing can ultimately result in the development of heart failure.

In wound healing, multiple signaling pathways are involved. One of these is the Wnt/Frizzled signaling pathway on which the research in this thesis is focused. This complex signaling pathway is still not completely unraveled and many pieces of the puzzle are still missing to fully understand it. The aim of the research described in this thesis was to investigate the role of this pathway in the wound healing process following $\mathrm{Ml}$ and to characterize the inhibitory potential of peptide fragments of Wnt proteins.

Research on Wnt/Frizzled signaling is intensified and evidence of the involvement in cardiovascular disease has grown robustly in the last years. In Chapter $\mathbf{2}$ we provide an overview of the involvement of Wnt/Frizzled signaling in a wide range of cardiac conditions including $\mathrm{MI}$, cardiac hypertrophy and heart failure. Interventions in Wnt/Frizzled signaling, either genetic or pharmacological, have been shown to influence the disease process. Results are sometimes inconsistent as to whether the pathway should be stimulated or inhibited, which may be attributed to differences in the animal models that were used. Variation in response to interventions can be attributed to the method of disease induction, gender and genetic background.

Our lab has previously demonstrated that the genetic background of mice is a critical factor for infarct healing following MI. To investigate a potential link between this divergent infarct healing and the activity of the Wnt/Frizzled signaling pathway we subjected four different mice strains (BALB/C, C57BL/6, FVB and Swiss) to MI, determined the expression profile of Wnt/Frizzled pathway components in the infarcted myocardium and correlated them to parameters that are indicative for (the 
development of) heart failure (Chapter 3). We found that gene expression profiles of Frizzled proteins and Wnt ligands in the infarcted myocardium were different between the mouse strains. In particular, Wnt/frizzled gene expression was significantly increased in C57BL/6 and FVB mice, but this elevation was absent in Swiss mice. Moreover, we found an inverse relationship between Wnt expression and end diastolic volumes in two strains (C57BL/6 and FVB), suggesting that Wnt signaling contributes to the regulation of wound healing in these strains. Furthermore, we analyzed gene expression patterns in human post-mortem infarct samples from different stages post-MI. This revealed a gene expression pattern that resembles the cellularity of the infarcted myocardium over time. However, expression levels of the analyzed genes were very low and variable, which was probably due to the formalin fixation of the tissue. Therefore, no firm conclusions can be drawn from these observations on human post-mortem infarct samples.

To target the Wnt/Frizzled pathway in a clinically relevant swine model of reperfused MI, we used a peptide fragment of Wnt5a - UM206 - that was previously shown to be beneficial for wound healing following $\mathrm{MI}$ in mice. In Chapter 4 we present evidence that adverse remodeling of the infarcted area was halted in the UM206-treated animals whereas a progressive dilation of the left ventricle was observed in the untreated swine between three and five weeks after MI. In the treated animals, infarct mass was significantly decreased, whereas it remained stable in the control group. Gene expression analysis only demonstrated significant increments for Frizzled 4 and LRP5 expression. No further evidence was found that could explain the results mentioned above. We therefore believe that at five weeks post-MI we might have missed these significant differences in gene expression levels in the early stage of wound healing. Effects on cardiac function were limited at this stage, although it is tempting to speculate that UM206 can prevent deterioration of the cardiac performance at a later stage.

In Chapter 5 we compared the results of eight individual studies in which the effect of UM206 on infarct healing was investigated in a mouse model of MI. In the first two 
studies we demonstrated beneficial effects of this peptide on cardiac dimensions, ejection fraction and lung weights. After these two initial studies, the beneficial effect of this peptide was lost. This led to a series of experiments aimed at unraveling the cause of this phenomenon. The effectiveness of UM206 was analyzed in relation to dose, timing, source of UM206 and genetic background of mice. In contrast to the first two sets of experiments, increased lung weights were absent in both saline and UM206 groups in the later experiments, suggesting that overt heart failure development was absent in these mice. The therapeutic gain that could be obtained with UM206 was thereby eliminated. We believe that this change in phenotype can be explained by the transition of housing conditions of the mice from open cages to individually ventilated cages at the turning point, which resulted in reduced exposure of the mice of inflammatory stimuli. Increasing evidence demonstrates that the inflammatory status has a distinct influence on the outcome of many cardiovascular diseases. Therefore we think that this change in housing conditions explains the loss of the heart failure phenotype and eliminated the capability of UM206 to show its beneficial effect on adverse cardiac remodeling. This demonstrates that the experimental conditions for research with animals can highly influence the outcome and complicates the translation to clinical practice.

The recent publication of the crystal structure of the Wnt/Frizzled complex gave new insights on the interaction between the Wnt ligand and the Frizzled cysteine rich domain (CRD). From this crystal structure, it could be deduced that UM206 has no direct interaction with the CRD. This questioned the working mechanism of UM206 and led to the development of novel peptide fragments, based on the two predicted sites of interaction between Wnt and the Frizzled CRD. In Chapter 6 we screened a systematically designed peptide library for the inhibition of Wnt3a induced canonical signaling in cells. Synthetically produced peptide fragments derived from the socalled 'thumb' and 'index finger' of Wnt were able to inhibit this signaling with an $\mathrm{IC}_{50}$ in the micromolar range. The design of the peptide library allowed us to investigate the effect of peptide length, palmitoylation of the 'thumb' fragment and the presence of a synthetic CLIPS scaffold. All these factors significantly influenced the antagonistic 
potency of the peptides. Simultaneous administration of both 'thumb' and 'index finger' peptides only resulted in an additive rather than a synergistic inhibitory effect. Our results demonstrate that these novel peptide fragments can serve as a new tool to inhibit Wnt signaling.

In conclusion, this thesis contributes to the ongoing efforts to resolve the complex mechanism of Wnt/Frizzled signaling by demonstrating the modulatory role in the structural adaptation following MI. Furthermore, it provides new directions for the development of Wnt/Frizzled antagonists that can be used in a wide array of diseases in which Wnt/Frizzled signaling plays a role. 



\section{Chapter}

Summary

Samenvatting

Valorisatie addendum

Dankwoord

Curriculum Vitae List of publications 


\section{Samenvatting}

Wereldwijd worden veel mensen getroffen door een hartinfarct. Een onderbreking in de toevoer van zuurstof en voedingsstoffen naar de vitale delen van het myocardium leidt tot schade aan het hart en brengt een ontstekingsreactie op gang. Dit is het begin van het wondhelingsproces, dat bekend staat als een zeer complexe reeks van cellulaire processen. De kwaliteit van het wondhelingsproces is belangrijk voor het behoud van de hartfunctie. Als dit proces slecht verloopt kan dit uiteindelijk leiden tot het ontwikkelen van hartfalen.

Meerdere signaaltransductiewegen zijn betrokken bij wondheling. Eén daarvan is de Wnt/Frizzled signaaltransductieweg waar het onderzoek in deze thesis op is gefocust. Deze complexe signaleringscascade is nog niet helemaal ontrafeld en er missen nog veel puzzelstukken om het mechanisme helemaal te kunnen begrijpen. Het doel van het onderzoek dat in deze thesis wordt beschreven was het onderzoeken van de rol van deze signaleringscascade in het wondhelingsproces dat optreedt na een hartinfarct. Bovendien hebben we het remmende effect op de Wnt/Frizzled signalering onderzocht van peptide fragmenten die afgeleid zijn van Wnt eiwitten.

In de laatste jaren is het onderzoek naar Wnt/Frizzled signalering in diverse aandoeningen toegenomen. Dit heeft veel gegevens opgeleverd over de betrokkenheid hiervan in hart- en vaatziekten. In Hoofdstuk 2 geven we een overzicht van de betrokkenheid van Wnt/Frizzled signalering in verschillende cardiovasculaire aandoeningen waaronder het hartinfarct, hypertrofie van het hart en hartfalen. Interventies in Wnt/Frizzled signalering, zowel genetisch als farmacologisch, hebben aangetoond het ziekteproces the beïnvloeden. De resultaten laten zien dat er soms tegenstrijdigheid heerst over de vraag of de signaaltransductieweg moet worden gestimuleerd of juist geremd. Dit kan wellicht worden verklaard door de verschillen in de dierenmodellen die zijn gebruikt. Variaties in de respons op de interventies kunnen worden toegeschreven aan de methode van ziekteopwekking, geslacht en genetische achtergrond. 
Ons lab heeft eerder aangetoond dat de genetische achtergrond van muizen een bepalende factor is voor het wondhelingsproces na een hartinfarct. Om te onderzoeken of er een mogelijke link aanwezig is tussen dit verschil in wondheling en de activiteit van de Wnt/Frizzled signalering hebben we vier verschillende muizenstammen (BALB/C, C57BL/6, FVB en Swiss) blootgesteld aan een hartinfarct (Hoofdstuk 3). Hierbij hebben we het expressieprofiel van verschillende Wnt/Frizzled signaleringsgenen in het infarctgebied bepaald en gecorreleerd aan parameters die een indicatie geven voor (de ontwikkeling van) hartfalen. Tussen de muizenstammen was er een verschil in genexpressie van Frizzled eiwitten en Wnt liganden in het infarctgebied. Met name in de C57BL/6 en FVB muizen werd er een significant hogere expressie gevonden van deze genen. Deze verhoogde expressie was echter afwezig in de Swiss muizen. Bovendien vonden we een omgekeerde evenredige relatie tussen Wnt genexpressie en het linker ventrikel volume in diastole (eind diastolisch volume) in twee muizenstammen (C57BL/6 en FVB). Dit suggereert dat Wnt signalering bijdraagt aan de regulatie van wondheling in deze muizen stammen. Verder hebben we genexpressie patronen geanalyseerd in humane post-mortem infarct samples van verschillende stadia van het wondhelingsproces. Dit gaf een genexpressiepatroon weer dat overeenkomt met het verloop van de cel dichtheid van het infarctgebied na het optreden van een hartinfarct. Echter, genexpressieniveaus van de geanalyseerde genen waren zeer laag en variabel. Dit is waarschijnlijk het gevolg van de formalinefixatie van het weefsel. Daarom kunnen er geen concrete conclusies worden getrokken over deze waarnemingen in humane post-mortem infarctsamples.

In een klinisch relevant varkensmodel hebben we een peptide fragment van Wnt5aUM206 - gebruikt om in te grijpen op de Wnt/Frizzled signalering. In dit model werd een infarct opgewerkt door gedurende twee uur een kransslagader af te sluiten en die vervolgens weer te openen, waarbij de huidige klinische praktijk van de behandeling van een hartinfarct zo goed mogelijk wordt nagebootst. Voorheen is in muizen aangetoond dat behandeling met dit peptide gunstig is voor de infarctheling. In Hoofdstuk 4 tonen we aan dat de uitrekking van het infarctgebied werd geremd in varkens die waren behandeld met UM206. Onbehandelde varkens lieten een verdere 
uitrekking van het linker ventrikel zien tussen drie en vijf weken na het induceren van het infarct. In de behandelde dieren nam de infarctmassa significant af over de tijd ten opzichte van de controle groep. Genexpressie analyse liet alleen significante verhogingen zien voor twee receptor eiwitten van Wnt namelijk, Frizzled4 en LRP5. Er kon geen ander bewijs worden gevonden dat de eerder genoemde resultaten kon verklaren. Daarom denken we dat deze mogelijke verschillen in genexpressieniveaus eerder tijdens de infarctheling hebben plaatsgevonden waardoor we ze op het tijdstip van opofferen gemist hebben. Verder waren de effecten op de hartfunctie beperkt in dit stadium. Het is echter aantrekkelijk om te speculeren dat UM206 de verslechtering van de hartfunctie kan voorkomen in een later stadium.

In Hoofdstuk 5 hebben we de resultaten van acht individuele studies vergeleken waarbij het effect van UM206 op infarctheling werd onderzocht in muizen waarin een hartinfarct werd geïnduceerd. In de eerste twee studies hebben we gunstige effecten van dit peptide laten zien op ventrikelvolumes, ejectiefractie en longgewichten. $\mathrm{Na}$ deze eerste twee studies zagen we dit effect niet meer terug. Dit heeft geleid tot een aantal experimenten om de onderliggende oorzaak hiervan te vinden. De effectiviteit van UM206 werd onderzocht in relatie tot de dosis, tijdsbestek van behandeling, bron van UM206 en de genetische achtergrond van de muizen. In tegenstelling tot de eerste twee studies waren verhoogde longgewichten afwezig in zowel controle als UM206 behandelde muizen in de rest van de studies. Dit suggereert dat de duidelijke ontwikkeling van hartfalen afwezig was in deze muizen. Het therapeutische voordeel dat behaald kon worden met UM206 was daardoor afwezig. We denken dat deze fenotypische verandering kan worden verklaard door verandering in de huisvesting van muizen. In de periode tussen de tweede en derde studie is de manier van huisvesting veranderd van open kooien naar individueel geventileerde kooien. Dit resulteerde in een verminderde blootstelling van de muizen aan inflammatoire stimuli. Er komt steeds meer bewijs beschikbaar dat laat zien dat de inflammatoire status een duidelijk effect heeft op de uitkomst van veel cardiovasculaire ziekten. Daarom denken we dat de verandering in huisvesting ertoe heeft geleid dat er geen ontwikkeling van hartfalen meer plaatsvindt. Dit heeft als gevolg dat de potentie van 
UM206 om een gunstig effect uit te oefenen op de wondheling is verdwenen. Dit benadrukt dat de experimentele condities voor onderzoek met dieren een grote invloed heeft op het resultaat en het bemoeilijkt de translatie naar de kliniek.

De recente publicatie over de kristalstructuur van het Wnt/Frizzled complex gaf nieuwe inzichten over de interactie tussen het Wnt ligand en het Frizzled cysteine rijk domein (CRD). Er bleken twee lusvormige interactiedomeinen te zijn die in de literatuur worden aangeduid als 'duim' en 'wijsvinger'. Van deze kristalstructuur kon worden afgeleid dat UM206 geen directe interactie aangaat met het CRD. Hierdoor werd het onwaarschijnlijk dat UM206 werkt als een directe inhibitor van de interactie tussen Wnt en Frizzled. Dit heeft geleid tot de ontwikkeling van nieuwe peptide fragmenten die gebaseerd waren op de twee voorspelde interactieplaatsen tussen Wnt en het Frizzled CRD. In Hoofdstuk 6 hebben we een peptidencollectie die is ontworpen vanuit dit uitgangspunt gescreend voor de remming van Wnt3a geïnduceerde signalering via $\beta$-catenine. Synthetisch geproduceerde peptide fragmenten die afgeleid zijn van de zogenoemde 'duim' en 'wijsvinger' van Wnt waren in staat om deze signalering the inhiberen met een $\mathrm{IC}_{50}$ in het micromolaire bereik. $\mathrm{De}$ peptiden die waren gesynthetiseerd stelden ons in staat om het effect van variaties in peptidelengte, palmitoylatie van het 'duim' fragment en de aanwezigheid van een synthetische brugstructuur aan het uiteinde van de lus, de zogenaamde CLIPS scaffold, te onderzoeken. Deze factoren hadden een significante invloed op het antagonistische effect van de peptiden. Gelijktijdige toediening van zowel de 'duim' als de 'wijsvinger' fragmenten resulteerde alleen in een additief effect in plaats van een synergistisch remmend effect. Onze resultaten laten zien dat deze nieuwe peptide fragmenten kunnen worden gebruikt om Wnt signalering op een nieuwe manier te remmen. 
Concluderend kunnen we zeggen dat dit proefschrift bijdraagt aan de voortdurende inspanningen om het complexe mechanisme van Wnt/Frizzled signalering beter te begrijpen. Dit wordt benadrukt door de modulerende rol van deze signalering in de structurele adaptatie van het hart na een infarct. Verder biedt het nieuwe aanwijzingen voor de ontwikkeling van Wnt/Frizzled antagonisten die kunnen worden gebruikt in een groot scala van ziekten waarin Wnt/Frizzled signalering een rol speelt. 




\section{Chapter}

Summary Samenvatting

\section{Valorisatie addendum}

Dankwoord

Curriculum Vitae List of publications 


\section{Valorisatie addendum}

Jaarlijks sterft een groot aantal mensen als gevolg van hart- en vaatziekten. Onder vrouwen is dit zelfs de meest voorkomende oorzaak van overlijden. Het veelvoorkomende hartinfarct en het ontwikkelen van hartfalen dat hiermee gepaard kan gaan heeft hier een groot aandeel in. Alhoewel tegenwoordig veel mensen de acute fase van een hartinfarct overleven door de progressie die wordt gemaakt in de behandeling hiervan, ontwikkelen veel mensen uiteindelijk toch hartfalen. De prognose voor mensen met hartfalen is met een 5 -jarige overlevingskans van $50 \%$ vrij slecht. Dit laat zien dat de huidige farmacotherapeutische behandeling tekort schiet en er behoefte is aan nieuwe therapeutische middelen. Het werk in dit proefschrift draagt bij aan de verkenning en ontwikkeling van nieuwe therapeutische middelen. Verder is de impact van hartfalen op de zorgkosten enorm. Met de toenemende levensverwachting en populatie zal dit in de toekomst alleen maar blijven stijgen, vooral als therapeutische middelen die hartfalen kunnen voorkomen achter blijven.

Het doel van het onderzoek in dit proefschrift was om de Wnt/Frizzled signaaltransductieweg als therapeutisch target voor het voorkomen van hartfalen verder te onderzoeken. Mocht dit leiden tot nieuwe therapieën voor het behandelen of voorkomen van hartfalen, dan is dit bijzonder interessant voor de gezondheidszorg. Indien de nieuwe peptiderge antagonisten, beschreven in dit proefschrift, verder worden ontwikkeld zodat ze in vivo kunnen worden toegepast, dan zijn ze ook toepasbaar voor andere ziektebeelden waar de Wnt/Frizzled signaaltransductieweg eveneens een rol in speelt. Dit zijn onder andere kanker, osteoporose, neurologische aandoeningen zoals dementie en andere hart- en vaatziekten.

Het gebruik van peptiden als medicijn in de gezondheidszorg is nog niet gebruikelijk maar komt wel steeds vaker voor; een voorbeeld hiervan is insuline bij diabetes type 2. Het heeft een aantal voordelen maar ook nadelen ten opzichte van niet-peptiderge moleculen. Voordelen zijn dat ze vaak specifieker werken en in een lagere dosis 
kunnen worden toegediend. Dit komt met name doordat ze een deel van het natuurlijke eiwit nabootsen en daardoor minder aspecifieke bindingen aangaan en dus minder bijwerkingen teweeg brengen. Het voornaamste nadeel is dat ze vaak snel worden afgebroken in het lichaam en daardoor maar een korte werkingsduur hebben. Ook is de orale beschikbaarheid meestal laag waardoor deze manier van toediening niet geschikt is en men dagelijks een dosis zou moeten injecteren om het gewenste effect te bereiken. Echter, als men zou moeten kiezen tussen het ontwikkelen van hartfalen of een dagelijkse injectie die dit zou kunnen voorkomen, dan zou het laatste de voorkeur hebben voor de grote meerderheid van de patiënten. Dit onderzoek laat zien dat peptiden, die afgeleid zijn van een natuurlijk eiwit, een goede bron kunnen zijn voor ontwikkeling van medicijnen en dat hiervoor zeker een toekomstperspectief is.

Er zijn enkele antagonisten bekend die de Wnt signaleringscascade kunnen remmen. Het aangrijpingspunt van deze antagonisten ligt veelal voor of na het punt dat het Wnt ligand een interactie aangaat met de Frizzled receptor. Dit houdt in dat ze niet specifiek op de Frizzled receptor werken. Aangezien de Wnt/Frizzled signaaltransductieweg zeer gecompliceerd is en downstream componenten ook betrokken zijn bij andere signaleringswegen, is het mogelijk dat deze antagonisten niet specifiek ingrijpen op de Wnt/Frizzled signalering. De nieuwe peptiden beschreven in dit onderzoek zijn ontworpen om specifiek aan de Frizzled receptor te binden op de plaatsen waar het natieve Wnt ligand ook bindt. Hoewel we niet specifiek hebben aangetoond dat ze ook daadwerkelijk een interactie aangaan met de Frizzled receptor, is deze manier van Wnt/Frizzled inhibitie innovatief.

In de toekomst moet de binding van deze nieuwe peptiden aan Frizzled receptoren worden bevestigd om zeker te zijn dat ze Wnt/Frizzled signalering remmen via de beoogde manier. Verder zullen ze geoptimaliseerd moeten worden om in vivo gebruikt te kunnen worden en zo het effect op het ziekteproces the testen. Aangezien er negentien Wht liganden en tien Frizzled receptoren bekend zijn zal ook de specificiteit voor de verschillende receptoren moeten worden gedefinieerd om zo een overzicht te krijgen welke delen van de Wnt/Frizzled signalering worden beïnvloed. 



\title{
Chapter
}

Summary Samenvatting

Valorisatie addendum

Dankwoord

\author{
Curriculum Vitae \\ List of publications
}




\section{Dankwoord}

Met het schrijven van het dankwoord ben ik aangekomen bij het laatste stukje van het 'boekje'. Hier wil ik dan ook een aantal mensen persoonlijk bedanken voor de vele leermomenten, de hulp bij het doen van mijn onderzoek, de 'koffie-gesprekken' en niet te vergeten de gezellige borrels!

Het begon allemaal in 2011 direct na mijn afstuderen aan de Universiteit in Maastricht, toen Matthijs mij de kans gaf om een promotieonderzoek te doen. Matthijs, jou wil ik dan ook als eerste bedanken. Dankzij jou heb ik mijn wetenschappelijke kennis aanzienlijk verbreed, vele nieuwe technieken geleerd, cursussen kunnen volgen en een aantal mooie congressen mogen bezoeken (ook mede dankzij de Hartstichting). Verder wil ik je ook bedanken voor de nieuwe inzichten die je me gaf. Waar ik vaak te moeilijk dacht, kwam jij met een makkelijke oplossing voor iets. Ook van je grote kennis over autotechniek heb ik een aantal keer gebruik mogen maken, waarvoor nogmaals bedankt!

Naast Matthijs ben ik ook mijn promotor Harry zeer dankbaar voor het tot stand komen van mijn proefschrift. De overkoepelende blik die je had bij het onderzoek gaf me altijd een gevoel van vertrouwen. Verder vond ik de begeleiding die je me gaf zeer waardevol en onze gesprekken gaven me altijd weer een goed beeld waar we stonden met het onderzoek.

Ook wil ik mijn dank uitspreken aan mijn $2^{\mathrm{e}}$ promotor Peter. Alhoewel je niet vanaf het begin af aan betrokken was bij mijn onderzoek wil ik je bedanken voor de zeer goede input bij het peptidenstuk. Ik ben dan ook blij dat we uiteindelijk nog een mooie draai aan mijn thesis hebben kunnen geven door het innovatieve peptidenwerk.

Dan wil ik graag de mensen bedanken die me hebben geholpen met het praktische werk. Lily, bedankt voor de vele coupes die je voor me hebt gesneden, gekleurd en geanalyseerd, zonder jou had ik dat nooit allemaal kunnen bolwerken. Peter, jij ook bedankt voor de ondersteuning die je me regelmatig gaf bij het celwerk. Daarnaast wil 
ik de collega's van het dierenlab, Jacques, Peter, Agnieszka en Helma ook heel erg bedanken voor het vele werk dat ze voor mij hebben verricht voor de proefdierstudies. Ook de collega's in Rotterdam, André, Daphne en Dirk, wil ik bedanken voor de samenwerking.

Evangelos, a.k.a Vagelis, Vango etc., thanks for all your help during my project and for being part of the team. We had a lot of fun on the lab but we also produced some nice papers together. Enjoy your 'little' family and I hope we can drink some Belgian 'biertjes' together in the near future! Verder wil ik de oud collega-aio's, Thijs, Bart, Raffaele, Jelly \& Pamela bedanken voor de gezellige momenten. Ger, Goor (Gregorio) en Paul, bedankt voor de leuke babbels en lunches. Ook de rest van de farmacologie collega's wil ik bedanken voor de fijne samenwerking.

Toen farmacologie en toxicologie samengingen kreeg ik een hoop mede-aio's erbij. Misha, Kristien, Charlotte, Mireille, Alie, Rianne, Carmen, Timme, Quan en Gesiele, ik vond het fijn dat ik jullie heb leren kennen. Bedankt dan ook voor de gezellige praatjes, koffiebreaks en niet te vergeten de borrels. Roger \& Misha, bedankt voor het organiseren van deze gezellige borrels en uitjes, maar ook voor de mooie gesprekken waarbij we flink hebben kunnen lachen. Ook de andere collega's van toxicologie bedankt voor de prettige sfeer!

Remo \& Brecht, het was fijn om af en toe even te relativeren en om te horen dat niet alleen mijn onderzoek af en toe wat frustraties met zich meebracht. Bedankt voor de lunches, diners en gesprekken, en succes met jullie nieuwe baan!

Verder wil ik mijn nieuwe collega's bij Medtronic en in het bijzonder van het 'Micrateam' bedanken voor de fijne sfeer. Vanaf de eerste dag voelde ik me al helemaal welkom. Robin: hoewel we na vijf jaar samen te hebben gestudeerd in eerste instantie ander vervolg gaven aan onze loopbaan, wil ik je bedanken voor de gezellige lunches op de uni en vooral voor de aanbeveling bij Medtronic! 
Mam, bedankt voor de steun tijdens mijn promotietraject. Je stond altijd voor mij klaar voor wat dan ook. Het was dan ook altijd fijn om elke maandagavond aan te schuiven bij het eten en om de week weer even door te nemen. Ook wil ik mijn schoonouders bedanken voor de vele etentjes, bbq's etc. waarbij ik altijd even af kon schakelen.

Lieve Joy, mijn laatste dank gaat uit naar jou. Je hebt me altijd gesteund tijdens de totstandkoming van dit proefschrift. Als ik weer eens te lang achter mijn laptop bezig was, was jij degene die ervoor zorgde dat ik toch even een momentje rust nam. Ik vind het heerlijk om met je te gaan uiteten, op vakantie te gaan of gewoon lekker onderuit op de bank te liggen. Ik hoop dat ik nog lang van je mag genieten op ons eigen stekkie. 




\section{Chapter}

Summary Samenvatting

Valorisatie addendum

Dankwoord Curriculum Vitae List of publications 


\section{Curriculum Vitae}

Kevin Carolus Martha Hermans was born on the $2^{\text {nd }}$ of July, 1987 in Brunssum, The Netherlands, where he attended and graduated from Rombouts College in 2007 by completing the Nature \& Health profile. After his graduation he enrolled in the bachelors program Molecular Life Sciences at the University of Maastricht. Following his Bachelor Degree in 2009, he started with his research master Cardiovascular Biology and Medicine. This was a two-year research master program organized by the Cardiovascular Research Institute Maastricht (CARIM). In 2011 he completed his Master Degree with an internship at the department of Physiology, Maastricht University.

In 2011 he started as a PhD student in the group of Dr. W.M. Blankesteijn at the department of Pharmacology (CARIM), which merged with the Toxicology department in 2015. During this PhD trajectory he presented his work as a poster at several national and international conferences. He followed several courses organized by the Dutch Heart Foundation, CARIM and the University of Maastricht. Parallel with his research activities, he has been active as a tutor within the Bachelor program of Biomedical Sciences and supervised several students during their internships.

From September 2015, he has been working as an associate Clinical Research Specialist at Medtronic, Maastricht, The Netherlands. 




\section{Chapter}

Summary Samenvatting

Valorisatie addendum

Dankwoord

Curriculum Vitae

List of publications 


\section{List of publications}

1. Uitterdijk $A^{*}$, Hermans KCM*, de Wijs-Meijler DPM, Daskalopoulos EP, Reiss IK, Duncker DJ, Blankesteijn WM, Merkus D. UM206, a selective Frizzled antagonist, attenuates adverse remodeling after myocardial infarction in swine. Lab Invest. 2016;96(2):168-76.

2. Hermans KCM, Daskalopoulos EP, Blankesteijn WM. The Janus face of myofibroblasts in the remodeling heart. J Mol Cell Cardiol. 2016;91:35-41.

3. Hermans KCM, Blankesteijn WM. Wnt Signaling in Cardiac Disease. Compr Physiol. 2015;5(3):1183-209.

4. Blankesteijn WM, Hermans KCM. Wnt signaling in atherosclerosis. Eur J Pharmacol. 2015;763(Pt A):122-30.

5. Altara R, Manca M, Hermans KCM, Daskalopoulos EP, Brunner-La Rocca HP, Hermans RJJ, Struijker-Boudier HAJ, WM Blankesteijn. Diurnal rhythms of serum and plasma cytokine profiles in healthy elderly individuals assessed using membrane based multiplexed immunoassay. J Transl Med. 2015;13:129.

6. Daskalopoulos EP, Hermans KCM, van Delft L, Altara R, Blankesteijn WM. Chapter 3 - The Role of Inflammation in Myocardial Infarction. In: Altara R, WM Blankesteijn, editor. Inflammation in Heart Failure. Boston: Academic Press; 2015. p. 39-65.

7. Daskalopoulos EP, Hermans KCM, Blankesteijn WM. Cardiac (myo)fibroblast: Novel strategies for its targeting following myocardial infarction. Curr Pharm Des. 2014;20(12):1987-2002.

8. Daskalopoulos EP, Hermans KCM, Janssen BJA, Blankesteijn WM. Targeting the Wnt/frizzled signaling pathway after myocardial infarction: a new tool in the therapeutic toolbox? Trends Cardiovasc Med. 2013;23(4):121-7.

9. Hermans KCM, Daskalopoulos EP, Blankesteijn WM. Interventions in Wnt signaling as a novel therapeutic approach to improve myocardial infarct healing. Fibrogenesis Tissue Repair. 2012;5(1):16.

* Authors contributed equally 

